\title{
FEMINISMO/S 30
}

Dramaturgia femenina actual. De 1986 a 2016

Eva García-Ferrón

Cristina Ros-Berenguer (Coords.)

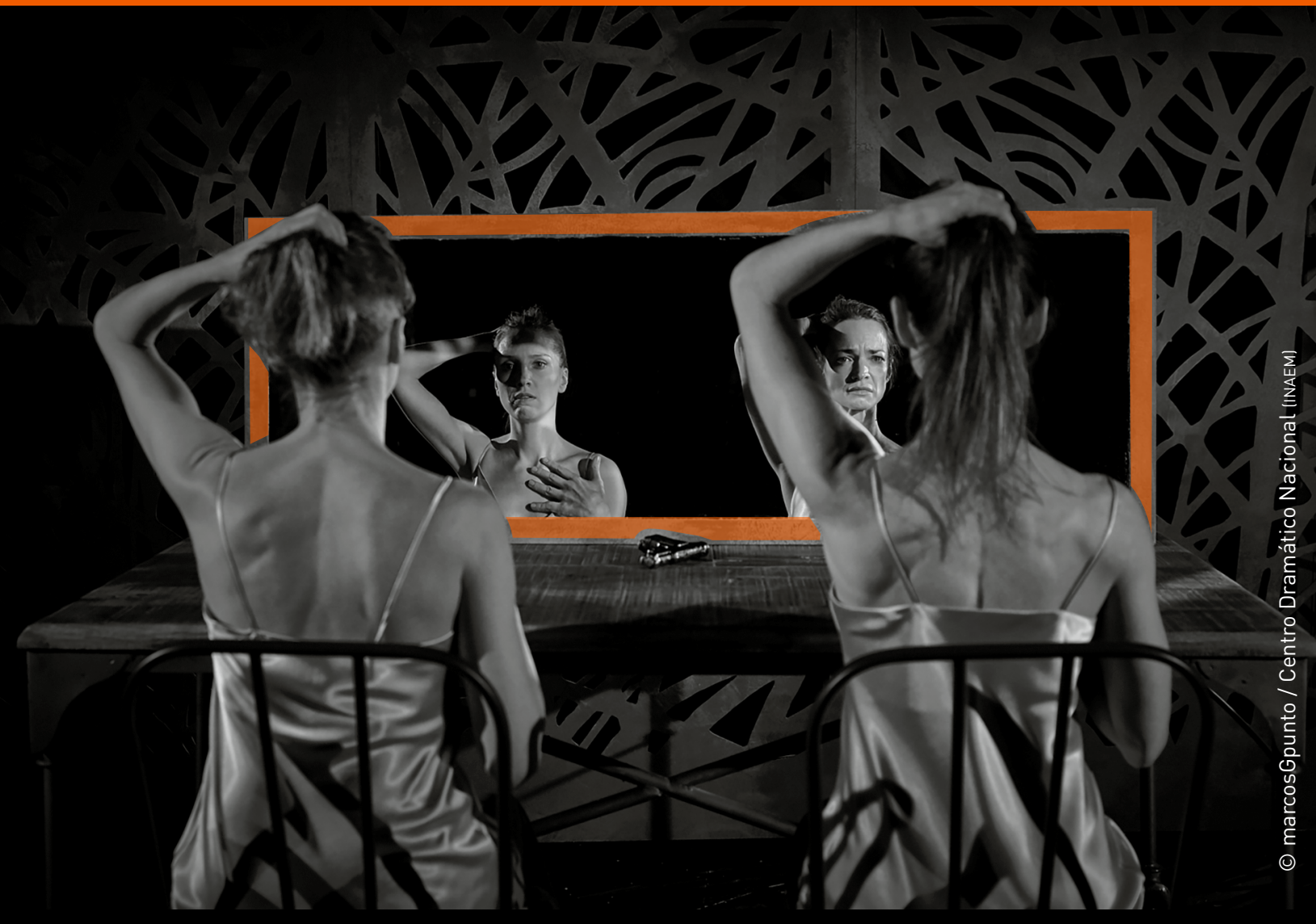





\section{FEMINISMO/S}

Revista del Instituto Universitario de Investigación

de Estudios de Género

de la Universidad de Alicante

Número 30, diciembre de 2017

\section{Dramaturgia femenina actual \\ De 1986 a 2016}

Eva García-Ferrón y Cristina Ros-Berenguer (Coords.) 



\title{
FEMINISMO/S \\ Revista del Instituto Universitario de Investigación de Estudios de Género de la Universidad de Alicante
}

\author{
Revista semestral \\ Editada por el Instituto Universitario de Investigación de Estudios de Género \\ de la Universidad de Alicante \\ con la colaboración del Vicerrectorado de Investigación y Transferencia de Conocimiento
}

Número 30, diciembre de 2017

Directora: Helena ESTABLIER PÉREZ (Universidad de Alicante)

Editora adjunta: Maribel PeÑAlVer VicEA (Universidad de Alicante)

\section{CONSEJO DE REDACCIÓN}

Mar ESQUEMBRE CERDÁ (Universidad de Alicante)

Purificación HERAS GONZÁLEZ (Universidad Miguel Hernández)

Carmen MAÑas Viejo (Universidad de Alicante)

Nieves MONTESINOS SÁNCHEZ (Universidad de Alicante)

Mónica Moreno SeCo (Universidad de Alicante)

$\mathrm{M}^{\mathrm{a}}$ Dolores Ramos (Universidad de Málaga)

María Pilar RodríGUEz PÉREZ (Universidad de Deusto)

$\mathrm{M}^{\mathrm{a}}$ Teresa RuIz CANTERo (Universidad de Alicante)

\section{CONSEJO ASESOR}

Nieves BARANDA LETURIO (UNED)

Ester BARberÁ HEREDIA (Universidad de Valencia)

Karine BERGÈS (Université de Cergy-Pontoise)

Mabel BuRín (Universidad de Buenos Aires)

Silvia CAPORAlE Bizzini (Universidad de Alicante)

Àngels CARABÍ (Universidad de Barcelona)

Rosa CoBo Bedía (Universidade da Coruña)

Pilar Cuder Domínguez (Universidad de Huelva)

Bradley S. EPPS (University of Cambridge)

Joaquín DE JUAN HERRERO (Universidad de Alicante)

$\mathrm{M}^{\mathrm{a}}$ Victoria GoRdillo (Universidad Complutense de Madrid)

Angela O'HAGAN (Glasgow Caledonian University)

Annabel MARTín (Dartmouth College)

Montserrat PALAU (Universitat Rovira i Virgili)

Eulalia PÉREZ SEDEÑo (Consejo Superior de Investigaciones Científicas)

Alicia PUlEo (Universidad de Valladolid)

Carme Riera Guilera (Universitat Autònoma de Barcelona)

Begoña SAN Miguel DEL Hoyo (Universidad de Alicante)

Marta SEgARRA (Universidad de Barcelona)

Cristina SEgura Graíño (Universidad Complutense de Madrid)

María del Carmen SIMÓN PALMER (Consejo Superior de Investigaciones Científicas)

Meri TORRAS (Universidad de Barcelona)

María Teresa Vera BALAnZa (Universidad de Málaga) 


\title{
REDACCIÓN
}

Instituto Universitario de Investigación de Estudios de Género de la Universidad de Alicante

Campus de Sant Vicent del Raspeig

Apdo. 99 E-03080 Alicante

Tel. 965909415 - Fax 965909803

e-mail: revistafeminismos@ua.es; iuieg@ua.es - web: http://ieg.ua.es

\section{SUSCRIPCIÓN}

Instituto Universitario de Investigación de Estudios de Género de la Universidad de Alicante Campus de Sant Vicent del Raspeig

Apdo. 99 E-03080 Alicante

Tel. 965909415 - Fax 965909803

e-mail: iuieg@ua.es - web: http://ieg.ua.es

Precio de cada ejemplar: $12 €$

\author{
Publicaciones de la Universidad de Alicante \\ Campus de San Vicente s/n \\ 03690 San Vicente del Raspeig \\ publicaciones@ua.es \\ http://publicaciones.ua.es \\ Teléfono: 965903480
}

\section{Edita:}

Instituto Universitario de Investigación de Estudios de Género de la Universidad de Alicante con la colaboración del Vicerrectorado de Investigación y Transferencia de Conocimiento

Cuenta con una Ayuda para la Publicación de Revistas Científicas del Vicerrectorado de Investigación y Transferencia de Conocimiento

ISSN: $1696-8166$

DOI: $10.14198 / \mathrm{fem} .2017 .30$

Depósito legal: A-910-2003

\author{
Diseño de cubierta: candela ink \\ Imagen de cubierta: $\odot$ marcosGpunto / Centro Dramático Nacional (INAEM) \\ Maquetación: Marten Kwinkelenberg \\ Impresión: Guada Impresores
}

Feminismo/s no se identifica necesariamente con los contenidos de los artículos firmados.

Prohibida la reproducción total o parcial de los artículos sin la autorización previa.

La revista está indizada en las bases de datos REDIB (Red Iberoamericana de Innovación y Conocimiento Científico), ISOC (Base de datos del Centro de Información y Documentación Científica del CSIC), ERIH PLUS (European Reference Index for the Humanities and Social Sciencies), MLA (Modern Language Association) CIRC, MlAR, Latindex, Dialnet, Ulrich's web y Google Scholar. 


\section{ÍNDICE}

Eva García-Ferrón y Cristina Ros-Berenguer

Introducción.

9

Dosier monográfico: «Dramaturgia femenina actual. De 1986 a 2016» I. Aproximaciones críticas

Eléonore Berger

Tuer la mère. Quand Luce Irigaray rencontre Angélica Lidell

Kill the mother. When Luce Irigaray meets Angélica Lidell

Cristina Casado Presa

Y no vivieron felices para siempre: la reescritura del cuento de hadas

y la problemática de la subjetividad femenina en Nueva historia de la princesa y el dragón de Carmen Resino

And they didn't live happily ever after: the rewriting of the fairy tale and the problematization of female subjectivity in Nueva historia de la princesa y el dragón by Carmen Resino

\section{Helen Freear-Papio}

Resistance retold: historical and mythical narratives in plays by

Romero, Resino, Pascual and De Paco Serrano

Recontando la resistencia: nuevas narrativas míticas e históricas en el teatro de

Romero, Resino, Pascual y De Paco Serrano

Eva García-Ferrón

Araña en bañera y Terraza de café por la noche, de Emma Cohen

Araña en bañera and Terraza de café por la noche, by Emma Cohen

\section{Luisa García-Manso}

Dramaturgas actuales y teatro escrito a pie de escena en España:

El meu avi no va a Cuba, de Victoria Szpunberg.....

Current women playwrights and atage-side written theater in Spain: El meu avi no va a Cuba, by Victoria Szpunberg

Pilar Jódar Peinado

En defensa y Canícula, de Lola Blasco: la revolución hecha teatro

En defensa and Canícula, by Lola Blasco: revolution turned theatre

\section{Maribel Martínez López}

Desmontando clichés o la evolución de los modelos de feminidad y masculinidad en los escenarios

Debunking clichés or the evolution of models of womanhood and manhood on stage 
Nina Namaste

Strawberry jam and roasted chicken: gender, corporeality, and identity formation in Mariló Seco's Mermelada de fresa (1999)

Mermelada de fresa y pollo al horno: género, cuerpo e identidad en Mermelada de fresa, de Mariló Seco (1999)

Adriana Nicolau Jiménez

Aspectos de la maternidad actual en El conejito del tambor de duracell

de Marta Galán

Aspects of current motherhood in the Duracell's bunny with drum by Marta Galán

Francisco José Peña Rodríguez

El teatro de Ana Merino: una propuesta para el siglo XXI

Ana Merino's theater: a proposal for the 21st century

Cristina Ros-Berenguer

Hacia el horizonte de lo colectivo: la «generación en red»y el teatro político de Lola Blasco

Towards the horizon of the collective: The "network generation" and the political theater of Lola Blasco

\section{En primera persona: entrevistas a cuatro voces de la dramaturgia femenina actual}

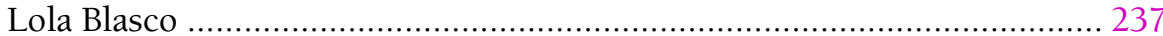

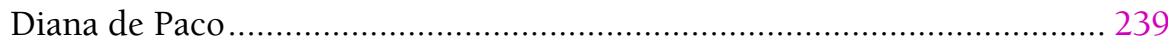

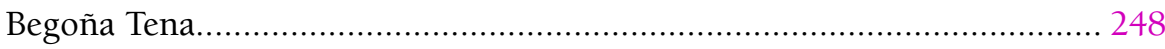

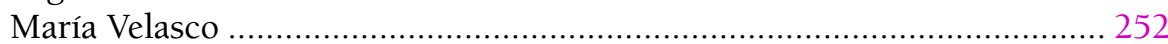

\section{Miscelánea}

Michelle Roche Rodríguez

La «revolución» de Teresa de la Parra: escribir la abnegación mariana desde la celosía.

Teresa de la Parra "revolution": to write the marian abnegation from the lattice

\section{Reseñas}

Isabel G. Gamero. Recensión de: Teoría feminista y liberalismo.

El devenir de una relación problemática. Anabella di Tullio Arias.

Universidad de Málaga, 2016 281

Reseña bio-bibliográfica 


\title{
INTRODUCCIÓN
}

\author{
Eva GARCÍA-FERRÓN \\ Eva.ferron@ua.es \\ Cristina Ros-BERENGUER \\ Cristina.ros@ua.es \\ Departamento de Filología Española, Lingüística General y Teoría de la Literatura \\ Facultad de Filosofía y Letras \\ Universidad de Alicante
}

En 2016 la dramaturga Lola Blasco recibía el Premio Nacional de Literatura Dramática por su obra Siglo mío, bestia mía. Desde que el Ministerio de Cultura comenzó a conceder el galardón, en 1992, solo otras dos dramaturgas lo habían obtenido: Lluïsa Cunillé en 2005 y Laila Ripoll (por un texto escrito junto a Mariano Llorente) en 2015. De veintiséis galardonados/as, tres fueron mujeres. Pocos meses antes de aquel noviembre en que a Blasco le fue entregado su premio, en junio, se había presentado en La Casa del Lector de Madrid un estudio según el cual solo el $23 \%$ de las obras teatrales que se representaron en España entre 2011 y 2014 habían sido escritas por mujeres. Los datos, elaborados por el Grupo Barraquianos de TRAGYCOM a partir de los registros del Centro de Documentación Teatral, revelaban, no obstante, que esa cifra suponía un incremento sobre los porcentajes conseguidos a lo largo de los años anteriores. El estudio demostró, concretamente, que en las últimas dos décadas la presencia de dramaturgas en el panorama teatral español se había duplicado, pasando del 11,1\% en 1993/94 al 23,1\% en 2011/14.

Sin duda, ni el carácter excepcional de los premios a Cunillé, Ripoll y Blasco ni los resultados de este estudio deberían sorprender a las investigadoras e investigadores de este campo, como tampoco a las/os protagonistas y agentes del mundo teatral, dado que son cifras que, como otras que podrían aducirse, confirman la situación de desigualdad entre hombres y mujeres a la hora de poner en escena sus textos. Si elegimos buscar presencia femenina en uno de los 
más destacados escaparates de la escritura dramática actual, podemos acudir al artículo que en el año 2010 publicaba la profesora Francisca Vilches de Frutos sobre la situación de las creadoras en el teatro español contemporáneo y donde citaba, como ejemplo de minoría flagrante, la mínima presencia de las mujeres en la Muestra de Teatro de Autores Contemporáneos celebrada anualmente en la ciudad de Alicante desde 1993. Las cifras aportadas por Vilches de Frutos se referían al periodo comprendido entre 2003 y 2008 y mostraban, en un total de 101 producciones, la presencia únicamente de 13 creadoras. Aunque la situación no parecía nueva en el teatro español, sí se calificaba como preocupante, puesto que, curiosamente, estas cifras eran similares a las alcanzadas por la producción dramática de las mujeres en el primer tercio del siglo XX.

Como vemos, la proporción de estrenos de obras escritas por mujeres en la primera década del siglo XXI era comparable a la que existía prácticamente un siglo antes, y si bien es cierto que las circunstancias sociales españolas harían especialmente difícil que las mujeres ingresaran y permanecieran como miembros de pleno derecho en la sociedad, en cualquiera de sus ámbitos, también lo es que las voces e iniciativas que, desde los años noventa del siglo pasado, advirtieron de su nula presencia en los escenarios tampoco consiguieron que su apoyo y sus esfuerzos por darle visibilidad a la producción femenina tuvieran la continuidad y la fuerza necesarias como para incrementar considerablemente su presencia. El deseo de recuperar espacios vedados y de reafirmar su propia identidad tuvo cierta respuesta desde finales de los años ochenta, ya que fue en 1986 cuando se creó la Asociación de Dramaturgas Españolas, cofundada por Patricia W. O'Connor y Carmen Resino. Esta fecha, que consideramos emblemática, aparece por ello en nuestro monográfico como propuesta de límite inicial para los estudios presentados. Las iniciativas que defienden y difunden el trabajo autoral femenino desde esa fecha por toda la geografía española, que Francisco Gutiérrez Carbajo recoge magníficamente en su introducción a Dramaturgas del siglo XXI, desembocan finalmente en ese 23\% de representatividad que comentábamos al principio.

A pesar de todo lo que el siglo XXI ha podido aportar al panorama teatral en general y al mundo particular de las dramaturgas y mujeres de teatro españolas (hablamos de nuevos medios y también nuevos contextos en los que desarrollar la comunicación, de crear nuevas muestras, encuentros, ciclos y festivales de teatro, de incentivar la investigación y la promoción y de facilitar la formación de los y las profesionales; hablamos también de nuevos conceptos de autoría y participación de la obra artística o de maneras diferentes de producción y distribución del teatro...), lo cierto es que la crisis económica y la inmediata crisis cultural han coartado y limitado muchas de las ofertas, las posibilidades 
y los caminos abiertos. De este modo, la creadora, luchadora incansable, sí, pero también víctima doble de las circunstancias -como mujer y como dramaturga-, se ha visto perjudicada. La consecuencia inevitable es, como se verá en la mayoría de los artículos que siguen, la asunción de que, para poder poner sus obras sobre la escena, la dramaturga debe aventurarse también por el camino de la dirección y de la producción, cuando, además, muchas de ellas también se han formado como intérpretes. Diversificar, arriesgarse, mantenerse constantemente comunicadas, en los medios y para los medios, es el único camino para mantener la vocación de ejercer el acto teatral como acto público.

La pregunta ahora mismo, tan pertinente como espinosa, es qué futuro se adivina en el horizonte teatral para la nueva y fecunda generación de dramaturgas que está creando ya en estos momentos o que se está incorporando al mundo de la escritura dramática. Hay motivos para ser razonablemente optimistas. En primer lugar, circunscribiéndonos a lo académico, la crítica especializada constata la abundancia de textos escritos por mujeres, y estos despiertan un interés genuino entre estudiosas e investigadoras españolas y extranjeras (mayor que entre los investigadores: buena prueba de ello es la autoría de las aproximaciones críticas que contiene este volumen); nos hallamos, por tanto, ante creaciones originales, complejas, con una sustancia dramática atractiva para aquellas/os cuyo cometido es ir más allá de la superficie de los textos.

Sin embargo, quienes mantienen vivo el teatro son los espectadores, las personas que, en esta contemporaneidad traspasada por la todopoderosa tecnología, acuden a las salas a presenciar un arte tan primitivo como absolutamente vigente. ¿Qué pueden brindar los textos escritos por mujeres a las mujeres y hombres de 2017 y de los años que vendrán? Por lo que se infiere de los artículos aquí reunidos, un universo vasto difícilmente reducible a un puñado de temas o formatos. Las dramaturgas de nuestros días escriben monólogos, obras con un reducido elenco de personajes y textos corales, piezas breves y extensas, comedias y dramas, creaciones surrealistas, textos de inspiración histórica o que reinterpretan cuentos tradicionales. Esta rica diversidad formal se corresponde con una profusión de asuntos que engloban, como es obvio, muchos de los temas que abordan los dramaturgos, pero a los que se suman algunos ausentes (nos atrevemos a afirmarlo) de los textos escritos por hombres, de forma muy llamativa la maternidad, asunto tratado por las autoras desde las más distintas perspectivas, algunas insospechadas y todas muy necesarias en el contexto social actual.

En definitiva, las dramaturgas de las últimas décadas del siglo XX y las primeras del XXI convocan y convocarán al público en torno al hecho teatral 
porque sus obras son elaborados espejos que nos muestran, sin simplificaciones ni maniqueísmos porque son creaciones artísticas, cómo somos, cómo podríamos llegar a ser y por qué caminos hemos de transitar las mujeres y los hombres de nuestro tiempo para construir un mundo más habitable.

La sección de «Aproximaciones críticas» de este monográfico se abre con el trabajo realizado por la investigadora francesa Eléonore Berger titulado «Tuer la mère. Quand Luce Irigaray rencontré Angélica Liddell». En él se analizan las posiciones a priori radicalmente opuestas que acerca del tema de la maternidad sostienen la psicoanalista y filósofa belga Luce Irigaray y la dramaturga Angélica Liddell. Comparando el texto «Le corps-à-corps avec la mère» que Irigaray leyó como conferencia en Montreal en 1980, y el planteamiento que Liddell propone en su espectáculo Todo el cielo sobre la tierra (el síndrome de Wendy) en 2013, Berger muestra cómo la dramaturga española trabaja el matricidio original denunciado por Irigaray para construir una versión violentamente moderna de la emancipación del deseo femenino. A través de los códigos feministas de los años setenta, el artículo descubre una Angélica Lidell que presenta de nuevo una relación con la maternidad marcada por el rechazo, el odio y la contradicción.

Las características de la producción de las dramaturgas de los 80 es el marco a partir del cual Cristina Casado Presa estudia un texto concreto en «Y no vivieron felices para siempre: la reescritura del cuento de hadas y la problemática de la subjetividad femenina en Nueva historia de la princesa y el dragón de Carmen Resino». Las creaciones de Paloma Pedrero, Maribel Lázaro, Lourdes Ortiz o Carmen Resino funcionaron como vehículos de apertura, puesto que cuestionaban valores sociales, morales y culturales fuertemente asentados en la ideología hegemónica de la España de aquellos años. Las mujeres habían sido representadas en escena de forma impropia, y estas autoras se proponen re-presentarlas poniendo en el centro de la escena las dificultades y vivencias de sus coetáneas. Para despertar las conciencias, Resino parodia el cuento de hadas y lo convierte en un discurso transgresor. Nueva historia de la princesa y el dragón es la reescritura de un cuento tradicional porque en ese tipo de narraciones las relaciones de poder son una de las premisas centrales, del mismo modo que en las interpretaciones feministas más modernas. Tanto en el cuento de hadas feminista como en la dramaturgia femenina de los 80 , y en este texto de Carmen Resino, el elemento de subversión central se encarna en la protagonista femenina. La princesa Wu-Tso es una heroína compleja y obstinada que desafía al dragón del patriarcado que le impide acceder al poder por su condición de mujer. 
Helen Freear-Papio analiza una muestra significativa de obras de dramaturgas españolas de las tres últimas décadas en «Resistance retold: historical and mythical narratives in plays by Romero, Resino, Pascual and De Paco Serrano». Este trabajo revela cómo los tradicionales bastiones narrativos del poder masculino, la historia y el mito, pueden ser terrenos fértiles para la dramaturgia femenina. Si se toman argumentos procedentes de la mitología o la historia y se reescriben desde puntos de vista más privados, las figuras femeninas emergen de la penumbra a las que las condenaba el rol secundario decidido por las crónicas de autoría masculina. En obras como Los eróticos sueños de Isabel Tudor, de Carmen Resino, o Las voces de Penélope, de Itziar Pascual, figuras femeninas muy conocidas se deshacen de las máscaras que habían sido obligadas a usar y despliegan en el centro del escenario toda su complejidad y su capacidad de acción, demostrando que la pasividad y la apatía fueron solo comportamientos enseñados a las mujeres para perpetuar el patriarcado.

En el trabajo «Araña en bañera y Terraza de café por la noche, de Emma Cohen», Eva García-Ferrón ofrece una biobibliografía de la polifacética artista, conocida sobre todo como actriz pero con una trayectoria literaria notable. Sus dos únicas obras dramáticas para adultos, escritas en su madurez, son el testimonio del interés de la autora por explorar nuevos territorios. Araña en bañera es un monólogo que explora el peso de la herencia familiar remota y próxima en una mujer lesbiana abandonada por su amante y que se dispone a suicidarse. Terraza de café por la noche es una apuesta audaz por actualizar el teatro surrealista, una materialización del arte dramático que, por sus temas intelectuales, sus protagonistas deshumanizados y su carencia de línea argumental, supone un reto para el/la autor/a y para su audiencia.

Luisa García-Manso nos propone adentrarnos en la dramaturgia de la autora Victoria Szpunberg a través de su Trilogía sobre la fragilidad de la memoria, donde se ensayan diferentes formas dramáticas de aproximarse a la representación de la dictadura argentina y de su exilio. En «Dramaturgas actuales y teatro escrito a pie de escena en España: El meu avi no va a Cuba, de Victoria Szpunberg», García-Manso se detiene en la primera obra de este proyecto, con la que la dramaturga nacida en Buenos Aires inicia un recorrido por recuerdos fragmentarios, transmitidos a través de su familia, de un pasado que marcó su vida. La autora del artículo interpreta la trilogía dentro del amplio contexto de la literatura de los hijos de la dictadura argentina, convertidos en autores y autoras que indagan en el pasado familiar como medio para construir su propia identidad. Siendo, además, un modelo de escritura dramática construido en parte desde la escena, con participación de los intérpretes, esta pieza le permite asimismo realizar una reflexión sobre las peculiaridades de los nuevos modelos 
de autoría teatral, sobre todo en lo que se refiere a la interacción entre la labor de escritura y la creación escénica.

El teatro español actual ofrece un muestrario significativo de realidades sociales, como las nuevas feminidades y masculinidades, las relaciones de pareja, los roles familiares, las relaciones interpersonales y el efecto de la irrupción de las nuevas tecnologías. Maribel Martínez López presenta diversos ejemplos de todo ello en su artículo «Desmontando clichés o la evolución de los modelos de feminidad y masculinidad en los escenarios». La obras teatrales funcionan como espejos para las/os espectadoras/es, y se convierten en valiosas herramientas didácticas y de lucha, de manera que permiten avanzar en la solución de muchos de estos conflictos. Textos como Whatsapp, de Juana Escabias, Hazme una perdida, de Mercé Sarriás o Cama, de Pilar G. Almansa, entre otros, llevan a escena las inquietudes vitales latentes en la sociedad contemporánea.

Nina Namaste explora la creación de una dramaturga andaluza en «Strawberry jam and roasted chicken: gender, corporeality and identity formation in Mariló Seco's Mermelada de fresa (1999)». Esta pieza teatral sigue la línea de obras de arte plásticas y literarias en las que prácticas insólitas relacionadas con la comida recrean o evocan estructuras de poder. La obra de Mariló Seco incide en la tendencia masculina a tratar a las mujeres como mercancía y en la complicidad de las propias mujeres al contribuir a perpetuar un sistema que subraya su dimensión física como objeto de disfrute para los hombres. La obra se abre con la protagonista intentando relajarse mediante el ritual de extender mermelada sobre su pelo; la inestabilidad mental del personaje toma forma escénica en el carácter fragmentario del texto, y el asunto central no es si la protagonista está o no desequilibrada, sino por qué se siente acorralada y no encuentra un modo satisfactorio de construir su identidad.

El tema de la maternidad aparece de nuevo bajo un tratamiento diferente en el artículo de Adriana Nicolau Jiménez «Aspectos de la maternidad actual en El conejito del tambor de duracell de Marta Galán», donde además se analiza la adaptación y la puesta en escena de la obra realizada por Marc Martínez en 2015. Partiendo de que las iniciativas escénicas que problematizan el tema de la maternidad y la paternidad parten mayoritariamente de autoras, este ensayo pone sobre la mesa un texto que muestra el desamparo emocional, laboral y económico que puede generar la maternidad en nuestra sociedad. Siguiendo aproximaciones feministas sobre esta materia, la autora del artículo analiza esta pieza teatral como alegato a favor de la politización de los cuidados y contra la devaluación del trabajo reproductivo de las mujeres, al tiempo que sostiene que su puesta en escena mostró en su día una interesante adaptación 
que menguó notablemente el alcance de reflexión sobre la dimensión política de la maternidad, evidenciando así la omnipresente perspectiva masculina.

La autora alicantina Lola Blasco, galardonada con el Premio Nacional de Literatura Dramática 2016, es objeto de dos de los estudios presentados en este volumen. Su teatro, englobado en esa dramaturgia emergente de autoras y autores unidos por su compromiso social y político, presenta particularidades que Pilar Jódar Peinado analiza a partir de la intención explícita de Blasco de influir en la capacidad crítica de los espectadores. Con su artículo «En defensa y Canícula, de Lola Blasco: la revolución hecha teatro» la autora del ensayo estudia dos de las obras más representativas de su teatro político, En defensa (Un concierto de despedida), del año 2011, y Canícula (Evangelio apócrifo de una familia, de un país), del 2016, a las que considera piezas esenciales de su teatro revolucionario y que analiza a través de lo que para la investigadora es el contexto creativo de Blasco: el metateatro, el teatro documento y el teatro de la revolución, así como el empleo de mitos y símbolos como modo de indagación de la insatisfacción social y existencial.

Por otra parte, en el artículo de Cristina Ros-Berenguer «Hacia el horizonte de lo colectivo: la «generación en red» y el teatro político de Lola Blasco», son los testimonios de la propia Blasco los que nos permiten acercarnos a su discurso político, siendo evidente entonces su concepción poética del drama y el enorme esfuerzo que le ha supuesto el poder mantenerlo sobre las tablas. Definidora de su propia generación creativa como aquella ligada a un nuevo concepto de identidad social, la dramaturga refrenda como ninguna varias de las posiciones críticas revisadas en el artículo que advierten de la existencia en nuestro teatro último de una manera a la vez heredada y propia de interpelar a la realidad, en la cual las dramaturgas españolas jóvenes configurarían una parte destacada de esta.

Tres obras recientes de la dramaturga, poeta y narradora Ana Merino (escritas en 2012, 2014 y 2016) son el objeto de estudio de Francisco José Peña Rodríguez en «El teatro de Ana Merino: una propuesta para el siglo $\mathrm{XXI}$ ». El investigador subraya, como otras autoras de estos artículos críticos, la conveniencia de análisis de la obra como un todo literario y, simultáneamente, de su puesta en escena. Solo esta visión holística permite a la estudiosa o al estudioso detectar las estéticas singulares que se van sumando a nuestra tradición teatral. La producción dramática de Ana Merino se interna en lo social de forma oblicua, ya que la complejidad de sus personajes (en su mayoría de clase media) no permite inferir un propósito didáctico evidente. De los textos de Merino emana lo que Peña Rodríguez denomina un «compromiso con la humanidad», y ello lo logra la autora especialmente por la maestría en 
el uso del lenguaje de sus criaturas, que favorece la identificación del lectorespectador con ellas.

A continuación de este bloque de aproximaciones críticas, nuestro monográfico presenta un apartado que protagonizan cuatro voces de la dramaturgia femenina actual: Lola Blasco, Diana M. de Paco Serrano, Begoña Tena Moya y María Velasco, que han colaborado generosamente con este proyecto respondiendo a distintas preguntas relacionadas con el teatro escrito por mujeres.

Para responder a nuestro cuestionario hemos elegido a cuatro dramaturgas de edades, formación y procedencia geográfica variadas. Sus fechas de nacimiento van desde 1973 hasta 1984, y sus textos han sido escritos mayoritariamente en la segunda década del siglo XXI. Nacidas en distintos puntos de la geografía nacional, dos de ellas desarrollan su actividad profesional en Madrid (María Velasco y Lola Blasco), mientras que las otras dos siguen vinculadas a las ciudades donde dieron sus primeros pasos profesionales, Valencia en el caso de Begoña Tena y Murcia en el de Diana M. de Paco. Todas han cursado estudios superiores de diversas especialidades (Dramaturgia, Comunicación Audiovisual, Historia del Arte y Filología Clásica), dos son doctoras y dos ejercen la docencia universitaria. Y todo ello lo han compaginado con una intensa y heterogénea actividad en el ámbito teatral. No es de extrañar, pues, que sus respuestas a nuestras preguntas contengan una carga considerable de reflexión, de experiencia y de fresca sabiduría sobre el tema que nos ocupa.

Salvo Diana M. de Paco, que es ante todo dramaturga (solo ocasionalmente coproductora de alguna de sus obras), estas mujeres reúnen en su persona todas las facetas posibles relacionadas con el hecho teatral. Tanto Begoña Tena como María Velasco y Lola Blasco son directoras y actrices (esto último con intensidad dispar). A ello hay que sumar la faceta de cantante de Tena y la de fundadora de una compañía teatral de Blasco. Su vocación surge en la primera juventud, incluso antes. De Paco rememora que «Desde mi infancia he tenido una estrecha relación con el teatro», y Lola Blasco reconoce que «Adoro el teatro desde que tengo uso de razón». Begoña Tena accedió primero a las tablas desde la interpretación, y María Velasco por la vía de la literatura, de la escritura dramática.

Coinciden en gran medida en su concepción del teatro como espacio de libertad y de encuentro con el público. Lola Blasco seguramente sintetiza el sentir de sus compañeras cuando explica que, muy pronto en su trayectoria, descubrió que los textos que le legaba la tradición constreñían la libertad que ella demandaba del arte dramático, que no respondían a sus aspiraciones, y que ello la condujo a crear nuevas historias que incluyeran roles nuevos para las mujeres. Begoña Tena aspira a desterrar de escena los estereotipos de género 
y a construir personajes femeninos que actúen como motores de la acción y la trama.

La idea de compromiso está presente, explícita e implícitamente y con distintas interpretaciones, en el discurso de estas dramaturgas. Abarca un amplio espectro de objetivos o anhelos; De Paco escribe sobre «Agitar las almas», y Blasco propone que, si el teatro es mímesis de la realidad, la creación de textos distintos, rompedores, puede en alguna medida modificar nuestro contexto. Los asuntos que les preocupan son diversos: la memoria histórica desde una perspectiva de género, las generaciones de niñas que están creciendo en entornos de violencia extrema, la cosificación de la mujer, la influencia que siguen ejerciendo sobre nosotras/os los clichés sexuales del heteropatriarcado en los que se educaron nuestros ascendientes, etc. El diálogo con el público es la herramienta para que el compromiso sea efectivo: la particularidad del género dramático, que permite concebir una realidad alternativa y exponerla en escena para desencadenar un intercambio con el espectador, es para estas creadoras crucial.

En cuanto a la situación de la dramaturgia española actual, estiman que la producción de sus compañeras es heterodoxa en contenido y forma, si bien la coincidencia en los temas sociales es innegable. Mencionan que a menudo nos hallamos ante textos que más que dar respuestas quieren proponer preguntas. Para alguna de ellas las obras de las dramaturgas son más valientes y comprometidas que las de sus compañeros de profesión. Begoña Tena, atenta a la escritura de las autoras más jóvenes, constata que éstas presentan en escena nuevas realidades sentimentales y sexuales. Se percibe en estas cuatro voces, por tanto, un optimismo notable (justificado, en nuestra opinión) respecto a la dramaturgia femenina, que atraviesa un momento excelente o, cuando menos, ha conquistado definitivamente un espacio propio del que carecía en otras épocas. 



\section{DOSIER MONOGRÁFICO: \\ DRAMATURGIA FEMENINA ACTUAL \\ DE 1986 A 2016}

I. APROXIMACIONES CRÍTICAS 

Para enlazar con este artículo / To link to this article:

http://dx.doi.org/10.14198/fem.2017.30.01

Para citar este artículo / To cite this article:

Berger, Éléonore. «Tuer la mère. Quand luce irigaray rencontre Angelica Liddell». En Eva García-Ferrón y Cristina Ros-Berenguer (coords.), Dramaturgia femenina actual. De 1986 a 2016. Feminismo/s, 30 (diciembre 2017): 21-30, DOI: 10.14198/fem.2017.30.01

\title{
TUER LA MÈRE QUAND LUCE IRIGARAY RENCONTRE ANGÉLICA LIDDELL
}

\author{
KILL THE MOTHER \\ WHEN LUCE IRIGARAY MEETS ANGÉLICA LIDDELL
}

\author{
Éléonore BERGER \\ Universidad de la Sorbonne Nouvelle-Paris 3 \\ eleo.berger@gmail.com \\ orcid.org/0000-0001-8128-5332
}

\section{Résumé}

Dans les années 70, des psychanalystes comme Julia Kristeva et Luce Irigaray repensent la maternité et la figure de la mère, à rebours de la pensée freudienne, afin de poser les bases d'une nouvelle appréhension et une nouvelle construction de l'identité féminine. Quarante ans de féminisme plus tard, Angélica Liddell hurle sa haine des femmes et de la figure maternelle sur les scènes européennes. Cet article a pour but de faire se rencontrer ces deux formes de pensées a priori radicalement opposées, notamment en comparant «Le corps-à-corps avec la mère» de Luce Irigaray et la lutte à mort que Liddell organise dans Tout le ciel au-dessus de la terre. Il s'agit de voir comment Liddell, peut-être contre son gré, travaille le matricide originel dénoncé par Irigaray pour délivrer une version violemment moderne de l'affranchissement du désir féminin.

Mots-clefs: Figure maternelle et figure féminine, Identité, Angélica Liddell, Luce Irirgaray, Féminisme.

\begin{abstract}
During the seventies, psychoanalysts such as Julia Kristeva and Luce Irigaray went against Freud's vision of both maternity and the figure of the mother by creating a new way of understanding these concepts to allow a different construction of feminine identity. Forty years of feminism later, the playwright and performer Angélica Liddell shouts her hatred of women and the figure of the mother on every European stage.
\end{abstract}

Feminismo/s 30, diciembre 2017, pp. 21-30

Los contenidos de la revista se publican bajo una licencia de Creative Commons Reconocimiento 4.0 Internacional (CC BY 4.0) 
This article aims to bring these two schools of thought, which at first glance appear diametrically opposed, together by comparing Irigaray's «Le corps-à-corps avec la mère» and the struggle shown by Liddell in Tout le ciel au-dessus de la terre. This paper intends to highlight how Liddell, possibly against her will, works with the original matricide illustrated by Irigaray and creates a violently new version of the female's freedom of desire.

Keywords: Mother's figure and feminine figure, Identity, Angélica Liddell, Luce Irigaray, Feminism. 


\section{INTRODUCTION}

«FOR ALL MOTHERS! FUCK YOU! MOTHER!» (Liddell 2013, 55). C'est sans équivoque qu'Angélica Liddell apostrophe la figure maternelle dans son spectacle présenté en 2013, Tout le ciel au-dessus de la terre (le syndrome de Wendy). Avec la radicalité et l'énergie empreinte de violence et d'éclatement qui caractérisent son œuvre depuis ses débuts, la dramaturge et sa compagnie Atra Bilis construisent une réflexion sur le passage de la vie adolescente à la vie adulte en mêlant le mythe de Peter Pan à la tuerie perpétrée à Utoya en juillet 2011. Le monologue qui occupe la dernière heure de ce spectacle permet le déploiement de la parole d'Angélica Liddell, qui quitte le personnage Wendy pour briser la barrière de la pudeur en son propre nom et déverser sur scène sa haine dirigée à l'encontre de «toutes les mères». En cela, son processus créateur vient conforter la constatation que fait Luce Irigaray dans «Le corps-à-corps avec la mère», une conférence qu'elle a donnée en 1980 à Montréal dans le cadre du cinquième colloque québécois sur la santé mentale organisé autour du thème des «femmes et la folie» et qui sert de point de départ de notre réflexion sur la portée féministe ambiguë de l'œuvre d'Angélica Liddell. Une partie de la réflexion d'Irigaray, dans cette conférence, se fait anthropologique: elle tente de reconstruire une forme de généalogie de la domination masculine, assurée par la main-mise faite sur le corps de la femme, le désir pour elle et son désir à elle. Elle part de cette hypothèse, s'inscrivant immédiatement à rebours de la pensée freudienne: «ce qui apparaît dans les faits les plus quotidiens comme dans l'ensemble de notre société et de notre culture, c'est que celles-ci fonctionnent originairement sur un matricide» (23). La haine que Liddell voue au monde entier n'épargne personne, mais se concentre particulièrement sur les figures féminines qu'elle rejette et dont elle regrette de faire partie dans son journal La Fiancée du fossoyeur: «[...] pardonne-moi de parler des femmes en étant femme [...] ça ne diminue en rien ma misogynie» $(2014,162)$. Cette misogynie revendiquée fait d'elle une personnalité souvent contestée, voire détestée. Dans You are my destiny (Le viol de Lucrèce) (2014), elle prend le point de vue de Tarquin, prenant de revers toute une tradition d'interprétation du mythe et excitant l'ire des spectateurs et plus particulièrement des spectatrices; 
Fabienne Pascaud écrit par exemple qu' «autour du viol de la sage et trop belle Lucrèce par Tarquin, dans la Rome antique du VIe siècle avant Jésus-Christ, elle [Angélica Liddell] a orchestré une toxique variation qui condamne et légitime à la fois le violeur».

Provocatrice et subversive, Liddell bouleverse les lignes d'interprétation. Le matricide est chez elle entièrement consommé, elle le consacre lorsqu'elle se désigne comme «née du sexe d'une détraquée mentale» dans la mesure où elle cherche par tous les moyens à s'éloigner de cette figure quand Irigaray prône une réunion avec celle-ci. Folie, féminisme, maternité et création sont des entités que Liddell fait jouer en permanence, notamment dans son exploration des limites et représentations du corps féminin. On peut donc supposer que le rapport conflictuel qu'entretient la dramaturge avec les figures féminines, et par extension avec les différents mouvements féministes dont elle se désolidarise, trouve un point d'ancrage dans le rapport conflictuel qu'elle entretient avec la figure maternelle.

\section{2. «MOI, SOEUR JUMELLE DE LILITH, ENNEMIE DES ACCOUCHEMENTS, DÉMON DANS LE DÉSERT [...]» (LIDDELL 2014, 163)}

Nous avons à veiller à autre chose: ne pas retuer la mère qui a été immolée à l'origine de notre culture. Il s'agit de lui redonner la vie, à cette mère, à notre mère en nous, et entre nous. Il faut que nous refusions que son désir soit anéanti par la loi du père. Nous devons lui donner droit au plaisir, à la jouissance, à la passion, lui redonner droit à la parole, parfois aux cris et à la colère. (Irigaray 30)

La figure paternelle est presque absente des œuvres d'Angélica Liddell, et l'on peut supposer que c'est la dramaturge elle-même qui endosse le rôle d'exécutrice de cette «loi du père» en consacrant le matricide. Déjà dans le «Triptyque de l'affliction», trois pièces sur le thème de la dégradation familiale (Monsieur et Madame Palavrakis (2001), Once upon a time in West Asphixia (2002) et Hysterica Passio (2003)), elle avait amorcé ce travail de démolition des figures parentales. Avec Lesiones incompatibles con la vida (2003): un spectacle de trente minutes où elle déclare ne pas vouloir d'enfants, elle passe pour la première fois de la fiction à la confession et prend en charge la parole à la première personne. Quelques années plus tard, dans Tout le ciel au-dessus de la terre, elle reprend une fois encore ce dispositif confessionnel en confondant les paroles du personnage de Wendy et le brut aveu de ses pensées qui jaillissent en logorrhée vindicative. Laccusation portée contre les mères fustige les «suppléments de dignité»: 
WENDY.- [...] Être mère, c'est le must. Être mère, ça rapporte tous les suppléments de dignité.

Dès que leur ventre se met à les démanger, elles réclament tous les suppléments de dignité.

Tu peux être la dernière des ordures, le simple fait d'être mère te rapporte tous les suppléments de dignité.

Tu peux être stupide et mauvaise, le simple fait d'être mère te rapporte tous les suppléments de dignité.

EN MAJUSCULES

Tu peux utiliser tes enfants pour te défendre, faire du chantage aux sentiments, le simple fait d'être mère te rapporte tous les suppléments de dignité. (68)

Ainsi la figure maternelle devient l'allégorie de l'hypocrisie du monde que la dramaturge ne cesse de dénoncer. En appuyant sur la fonction utilitariste à l'échelle sociale de l'image de mère, Liddell opère une déconstruction -par la désacralisation- du mythe de la femme-mère, cette figure de Marie ancrée dans la culture occidentale faisant de la maternité un accomplissement pour le sujet féminin. Irigaray pense qu'il est «nécessaire, pour ne pas être complice du meurtre de la mère, que nous affirmions qu'il existe une généalogie de femmes» (29-30). Pour Liddell, cette généalogie est un cycle dont il s'agit plutôt de s'affranchir: tuer la mère, c'est justement s'éloigner de la tare, de la «détraquée mentale». Elle lie ainsi la folie de la mère et la folie de la fille, rendant la première responsable de la seconde au coeur d'un mouvement cyclique aussi indéfectible que pessimiste:

Après avoir accouché, les femmes n'ont rien d'autre, les mères pétrissent leurs filles avec ce qu'il y a de pire en elles pour que l'histoire se répète. La fille de Wendy, la fille de la fille de Wendy, la fille de la fille de la fille de Wendy, la fille de la fille de la fille de la fille de Wendy... (70)

En effet, sa singularité se veut violemment coupée de toute origine et c'est ce qu'elle exprime dans son journal La Fiancée du fossoyeur:

Dans le ventre de ma mère, j'étais déjà brisée. Les yeux, les bras et les jambes mélangées comme des morceaux de boeuf dans un bouillon prophétique. [...] Quel genre d'homme peut trouver son origine dans un paysage, alors qu'il n'y a d'autre origine qu'un ventre débordant de liquide fécal. [...] Le moindre conflit me donne la nausée. Ce doit être une séquelle. Laffrontement me ramène à la division originelle de mes extrémités dans le sein maternel. Je ne le supporte pas. (91)

A l'origine ne se trouve pas une sécurité, un lieu protecteur, mais bien une division. Division qui par la suite engendre une monstruosité chronique et de transmission: «Les mères font de leurs filles leurs jumelles nauséabondes, sans même le faire exprès, sans même s'en rendre compte, elles pétrissent 
avec ce qu'il y a de pire en elles» déclare Liddell dans Tout le ciel au-dessus de la terre (68). Irigaray se prend à rêver à la fin de sa conférence à une «femme célébrant l'eucharistie avec sa mère [...] [qui] pourrait être délivrée de toute haine ou ingratitude vis-à-vis de sa généalogie maternelle» (33). Mais Liddell ne cherche pas cette libération car, au contraire, elle travaille avec l'aliénation. Il s'agit pour elle de rompre le cycle de transmission généalogique pour faire quelque chose d'autre de cette «tare»; de la folie congénitale, elle bascule alors vers une appropriation de diverses formes de folies qu'elle utilise à des fins créatrices. Elle ne travaille en effet qu'à partir de matériaux qui entretiennent une intimité essentielle avec des formes de folie: la douleur, le meurtre, l'idiotie, le mal de vivre, la bile noire dont sa compagnie porte le nom. En cela, elle semble incarner l'être de douleur dépeint par la psychanalyste Julia Kristeva dans son essai sur la littérature et l'abjection:

La douleur comme lieu du sujet. Là où il advient, où il se différencie du chaos. Limite incandescente, insupportable entre dedans et dehors, moi et autre. Saisie première, fugace: «douleur», «peur», mots ultimes visant cette crête où le sens bascule dans les sens, l'«intime» dans «les nerfs». Lêtre comme mal-être. (165)

Le mal-être pourtant n'est jamais chez Liddell un apitoiement, à la plainte se substitue une forme de dissection poétique et scientifique. De ses émotions-symptômes, elle déduit des syndromes. Tout le ciel au-dessus de la terre constitue une série des réflexions, constructions, variations autour du «syndrome de Wendy». Elle choisit de prendre le contre-pied en n'essayant jamais de se présenter sous l'apparat de la raison ou du raisonnable, travailler avec la folie lui permet de travailler avec une condition féminine pour laquelle elle ne prend pas les armes mais plutôt contre laquelle elle s'arme:

Tout comme j'ai conscience de la mortalité ou de la douleur, j'ai conscience - brutalement conscience - d'être femme. Je ne peux pas éviter de me sentir femme. C'est ancré en moi, je ne peux pas m'en défaire. Et cela implique des tas de choses à supporter, comme ces petits rituels d'humiliation qui nous sont imposés par le simple fait d'être femme. C'est pour moi insurmontable. Alors je dois transformer la douleur en quelque chose d'autre: quelque chose de beau. Non pas que je trouve de la beauté dans l'horreur, mais j'ai besoin de transformer l'horreur pour survivre. $(2012,45)$

Il s'agit alors pour elle non seulement de renverser ce qu'elle considère comme le privilège moral hypocrite de la figure maternelle, mais surtout de ne pas faire advenir cette fonction maternelle. 


\section{3. «JE PRÉFÈRE LES ENFANTS SANS ENFANTS. C'EST CE QUE JE PRÉFÈRE. LES ENFANTS SANS ENFANTS» (LIDDELL 2013, 67)}

C'est là toute la problématique du «syndrome de Wendy»: comment échapper à cette figure maternelle, symbole de l'abjection du monde des adultes? Comment soi-même, étant femme, ne pas devenir mère? Pour Luce Irigaray, la réponse est claire: la femme est indissociable de son rôle de mère, mais celle-ci ne doit pas être considérée uniquement par le prisme biologique. Être mère c'est aussi et surtout être créatrice, donner naissance à une œuvre au sens large: «nous procréons et créons autre chose que des enfants: de l'amour, du désir, du langage, de l'art [...]» (Irigaray 27). Liddell, toute mère de ses œuvres qu'elle est, affirme pourtant une singularité particulière, que ce soit métaphoriquement ou concrètement car elle se refuse à la fonction reproductrice:

PETER. - Vous jouez toutes à être mères. Vous adorez être mères.

WENDY. - Je ne veux être la mère de personne.

$[\ldots]$

PETER. - Les mères sont des raclures, des salopes, des vraies raclures!

WENDY. - Où as-tu mal, Peter?

PETER. - Laisse-moi, ce n'est pas ce genre de douleur! Je peux très bien faire sans mère. Je n'ai pas besoin d'une idiote de mère.

WENDY. - Je suis Wendy, je suis Wendy, je suis Wendy, je suis Wendy, je suis Wendy, je suis Wendy.... (19-20)

A cette fonction, elle trouve deux alternatives possibles. Dans le long monologue qu'elle performe en 2003, Lesiones incompatibles con la vida, Liddell déclare qu'elle ne veut pas d'enfants et utilise pour se représenter la métaphore d'une épidémie de ressentiment. Cette notion de «contagion» est intéressante en ce qu'elle constitue une alternative à celle de «reproduction»: la transmission s'effectue de côté, par endroits, comme un virus. D'un point de vue poétique, l'œuvre de Liddell peut être abordée sous ce prisme épidémique. Elle transmet le ressentiment et la haine car elle dépasse le cadre du théâtre en mettant en place un dispositif de création traversé par ses expériences personnelles et ses émotions face au monde. De plus en plus, journal intime, confession et pièce de théâtre se confondent et la personne contamine le personnage. Cette confusion des cadres génériques, tissu de contagion, permet la création d'un lien entre traumatisme personnel et histoire collective. Cela se produit entre pédophilie, peur de vieillir et drame d'Utoya dans le cas de Tout le ciel au-dessus de la terre: les jeunes garçons tués sur l'île deviennent l'objet du désir de Wendy. En creusant sa singularité et maniant l'intime, le je, Liddell trouve une première alternative au modèle reproductif. Mais l'on peut considérer que sa position de colère, de violence et de rejet des figures féminines est en elle-même 
une réinterprétation de ce schéma de construction de l'identité. Hélène Rouch, biologiste travaillant sur les limites de l'identité, se penche sur le rapport au placenta, ou plutôt, au placenta en lui-même. Pour elle, il est la membrane par excellence, permettant de penser la subjectivité, toujours en rapport à l'autre. Alors que chez Irigaray le placenta apparaît comme un gouffre terrifiant car écarté de la femme, il est chez Rouch un espace d'accueil. Elle remarque notamment qu'au niveau des cellules, il n'y a pas systématiquement des mécanismes de contre-agression: mais plutôt que la membrane peut accepter le corps étranger. Elle remet ainsi la notion d'identité qui repose sur l'exclusion de l'autre, et sur laquelle Irigaray s'appuie, peut-être inconsciemment. Le placenta comme «tiers»: c'est aussi une réponse aux psychanalystes, elle donne une autre idée de la mère, et de la supposée fusion naturelle entre la mère et l'enfant. Elle montre bien que et l'enfant et la mère sont dans la perte. Elle met ainsi en lumière l'archaïsme auquel s'accroche encore la pensée d'Irigaray tout en se débattant pour s'en extirper. Irigaray dénonce l'image de la mère que l'absence de corps-à-corps crée: «La mère est devenue monstre dévorant, par effet en retour de la consommation aveugle d'elle dans son ventre» (27) mais ne voit le positif que l'on peut trouver dans cet éloignement. Liddell développe elle aussi le rapport de la maternité avec la dévoration, mais en inversant ce rapport dans Tout le ciel au-dessus de la terre: "Je secrète à toute heure un lait sulfureux / qui ne nourrit pas» (57). Pour elle, la mère ne nourrit pas, elle ne se nourrit pas. Elle, symbole de la reproduction, devient une figure de la stérilité. Cette figure paradoxale permet alors le développement d'un personnage féminin en lutte avec sa condition, un personnage pour qui la maternité est tout à la fois un apport, un supplément, et pourtant un manque, une absence, un estomac vide qui demande à être comblé. En quelque sorte, Liddell, dans sa radicalité, obéit au programme d'Irigaray, elle «prend acte» de la coupure du cordon.

4. «JE SUIS VÊTUE DE CHAIR ET DE RIEN D'AUTRE» (LIDDELL 2014, 78)

Luce Irigaray lance un appel à la fin de sa conférence:

Nous avons aussi à trouver, retrouver, inventer, découvrir, les mots, les phrases, qui disent le rapport le plus archaïque et le plus actuel au corps de la mère, à notre corps, les phrases qui traduisent le lien entre son corps, le nôtre, celui de nos filles. Nous avons à découvrir un langage qui ne se substitue pas au corpsà-corps, ainsi que tente de le faire la langue paternelle mais qui l'accompagne, des paroles qui ne barrent pas le corporel mais qui parlent «corporel». (31)

Il s'agit de contrer ce matricide originel, de créer des liens entre toutes les femmes, d'encourager la sororité par un engagement concret du corps et du 
langage. Elle propose une alternative intéressante en préconisant et décrivant des conditions concrètes de production de ce nouveau langage: il faut alors parler en donnant le sein, parler dans l'échange amoureux, toujours parler pour vivre différemment un rapport au corps. Pour consacrer le matricide plutôt que le conjurer, Liddell n'en construit pas moins un lien corps/langage neuf. Ce lien est assuré d'une part par la pratique de la performance qui accompagne tous ses spectacles, et d'autre part par celle d'une diction particulière de ses textes qui confine à la profération car les paroles sont criées, le rythme est particulier et souvent accompagné d'une forte musique. Irigaray s'interrogeant sur le corps féminin réactive l'ancestrale comparaison de la mère à la terre. L'homme-territoire serait alors la frontière du langage, la délimitation qui oublie la fertilité de la terre. Cette métaphore permet de penser le problème que soulève Irigaray en termes géographiques et politiques de territorialisation. Des penseurs comme Bernard Debarbieux rappelle le rôle des «hauts lieux»: des lieux qui rappelle la présence de la terre et son pouvoir irrépressible d'échappée et de construction nouvelle, échappant au pouvoir de territorialisation des hommes. Ces «hauts lieux» sont des montagnes, des fractures dans l'espace physique qui rappellent la terre où nous posons nos pieds. De la même manière, le nombril est un lieu déhiscent, une cicatrice permettant le repli vers la mère-terre; et la scène est pour Liddell l'endroit de la vérité, son haut lieu faisant se rencontrer corps, espace et langage dans la vocifération et la performance. Pour Liddell, c'est la stérilité qui est un mode nouveau d'affirmation du corps en scène, corps désirant plus que désirable. Là où Irigaray pense substitution ou continuité «œuvre»/«enfant» en ne dissociant jamais création et procréation, Liddell pense une alternative radicale: «Soit tu as des enfants, soit tu te consacres à la pensée». Pour elle, la procréation est une impasse: «Durant neuf mois, les membres se sont mal combinés à cause du retard mental de ma mère, [...] et c'est finalement une créature aberrante, non viable, incapable de survivre à l'hostilité du monde qui a vu le jour» (2013, 91). Irigaray encourage à «découvrir la singularité de notre jouissance», Liddell explore et expose sa singularité dans la jouissance. Elle le fait par le biais de la performance à l'ouverture de Tout le ciel au-dessus de la terre, le spectacle s'ouvrant sur un rituel masturbatoire d'une durée d'environ quinze minutes. La performeuse se masturbe sur un monticule de terre, dans le silence le plus total, déjouant immédiatement barrières de la pudeur et de la décence pour mettre en lumière un corps féminin esseulé et en jouissance. En cela, elle répond bien paradoxalement à l'injonction d'Irigaray: «A travers tout ça, ce que nous avons à faire (mais il ne s'agit pas de faire l'un avant l'autre), c'est de découvrir notre identité sexuelle, c'est-à-dire la singularité de notre auto-érotisme, de notre 
narcissisme, la singularité de notre homosexualité» (32). Tout le ciel au-dessus de la terre organise une variation sur ce désir:

Les êtres que j'aime sont tellement petits,

tellement pâles,

tellement enfants

que mon corps répond comme celui d'une mère mais incongrue.

Je sécrète à toute heure un lait sulfureux

qui ne nourrit pas.

[...]

Moi, je me masturbe.

Face à la souffrance, je me masturbe.

Pas de sentiments. Pas d'amour. (91)

En mettant en avant masturbation et désir pédophile, voire nécrophile, Liddell occupe le terrain de la provocation, de la volonté de se constituer en corps désirant singulier. Elle emploie les codes féministes des années 70 en les dévoyant pour créer une œuvre hybride. Mère, mais «incongrue», Liddell développe spectacle après spectacle un rapport à la maternité marqué par le rejet, la haine, et la contradiction. Elle crée, tout en sortant du schéma traditionnel de procréation. Il s'agit pour elle de faire œuvre autrement, c'est-à-dire d'être femme autrement.

\section{RÉFÉRENCES BIBLIOGRAPHIQUES}

Debarbieux, Bernard. «Le lieu, le territoire et trois figures de rhétorique». Espace Géographique 24.2 (1995): 97-112.

Irigaray, Luce. «Le corps-à-corps avec la mère». Sexes et parentés. Paris: Les Editions de Minuit, 1987.

Kristeva, Julia. Pouvoirs de l'horreur. Essai sur l'abjection. Paris: Seuil, 1980.

Liddell, Angélica. La Maison de la force. Tétralogie du sang. Trad. Christilla Vasserot. Paris: Les Solitaires Intempestifs, 2012.

Liddell, Angélica. Tout le ciel au-dessus de la terre (el sindrome de Wendy). Trad. Christilla Vasserot. Paris: Les Solitaires Intempestifs, 2013.

Liddell, Angélica. You are my destiny (Le viol de Lucrèce). Le cycle des résurrections. Trad. Christilla Vasserot. Paris: Les Solitaires Intempestifs, 2014.

Liddell, Angélica. La Fiancée du fossoyeur. Le cycle des résurrections. Trad. Christilla Vasserot. Paris: Les Solitaires Intempestifs, 2014.

Pascaud, Fabienne. «Entre douleur et plaisir, les tortures scéniques d'Angelica Liddell». Télérama (2014).

Rouch, Hélène. «Le placenta comme tiers». Langages 21.85 (1987): 71-79. 
Para enlazar con este artículo / To link to this article:

http://dx.doi.org/10.14198/fem.2017.30.02

Para citar este artículo / To cite this article:

Casado Presa, Cristina. «Y no vivieron felices para siempre: la reescritura del cuento de hadas y la problemática de la subjetividad femenina en Nueva historia de la princesa y el dragón de Carmen Resino». En Eva García-Ferrón y Cristina Ros-Berenguer (coords.), Dramaturgia femenina actual. De 1986 a 2016. Feminismo/s, 30 (diciembre 2017): 31-46, DOI: 10.14198/fem.2017.30.02

\title{
Y NO VIVIERON FELICES PARA SIEMPRE: LA REESCRITURA DEL CUENTO DE HADAS Y LA PROBLEMÁTICA DE LA SUBJETIVIDAD FEMENINA EN NUEVA HISTORIA DE LA PRINCESA Y EL DRAGÓN DE CARMEN RESINO
}

\author{
AND THEY DIDN'T LIVE HAPPILY EVER AFTER: \\ THE REWRITING OF THE FAIRY TALE AND \\ THE PROBLEMATIZATION OF FEMALE SUBJECTIVITY \\ IN NUEVA HISTORIA DE LA PRINCESA Y EL DRAGÓN \\ BY CARMEN RESINO
}

\author{
Cristina CASADO PRESA \\ Washington College, Maryland \\ ccasadopresa2@washcoll.edu \\ orcid.org/0000-0001-5767-4119
}

\section{Resumen}

Este artículo propone una lectura de Nueva historia de la princesa y el dragón (1989), de Carmen Resino, en clave de cuento de hadas feminista. Enmarcada en la nueva dramaturgia femenina que irrumpe en la escena española en la década de los 80, analizaremos cómo el drama de Resino se sirve del intertexto del cuento de hadas tradicional para parodiarlo, destruirlo y reemplazarlo. En esta pieza de Resino, este referente universal que es el cuento de hadas sirve para analizar y problematizar las complejidades y paradojas del proceso de identidad femenino, subraya el conflicto entre las expectaciones culturales y las necesidades personales, lo público y lo privado, y la conflictiva relación entre mujer y poder, que imposibilita el resolutivo final de «y vivieron felices para siempre».

Palabras clave: Carmen Resino, dramaturgia femenina, cuentos de hadas, feminismo, España. 


\begin{abstract}
This article proposes a reading of Nueva historia de la princesa y el dragón (1989), by Carmen Resino. Framed in the new drama written by women in the scene of Spain in the 80s, we will analyze how the play uses the intertext of the traditional fairy tale in order to parody, destroy and replace it. In this piece, the universal referent of the fairy tale is the vehicle to analyze and problematize the complexities and paradoxes of the feminine identity process, underlines the conflict between cultural expectations and personal needs, and the conflictive relationship between women and power, which makes the conclusive ending "and they lived happily ever after» impossible.
\end{abstract}

Keywords: Carmen Resino, female playwrights, fairy tales, feminism, Spain. 


\section{INTRODUCCIÓN}

Carmen Resino forma parte del grupo de dramaturgas a las que Patricia O'Connor denominó como el «reto de la democracia» $(1988,49)$ y que también pertenece a la generación que sufre el «desencanto» que parece dominar a la sociedad española después de la euforia inicial tras el fin de la dictadura y la instauración de la Democracia ${ }^{1}$.

La década de los 80 supone para el teatro español el auge de una serie de autores masculinos como José Luis Alonso de Santos, José Sanchis Sinisterra, Ignacio Amestoy o Fermín Cabal, quienes prefieren en su producción teatral situaciones cotidianas que permitan crear un teatro crítico, mientras buscan un público nuevo que se vea reflejado en sus obras. Su dramaturgia, al mismo tiempo que la desaparición de la censura y la vinculación de estos autores con el teatro independiente, permite una experiencia teatral más allá del texto, en tanto que han sido, o son, actores y directores ${ }^{2}$.

1. Velázquez y Memba definen esta generación como «perdida y fragmentada» (16), una generación que fue incapaz de derribar al dictador y tuvo que conformarse con su muerte, lo que les hizo cuestionar si serían capaces de desplazar a los franquistas reconvertidos sin el apoyo de una oposición fuerte. En consecuencia, después de 1977, etapa de activismo político y participación sin precedentes, llegaron esos años desencantados, entre 1979 y 1981, caracterizados por un «escepticismo, próximo, en muchos casos, a la desesperación» (16).

2. Sirva como ejemplo el hecho de que Sinisterra organizara el grupo Teatro Fronterizo, que desde 1977 representa textos que se sitúan en el límite de la teatralidad, creando una especie de nueva categoría fronteriza entre géneros que se aparta de la moda de la espectacularidad. Su obra dramática siempre está caracterizada por su posición alternativa a los lenguajes teatrales tradicionales, aunque aparezcan inscritos en las estéticas más variadas. De hecho, al propio teatro dedica textos como ¡Ay Carmela! (1987) o El lector por horas (1999). Por su parte, José Luis Alonso de Santos insiste en el tratamiento de personajes que tienen razones suficientes para estar dentro de la delincuencia, pero al presentarlos en clave de sainete colabora de manera extraordinaria a su buena recepción, como en el caso de La estanquera de Vallecas (1981) o Bajarse al moro, (1985). Por otro lado, una de las obras más conocidas de Ignacio Amestoy, Dionisio Ridruejo, una pasión española (1982), propone un verdadero drama político con ribetes de tragedia que abre las inmensas posibilidades que muestra el autor para ese género. El caso de Fermín Cabal viene marcado en gran medida por su procedencia del teatro independiente. Pese a su tonalidad realista, no desperdicia referencias simbólicas muy eficaces, como se hace

Feminismo/s 30, diciembre 2017, pp. 31-46 
Es indudable que la producción teatral femenina de la época comparte numerosos rasgos con la de sus colegas masculinos, ya que también pugna por la introducción de discursos alternativos y se aleja de las representaciones convencionales. No obstante, también lucha por el reconocimiento de la existencia de una dramaturgia femenina con un lenguaje propio. En este sentido, en un coloquio moderado por Lourdes Ortiz en 1987 que después publicaría la revista Primer Acto, Paloma Pedrero considera que «hay todo un lenguaje femenino -teatral en este caso- que debe ser proyectado», a lo que Maribel Lázaro añade que, como dramaturgas, buscan «elevar a nivel protagonista» su mundo (15). En consecuencia, estas autoras ofrecen personajes, temas y discursos que se resisten a las normas y limitaciones del orden establecido, ejerciendo una crítica más o menos explícita ante las tendencias predominantes de la cultura española en relación a la problemática femenina. Obviamente estas restricciones no son tan fuertes como durante la dictadura de Franco (19391975), pero aún es posible encontrarlas en la sociedad española de la época, donde el clima de aperturismo y cambio se conjuga con el peso de la represión y los valores tradicionales que aún siguen vigentes en la memoria colectiva.

De esta forma, estas piezas teatrales contribuyen a poner de manifiesto que estos años no son tan abiertos o tolerantes como podría parecer, por lo que esta producción dramática exhibe una mirada inconformista y crítica ante un contexto social y cultural específico. Asimismo, todas estas obras se pueden leer desde una perspectiva feminista, la cual ofrece un discurso alternativo capaz de cuestionar la representación femenina hasta el punto de poder permitirnos hablar del surgimiento de una nueva estética teatral femenina. El principal vehículo del que se sirven estas dramaturgas no es otro que unos personajes femeninos claramente transgresores que intentan desestabilizar algunas tradiciones imperantes en el contexto de la España contemporánea.

Patricia O'Connor, una de las investigadoras que, como sabemos, más ha contribuido, no solo al descubrimiento, sino también a la promoción de este grupo de autoras españolas, fue la principal responsable de su carta de presentación. El número especial de la revista Estreno, en el otoño de 1984, no deja lugar a dudas sobre su intención de mostrar al público «quiénes son las dramaturgas españolas y qué han escrito». En un número monográfico, dedicado íntegramente a la producción teatral femenina, O'Connor plantea una serie de preguntas a un grupo de figuras femeninas del entorno teatral y

patente en sus obras Tú estás loco, Briones (1978), Fuiste a ver a la abuela??? (1979) o Vade retro! (1982). 
literario en general, partiendo de la premisa de que antes de mediados del siglo $\mathrm{XX}$, apenas había dramaturgas en España:

Estrenaban alguna que otra pieza teatral Gertrudis Gómez de Avellaneda, Emilia Pardo Bazán o Concha Espina, pero no se les recuerda principalmente por su dramaturgia. Aunque en la posguerra ha salido una verdadera pléyade de escritoras brillantes en la novela, el cuento y la poesía, sigue escaseando la mujer que escribe para teatro; aun es más raro que estrene. $(1984,13)$

Los interrogantes que lanza O'Connor buscan razones que puedan explicar esta curiosa ausencia de la mujer en la dramaturgia contemporánea, y así, se plantea la aptitud de la mujer para escribir teatro, se cuestiona también la existencia de intereses y prejuicios especiales que le cierran el paso a los escenarios. Asimismo, alude a la creencia de que la mujer prefiere expresarse simple y espontáneamente a través de la confesión íntima, y discute las razones por las que el escenario teatral parece ser tan inasequible para las mujeres.

Ante estas cuestiones, lo que se desprende de las declaraciones de estas escritoras, a pesar de una cierta variedad de respuestas, es que existe una problemática común y reconocida en tanto que todas las entrevistadas coinciden en algunos aspectos: todas admiten las trabas que las mujeres sufren para representar sus obras de teatro debido a unos prejuicios que no han considerado a la mujer apta para la faceta de autora o directora de teatro; de igual manera, y significativamente, todas describen el mundo teatral y su ambiente como cerrado y masculino.

Patricia O'Connor amplió su exploración sobre la producción teatral femenina en más estudios, aparte del famoso número de Estreno, siendo el más reconocido su indispensable obra Dramaturgas españolas de hoy. Una introducción. En ella O'Connor da un paso más en su investigación, tratando de dar con las razones que han llevado a tan acusado silencio femenino en el teatro español, y centra su atención en razones sociales y culturales en las que cobra gran importancia la propia historia de España. En efecto, la especial mezcla cultural española, es, sin duda, el punto de partida para originar la arraigada opinión de que la mujer no debe invadir el dominio masculino, es decir, la esfera pública, ni con su presencia ni con sus palabras. Según recoge O'Connor, en este sentido ha tenido gran peso la costumbre islámica conocida como «purdah», que significa cortina o reclusión femenina, reforzada en la tradición clásica por Platón, combinada con parecidas actitudes greco-romanas, judías y cristianas, y perpetuada en obras como La perfecta casada de Fray Luis de León (1583). Todo ello contribuyó a forjar esa imagen de la mujer virtuosa y callada, dedicada a su hogar, cuyo consuelo era creerse «reina de la casa» (10), un dechado de virtudes en los que la modestia y la sumisión brillan con 
luz propia y, además, «haciendo sinónimos ignorancia e inocencia», lo que convierte a la mujer instruida en objeto de burla (O'Connor 1988, 15)3.

Partiendo de estas premisas, O'Connor concluye que no es de extrañar que, examinando la producción teatral femenina en España en las décadas de los 40 y 50, la encontremos escasa, y que además presente características que son, en cierto modo, bastante previsibles y limitadas a la representación de un idealizado e inexistente mundo femenino. En estos dramas destaca la exaltación de la mujer virtuosa y sumisa, la mujer como complemento a exhibir: un objeto. Como recoge O'Connor, este tipo de teatro, que ignora la subjetividad femenina, sigue vigente en décadas posteriores. Se da mucha importancia a los personajes masculinos, mientras que se repiten los estereotipos femeninos negativos, de forma que se perpetúa el canon patriarcal «al intercalar intertextos y códigos masculinos» $(1988,44)$.

Frente a esta producción marcadamente tradicional, los primeros indicios de cambio se vislumbran en las décadas de los 60 y 70, que muestran un tímido esfuerzo por equilibrar los roles femeninos y masculinos. No obstante, no es hasta mediados de la década de los 80 que es posible apreciar un cambio, al aparecer una nueva concepción teatral que denota orgullo de la identidad femenina. En palabras de O'Connor: «a new awareness and pride in women increasingly pervades the plays of the new women playwrights and the nonconformist writers of the Franco era» $(1990,311)$.

Virtudes Serrano considera que se pueden distinguir dos actitudes estéticas y personales: la de la «inversión del canon establecido y búsqueda de nuevos caminos», claramente renovadora; y la de la coexistencia con él a pesar de una disconformidad que califica de «moderada» $(1994,357)$. Estas nuevas posiciones estarán reflejadas en obras que prestan especial atención a la mujer, rechazando las visiones y límites del pasado, para dar paso a un discurso genuinamente femenino. No obstante, autoras como Raquel García Pascual matizan que «la suya no es creación únicamente con mujeres, sobre

3. Urszula Aszyk coincide con O'Connor en la escasez de dramaturgas en España, pero resalta que al contrario que en otros países, y con excepciones como Santa Teresa, las españolas no tuvieron acceso a los libros hasta bien entrado el siglo XIX, describiendo a numerosas escritoras como «autodidactas». También se hace eco de la herencia cultural española reseñada por O'Connor, y añade: «Por lo que se refiere al teatro, las espectadoras españolas del siglo XVI y XVII, es decir, de la época del Siglo de Oro y del gran desarrollo de los corrales de comedias, quedaban separadas de los espectadores hombres, lejos del espacio escénico, en la incómoda cazuela. Y sólo algunas privilegiadas podían ver el espectáculo desde las ventanas de las casas vecinas, pero también ellas estaban aisladas del espacio teatral por las rejas. Las que como actrices salían al escenario, se convertían, claro está, en mujeres públicas» (48). 
mujeres, para mujeres» (324) y argumenta que no buscan marcar distancias con otros creadores, sino con los códigos de convivencia patriarcales. Por lo tanto, aunque estas autoras rechazan la etiqueta de feministas, los efectos de la segunda ola de feminismo influyen en su toma de conciencia de los efectos del patriarcado y en la forma en la que este concibe a la mujer como un ser domesticado, pasivo y dependiente.

Como bien señala M. Jesús Salinero Cascante, tradicionalmente «la mujer está hecha para ser contemplada hasta en el último detalle de su anatomía corporal» (51), y esta tradicional representación le depara una posición de supeditación y pasividad, limitada a la función de complemento de la parte dominante, la masculina. Cuando esta representación de mujer es trasladada al terreno del teatro, nos encontramos con que tradicionalmente ha sido la mirada masculina la que ha creado estas representaciones de mujer, mientras que las propias interesadas han adoptado e interiorizado la recreación masculina que de ellas se ha hecho.

\section{DRAMATURGIA FEMENINA DE LOS 80 Y LA PROBLEMÁTICA DE LA SUBJETIVIDAD FEMENINA}

En contraposición a estas generaciones anteriores, la generación de dramaturgas de los 80 empieza a cuestionar cómo se mantiene, promueve o muestra la normativa de género vigente y ofrece alternativas de representación, donde la mujer va a cobrar el protagonismo al formular discursos transgresores; discursos que invitan a la reflexión por parte de la audiencia, a la que se le ofrecerá, por lo tanto, mirar a través de otros ojos distintos. Ya que la estructura y el mantenimiento de las relaciones de género se basan en normas culturales, una exposición de estas puede llevar a su cuestionamiento, y de ahí a su transformación y cambio. En consecuencia, esta producción dramática nace del reconocimiento de una representación indebida, lo que lleva a la protesta por el tipo de personajes representados e, inevitablemente, busca una forma de producción que rompa con las anteriores. Así, se va a «re-presentar» a las mujeres como sujeto, es decir, trasladar los problemas de la mujer, sus experiencias y sus historias al centro del escenario.

Esta generación de dramaturgas muestra diferentes tipos y grados de opresión femenina, al tiempo que los rechaza a través de estrategias de subversión ${ }^{4}$.

4. Además de Carmen Resino, existen numerosas autoras cuyas piezas comparten estas características. Por ejemplo, Maribel Lázaro recrea la caza de brujas en la Galicia del siglo XVII en Humo de Beleño (1986), Pilar Pombo recupera la Guerra Civil española en su drama En igualdad de condiciones (1996). Por otra parte, Lidia Falcón retoma la historia más reciente con Las mujeres caminaron con el fuego del siglo. Concha Romero 
En suma, esta dramaturgia anticipa una liberación de la relación jerárquica entre el hombre y la mujer y una clara intención de reescribir las tradicionales prescripciones de género.

Carmen Resino publica su primera obra en 1969 con el título de El presidente, pero su nombre comienza a sonar con fuerza en la década de los 80, cuando, tal y como señala Mariano de Paco, «en pleno auge creador de los autores realistas, iniciaban su andadura los autores del nuevo teatro; sin embargo, a causa del habitual olvido [...] no es su obra conocida como se merece» (304). Desde entonces, sus piezas han ido delineando una propuesta teatral en la que destaca el tema de la mujer en una sociedad dominada por hombres. De acuerdo con Jon Gabriele, «la obra dramática de Resino emprende a nivel específico la investigación de la identidad femenina y a nivel universal el sondeo de la situación del individuo cuya libertad de expresión personal le es impedida por tácticas autoritarias» (93). Asimismo, estudiosos como De Paco resaltan su capacidad de usar la historia como «marco de referencia o ambientación en el que crea liberalmente historias, situaciones o personajes» (304), haciendo hincapié en el interés de la autora por «la problemática relación entre los individuos y el destino. Las dificultades para lograr la propia realización; la frustración que continuamente amenaza a los seres humanos por el hecho de serlo» (304).

\section{NUEVA HISTORIA DE LA PRINCESA Y EL DRAGÓN COMO UNA APROPIACIÓN FEMINISTA DEL CUENTO DE HADAS TRADICIONAL.}

Nueva Historia de la princesa y el dragón ha sido descrita por Patricia O'Connor como «allegory of Women's anxiety about authority» $(1988,387)$, y reúne todos los rasgos de la dramaturgia de Resino descritos anteriormente. Del mismo modo, permite una lectura feminista como subversión de la vieja tradición del cuento de hadas para contar una nueva historia desde el punto de vista de la mujer.

Cuando hablamos de Nueva historia como la reescritura de un cuento de hadas, debemos entenderla como una respuesta en contra de las relaciones de poder, que son una de las premisas centrales en los cuentos tradicionales, pero también en las interpretaciones feministas más modernas. Esto se hace evidente en el hecho de que, en numerosos cuentos de hadas populares, el

publica en 1983 Un olor a ámbar, obra que tiene como protagonista el cuerpo incorrupto de Santa Teresa, mientras que su obra Las bodas de una princesa (1982) muestra a una jovencísima Isabel de Castilla en su difícil camino al trono. Romero retoma de nuevo la figura de la reina Isabel en sus últimos años de vida y el conflicto con su hija Juana en Juego de Reinas (1991). 
personaje principal femenino (la princesa, en muchas ocasiones) se encuentra en peligro, su príncipe encantador la rescata, y viven felices para siempre. En consecuencia, las mujeres son presentadas a menudo como personajes dóciles y maternales, mientras que los hombres aparecen como personajes poderosos y resueltos. Estas historias han modelado, como afirma Gilbert, lo que una cultura considera un final feliz o infeliz (129), mientras Karen Rowe añade: «traditional fairy tales fuse morality with romantic fantasy in order to portray cultural ideals for human relationships»(209). Es más, Jack Zipes, en Fairy Tales and the art of subversion describe los cuentos de hadas como elementos que sutilmente influyen en la sociedad a la hora de ver el mundo. Zipes subraya cómo estos cuentos ofrecen una representación de los roles tradicionales de género y sus comportamientos. Adicionalmente, advierte que los lectores impresionables verán estas representaciones como una manera de confirmar el destino de un personaje según su género.

Por otra parte, como declara Donald Hasse, «awareness of the fairy tale as a primary site for asserting and subverting ideologies of gender is evident throughout the genre's story» (2), e insiste en la necesidad de nuevas aproximaciones «that can situate the fairy tale's treatment of gender in relation to the diynamics of history and the shifting boundaries of society, culture and nation» (12). En este sentido, como respuesta a la tradición, es posible apreciar una serie de reescrituras o reinterpretaciones de estas historias tradicionales, tanto que ponen de relieve cómo revierten aquello que de mentalidad patriarcal y de imposición de género se puede apreciar. Estas versiones del cuento tradicional promueven un diálogo donde la prevalencia de los discursos masculinos es expuesta y criticada, y proponen alternativas a estas posiciones tradicionales de género.

Así, podemos apreciar la proliferación de cuentos de hadas en clave feminista que, o bien reescriben los tradicionales, o bien se apropian de los mismos como intertextos para transmitir un discurso de género. Esta nueva producción cultural busca dar voz a la mujer, y exponer a través de la subversión de los presupuestos tradicionales las limitaciones de los roles de género, sus estereotipos y los modelos conservadores de comportamiento.

Carmen Resino nos advierte de sus intenciones desde el mismo título de la pieza, donde la historia de la princesa y el dragón, evocadora de numerosos cuentos, es alterada con la inserción de la palabra «nueva». El drama gira alrededor de la princesa Wu-Tso, quien debe aceptar un matrimonio de Estado con el débil heredero del trono japonés, en contraposición a su deseo de ser la heredera de su padre y sentarse en el trono de China. Wu-Tso muestra un carácter desafiante desde el principio del drama, cuando se enfrenta a su padre acerca de su derecho a ser emperador antes que su hermano: «Soy mejor que 
él, física y moralmente, tú lo sabes. Y además soy la primogénita» (11). Aun sabiendo que las palabras de $\mathrm{Wu}$-Tso son ciertas, la respuesta del emperador es simple a la par que reveladora: «Pero es varón» (11). Wu-Tso tampoco encuentra apoyo en su madre, quien ante las protestas de la joven solo atina a contestar: «No tienes que maldecir tu destino. Las mujeres, hija, lo tenemos tan abocado a las desgracias que el tuyo debería parecerte un privilegio» (29). En consecuencia, Wu-Tso es enviada a Japón, desposándose por obligación con un hombre al que desprecia y ganándose desde el primer momento la enemistad de la emperatriz, quien la considera un peligro para la dinastía y la sucesión.

Sin embargo, Wu-Tso, a través de una serie de maniobras tan maquiavélicas como brillantes, logrará el poder, dejando a su paso un camino sembrado de muertes violentas. En palabras de la propia Resino, «rechaza el papel que la sociedad y la preeminencia masculina le han asignado, luchará por contestar estos esquemas y conseguir el poder» (3). De este modo, Wu-Tso se revela como un personaje femenino que se rige por un código impensable en su época y que expresa su intención de lograr sus propósitos a toda costa: «Yo quiero ser siempre yo, resultar nueva cada mañana y llevarme a la boca cada día un bocado distinto» (56).

Irónicamente, la princesa acaba también por convertirse en una víctima de sus propias aspiraciones. Wu-Tso debe renunciar al amor, ilícito, que encuentra en el general Taisho, y sus acciones traen como resultado su propia muerte, como ha sucedido con sus antecesores. La misma protagonista del drama esboza una triste mueca en su último aliento, con lo que reconoce su derrota, y con eso lo que se refleja en la obra es el hecho de que Wu-Tso sólo va a ser reconocida como emperador una vez que ha muerto.

En el drama de Resino son visibles los elementos clásicos del cuento, si bien han sido transformados y adaptados. Aunque ha nacido princesa, Wu-Tso no vive en un castillo esperando a su príncipe, sino que está obligada a un matrimonio político: «Por muy bien que la naturaleza te haya dotado, tu destino es otro. [...] Dar hijos al emperador de Japón» (27). Por otra parte, el objeto mágico del cuento no es otro que el poder, y el dragón a vencer es el patriarcado, que le recuerda constantemente la inaccesibilidad al poder por su condición de mujer.

Como vemos, enemigo formidable, y presente en numerosos cuentos de hadas, el dragón se erige como el gran obstáculo para el final feliz. Desatado y desbocado, la fuerza del dragón puede llegar a ser destructiva, pero promete algo mejor y más hermoso si se logra vencerlo: el beso de amor verdadero, la transformación de la sirvienta en reina o el joven humilde que se convierte en rey. Y, sin embargo, en el cuento tradicional, su destrucción rara vez ocurre a 
manos de una mujer. Así pues, debemos resaltar que, al enfrentarse al dragón del patriarcado, Wu-Tso desafía el papel tradicional de princesa cautiva e indefensa, y toma el lugar del héroe que se enfrenta al desafío último.

En este sentido, precisamente es un rasgo característico tanto del cuento de hadas feminista como de la dramaturgia femenina de los 80 el que el elemento de subversión más evidente se encarne en la protagonista femenina. Wu-Tso dista de ser una mujer pasiva que espera la llegada de un príncipe que la libere de sus ataduras. Resino la describe como: «Bella y delicada. Es absolutamente indispensable para la adecuación del personaje su apariencia frágil, lo que contrastará con su enorme fuerza interior e incluso su destreza física» (9). Además, en su primera aparición, Wu-Tso aparece «ataviada como un guerrero de modo que cuesta identificarla con una mujer» (25). Al igual que en los cuentos tradicionales, se hace hincapié en la belleza de la princesa, pero ya en la descripción inicial que Resino hace de su personaje, aparecen los síntomas de transgresión cuando afirma que «es una mujer joven y bella, con brevedad y armonía de muñeca. Sus facciones, no obstante y a pesar de su delicadeza, dejarán escapar algo terrible y cuando no se sienta observada, su belleza se descascarillará» (9). Ese resquicio en su belleza desvela la verdadera personalidad de la princesa: una mujer determinada, dispuesta a romper las leyes y a manipular a los que la rodean en su propio beneficio y a cualquier precio. De este modo, WuTso observa «con evidente desprecio» a Fu-Hi, quien va a convertirse en su esposo, y declara que «si no es capaz de aguantar mi mirada mal podrá sostener la espada» (35). Asimismo, aun casada con $\mathrm{Fu}-\mathrm{Hi}$, Wu-Tso comienza un romance ilícito con el general Taisho. El inicio de la seducción entre ambos se representa de forma paralela al suicidio de $\mathrm{Fu}-\mathrm{Hi}$, quien decide auto inmolarse en un intento de lograr una reparación de la situación en la que todos los personajes se hallan inmersos. La escena es descrita como «un bordado de encuentros y persecuciones: un tiovivo exacerbado y sensual» (45), al tiempo que Fu-Hi «desenvaina despacio la espada [...] y la alzará sobre su vientre. [...] Finalmente se la clavará lanzando un agudo grito» (46). Por lo tanto, la fantasía amorosa del cuento tradicional es sustituida por un erotismo crudo y agresivo, subvirtiendo efectivamente el estereotipo femenino romántico y sumiso.

La culminación de la relación entre Wu-Tso y Taisho viene a funcionar como el principal punto de inflexión del drama. Tras haber eliminado a todos los que se interponen en su camino al trono:

Wu-Tso y el general están inmersos en su amor. [...] Después, Wu-Tso se incorpora penosamente. Taisho sigue en el suelo de espaldas al espectador. Wu-Tso le mira jadeante y con el pie, le da la vuelta: Taisho está muerto, con 
su espada clavada en el vientre. Wu-Tso sonríe de forma siniestra: de su boca brota un hilillo de sangre. Trabajosamente, cogerá la espada del Emperador y su kammuri e irá subiendo hacia el trono. Una vez allí [...] colocará la espada sobre sus rodillas Y sobre su cabeza el kammuri. Seguidamente, abre su kimono y en su total desnudez habrá una enorme herida. [...]Wu-Tso intentará reír abiertamente pero será una risa inaudible: simplemente una mueca nacida del propio cadáver que ya convive con ella. (64)

Este momento de la obra teatral supone la subversión última del cuento, ya que la unión amorosa de $\mathrm{Wu}$-Tso y Taisho se descubre como un ritual en el que se entremezclan amor y muerte, y, por ende, como un macabro contraste al beso de amor verdadero que encamina el cuento de hadas al preceptivo final en el que «vivieron felices para siempre».

Por otro lado, merece la pena examinar asimismo el resto de las figuras femeninas de la pieza. En primer lugar, la madre de $\mathrm{Wu}$-Tso vive dominada por el sistema patriarcal y existe como una representación de «las mujeres de la época en particular, pero también el símbolo de las mujeres a través de la historia» (9). Su discurso es únicamente el del sufrimiento. Ante los deseos de poder de $\mathrm{Wu}$-Tso y su negativa a la resignación, replica: «Te quedan dos caminos, Wu-Tso: la resignación o la desgracia. Si te resignas todo llegará a serte indiferente, con lo cual el sufrimiento puede parecerte otra forma de ventura» (29). Sus palabras se revelan como un presagio del final de su hija, y personifica la falta de opciones para la mujer. Por otra parte, la emperatriz de Japón encarna otra interpretación del mismo concepto. Acostumbrada a su papel secundario, «el trono y la dignidad imperial es lo primero para ella y al afianzamiento de su dinastía dedicará sus últimas fuerzas» (10). Es así que reconoce a $\mathrm{Wu}$-Tso como una amenaza y se une al patriarcado para subyugarla.

Igualmente, debemos prestar atención a los referentes masculinos del drama. El padre de Wu-Tso es descrito como «el poder omnímodo y patriarcal de una época de preeminencia masculina en la que éste decidía los últimos movimientos de sus hijos y, sobre todo, de sus hijas» (14). Por su parte, el personaje del General Taisho merece mención especial. Descrito a través de su valor y de las proezas que ha llevado a cabo, al final no es capaz de cumplir con su papel de héroe salvador. Como reseña Resino: «ha hecho de la fidelidad al trono y a las armas su única razón», y aunque «siente que es frágil» (12) ante la seducción de la princesa, al final también se consolida como parte del patriarcado que intenta reprimir a $\mathrm{Wu}$-Tso.

Por tanto, como estamos viendo, la verdadera maldición de la princesa reside en la imposibilidad de escapar de su condición de mujer, o lo que es lo mismo, en su incapacidad para vencer al dragón del patriarcado. Al final de la obra, el señor de Kamakura llega hasta el trono donde se encuentra el cadáver 
de $\mathrm{Wu}$-Tso, tras haberse hecho con el palacio imperial, y después de contemplar la figura del emperador Wu-Tso, ya sin vida, el señor de Kamakura la toma en sus brazos y la presenta a sus soldados como «la más bella de las ofrendas. Ninguno podría pensar en un botín más significativo y hermoso» (65). Por consiguiente, $\mathrm{Wu}$-Tso ha sido derrotada incluso en su muerte, donde una vez más es despojada de su agencia y de su subjetividad para convertirse en un mero objeto, definido por su belleza.

En suma, Resino presenta un drama en el que los temas de agencia, voz y poder son centrales. Tradicionalmente, la posición de poder respaldada suele situarse con el protagonista masculino, pero Nueva Historia está tratando de iluminar otros discursos de género para la audiencia. El género está tan arraigado en nuestra cultura, nuestros comportamientos, nuestras actitudes y nuestros deseos que parece completamente innato. Sin embargo, el género en sí mismo es un fenómeno que se construye y difunde a través de prácticas sociales de maneras distintivas, en diferentes contextos y con una variedad de personas. Históricamente, el género ha sido visto como claramente definido y binario: dos categorías distintas, masculina y femenina. Butler argumentó «act which is both intentional and perfomative» (139), pero existen restricciones sociales sobre quién debe actuar. Como hemos visto en Nueva historia, si estas limitaciones sociales no se cumplen, puede haber consecuencias para comportamientos que se consideran socialmente inapropiados.

Sin embargo, Nueva historia toma una posición de rechazo a los estereotipos de género, su personaje principal lucha por su voz y su agencia, y expresa su rechazo al discurso masculino dominante tradicional para iniciar una estructura de poder de género alternativa. El papel arquetípico de las mujeres en las versiones tradicionales de la historia -como la víctima vulnerable, damisela en apuros o el premio bonito para el héroe masculino- ha sido expuesto, reescrito y, en última instancia, recuperado para las mujeres. Los elementos del cuento de hadas no sólo proporcionan a Resino un material radical y represivo, sino que también le permiten rechazar la voz autorizada a favor de la voz femenina que ha sido reprimida. La princesa Wu-Tso no es una restauración feminista sencilla o idealizada, sino que ha sido creada partir de una humanidad intrincada que le permite trascender los roles de género convencionales.

Nueva historia funciona como cuento de hadas feminista en tanto que Resino ofrece una promesa de nueva percepción de género, logra alterar las visiones de la audiencia en términos de imágenes tradicionales de género, sus pautas y sus códigos, y ofrece una versión dramática en la que la historia ha sido modificada en aspectos esenciales. A través de una heroína implacable y determinada, Resino derriba asunciones respecto a los roles de género al tiempo 
que muestra que las construcciones de género siguen estando presentes. Como Crew argumenta, las reescrituras de los cuentos «challenge and make visible sexist discourses» (92), de forma que la audiencia, conocedora del género, podrá identificar formas alternativas de actuar de una manera socialmente más justa. Las verdades universales de los cuentos tradicionales ya no son dominantes, y las creencias sociales inscritas en ellos han sido alteradas y, sobre todo, cuestionadas.

Sin embargo, debemos matizar algunos aspectos acerca de esta dramaturgia, ya que las subversiones encontradas en estos textos no funcionan de manera absoluta como voces liberadoras de una sociedad represiva. Mientras estos dramas pueden entenderse como una reclamación de apertura de costumbres y cambio de valores, también son un reflejo de sentimientos de dolor, soledad e incomunicación. No obstante, es en esta opresión donde se encuentra una de las claves del teatro de Resino y del resto de las autoras teatrales de los 80 . Al presentar una serie de personajes femeninos oprimidos y las diferentes resoluciones de sus historias alejadas del preceptivo matrimonio como final feliz, o al menos de un final feliz convencional, se pone de manifiesto la dicotomía entre la mujer representada tradicionalmente y la mujer real. Nuestras autoras muestran cómo los diferentes valores y las relaciones del poder no deben darse por sentados. Es así que sus dramas se convierten en una crítica al sistema y expresan la necesidad de romper esa dicotomía opresiva de sumisión. Sus dramas apelan a la necesidad de hacer desaparecer la limitación de la mujer y también de potenciar valores femeninos positivos. Los conflictos que se manifiestan en Nueva historia de la princesa y el dragón se revelan como atemporales, haciendo hincapié en los obstáculos que encuentra la mujer, de antes y de ahora, sea princesa o plebeya.

Asimismo, el material que aportan estas dramaturgas a través de su producción es enormemente enriquecedor para debatir la situación y reflexiones de la mujer en la España del momento. Las ambigüedades y las diferencias deben ser analizadas como un reflejo de los acontecimientos dramáticos y cambios vertiginosos que España experimentó durante el siglo XX, especialmente desde el punto de vista de la mujer en una época en la que existe un choque y también una convivencia, desde el conflicto entre la libertad que trajo la democracia y el concepto esencialista de la mujer que había sido característico de España durante mucho tiempo, y que aún persiste en los momentos en que aparece esta producción teatral. De este modo, es posible afirmar que, aunque no se puede hablar de una aplicación del discurso feminista de una forma radical, bien podemos señalar la existencia de una estética femenina en las estrategias de 
representación en tanto que nos ofrecen personajes que son únicos, diferentes y muestran una clara consciencia de sí mismos, sus pensamientos y emociones.

Existen muy pocos finales felices en esta producción teatral. Las protagonistas de las piezas luchan contra los preceptos aprendidos en la época, sufriendo enormemente por ello en numerosas ocasiones. No obstante, las representaciones de estas mujeres amplían los límites de lo que significa ser «subversiva» o «transgresora». Así, poco a poco, lo que antes resultaba impensable ahora se representa o al menos se publica, y temas que eran considerados tabú van surgiendo en estas obras. Al mismo tiempo, estas autoras permiten que sus personajes cuestionen ciertos conceptos que antes se daban por sentados, como el silencio de la mujer durante la dictadura, la censura, auto impuesta en innumerables casos, o la abnegación y pasividad tradicionalmente inherentes a la condición femenina. En este sentido podemos afirmar que existe un claro elemento de rebelión contra el legado social, teatral y cultural de la dictadura que persiste a pesar de la instauración de la democracia.

\section{CONCLUSIONES}

El análisis de esta obra nos lleva a reconsiderar las características de las mujeres que han poblado la escena en el teatro español a través de un contraste entre los modelos antiguos y su convivencia con estas nuevas representaciones que luchan por desterrarlos, en una encrucijada ideológica en la que se producen grandes cambios en los estándares sociales y donde se hace imprescindible definir la identidad, encontrar una voz y despertar la conciencia, lo que afecta no solo a sus obras sino, también, al resto de la sociedad española.

Aunque la crisis del teatro español afectó irremisiblemente a nuestras autoras, y muchas de ellas han abandonado la producción dramática, es indudable que sus obras despertaron una conciencia dormida en una audiencia que asistió a una nueva producción teatral que logró crear nuevas formas de mirar y reflejó las nuevas expectativas y preocupaciones de la mujer en un momento de cambio político y social.

En conclusión, Nueva historia de la princesa y el dragón y la producción dramática de las dramaturgas de los 80 actuaron como vehículos de apertura que han contribuido a la legitimización de los sujetos femeninos que se muestran en los márgenes del sistema. Aunque sencillas en apariencia, estas piezas se atreven a cuestionar la estabilidad de la sociedad, de la sexualidad y, en definitiva, de los valores sociales, culturales y morales arraigados en la ideología hegemónica de la España de la época. Y no menos importante, se constituyen en una celebración de lo diferente y descubren una diversidad de voces que tradicionalmente han sido silenciadas. 


\section{REFERENCIAS BIBLIOGRÁFICAS}

Askyz, Urszula, «Las mujeres dramaturgas en España: en busca de la identidad». Estudios sobre escritoras hispánicas en honor de Georgina Sabat-Rivers. Ed. Lou Charnon-Deutsch. Madrid: Editorial Castalia, 1992, 45-61.

Butler, Judith. Gender trouble. New York, NY: Routledge, 1990.

Crew, Hilary S. «Spinning new tales from traditional texts: Donna Jo Napoli and the rewriting of fairy tale». Children's Literature in Education 33.2 (2002): 77-95.

Gabriele, John P. «Estrategias feministas en el teatro breve de Carmen Resino». Letras Femeninas 1/2 (1995): 85-95.

García-Pascual, Raquel (ed.). Dramaturgas españolas en la escena actual. Madrid: Castalia, 2011.

Gilbert, P. (1994). «And they lived happily ever after: Cultural storylines and the construction of gender». The need for story: Cultural diversity in classroom and community. Eds. Dyson A. H. y C. Genishi. New York, NY: Teachers CollegePress, 124-145.

Haase, Donald. Fairy Tales and Feminism: New Approaches. Detroit: Wayne State University Press, 2004.

Lázaro, Maribel. «Los horizontes del teatro español. Nuevas autoras». Primer Acto 220 (1987): 10-21.

O'Connor, Patricia. « ¿Por qué no estrenan las mujeres en España?». Estreno 10.2 (1984): 13-25.

O'Connor, Patricia. Dramaturgas españolas de hoy. Una introducción. Madrid: Fundamentos, 1988.

O'Connor, Patricia. «Women Playwrights in Contemporary Spain and the MaleDominated Canon». Signs 2 (1990): 376-390.

Paco, Mariano de. «El Teatro Histórico De Carmen Resino». Anales de la Literatura Española Contemporánea 3 (1995): 303-314.

Pedrero, Paloma. «Los horizontes del teatro español. Nuevas autoras». Primer Acto 220 (1987): 10-21.

Resino, Carmen. El Presidente. Madrid: Quevedo, 1968.

Resino, Carmen. Nueva historia de la princesa y el dragón. Madrid: Lucerna, 1989.

Rowe, Karen E. «Feminism and Fairy Tales.» Women's Studies 6.3 (1979): 209-226.

Salinero Cascante, Maria Jesús. «El cuerpo femenino y su representación en la ficción literaria». Piel que habla. Eds. M. Azpeitia, M. J. Barral, L. E. Díaz, T. González Cortés, E. Moreno, T. Yago. Barcelona: Icaria, 2001, 39-76.

Serrano, Virtudes. «Hacia una dramaturgia femenina.» Anales de la Literatura Española Contemporánea 3 (1994): 343-364.

Velázquez, José Luis y Javier Memba. La generación de la democracia: historia de un desencanto. Madrid: Ediciones Temas de Hoy, 1995.

Zipes, Jack David. Fairy Tales and the Art of Subversion: The Classical Genre for Children and the Process of Civilization. New York: Wildman Press, 1983. 


\title{
RESISTANCE RETOLD: HISTORICAL AND MYTHICAL NARRATIVES IN PLAYS BY ROMERO, RESINO, PASCUAL AND DE PACO SERRANO
}

\author{
RECONTANDO LA RESISTENCIA: NUEVAS NARRATIVAS \\ MÍTICAS E HISTÓRICAS EN EL TEATRO DE ROMERO, \\ RESINO, PASCUAL Y DE PACO SERRANO
}

\author{
Helen FREEAR-PAPIO \\ College of the Holy Cross, Worcester, Massachusetts \\ hfreear@holycross.edu \\ orcid.org/0000-0002-4117-6809
}

\begin{abstract}
In this article we will look at a small but cohesive sample of plays by female dramatists of democratic Spain from the 1980's to the present, in which the dramatic retelling of history and myth has evolved in time as it accompanied the emergence of stronger female narratives. We will focus on plays that feature female protagonists whom we think we already know from history or mythology and who confront culturally predominant male narratives. In each case, the playwright offers her characters a unique opportunity to deconstruct and re-write these stories, or even to demythify and re-inscribe myth. These writers emphasize the credibility of their female characters as they urge their spectators to question the legitimacy of traditional patriarchal roles for women and to look beyond a purely masculine point of view to a more pertinent and comprehensive view of the problems that exist in the world outside the theater.
\end{abstract}

Keywords: myth, history, woman-authored theater, female characters, resistance.

\section{Resumen}

En este artículo veremos una muestra pequeña pero coherente de obras de dramaturgas de la España democrática, desde los años 80 hasta la actualidad, en las que se ve una relectura de la historia y del mito. Nos centraremos en las obras protagonizadas por mujeres que ya reconocemos de la historia o de la mitología y veremos cómo estas

Feminismo/s 30, diciembre 2017, pp. 47-68

Los contenidos de la revista se publican bajo una licencia de Creative Commons Reconocimiento 4.0 Internacional (CC BY 4.0) 
figuras se enfrentan a las narrativas masculinas predominantes. En cada caso, la dramaturga ofrece a sus personajes una oportunidad única para deconstruir y re-escribir estas historias, o incluso para desmitificar y luego re-escribir unos mitos. Estas escritoras enfatizan la credibilidad de sus personajes femeninos mientras piden a su público que cuestione la legitimidad de viejos papeles patriarcales para mujeres, que mire más allá de un punto de vista puramente masculino y que proponga una visión más pertinente y completa de los problemas que existen en el mundo fuera del teatro.

Palabras clave: mito, historia, teatro de mujer, personajes femeninos, resistencia. 


\section{INTRODUCTION}

From the vantage point of 2017, we can look back over the last three decades of works by female dramatists in democratic Spain with a degree of historical and literary perspective. With a critical eye, we can make out a cementing of literary generations, a progression of developing personalities and a flourishing of themes, always underpinned by the constant, keen awareness of the importance of giving women a voice. This paper will look at a small, but cohesive, sample of plays from the 1980's to the present in which the dramatic retelling of history and myth has evolved in time as it accompanied the emergence of stronger female narratives. Generally, we shall focus on plays that feature female protagonists who confront culturally predominant male narratives. Within that group, we will consider more specifically the appearance on stage of figures whom we think we already know from history or mythology. In each case, the dramatist presents to her characters a peculiar opportunity to deconstruct and rewrite those histories, or even to demythify and then reinscribe our own myths. These playwrights emphasize the believability of their female characters as they ask their audiences to reevaluate the legitimacy of age-old patriarchal roles for women; meanwhile they offer thoughtful meta-commentaries on the nature and power of women's writing.

We shall begin this study by looking at three plays, two written by Concha Romero and one by Carmen Resino, dramatists who belong to the first generation of female playwrights of democratic Spain. Both writers chose to reclaim and stage the lives of two famous queens, Isabel I of Castile and Elizabeth I of England. In Romero's 1988 play, Las bodas de una princesa, we meet a young princess Isabel who stands up to the nobles seeking to usurp her power as they consolidate their own. By the end of the play, we clearly hear the strong voice of the future queen who will unite Spain. In Juego de reinas, published just one year later, Romero further emboldens her female characters. The audience witnesses a series of intimate and contentious conversations between Isabel and her daughter, two women who completely disagree about how a woman should rule. Carmen Resino picks up the gauntlet of recovering lost female voices laid down by Romero in her Los eróticos sueños de Isabel Tudor (1992), 
a play that can now be considered a pivotal, transitional work in Spanish women's theater. In terms of style, Resino cast aside realism and turned to complex dramatic techniques more commonly associated with the so-called second generation of female dramatists. Through flashbacks, dream sequences and metatheater, she frees Elizabeth I from the restrictive persona of the cold Virgin Queen and reveals to the audience a woman who, having learned to embrace her until then repressed sexuality, succeeds in balancing her public duties with her private desires.

Las voces de Penélope (1998) and Polifonía (2000), respectively, are among the early works of Itziar Pascual and Diana M. de Paco Serrano, two prolific members of the second generation of female dramatists. The very structure of these plays immediately sets them apart from their predecessors. Characterized by out-of-sequence events and constantly shifting and dividing characters, these works form a sort of puzzle to be assembled by the audience. De Paco and Pascual here prefer myth to history in the exploration of female roles because they understand how its symbolic, cyclical nature creates a fertile environment for the discussion of timeless, universal themes. In fact, both choose to retell the story of Penelope, the archetypal passive and obedient wife of ancient legend, who waits dutifully and loyally for Ulysses, her heroic husband, to return from war. Pascual gives voice to mythical and modern-day Penelopes to confirm female passivity as an unhealthy, gendered role that women have been conditioned to play. De Paco's Penelope, by contrast, is in the company of a trio of other famous heroines, Medea, Clytemnestra and Phaedra, each of whom must come to terms with a violent past by creating an authentically personal version of her infamous story. By demythifying the heroes and elevating female discourse, both authors offer to their modern-day audience a new woman-authored, gynocentric mythology.

Lastly, we will look at two of Pascual's and de Paco's more recent works. Both authors continue to give voice to famous historical and mythical women but they also expand the focus of their plays to include a more pointed criticism of today's society. Pascual's Variaciones sobre Rosa Parks (2007), for example, mixes history and myth together. On the one hand, it is the untold biography of a dying and senile Rosa Parks, while on the other, it is a modern retelling of Antigone by Sophocles. Pascual's decision to split Rosa Parks into two distinct and embattled characters allows the audience to witness a more honest assessment of certain events that energized the civil rights movement. Pascual uses one woman's moment of defiance, of civil disobedience, to criticize many more of modern society's failings, including poverty, apathy and racism. In her Casandra (2016), de Paco returns to a mythological world, one 
that nevertheless bears a strong resemblance to modern times, to challenge the traditional myth of Cassandra, who puts on stage an alternate version of her life story, equally as believable and equally as compelling as that of the original male version of her myth. In her story, Apollo is the villain, the monster responsible for the death and destruction caused by the Trojan War. Casandra should be read as a treatise against fake news and propaganda that still leads nations into war in our modern world. It also reminds us just how difficult it is to uncover the truth and how much harder it is for women to be heard and respected when they are the ones who speak truth to power.

\section{REALISTIC RETELLINGS OF HISTORY}

Romero's Las bodas de una princesa (1988) and Juego de reinas o razón de estado (1989) present Isabel during two distinct moments of her life. In the former, she is an adolescent princess caught in the midst of a power-struggle for sucession to the throne of Castile, while in the latter she is an elderly queen whose steady, forceful presence is juxtaposed with the increasingly unhinged emotional fragility of her daughter, Juana la Loca. Las bodas is realistic in style and presents all events in chronological order. Isabel's failure to appear until the third scene highlights how little volume her voice has in the patriarchal world that she inhabits. The men in power strategize and scheme about Isabel's political value, using her as a pawn as they decide her marriage plans. Despite the force of power-hungry men objectifying and monetizing the young Princess, she remains nobly defiant. When we finally do meet Isabel, she is in the privacy of her room, seated by the window, sewing. This wholesome pastime, like spinning, is an unmistakable allusion to premodern femininity and perhaps even a subtle nod to Homer's Penelope who spends years weaving, and unweaving, as she fends off suitors ${ }^{1}$. The question implied by the Homerian connection is whether or not Isabel, too, will give in to self-sacrifice and passive resignation. Her first words indicate that she will not: « ¿ástima que las princesas no podamos casarnos libremente! Siempre son los otros que deciden nuestras bodas» $(1988,23)$. The scene crisply forewarns the audience that this young woman will not be a pushover; she will not sit by submissively while men decide her fate.

Indeed, her conduct in public shows the beginnings of the birth of Isabel I as a savvy political and military leader. She is composed and shows a keen understanding of the importance of her role in the future of Castile. Although

1. Carolyn J. Harris observes that Isabel is «la mujer que espera encerrada, mirando por la ventana y soñando con un futuro incierto» $(1993,22)$.

Feminismo/s 30, diciembre 2017, pp. 47-68 
upset and dismayed to learn that she may be forced to marry the King of Portugal, Isabel hides her emotions and calmly counters the notion with logical reasons why the marriage should not take place. Only back in her room does she collapse into tears and declare that she will never marry him. Isabel's private reaction is that of a "very human and vulnerable young woman whose solutions to problems are still naive, but whose determination suggests promise for further development and eventual triumph» (Podol 30). A similar pattern is followed when the nobles conspire to have her marry one of them so that they may thus control the young princess and appropriate her power. Isabel fights back with intelligence, suggesting to one of the nobles that, «sería una lástima utilizar la boda de una princesa para resolver un conflicto interno cuando hay alianzas con el exterior más convenientes. Está Francia, Inglaterra, Portugal y también Aragón» $(1988,66)$. Isabel is acutely aware of her role in the configuration of history and is determined to make the best decision for her country. She understands that she must balance her public and private identities if she is to be successful in both.

Isabel eventually marries Fernando of Aragon, and her newly-gained political acumen is evident as she negotiates the terms of this union: «y cuide de que mis derechos queden garantizados. Los dos aportamos lo mismo y no quiero ser una reina consorte. En Castilla y Aragón tanto debe mandar él como debo mandar yo. Si no acepta tampoco con él me caso» (72). The message of female empowerment may seem weakened somewhat by the fairytale ending, but there are still many positives to be taken from the play, including the re-appropriation of women's history and the fact that Isabel is cast as an intelligent, albeit emotional, young woman who successfully takes control of her destiny while never ignoring the political ramifications of her actions. «Ha encontrado la forma de dirigir su vida personal y pública a la vez que impone su visión y su punto de vista» $(1993,23)$, to use Harris' phrase.

In Juego de reinas, Romero picks up the queen's story at the end of her life. The more public political intrigue of Las bodas de una princesa is pushed now into the background so that she can squarely focus on the difficult relationship between mother and daughter. Romero not only foregrounds her female protagonists, allowing their view of events to assume unrivaled importance, but also silences the men. In fact, no male voices are heard in this play at all. What political framework does exist in Juego de reinas is built around the transfer of power: Isabel is reaching the end of her life and Juana, her only living child, must be ready to assume the throne. It is not exactly court intrigue that moves her plot, however. Romero wants to shine a light on Juana's madness. The male-dominated version of history is clearly rewritten in the long 
dialogues between mother and daughter, during which it becomes clear that private sacrifices are required to attain and hold on to public power, sacrifices that Isabel accepted for the good of her country. Providing the counterpoint to this position, Juana claims that Isabel's personal sacrifices had been too great and denies that she would ever sacrifice her private life as queen. The mother and daughter represent two extreme positions: Isabel is focused on Spain's future, no matter the personal cost, while Juana, who describes her life as «un cuento de hadas» $(1989,4)$, lives obsessively for her husband. Isabel sees the danger inherent in her daughter's emotional blindness, and tells her, «no esperes que nadie te resuelva los problemas. Debes tener criterios propios y saber imponerlos incluso a tu marido si es necesario. Tú serás la reina. Él sólo rey consorte. No lo olvides nunca» (20). Her advice falls on deaf ears as Juana's personal happiness and eventually, her sanity, will be destroyed as she allows herself to be governed only by her emotions. Isabel's life of personal sacrifice for political gain, the repeated triumph of reason over emotion, will be exposed as a politically brilliant yet personally destructive strategy. Taken together, the plays show an evolution in Romero's retelling of a famous life. From a young age Isabel has learned to be acutely aware of all that rests on her shoulders, but, despite her political successes, the end of Juego de reinas reveals the often hidden personal cost. Isabel sums up her life this way: «cumplí mi destino como un hombre aunque haya sufrido como una mujer» (47).

\section{A BRIDGE BETWEEN GENERATIONS.}

At first glance, Romero's plays appear to share a lot, both structurally and thematically, with Los eróticos sueños de Isabel Tudor (1992). Like Romero's Isabel, Resino's Elizabeth faces problems that arise from being a powerful female figure in a male-dominated world. However, in place of the powerful realism and linear plot progression used by Romero, Resino utilizes a much more complex dramatic style. Chronological time is broken up by flashbacks and dream sequences and objective realism is regularly thwarted by duplicitous and disguised characters as well as by the injection of metatheatrical commentary. In retrospect, we can see that Resino is constantly distancing herself from Romero's earlier realistic model and tending towards the much more complex, postmodern techniques of the second generation of dramatists.

Los eróticos sueños' revision of patriarchal history is evident from its very title. That Elizabeth I should have erotic dreams is a far throw from the traditional image of the frigid, virginal queen. The subtitle, La quimera y lo util, and Resino's comments following the list of dramatis personae serve to signal to the spectator that all is not as it seems: 
Sin embargo, todos estos personajes, al igual que María-Ana, no son más que desdoblamientos de la reina, que diversificaciones de ese monólogo íntimo en el que se debate: la continua dialéctica entre la obligación y el deseo; la circunstancia histórica y el ser como individuo. (12)

Resino reveals upfront that all the characters presented are projections of Elizabeth's mind and reminds us that we are witnessing one long interior monologue, not a series of dialogues between the queen and other characters. One might assume that this information could help us understand the events that unfold, but the opposite is true. Resino layers fiction upon fiction, juxtaposing dream and reality, until we lose track of the real Elizabeth and are forced to treat «history» subjectively, which is an innovation in itself.

The historical episode that serves as a backdrop for this intimate drama of self-discovery is the English victory over the Spanish Armada in 1588. Cecil, the prime minister, wants Elizabeth to confront increasing Spanish aggression yet he cannot get her to engage with the problems facing her nation. We soon learn that Elizabeth is distracted from her regal duties by her private desires; she is secretly in love with Phillip II of Spain, the protagonist of her erotic dreams. In these dreams, however, Phillip always turns into Elizabeth's nemesis, Sir Francis Drake, causing her to awaken frustrated and irritated. Fantasy and reality become still further intertwined when she receives a message, purportedly from Phillip, inviting her to a clandestine romantic rendezvous. When Phillip is admitted to her quarters, the spectators witness a magnificent play within a play, in which the king and queen flirt, gossip and enjoy erotically charged, intelligent conversation, laden with double-entendres. As the scene progresses, Elizabeth realizes that, just as in her dreams, the man seducing her is again Drake, disguised as Phillip. Nonetheless, she chooses this time to accept Drake's advances in order to spend two more days fulfilling her private erotic desires, which have in this moment obscured her public responsibilities.

The effects of the constant tug of war between Elizabeth's desires and duties are evinced in the juxtaposition of two scenes: one between Elizabeth and María-Ana, her lady in waiting, and the other between the queen and her prime minister, Cecil, who is plainly the voice of reason, of historical reality, of political responsibility and of the patriarchy. His interactions with Elizabeth in and about the public realm provide a frame for the more controversial and intimate discussions between Elizabeth and María-Ana as well as for the love scene between Elizabeth and Phillip/Drake. Ultimately, the audience realizes that the Elizabeth who appears with Cecil seems less convincing, even almost untrustworthy, as if she were merely pretending to be queen. By contrast, the private Elizabeth, the one seen with María-Ana and Phillip/Drake seems to 
be more genuine. These contradictory images enact the illusion/reality dichotomy alluded to in the play's subtitle and force the audience to piece together a richer, more complex and therefore more accurate image of the famous queen.

Initially, María-Ana clearly represents all the emotions that Elizabeth had denied and suppressed in order to become a powerful leader: «es joven, muy bella y sin embargo se parece a Isabel: es como una proyección retrospectiva y en cierto modo equivocada de la reina» (14). María-Ana is the whore and Elizabeth the virgin, but this binary relationship will flip-flop throughout the play, repeatedly putting in doubt the veracity of Elizabeth's traditional image. Elizabeth frequently calls María-Ana a slut and criticizes her inappropriate behavior, yet María-Ana responds to her attacks with brutal honesty, challenging the legitimacy of the queen's chaste public image and forcing her official persona to face the truth about her real, private yearnings. Eventually, Elizabeth will switch roles with María-Ana, and she is acutely aware of doing it: «ite das cuenta, Ana? En este momento tenemos los papeles cambiados: yo debería ser la celestina y tú la virgen» (34). María-Ana is uncomfortable with the transformation in her mistress: «Perdonadme, señora, lo que deseo es que volvamos a nuestros hábitos y, sobre todo, veros como siempre: ¡Fría, distante, con esta realeza tan magnífica!» (46). To this Elizabeth responds, «(Casi para sí)... Y tan engañosa» (46). Emotion has overcome reason, private desires have eclipsed public responsibilities and Elizabeth has become the subject who controls her own drama instead of an object controlled by the norms and exigencies of the patriarchal society, in which she must not only live as a woman, but over which she must also rule. Elizabeth's recognition of the validity of the powerful emotions that she felt in private have given her a sense of power and confidence to return, reinvigorated, to her public role. The play ends with a meeting between Elizabeth and Cecil in which she finally agrees to receive Drake and to fashion a military strategy that will destroy Phillip's hopes of invading England. This decision, of course, will result in the defeat of the Spanish Armada. The last image in the play is an unequivocal admission that Elizabeth's existence as a formidable public figure is due, in part, to the understanding and acceptance of her sexuality. Standing in front of a full-length mirror as she prepares to receive Drake, she exclaims: "(Entre el insulto, la complicidad y el reto.) Isabel Tudor, reina de Inglaterra... jzorra!» (80).

These three historical dramas by Romero and Resino are structured around the push and pull of the public/private dichotomy. The private persona behind the public façade is an image that contrasts with the audience's preconceived notions of these historical figures, notions learned from male-documented versions of history. The revision and reinterpretation of the private processes 
behind famous public events and decisions make for fascinating, thought-provoking theater. Female characters with agency make their voices heard over those of the monstrous din of the status quo: they are new role models for the modern woman to admire and imitate.

\section{HARNESSING THE POWER OF MYTH AND HISTORY: RELLING PENELOPE'S STORY}

With Los eróticos sueños de Isabel Tudor we have left behind the first generation of female Spanish dramatists and are moving on to plays by Itziar Pascual (Las voces de Penélope, 1998) and Diana M. de Paco Serrano (Polifonía, 2000), members of the current (second) generation ${ }^{2}$. Diana de Paco describes the theatrical philosophy of her generation: «en general, se aleja de los parámetros realistas que caracterizaban la dramaturgia de los ochenta y busca en la deconstrucción de la estructura del texto y la fragmentación de las bases tradicionales la expresión de una nueva estética» $(2003,91)$. This new aesthetic can be seen in the use of a variety of complex dramatic styles including fragmented dialogue, out-of-sequence events, deconstruction of memory, role-playing, metatheater, intertextuality and the dissolution of self (Floeck 2004, 191). The audience also assumes a relatively more active role. This style of theater forces each spectator to put together the pieces of the mosaic created on stage, and in so doing, to participate in the creation of meaning $(2004,191)$. Topics common to these two playwrights include myth, gender violence, war, immigration, racism, female identity, the role of women in society and the economic crisis. These pertinent, diverse and highly relevant themes are often presented through the eyes of a female protagonist, one who offers the spectator a new lens through which to view these pressing issues.

In Las voces de Penélope, Pascual tells her story through a complex, multifaceted structure, fractured across twenty scenes ${ }^{3}$ : six of them correspond to Penelope's ancient, mythical world, thirteen take place in the present-day spaces of the other two characters, La mujer que espera and La amiga de Penélope, and the twentieth, which brings the three characters together in a

2. Penelope is the protagonist of both these plays and I would be remiss if I did not point out the existence of Carmen Resino's Penelope (Pen) in Ulises no vuelve. Written in 1974 and published in 1983 it falls outside the parameters of this study. Nonetheless, it is important to have this play - with its cowardly Ulysses who hides to avoid going to war and its rebellious Pen who is forced to be complicit in her husband's deception - in the back of our minds as we read about other Penelopes.

3. See Elisa Sanz's article for an excellent description of how the play is organized. 
timeless, mythical space $e^{4}$. Pascual, like Resino before her, chooses to split the character of Penelope, but does not reveal this plot twist until the end of the play. Las voces de Penélope moves back and forth from the mythical past to the present day, forcing the audience to sew together the threads of each woman's story. Gradually, the spectators become aware that the common thread shared by the characters is that they are all versions of Homer's Penelope. As John Gabriele observes, Pascual's three characters, «evolucionan independientemente, pero acaban por fundirse», creating what he calls a «concretización colectiva del Yo» (144).

In Penelope's first few scenes, she appears resigned to her fate. She sees herself as a victim of her circumstances and declares that she would rather die than keep on waiting: «no tengo razones para comer. No tengo razones para respirar. No tengo razones para vivir» (Pascual 2002, 313). By her fifth appearance in the play, she has reached the breaking point. She understands that she must either completely discard the myth that holds her hostage and refuse to be a victim or begrudgingly admit defeat and remain the obedient, mythical heroine. Penelope takes stock of the many important roles that she has assumed in her husband's absence: «madre, padre, reina, amiga, gobernante: todos los papeles para una única actriz», and she continues to name and then reject the one role that for years had been her destiny: «todos [los papeles] menos uno. Víctima no» (320). Penelope's empowerment is particularly apparent in the scene in which she greets a stranger, a man who has arrived in Ithaca after a long journey. It is Ulysses, but we never hear him speak; we only hear Penelope's side of the conversation. She tells the stranger that her absent husband is someone who «[...] vagamente me recuerda», but then stops herself saying, "pero no hablemos de ello. Son historias viejas» (321). Penelope will cast off this vieja historia and will replace it with a new myth of her own creation. By the end of the play, she recognizes that her waiting was not a submissive act, but rather an assertive act of defiance: «la espera es una forma de resistencia [...] la espera me hizo más fuerte, más segura y descreída [...] esperé a mí misma. Esta es mi verdadera historia» (331-332). Penelope has understood that she was trapped in someone else's story, playing a role that did not reflect her true identity.

La mujer is a modern Penelope and her character follows a similar trajectory to that of her mythical counterpart. Initially, she is portrayed as a passive and depressed victim incapable of moving on with her life after her boyfriend

4. From this point on I will refer to La mujer que espera as La mujer and La amiga de Penélope as La amiga. 
has left her. La mujer is paralyzed by self-doubt and can do nothing but wait for her lover to return. However, through the constant encouragement of her friend, La amiga, she eventually frees herself from this most destructive of roles. Her epiphany occurs during a delightful scene in which she opens her heart to a potted plant:

No he sabido... medir. Yo me he hundido entre tanto «ya veremos». Él se ahoga ante mis excesos y se desespera con mis carencias. (Pausa.) Será por eso que nunca he sabido regar las plantas. O las ahogo o se me secan. Hay que aprender a escuchar. Es una voz que está debajo de los pasos. Te dice: ahora. Y luego dice: basta. Si hubiera aprendido antes no serías tan pequeña. Habrías crecido más. (Pausa.) Yo también. (325-326)

She is now La mujer que esperó, and she explains to La amiga how she broke free of the myth: «aprendes a ver. Menos mitos, menos pedestales, menos héroes. Y también menos princesas de cuento» (329). Like Penelope, she rejects old stories and understands the vital need to create new ones.

La amiga is a more nuanced character. More upbeat and optimistic than Penelope and La mujer, she spends much of the play consoling La mujer and offering herself up as an example of a woman who would never wait for a man: «a mí eso no me pasaría nunca. A mí no. Yo lo tengo muy claro. Por ahí no paso. ¿Y por qué no le dejas? ¿Y por qué? Tú vales mucho más» (303). In fact, at times it seems that Pascual has put her on stage as a literary device, to prevent the play from falling into a series of monologues and to introduce some levity into the unfolding story. The engaged spectator can see beyond her formalistic function, though, and we do eventually discover that she too has spent many years waiting, waiting for her unfaithful and ungrateful lover to change. After finally ending this destructive relationship, she is now able to see the advantages of self-reliance: «cuando estás sola, observas más. Te fijas. Y el paisaje cambia» (324). She directs her newfound energy outwards into society, towards helping other women. For example, she dictates to La mujer a powerful treatise, bolstered by extensive statistical data, on the lack of women's rights in contemporary society that will be published by the local university. La amiga has rejected the myth of passivity and has become an active promoter of authentic female roles as well as a powerful voice of female resistance against the patriarchy. The Homeric motif of the passive woman who dutifully awaits her man's return is completely subverted in Las voces de Penélope. Ulysses' famous voyage has been hijacked. As La mujer observes: «A Ulises también le cambió el viaje. Pero esa es otra historia. Que le cuente él... Si quiere» (330). It is the women, not Ulysses, who make a voyage of discovery, albeit an internal one, into a deeper sense of self, a space that Penelope defines as «el diminuto 
espacio del ser y el estar» (331). All three versions of Penelope were waiting to discover themselves.

Polifonía, by Diana M. de Paco Serrano, offers another take on myth's innate power to address the retelling of women's stories. On stage in Polifonía are three of the most infamous female characters of Greek tragedy: Medea, Clytemnestra and Phaedra. The women awake to find themselves in a dark and gloomy grotto in a corner of the underworld (called «the prison» in the stage directions). The women, brought here by Penelope, demand to know where they are and why she is holding them there. Polifonía comprises fifteen short scenes: seven occur in the mythical present of the play, in the grotto, and the remaining eight are set somewhere in a vague time and space of memory. Unlike Pascual, whose only voices are female, de Paco also lets us hear the mythical heroes themselves. In the retrospective and elusive space of memory, we watch as Phaedra confronts Hippolytus and Theseus, Medea challenges and defies Jason, Clytemnestra battles with Agamemnon and Orestes, and Penelope faces first Telemachus and finally Ulysses. In these flashbacks, the men condemn themselves in their own words, ironically participating in the deconstruction of their own myths. As Floeck explains, «las heroínas arrancan las máscaras de la cara de sus esposos y lo que descubren detrás son instinto sexual, brutalidad, violencia, egoísmo y corrupción» $(2009,16)$. That De Paco «permits» these husbands and sons to present their own self-defense is important for at least three main reasons: it cleverly gives the spectators the impression that what they hear is unfiltered testimony; it casts ancient wives as reliable eye-witnesses; and it asks that we the audience be the judge.

One by one, the women awake and begin to remember their pasts. They retell their violent stories to one another in versions that seem more authentic than the «originals». Phaedra explains how she made the decision to commit suicide when it became clear that Hippolytus, selfish, immature and stubborn, would never return her love. Clytemnestra, rejecting the long-held notion that she killed Agamemnon to be with her lover Aegisthus, assertively defends her actions. She exclaims to Orestes: «Egisto no tenía nada que ver, no he actuado como mujer, no he sido yo quien ha obrado, sino la justicia vengadora» (84). Clytemnestra had to avenge her daughter Iphigenia's death. She could never forgive Agamemnon for sacrificing Iphigenia to the gods in exchange for political favors. Medea, too, will justify her act of violence, the murder of her children. We will listen as she explains to them the reasons for this terrible crime:

No, no se trata de venganza, se trata de ahorraros la amargura de un final inevitable, antes de que tengáis uso de razón, si llegáis a tenerlo. ¿Para qué 
dejaros navegar a la deriva, en medio de la tormenta, si el trayecto es terrorífico y el único final es el abismo? ¿Para qué esperar a que sean vuestros inocentes labios, ahora mudos, los que me supliquen una muerte sin dolor, sin conciencia? Yo sé lo que os espera porque ya he alcanzado el final. Os amo, os amo tanto que no puedo permitiros una pena que os consuma poco a poco. (67)

Medea insists that she acted out of pure, maternal compassion, telling Jason, «no ha sido una venganza, Jasón. No te la merecías. Yo no he pensado en ti, sino en ellos. No me arrepiento» (92). At last, all three women emerge from the spaces of memory, from these unexpected conversations with their husbands and sons, feeling validated and empowered because their versions of events have finally been put into the record, so to speak. But what about Penelope?

Penelope has listened patiently and with great interest to Medea, Phaedra and Clytemnestra, but it is only after their violent stories are retold and she has embroidered them on her tapestry that the other women may finally question why she is holding them captive. Phaedra asks her:

¿Y tú, Penélope? Solamente quedas tú. ¿Cómo termina tu historia? ¿Qué crimen has cometido? ¿Qué desgracias te han atormentado a lo largo de tu vida? Aunque lo niegues, ha de haber una razón que te haga estar junto a nosotras, ¿Qué es lo que te une a Clitemnestra, a Medea o a mí? Vamos, sé sincera. (93)

Penelope is adamant that she has nothing to hide: «me molesta vuestra insistencia [...], no ha habido ningún motivo de desasosiego en mi vida, excepto la ausencia de Ulises» (93). Having heard about Ulysses' adventures as she wandered around the world in exile, Medea knows more than Penelope realizes. Ulysses did return to Ithaca, but the man who returned, Medea explains, was «un hombre extraño, salvaje y bárbaro que ya no [le] amaba» (95). The real reason why Penelope has not completed her tapestry is that she killed Ulysses and even she finds it difficult to sanction this newest version of the oldest of myths. However, De Paco creates a sense of ethical comradery through these women's stories that at long last gives Penelope the strength to speak. Penelope's iconic tapestry, which in Polifonía was to be her husband's shroud, becomes instead a new female chronicle, a female-authored version of old stories, a new mythology. After Medea, Phaedra and Clytemnestra drape themselves at the end of the play in Penelope's cloth, now a symbol of female power, they clarify in unison: «Penélope era la parca. De ella dependía que la historia siguiera su ciclo natural o quedara suspendida y reinara el olvido» (106). Penelope's documentation of a new history, of a new myth, was only possible by denying her husband his mythical status and simultaneously being supported and inspired by other women who had managed to accomplish something similar. 
Both Pascual and De Paco use the story of the passive, obedient wife as a point of departure for their rewriting of myth. Pascual creates a fragmented Penelope and, as Harris concludes, «the presentation of the stories of three Penelopes in Pascual's work leads spectators to recognize that waiting on another [person] is not a natural part of female identity but a role that women have assumed» $(2003,6)$. Pascual's Penelopes show a path to self-knowledge and self-empowerment through the rejection of this destructively subservient gendered role. De Paco's Penelope has surrounded herself with women who, as Ragué-Arias notes, are «producto[s] de la violencia y del miedo» (727). Why? Because she too has committed a crime. She has destroyed both the man and his myth, and has put in their place a new myth, one written from a female perspective. Both dramatists hear the call of those silenced in the past and both will continue to deconstruct old paradigms, letting female voices come to the fore and offering modern audiences new, more sensitive ways to interpret old stories.

\section{RADICAL RETELLINGS: HISTORY, MYTH AND BEYOND}

In Variaciones sobre Rosa Parks (2007), Pascual gives voice to the African American Civil Rights icon. As the title indicates, this play does not proport to offer a definitive image of Rosa Parks. Instead, the word variaciones implies a more multifaceted and less simplistic approach to the historical figure. Variaciones sobre Rosa Parks is not just a straightforward retelling of historical events; it is a personal and authentic interior narrative that presents a nuanced image of Rosa Parks and her struggles to come to terms with her individual role in the history of her country. In a sense, it is a subtler exposition of the public/private dichotomy around which Resino and Romero's history plays were structured. Pascual's Rosa Parks was not born a queen, but her small act of personal courage, of unwitting social activism, forever altered the direction of racial history in the United States. Her existence as a private citizen ended the moment she refused to give up her seat and it is this transformation upon which Pascual plays to show how Rosa's bravery was never fully recognized or rewarded. On the contrary, Rosa is shown at the end of her life, living in poverty in Detroit. Like Romero and Resino before her, Pascual puts a famous historical figure on the stage and asks the audience if the price she paid at the personal level was worth her place in history.

Pascual anchors the play in the tension created between two dueling personalities. The protagonist is Rosa Parks, an old woman suffering from dementia who feels that her biography, written many years earlier, no longer tells the story of her life as she remembers it. «Ese libro ya no me sirve, ahora 
veo las cosas de otro modo» (31). Rosa narrates these elusive and shifting memories into a tape recorder, feeling compelled to document her life story before she dies. She is both helped and hindered in her storytelling by the antagonist, La sombra de Rosa Parks, her alter ego and the product of her dementia. ${ }^{5} \mathrm{La}$ sombra is adamant that she not be ignored: «si quieres contar tu historia vas a tener que contar conmigo. Vas a tener que aceptarme. Yo también formo parte de tu historia. Yo soy una parte de ti» (32). This ingenious splitting of the character of Rosa Parks into two at times contrasting halves allows Pascual to privilege dialogue over monologue and to offer competing recollections of the same autobiographical event.

The advantages of putting these two conflicting voices on stage are particularly clear in the scene in which Rosa and La sombra quote and discuss Sophocles' Antigone. The two characters are shown in a prison cell, recreating Rosa's incarceration after her arrest. Both women read Antigone together and use it to uphold their clashing positions. La sombra tells Rosa that it is time to stop protesting because things will not end well: « $i$ Quieres que tu vida sea una tragedia? Ismene, la que acepta los límites, sigue viva» (57). Rosa Parks rejects this defeatist attitude and refuses to give in: «Cómo se vive con eso? ¿Perder a los tuyos, perder tus derechos y no hacer nada? ¿Cómo se sale de esta cárcel? ¿Bajando la cabeza? ¿Una vez más?» (58). She knows that Antigone ends in tragedy but understands that «la libertad no es gratis» and that «no estamos exentos del dolor por nuestras acciones» (59). By discussing Antigone directly, Pascual chooses to foreground the parallels between the mythical and modern-day heroines who protested tyranny and defied the flawed laws of their times in defense of their moral values. It also tempts us to read the entire play as a contemporary dialogue between a reluctant and accidental Antigone (Rosa Parks) and her law-abiding sister, her dramatic foil, Ismene (La sombra). As Söderbäck observes, the character of Antigone is never far away when talking about civil disobedience:

Whenever and wherever civil liberties are endangered [...] when injustices take place - wherever she is needed, Antigone appears. And although the details and context may vary, certain elements of the story always remain the same: the lone individual fighting against state power, the kinship burial rites, and, interestingly, her status as a woman. Because whatever group or interest Antigone is brought in to defend [...] it is always as a woman [...] that she appears on stage. (3)

5. From this point on I will refer to this character as La sombra. 
Another scene that takes on more weight when viewed through the lens of Antigone is the one during which we witness the first and most detailed retellings of the events leading up to and including Rosa' refusal to move to the back of the bus. This is not an objective record of what happened, it is Rosa' interior monologue, performed, as on that fateful day, in the present tense, as she was riding home after a long day working as a seamstress (another modern-day Penelope, waiting, in this case, for basic human rights). La sombra punctuates Rosa's stream of consciousness with the words of two other characters in the story, the conductor and the racist white man who wants Rosa's seat. More than a metronomic back-and-forth, the dialogue at times wanders distractedly from the main subject to other, related stories. For example, La sombra recounts the brutal killing of Emmett Till, murdered for whistling at a white woman, and later Rosa interjects that she sees a young girl through the bus window and ponders what the future might hold for her: «me pregunto si ella disfrutará del final del 'iguales pero separados'. Me pregunto si ella podrá estudiar en una escuela sin segregaciones. Me pregunto si ella dejará de ver carteles que ponen 'for colored use'» (45). At length, the dialogue comes around to that moment when Rosa Parks was told to give up her seat. As she speaks, we feel with her the paralyzing weight of centuries of oppression:

No puedo moverme. No puedo, no quiero, no voy a hacerlo, me cargo sobre la silla, peso. De repente mi cuerpo pesa un quintal, peso como el autobús entero. De repente el mundo pesa menos que mi cuerpo y sé lo que arrastra. Arrastra los sueños de Emmett Till [...] arrastra el miedo de las noches de cruces, de sangre y caperuzas blancas [...] las vidas perdidas, los sueños rotos, los asesinatos impunes [...] los insultos de todos los que fueron atacados y agredidos. (50)

The interior narratives of this doubly-marginalized woman of color present her as a genuine human being who felt a range of powerful emotions we all can imagine, rather than reducing her to a paradoxically inimitable idol.

The second and third retellings of this story offer even darker accounts of events, now told in the past tense with the benefit of historical perspective and through the cruel filter of senile dementia. The immediate audience for these narrations is a group of foreign journalists who have tracked Rosa Parks down in Detroit and have come to interview her. Rosa offers one account of this interview while La sombra narrates a second. Rosa's version highlights the toll taken on her life by her decision. She was not only ostracized by white society for her disobedience, but also criticized and vilified by African Americans, for many suffered during the boycotts and civil unrest that unfolded in the wake of her arrest. Rosa explains how poorly she was treated: «los que habían aceptado 
su destino de esclavos me llamaban imbécil [...]. Se lo tiene merecido, estaba prohibido, ella se lo ha buscado, decían. Es mujer, negra y pobre, ¿quién se ha creído?, decían entre risas» (85). Her account is constantly criticized and undermined by La sombra who eventually silences her alter ego so that she may now «contar la historia a mi modo» (91). La sombra's version of the interview, with which the play closes, leaves us with the image of a poor and irritable elderly woman, hard of hearing and suffering from dementia. She seems tired of retelling her story and the audience finds itself weighing on one scale the value of her victory against all its consequences on the other. In Variaciones sobre Rosa Parks, Pascual shows just how fluid and ambivalent narrations of historical events can be. The precise allusion to Antigone, moreover, roots Pascual's criticism of twentieth-century racism, poverty and apathy in the very bedrock of ancient European theater. Her Rosa Parks becomes a monument to all who have defied unjust laws and, at the same time, an enduring ethical reminder for those whose suffering was thereby lessened.

Diana de Paco returns to the mythological world in 2016's short monologue, Casandra, to reappropriate the story of the daughter of King Priam and Queen Hecuba for the modern age. Cassandra has always been portrayed as a victim of her circumstances. As a young priestess and princess of Troy she spurned Apollo's advances, for which he spat in her mouth, condemning her to spend the rest of her life foreseeing the future and telling life-saving truths that no one would ever believe. As Virtudes Serrano explains, mythical tradition sees Cassandra as a "predictora no escuchada de la caída y de la destrucción de Troya, y como la joven esclavizada que correrá la misma suerte que Agamenón, su tiránico captor, sin haber tenido ella culpa alguna» (230). Diana de Paco has long been fascinated by Cassandra's tragic and compelling story and here, as if talking to Cassandra, she explains what drew her to write a play about this particular Greek heroine:

En realidad, tú tenías el poder, perdona Casandra, porque no te creí: eras sabia, dabas miedo, estabas maldita: una consecuencia que se convertirá en el destino inapelable de muchas heroínas griegas y que, desgraciadamente, es símbolo de la situación de muchas mujeres en la actualidad. (2017)

Diana de Paco's Cassandra will not passively accept this portrayal. She will offer another accounting of her life. She is, as we can see from this, her first statement, an emboldened and defiant heroine:

Yo soy Casandra. La hija, la hermana, la traidora, la puta, la loca. Casandra endiablada. Casandra molesta, incómoda para todos. Casandra rechazada. Casandra despreciada y azotada. Casandra viva. Casandra enamorada. 
Casandra poseída por Baco. Casandra que vio perecer Troya porque los hombres decidieron no creerla. Casandra maldita. $(2016,233)$

Naming and appropriating the labels and insults that have accompanied her through the ages, she negates the destructive power of even the worst of them. This is a potent one-woman show and we will not hear directly from any other character; the audience will hear everything through the ominous voice of Cassandra. Ironically then, the spectator is asked to believe the new version of events put forth by the cursed seer whom no one can believe. Will the audience believe her this time?

Cassandra sets her story in the time right after the fall of Troy and right before Agamemnon kidnaps her and takes her home as part of his spoils of war. Mixing stories of her past and present with those of her future, Cassandra reasserts her own identity by first re-appropriating negative descriptions and then by ruining the reputation of the god who destroyed her life. Apollo, the villain in Cassandra's story, is shown to be ambitious and cruel, blinded by lust, rejection and an insatiable need for power. She offers the audience this unflattering description:

El gran Apolo. El dios rechazado por una niña. El varón que no soporta ser ignorado por una mujer. El hombre divino que tiene que demostrar quién manda... El cobarde que castiga a la joven sacerdotisa por no querer ser su pareja, porque no lo soporta. [...] El equilibrado, sensible y justo Apolo. Apolo celoso y engreído. Apolo ambicioso y ciego de poder. Apolo dios inmortal que ordena el desastre. (233)

In this retelling, the events leading to the death and destruction of the Trojan War begin when Apollo curses the young prophetess. Cassandra tells the audience that it was Apollo who spread the false narratives that started the war. In short, what she tells us differs greatly from the original myth. In her account, there was no Helen of Troy. She was just a femme fatale invented by Apollo to provoke a war that satisfied his lust for violence. Paris was just another victim of Apollo's cruelty, used as a scapegoat to justify war. Paris and Cassandra, who were raised together but who were not biological siblings, were lovers, not Paris and Helen. Cassandra describes their relationship as tragic yet pure, as opposed to Paris' supposed relationship with Helen, which was based on adultery and deception. Before the war even starts, Paris dies while protecting Cassandra from the wrath of Apollo. Once Cassandra reveals the god's secret, that he is the master of the false narrative, she can free herself from the tremendous guilt she felt when her warnings and predictions went unheeded.

Casandra is unquestionably a tale of female empowerment, and like Pascual in Variaciones sobre Rosa Parks, De Paco also opens her work to broader social 
criticism, decrying the cruelty of war, the dangers inherent in spreading fake news and the hazards of apathy. Hecuba, Casandra's mother, plays a similar role to La sombra in Variaciones and to Ismene in Antigone. She is unable to defy her husband and therefore cannot protect her children. Hecuba choses to do nothing: «mi madre lloraba en silencio porque creía que era lo mejor para todos. Mamá, siempre has llorado tus verdades en lugar de decirlas» (234). Cassandra will not be silenced and, although she understands her mother's motivations, she cannot live her life without fighting for what she knows to be true. Cassandra asks her mother towards the end of the play: «iFingir que no se cree la verdad es malo, madre? ¿Cerrar los ojos nos hace culpables?» (239). For Cassandra, taking no action against injustice is not an option. She, like the women of Polifonia, wants to set the record straight and place blame in the correct place, in this case, on a god. By defying Apollo, she is challenging the norms of her society and encouraging other women to do the same. Through the figure of Cassandra and her echoes of Antigone, Diana de Paco invites her spectators to open their eyes to injustice, to speak out against it and to defy those who wish to keep women subservient.

\section{CONCLUSIONS}

Myth and history, narrative bastions of male power, have perhaps unexpectedly proven themselves to be fertile areas for female writers. All the dramatists considered here have «rescued» famous or infamous women from sometimes millennia-old, male-dominated chronicles. Retelling their stories from much more «private» points of view, these figures emerge from the penumbra of their public, male-authored roles. In traditional narratives, the protagonism of female characters is permitted only if it ennobles or improves the legends of their husbands or sons. In these contemporary woman-authored plays of democratic Spain, however, well-known female figures discard the masks made for them by others and take center stage to tell their own stories. Moving away from a linear realism, the dramatists present their stories out of sequence, forcing the audience to be an active participant in the unfolding events. Sometimes, they split their characters into egos and alter egos, opening their plays to more than a single interpretation of a particular character. Other times, interior monologues are used to great effect, taking us through the mental processes behind momentous decisions. Passivity and apathy are shown to be behaviors taught to women by the self-perpetuating patriarchy. The retelling of their resistance seeks to write three-dimensional women back into two-dimensional history and myth. This is not merely a compensatory technique, however. Whether the spotlight is shining on an English queen, a Penelope or a Sophoclean Rosa 
Parks, it is always a woman's voice that is speaking to us. This is another step toward the creation, better late than never, of the female role model who is missing from traditional history and myth. Looking back over the last thirty years of women's theater from the vantage point of 2017, we witness a movement away from a simple revision of women's roles. Instead, more and more frequently, these authors use the narrative paradigms of history and myth as a point of departure to address broader issues such as poverty, human rights and racism. Such universal themes are the very territory of myth and by presenting them from a female perspective, the dramatists challenge their audiences to look beyond one «authoritative» narrative, beyond a single, male-inscribed point of view, to a more pertinent and complete vision of the problems facing the world outside the theater.

\section{WORKS CITED}

Floeck, Wilfried. «¿Entre posmodernidad y compromiso social? El teatro español a finales del siglo XX». Teatro y sociedad en la España actual. Eds. Wilfried Floeck and María Francesca Vilches de Frutos. Frankfurt am Main: Vervuert, 2004. 189-207.

Floeck, Wilfried. «Introducción a Polifonía». In Diana de Paco Serrano. Polifonía. Murcia: Universidad de Murcia, 2009. 9-21.

Gabriele, John P. «Personajes descentrados y realidades fragmentadas: aspectos posmodernos de la dramaturgia de Itziar Pascual». Hecho teatral 3 (2003): 135-150.

Harris, Carolyn J. «Isabel y Juana: protagonistas históricas del teatro de Concha Romero». Estreno 19.1 (1993): 26-28.

Harris, Carolyn J. «Myth, Role, and Resistance in Itziar Pascual's Las voces de Penélope». Gestos 36 (2003): 91-101.

Paco Serrano, Diana M. de. «La reescritura de las heroínas griegas desde la perspectiva de las dramaturgas españolas contemporáneas». Hecho teatral 3 (2003): 89-111.

Paco Serrano, Diana M. de. Casandra. Casandras. Madrid: Esperpento Ediciones Teatrales, 2016. 232-240.

Paco Serrano, Diana M. de. Polifonía. Casandras. Madrid: Esperpento Ediciones Teatrales, 2016. 40-106.

Paco Serrano, Diana M. de. «CASANDRAS. ¿Por qué Casandra?» El Kiosko Teatral 1 (2017) <http://www.aat.es/elkioscoteatral/las-puertas-del-drama/dramaextra-1/casandras-por-que-casandra>, consulted 10-08-2017.

Pascual, Itziar. Las voces de Penélope. Ni Ariadnas ni Penélopes: quince escritoras españolas para el siglo veintiuno. Ed. Carmen Estévez. Madrid: Castalia, 2002. 295-332.

Feminismo/s 30, diciembre 2017, pp. 47-68 
Pascual, Itziar. Variaciones sobre Rosa Parks. Madrid: Universidad Complutense, 2007.

Podol, Peter L. «Three Stages in the Life of Isabel: Plays by Alberto Miralles, Manuel Martínez Mediero and Concha Romero». Estreno 16.1 (1988): 28-31.

Ragué-Arías, María José. Review of Diana de Paco Serrano. Polifonía. Murcia: Universidad de Murcia, 2009. Signa 21 (2012): 725-28.

Resino, Carmen. Ulises no vuelve. Madrid: Centro Español del Instituto Internacional del Teatro, 1983.

Resino, Carmen. Los mercaderes de la belleza. Los eróticos sueños de Isabel Tudor. Madrid: Fundamentos, 1992.

Romero, Concha. Las bodas de una princesa. Madrid: Lucerna, 1988.

Romero, Concha. Juego de reinas o razón de estado. Madrid: Editorial J. García Verdugo, 1989.

Sanz, Elisa. «Las voces de Penélope: Revisión contemporánea de un mito». Parnaseo. ciber-paseo por la literature. <http://parnaseo.uv.es/Ars/Autores/Pascual/obras/ elisa_sanz.pdf>, consulted 08-08-2017.

Serrano, Virtudes. «Casandra, otra voz para el presente». Casandras. Madrid: Esperpento Ediciones Teatrales, 2016. 230-231.

Söderbäck, Fanny. Feminist Readings of Antigone. Albany: State University of New York Press, 2010. 


\title{
ARAÑA EN BAÑERA Y TERRAZA DE CAFÉ POR LA NOCHE, DE EMMA COHEN
}

\section{ARAÑA EN BAÑERA AND TERRAZA DE CAFÉ POR LA NOCHE, BY EMMA COHEN}

\author{
Eva GARCÍA-FERRÓN \\ Universidad de Alicante \\ eva.ferron@ua.es \\ orcid.org/0000-0002-5590-9153
}

\section{Resumen}

Este trabajo es un acercamiento a la figura de Emma Cohen y a sus dos textos dramáticos para adultos, Araña en bañera y Terraza de café por la noche. Nuestro propósito es comenzar a subsanar la total ausencia de estudios sobre esta artista de curiosidad insaciable cuya creación se diversifica en disciplinas variadas. Las obras a las que nos aproximamos son muy diferentes y, a la vez, representativas ambas del rico universo de Cohen, de sus preferencias literarias, de su estilo. El análisis de estas dos piezas, que no agota esta aportación, nos ofrece un mirador privilegiado para apreciar y entender la creación de la autora.

Palabras clave: Emma Cohen, teatro, monólogo, Surrealismo, lesbianismo.

\begin{abstract}
This work is an approach to the figure of Emma Cohen and her two dramatic texts for adults, Araña en bañera and Terraza de café por la noche. Our purpose is to begin rectifying the complete lack of research on this artist whose insatiable curiosity led her to diversify her creation into different disciplines. The plays that we are researching are significantly different and, at the same time, both of them are representative of the rich universe of the writer, her literary preferences, her style. This contribution does not exhaust the study of these two pieces. However, it offers a privileged viewpoint to appreciate and understand the creation of this author.
\end{abstract}

Keywords: Emma Cohen, theatre, monologue, Surrealism, lesbianism.

Feminismo/s 30, diciembre 2017, pp. 69-92

Los contenidos de la revista se publican bajo una licencia de Creative Commons Reconocimiento 4.0 Internacional (CC BY 4.0) 



\section{EMMA COHEN, «INCAPAZ DE SER SOLO ACTRIZ»}

Emma Cohen es una mujer polifacética, una artista e intelectual relevante dentro del panorama cultural español de la segunda mitad del siglo XX. Sin embargo, al acercarse a su figura sorprende la superficialidad y dispersión de la información relacionada con su actividad profesional. La mayor parte de las referencias a ella y su trabajo proceden de la prensa de los días siguientes a su muerte, ocurrida el 11 de julio de 2016. Compatibilizar el innegable interés de su actividad creadora con esta carencia de estudios y materiales académicos constituye un reto para la investigadora. El objetivo de este trabajo es esbozar una biobibliografía lo más rigurosa posible de la autora y analizar sus textos dramáticos Terraza de café por la noche y Araña en bañera ${ }^{1}$.

Emma Cohen es conocida en España por sus interpretaciones en cine, teatro, radio y televisión; no obstante, fue una mujer extremadamente curiosa, que se aventuró en facetas muy distintas. Su labor literaria, centrada en la narrativa y, en menor medida, en el teatro, fue constante desde que publicó su primera novela en 1983 y casi hasta el final de su vida, pero también se atrevió con la dirección cinematográfica, la escritura de guiones televisivos y radiofónicos, las colaboraciones periodísticas, la docencia escénica, la ilustración y el colaje².

Emmanuela Beltrán Rahola, nacida el 21 de noviembre de 1946 en Barcelona en el seno de una familia burguesa, desde que tenía poco más de veinte años se integró de modo activo y atrevido en la vanguardia social y

1. Agradecemos a Helena de Llanos que nos proporcionara el texto inédito de Araña en bañera. Su deseo y el nuestro es que se visibilice la creación de Emma Cohen, de quien se siente nieta: «...soy nieta de Fernando Fernán Gómez y no llevo su apellido, también soy nieta de Emma Cohen y no llevo su sangre. Me gusta sentir que juntos formamos un triángulo familiar bastardo, tres puntas conectadas en el interior de la casa de mis abuelos, donde ahora vivo» (Llanos).

2. Este interés por el colaje es un indicio de su predilección por el surrealismo. El colaje pictórico fue creado en 1912 por Juan Gris, a quien siguió Picasso con sus "papiers collés». El colaje tenía un propósito estético cubista, pero también pretendía materializar el principio surrealista de situar cosas fuera del lugar al que están destinadas. Señala Francisco Aranda que Max Ernst fue quien «exploraría este filón hasta las últimas consecuencias literarias y psíquicas dentro del surrealismo» (25).

Feminismo/s 30, diciembre 2017, pp. 69-92 
cultural española y europea. Luis Alegre destaca que en Barcelona frecuentó el ambiente de la gauche divine, y más tarde, en Madrid, el mundo de la noche de Oliver o Bocaccio y las tertulias del Café Gijón, «donde su belleza y su gracia surrealista arrasaban». Alegre, que llegó a conocerla personalmente en su madurez, afirma: «Siempre fue rebelde, ácrata, inteligente, chispeante y muy inquieta, incapaz de ser solo actriz».

Cohen estudiaba la carrera de Derecho cuando tuvo su primer contacto con la escena en el TEU (Teatro Estable Universitario). En 1968 viajó a Francia para asistir al Festival de Teatro de Nancy y aprovechó la ocasión para acudir a París, donde vivió el Mayo del 68 codo con codo con los jóvenes franceses, hasta el punto de ser detenida (Bugallal). El texto La libreta francesa. Mayo del 68 es un documento valiosísimo que recoge estas vivencias, un diario de lo que presenció entre el 29 de abril y el 1 de junio en París (Cohen 2008).

La interpretación fue su ocupación principal durante los setenta. En 1973 recibió la Medalla del Círculo de Escritores Cinematográficos a la mejor actriz, y fue en aquellos años cuando la revista Fotogramas la entronizó como «Musa del underground» (Dufour). En el cine fue dirigida por realizadores como Roberto Bodegas, Eloy de la Iglesia, Fernando Colomo, José Luis Garci, Imanol Uribe y José Luis García Sánchez (Alegre). Daniel María subraya que su mayor aportación como actriz a nuestro séptimo arte corresponde «al cine más arriesgado, poético y outsider del panorama español». En cuanto al teatro, participó, entre otros muchos, en dos montajes emblemáticos al comienzo de su carrera: Marat-Sade, dirigido por Adolfo Marsillach en 1968, y Un enemigo del pueblo, estrenado en 1971 bajo la dirección de Fernando Fernán-Gómez (Dufour).

El trabajo de Daniel María «Para la libertad: la literatura de Emma Cohen» es el único que existe sobre la producción literaria de la autora. Señala este que a la primera etapa literaria de Cohen pertenecerían las novelas Toda la casa era una ventana (1983) y Negras tierras negras (1988), así como la narración juvenil Alba, reina de las avispas (1986), protagonizadas todas ellas por mujeres muy jóvenes y niñas. En 1990 publica Hechizos, filtros y conjuros eróticos y el relato juvenil Miranda Hippocampus o La Isla del Aire. Tres años más tarde aparecen las novelas Muerte dulce y Rojo Milady. Tras la publicación de Loca Magnolia en 1996 se abre un paréntesis de quince años en cuanto a su novelística, hasta que en 2011 se edita Ese vago resplandor, «la más ambiciosa de sus narraciones [...], es un ejercicio de ensayo periodístico, novela y autoficción» (María). En 2014 publica su última novela, Magia amorosa para desesperadas y desesperados.

Los textos dramáticos de Emma Cohen son pocos, y solo algunos de ellos están editados. En 2008 publicó una obra infantil, La boca del árbol. Otro texto infantil, Libeliula, que se había estrenado en julio de 2008 en la Exposición 
Internacional de Zaragoza, se editó en 2010. En 2011 publicó Terraza de café por la noche, de la que nos ocupamos a continuación. En cuanto a las inéditas, además de Araña en bañera, Cohen realizó una adaptación de la novela La antesala, de Ramón J. Sender, que lleva por título Nazaria, y una adaptación de Peter Pan para radioteatro (María).

\section{ARAÑA EN BAÑERA Y TERRAZA DE CAFÉ POR LA NOCHE}

Los dos únicos textos dramáticos originales y para público adulto de la autora son una excelente muestra de su audacia, de su deseo de explorar en el terreno del arte y la literatura. Este trabajo aborda un acercamiento a ambos para establecer si hay un sustrato común en ellos y para valorar (en la medida en que lo permite la extensión de lo que sigue) cada uno en su individualidad.

Araña en bañera se estrenó el 17 de noviembre de 2008 dentro de un ciclo SGAE de Lecturas Dramatizadas. La lectura, bajo la dirección de Carmen Losa, tuvo lugar en la sala Manuel de Falla de dicha entidad y fue presentada por Emma Cohen (Artezblai). Esta Tragicomedia de soledades en un acto, según la subtitula la autora, tiene como protagonista a Sofía Espíritu, que inesperadamente es abandonada por su amada, Patri, el día de su cumpleaños y cuando está a punto de ser desahuciada de su casa. Mientras graba un testamento oral en el que lega simbólicas pertenencias de varios ancestros a personas de su entorno, Sofía evoca las trayectorias vitales de sus ascendientes, desde su tatarabuela filipina Sofía hasta su tía Carlota. Esta última, con quien la protagonista tuvo una estrecha relación y en cuya casa transcurre la acción dramática, era también homosexual. Una araña de grandes dimensiones está presente en escena desde el comienzo de la obra. Simboliza la muerte, el deseo o la necesidad de morir.

Terraza de café por la noche fue escrita en 2010 y publicada en 2011 por La Página. La obra, que no ha sido estrenada, toma su título del óleo pintado por Vincent Van Gogh en 1888. Dado el carácter surrealista de la pieza, resulta improcedente sintetizar su argumento. La autora pone en escena a los seres pintados por el holandés, les asigna nombres y les hace dialogar. Hacia el final se suman a estas criaturas Van Gogh y Gauguin (el Joven Van Gogh ha estado en la terraza del café casi desde el comienzo), y se alude a la relación que ambos mantuvieron en Arles. El lenguaje de los diálogos y las acotaciones es elaborado y poético; la dramaturga reconoció que su redacción había sido ardua pero gratificante: «Me resultó de lo más placentero escribirla, complejidades incluidas» (Garrido). El mismo año de la publicación de este texto Cohen pronunció en Tenerife una conferencia titulada «Teatro y literatura en el teatro español de vanguardia», en la que demuestra su saber sobre el tema, su interés específico 
por el surrealismo ${ }^{3}$, su devoción por Antonin Artaud y un conocimiento de los ecos de las vanguardias incluso en autores actuales (Rodrigo García y Angélica Lidell). Es muy estimable la aportación de Cohen para tratar de recuperar un teatro tan olvidado como relevante en la historia literaria de España: «...los dramas escritos durante la época surrealista constituyen la escuela dramática más intelectual, más atrevida artísticamente, más moderna de la España del siglo XX» (Sheklin Davis 350).

Estamos ante dos textos cercanos en el tiempo pero notablemente distintos: Araña en bañera es un monólogo de factura clásica (aunque de contenido contemporáneo) en el que Cohen se sirve de su experiencia como narradora para que la protagonista despliegue sobre las tablas las vidas de varios parientes; Terraza de café por la noche, en cambio, es una sucesión de escenas en las que más de treinta personajes interactúan sin que exista un hilo argumental aparente. No obstante, las dos piezas comparten algunos rasgos, y es posible establecer paralelismos incluso entre sus divergencias. Nos ocupamos a continuación de rastrear ambas cuestiones.

\subsection{Los títulos y los subtítulos}

Las tres primeras palabras de Terraza de café por la noche son dos sustantivos unidos por una preposición y sin artículos, lo cual les confiere un carácter genérico; el sintagma preposicional es igualmente poco concreto. Como ocurre con frecuencia en pintura, el título que Van Gogh eligió para su obra (y que Cohen toma prestado) nos remite, simultáneamente, a cualquier café con terraza de no importa qué noche y a un café y una noche específicos: los que quedan fijados para la posteridad en el lienzo. Asimismo, en Araña en bañera la presencia de dos sustantivos sin determinantes y unidos por una preposición transmite al lector/espectador la imagen de los dos conceptos desnudos, es decir, cualquier araña en cualquier bañera. El título vincula dos elementos que en la vida cotidiana se presentan asociados, pues las arañas prefieren los ambientes húmedos; sin embargo, conforme avanzamos en la lectura descubrimos que ambos son

3. Este interés es un reflejo de su actitud vital. El impacto de este movimiento, expresado por Francisco Aranda en 1981 en estos términos, sigue tan presente como augura el final de la cita: los surrealistas «quisieron operar una revolución en los espíritus y lo consiguieron. [...] asomémonos a la intimidad de un hogar joven, entremos en los recintos de una universidad, observemos las modificaciones en los criterios del comportamiento sexual, [...] reparemos en el arreglo de un escaparate, un cartel, un anuncio publicitario... y por todas partes comprobaremos la presencia de la acción surrealista. No es el surrealismo el único culpable del actual estado de cosas, aunque su contribución ha sido enorme. Conviene seguir vigilándolo, porque su agresión continúa» (18-19). 
símbolos de algo más trascendente: la araña, enorme y acechante, es aquí la muerte, mientras que la bañera representa el hedonismo implícito en un baño en agua caliente y perfumada, es decir, es un epítome de los placeres de la vida, de la vida en definitiva.

En cuanto a los subtítulos, el de Terraza de café es Peripecia soñante, dos palabras elegidas con cuidado por la autora. El sustantivo «peripecia» es definido por el DRAE de este modo: «En el drama o en cualquier otra composición análoga, cambio repentino de situación debido a un accidente imprevisto que altera el estado de las cosas». En el sentir de los hablantes, el término tiene un matiz de aventura, de giro lúdico. El adjetivo «soñante» alude al protagonista formal del texto («Soñante Impactado») al tiempo que anticipa el papel destacado de los sueños, tema eminentemente surrealista, en este.

Araña en bañera es subtitulada por Emma Cohen Tragicomedia de soledades. La obra es tragicómica porque los episodios (y la síntesis que de ellos se destila) de las vidas de sus familiares que nos presenta la mujer que monologa son, como cualquier existencia vivida con intensidad, una mezcla de hechos cómicos y dolorosos. El sustantivo plural «soledades» es también adecuado, ya que los personajes que desfilan por escena son hombres y mujeres con una rica vida social, familiar y amorosa, pero unos y otras viven, por distintas causas (frustraciones, adicciones, preferencias sexuales) dentro de un aislamiento innato que nadie logra franquear.

\subsection{Propósito y sentido}

En Araña en bañera Emma Cohen, profundamente libre, libertaria y feminista, crea, desde la madurez de sus sesenta años, un texto dramático en el que una mujer lesbiana monologa sobre el delicado momento vital que está atravesando. Su soliloquio, pese a ser el preámbulo de su suicidio, se convierte en un alegato a favor de la vida moteado de humor, en una apología del valor de vivir haciendo uso de la libertad personal y del arrojo para superar los obstáculos sociales, económicos o familiares. Los seres humanos cuyas vidas nos pone ante los ojos Sofía Espíritu son, como ella misma, personas lastimadas por su circunstancia, pero que triunfan en su propósito de vivir soberanamente.

El sentido último de Terraza de café revela de modo aun más manifiesto el espíritu rebelde e investigador de Cohen, por su apuesta de actualizar el teatro surrealista en una obra que es un ejercicio de inclusión de la mayoría de los ingredientes propios de esa corriente. Escribir en 2010 una pieza surrealista puede antojarse anacrónico en términos estrictamente teatrales; lo que sucede es que esta escritora, tan ajena a la búsqueda del éxito o la notoriedad pública, persigue un propósito personal: 
El teatro surrealista, lleno de personajes deshumanizados, temas intelectuales, yuxtaposiciones e inconsistencias irracionales, es un ejemplo por excelencia de un arte que excita la hostilidad del espectador común. [...] El surrealismo mismo encierra un principio de incomunicación. (Sheklin Davis 347)

Es cierto que la aproximación a un texto surrealista, incluso para quien lo estudia, presenta dificultades desalentadoras. Pero la escritora halla en el surrealismo un espacio de libertad creadora absoluta, apto para abrazar y transferir un bagaje personal que desbordaría el marco impuesto por un texto más convencional. En la entrevista de Garrido ya mencionada, Cohen expone el fin de Terraza de café: «...significa para mí transmisión, ofrecer a otras personas lo mejor de mí. E imagino que las influencias son incalculables, ya que la diosa curiosidad me ha empujado a ser una consumada lectora y vividora». Esta creación es, por un lado, la realización del deseo de la autora de convertir una tela que la deslumbra en un ente vivo y, por otro, un ejercicio de ensalzamiento de la imaginación en la línea del dogma codificado por Louis Aragon en su obra de 1926 Le Paysan de Paris: "Tout relève de l'imagination et de l'imagination tout révèle» [Todo compete a la imaginación y de la imaginación todo se revela] (Morris 189).

Refiriéndonos todavía a la identificación de Cohen con las vanguardias, la elección del cuadro de Van Gogh como tema de la pieza debe vincularse con la declarada admiración de la dramaturga por Antonin Artaud, quien, en su texto Van Gogh, el suicidado por la sociedad, afirma que el arte del holandés supuso una revolución de dimensiones universales:

Porque la pintura de Van Gogh no se opone a cierto conformismo de las costumbres sino al de las mismas instituciones. Y después del paso de Van Gogh por la tierra, ni la naturaleza exterior, con sus mareas, sus climas y tormentas equinocciales puede conservar la misma gravitación. (4)

\subsection{Asunto y temas}

El tema central de Araña en bañera, como anuncia su subtítulo, es la soledad, rasgo que comparten todos sus personajes. Si bien ninguno de ellos experimenta una soledad externa, en la pieza es visible la desconexión de otros personajes a la que le conducen a cada uno sus flaquezas, sus excentricidades o su inconformismo ante las convenciones. Este inconformismo no alcanza la categoría de rebeldía porque no es así como lo narra la protagonista, Sofía Espíritu; se manifiesta con unos comportamientos que, desde la naturalidad, atropellan lo convencional sin miramientos y conducen a estos seres a menudo a la exclusión. La pieza contiene también, como se verá, un sentido y festivo alegato en favor de la normalización de la homosexualidad femenina. 
Resulta complejo reducir a pocas palabras el asunto de este cuasi monólogo, tantos son los caminos por los que transita la dramaturga. Junto a la soledad, solapándose de hecho con ella, otro eje de la obra lo conforman el amor y el desamor, entre Sofía y su amante, y también entre cuantos hombres y mujeres evoca. Las ideas del suicidio y la muerte no se ausentan en ningún momento del texto, porque la presencia de la araña los connota. Las relaciones familiares (inquebrantables a veces, fragilísimas otras) son asimismo un tema relevante. La vida profesional de los parientes rememorados, varios de ellos artistas, se imbrica con la personal, por lo que el mundo del cine, el teatro y la música es otro de los asuntos tratados. Dado que Sofía tiene ancestros que practicaron el hurto y la estafa, que fueron adúlteros o alcohólicos, ante nuestros ojos comparecen seres humanos que ejemplifican debilidades y vicios de todo tipo. Por último, el sexo sobrevuela toda la acción dramática.

Respecto a Terraza de café, contamos con la voz más autorizada, la de la autora: «La línea argumental es Van Gogh en sí mismo, lo que despierta su obra y su ser» (Garrido). Sin duda, «lo que despierta» la obra y la complejidad artística y personal del holandés es, como formulación de la línea argumental de un texto dramático, deliberadamente abstracta y abarcadora. Cohen define de la mejor forma posible el argumento al verbalizarlo de modo tan difuso. Hay que tener presente que el teatro surrealista supuso un vuelco en los valores dramáticos: los dramas no se escribían ya para relatar historias, sino para escenificar paradojas de significado trascendental o universal. Lo explica, de modo no tan distinto a nuestra autora, Sheklin Davis:

El tema en el teatro surrealista tomaba forma como sentimiento penetrante. Es decir, no era una bien definida idea central, [... ] sino que, como escribe Juan Guerrero-Zamora, trasciende sobre la acción, «la informa de su espíritu, la vuelve sueño, con lo que no es la idea lo que predomina, en el plano de la comunicación, sobre la vivencia, sino la vivencia lo que desenvuelve la idea».

(328-329)

En Terraza de café no hay un desarrollo lógico del argumento ni se indica el fondo de la acción: el elemento esencial es la acción misma. Los personajes no se presentan, simplemente dialogan, y la relación entre causa y efecto se ha eliminado. Con todo, desde la primera escena es perceptible ese «sentimiento penetrante» al que alude Sheklin Davis. Fijémonos en el arranque de la pieza, donde ya se observa lo que ocurrirá a lo largo de toda ella: el discurso racional es sometido a un proceso de dislocación, las palabras se combinan de modos inesperados y el resultado son unos diálogos tan ininteligibles como sugerentes. Tras la hermosa acotación inicial que describe cómo la iluminación muestra progresivamente el callejón, el cielo, la terraza, el edificio del café y la gente 
hasta desvelar el óleo en su totalidad, y cómo del fondo del callejón emerge un joven («en chándal ocre y casco negro», 13) y avanza por la calle empedrada para detenerse donde Van Gogh lo pintara, se producen las primeras intervenciones de los personajes:

NIÑA. - Mira, mamá, un soñante impactado.

El joven sigue con el casco, se recompone el chándal y va hacia la MUJER con

NIÑA sentada frontalmente al fondo del café.

SOÑANTE. - (A la NIÑA) ¿Y mi bicicleta?

La NIÑA se encoge de hombros y señala hacia el callejón pintado en negros.

Tras un breve diálogo entre la Mujer y el Soñante, se inicia otro de réplicas cortas y tono lírico entre la Mujer y la Niña, con alguna intervención esporádica del Soñante:

MUJER. - Ansío vida en ámbar, sirenas serpentinas, musgo, cumbres de coral, encaje de algas, menta, azahar, surtidor de ballenas [...]

NIÑA. - Calcomanías. Cromos. Canicas.

MUJER. - Manhattan. Praderas de colza florida.

NIÑA. - Esponja salina. Selva de bambú.

MUJER. - Teatro Nó.

NIÑA. - Patinadoras chinas. [...]

MUJER. - Sócrates, Cervantes, Shakespeare, Kafka, Rilke, Dostoyevski.

NIÑA. - Poe, Lovecraft, Hesse.

MUJER. - Cancuén, Altamira, Giróvago.

NIÑA. - Petra.

MUJER. - Caléndula. Ópalo. Granate. (14-16)

La obra, como se ha dicho, alude a los temas más afines al surrealismo: los sueños, el amor, el elemento misterioso ${ }^{4} \ldots$ La misma personalidad de Van Gogh es próxima a lo surrealista: consideremos, por ejemplo, que los surrealistas se sintieron fascinados por las mutilaciones, que relacionaban con la forma artística del colaje .

Por encima de esos temas o impregnándolos a todos con su sustancia, se distingue el asunto del conocimiento. Emma Cohen reconocía a propósito de la creación de esta obra su permanente curiosidad personal. Abordar la compleja figura de Van Gogh y cuanto subyace a una pintura suya a través de una obra

4. En el contexto de una creación surrealista, no es fácil aislar ejemplos de presencia de lo misterioso, puesto que lo onírico e ilógico están siempre presentes. Esta acotación sería un caso manifiesto: "Silencio: pasan dos ángeles. Un ángel negro y un ángel blanco cruzan (en diagonal) la escena. De la gran puerta del café, surge el ángel negro, del local iluminado situado a la derecha, el ángel blanco, y ambos pasan por delante del SOÑANTE, casi rozándose en el centro» (33).

5. El final de Terraza de café... contiene una recreación de la automutilación del pintor. 
literaria surrealista implica un deseo de profundización y perspectivismo muy osado. Servirse del prisma del surrealismo para aproximarse a una realidad enriquece nuestra percepción de esta de forma exponencial:

Hoy en día apreciamos sobre todo del surrealismo, no ya solo su técnica, que es una consecuencia de su base filosófica, sino su deseo de eliminar el sistema dualista de conocimiento del ser humano, de abolir las oposiciones entre vida/ muerte, sueño/vigilia, objetividad/subjetividad, etc. (Hernández)

La mirada de Emma Cohen sobre la pintura de Van Gogh se sitúa en un plano superior, original y, en consecuencia, nos proporciona una visión diferente, más ancha, más rica.

\subsection{La lista de personajes}

¿Cómo nos son presentados los personajes en cada uno de estos textos? En Araña en bañera, en la lista de personajes estos figuran por orden de aparición. La autora no hace distinciones entre los que aparecerán físicamente sobre el escenario (Sofía -la protagonista-, Patri -su amada-, Manu y Tricia -los hijos de esta-) y todos los demás, que solo se muestran en el espectáculo «proyectados» a medida que la protagonista va reconstruyendo sus vidas: Bisabuela Sofía, Bisabuelo Alfonso, Margarita Xirgu, Rafael Aguilar, Carlotica de Aguilar, Madre de Sofía, Esférico masculino, Esférico femenino, Esférico mixto y Zeus. La araña también comparece en la lista de personajes y, como el resto, lo hace por orden de aparición. La presencia de figuras masculinas es reducida, puesto que la intención de Cohen es ofrecer un universo predominantemente femenino. Los masculinos son aquí personajes menos poliédricos que los femeninos, y están cargados de defectos que los retratan como seres frágiles y dependientes.

Sofía Espíritu Aguilar es presentada como una mujer «De 30 a 50 años». Esta indeterminación se aplica también a los personajes de la bisabuela Sofía ( Pasados los 40»), el bisabuelo Alfonso («Pasados los 50») y Patri ( «De 30 a 40 años»). Además, la dramaturga nos ofrece una somera información sobre cada una de sus criaturas: la bisabuela Sofía tiene «el pelo muy negro» y es «bellísima»; el bisabuelo Alfonso es «Alto, de voz recia»; Margarita Xirgu aparece «En todo su esplendor». A otros personajes los califica con un único adjetivo: «Apuesto» (Rafael Aguilar), «Dulce» (Carlotica de Aguilar), «Resuelta» (Madre de Sofía), «Agradable» (Patri). Solo se extiende algo más en el caso de la protagonista, Sofía Espíritu Aguilar: «No importa que esté gorda o flaca, a pesar de los pesares, guarda cierto vago resplandor».

En Terraza de café por la noche el elenco se compone de veinte personajes con nombre más «14 esperanzados». La lista se ordena a partir de una 
numeración que la autora ha atribuido a cada figura del cuadro y que el lector puede consultar en una reproducción de este en una de las primeras páginas de la edición. Solo cinco de los personajes tienen nombre propio: Peter Blue, Úrsula de Londres (en realidad Úrsula de Layer, la hija de la patrona de la casa donde vivió en Londres Van Gogh y de la que se enamoró), Rachel (la prostituta de Arles a la que, supuestamente, Van Gogh regaló su oreja cortada a modo de pago), Vincent Van Gogh y Paul Gauguin. El resto de personajes tienen nombres genéricos o descriptivos: Figura Oscura, Bohemia Solitaria, Cochero, etc. Tanto la mezcla de personajes reales e irreales como la falta de individualidad (más obvia en el caso de los segundos) son características del teatro surrealista, como advierte Sheklin Davis:

En efecto, sus personajes no tienen ninguna individualidad; son clasificaciones: El Hijo, El Joven, La señora fatigada, La hermana de la Caridad, etc. Cuando llevan nombres, estos son completamente ordinarios y sin significado [...] Los nuevos dramaturgos no se interesaban en casos individuales; según ellos, los temas universales exigían personajes universales [...] Así el individuo recibía atención solo en cuanto sus emociones, acciones y sentimientos fueran significantes en un sentido general y en otro contexto que el suyo. (344-345)

Si en Araña en bañera Cohen prevé las dificultades que un elenco extenso plantea para la puesta en escena mediante las apariciones de personajes proyectados, en este caso en la misma lista de personajes especifica quién puede hacer doblete: «Ángel negro: Puede encarnarlo uno/a de los esperanzados» o «Rachel: prostituta (misma actriz que interpretó a Úrsula de L.)». El modo de caracterizar a los personajes es similar en ambos textos: mediante la edad, siempre aproximada ( «Andarina Yellow: Entre 18 y 30») o con un par de palabras, incluso una sola («Pelirrojo», «Forzosamente ágil», «Baila de fábula»).

\subsection{Araña en bañera: la araña omnipresente y el triunfo del amor lesbiano}

Al estudiar Araña en bañera lo primero que nos preguntamos es cuál es la identidad o la esencia de esta araña que escolta a Sofía durante toda la representación. En la nómina de personajes es descrita de la siguiente forma: «De tres metros de alto. Gótica, tutsi. Autohinchable.» Esta caracterización nos informa de sus espectaculares dimensiones y aporta dos adjetivos sugerentes: lo «gótico» ofrece las pautas estéticas para la construcción de esta figura; «tutsi» es un guiño exótico para aludir a la negrura del arácnido. Es «autohinchable», puesto que ha de aumentar de tamaño progresivamente al comienzo de la obra y disminuir hasta casi desaparecer al final. Cohen descarta que se muestre en 
escena proyectada: es imprescindible la presencia real de esta alegórica criatura sobre las tablas para mantener la tensión dramática ${ }^{6}$.

Para desentrañar el significado de la araña hemos de rastrear algunas de las alusiones que a ella se hacen a lo largo de la obra. En las primeras páginas alguien llama por teléfono y, cuando la protagonista le menciona la presencia de la araña en la bañera, su interlocutor se refiere a Louise Bourgeois (se deduce de las palabras de Sofía). La conexión estética entre la araña que describe Cohen y las de esta escultora es indudable ${ }^{7}$. La primera alusión al vínculo entre la araña y la muerte la hallamos cuando Sofía se dirige a su hija en el testamento oral que está grabando. A modo de despedida, y para exonerarla de cualquier responsabilidad que pudiera sentir la chica ante el suicidio de su madre, le recalca: «Y que sepas que no me borro por tu culpa: hay una araña en mi bañera y punto». Aunque la frase es críptica, conduce al lector/espectador a asumir la filiación de la araña con la muerte ${ }^{8}$.

Existe en el texto una interacción discontinua pero que se prolonga hasta el final entre la protagonista y esta criatura. Por ejemplo, justo cuando Sofía da principio al relato de su vida amorosa, la araña se comunica con ella de un modo impreciso, como reflejan las acotaciones y las palabras de la protagonista: «(se revuelve contra el insecto, le grita), ipues te esperas!, ¡antes debo arreglar algunas cosillas!». Se diría que el ente la azuza para que cometa el suicidio cuanto antes. Sofía se resiste; las «cosillas» de las que ha de ocuparse son la grabación de su propio testamento y la rememoración de la vida de sus antecesores.

Cada cierto tiempo se alude a la araña mientras se recorre la historia familiar, y estas referencias van intensificando el papel del artópodo como metáfora de la muerte, como cuando Sofía vuelca en una gran copa un frasco de pastillas

6. En Terraza de café por la noche hace una breve aparición una descomunal araña que "avanza por el pasillo central del patio de butacas" y, tras alcanzar el escenario y que algunos de los personajes aludan a ella, "se adentra en la tela [...] se la traga la negritud del callejón» (47-49).

7. Louise Bourgeois (1911-2010) es una pintora y escultora franco-americana cuya dilatada carrera fue reconocida por la comunidad artística cuando contaba con setenta años. El motivo de la araña estuvo presente en su obra desde 1947, fecha en que empezó a dibujarlas, hasta el final de su vida. La mayor de sus esculturas de arañas es Maman (1999), realizada en acero y de casi nueve metros de altura, que se encuentra en el Museo Guggenheim de Bilbao (Museo Guggenheim de Bilbao).

8. Pese a que no nos consta que Cohen conociera la historia del suicidio de Alejandra Pizarnik, es oportuno recordar aquí que, cuando esta se quitó la vida en noviembre de 1972, se hallaron sobre su mesa unos versos: «en el centro puntual de la maraña, / Dios, la araña». Se trataba de una cita literal de un poema de Borges, a cuyo segundo verso se le habían quitado las primeras palabras: «En el centro puntual de la maraña / Hay otro prisionero, Dios, La Araña» (Dalmaroni 3).

Feminismo/s 30, diciembre 2017, pp. 69-92 
y, después de añadir hielo, limón y ron, «deposita la copa recién preparada en lugar visible, cerca de la araña». Es esta, pues, quien «custodia» el brebaje letal. Además, cuando la protagonista invoca, desesperada, a la amante que la ha abandonado para permanecer con su marido, la mención de la araña parece suficiente para que aquella entienda el peligro en que se encuentra: «Patri, me mata la espera. Patri, él no se va a tirar por la ventana. Patri, él no tiene una araña en su bañera».

Estando ya el final de la obra muy próximo, Sofía Espíritu se inclina hacia la araña y le propone bailar con ella. Esa danza parece anunciar el final de la mujer, es el preludio de su suicidio. Mientras bailan, la protagonista (se) pregunta cuál de todos sus antepasados muertos ha enviado al gigantesco emisario de la parca:

¿Quién te manda, querida? [...] ¿El abuelo Alfonso se aburre? [...] ¿Acaso madre sigue sin disfrutar de los hombres? [...] ¿Tita Carlota quiere verme bailar? Déjate abrazar, araña guapa, que te voy a bailar bien bailada. Contigo es fácil, ¡tienes tantos brazos y ahora mismo estás tan suave!

A pesar de que resulta obvia la capitulación de Sofía ante la criatura que la ha estado asediando en el transcurso de la tragicomedia, no es la muerte quien vence en esta batalla sobre las tablas, sino el amor entre dos mujeres.

Sofía, Patri y Carlota, las mujeres con más protagonismo en la pieza, son lesbianas. Al convertirlas en el centro de la historia, la intención de Emma Cohen no es profundizar en el concepto de lesbianismo, aunque el desarrollo de la obra sí subraya cómo la fractura de la norma social heterosexual por parte de estas mujeres genera en su entorno un rechazo y una incomprensión intensos 9 .

Sofía Espíritu Aguilar es, con la araña, el puntal de este texto. El verdadero arranque de la pieza se encuentra varias páginas después de su inicio formal, cuando Sofía rompe la cuarta pared por primera vez (lo hará reiteradamente), ofrece sendas copas a un espectador y una espectadora y, tras hacer el gesto de brindar con ambos, comienza su monólogo: «Antes de amar a Patri estuve casada con un hombre estupendo que de repente me tomó manía y me abandonó. ¡Plas! Se borró de la casa y de mi piel». Sintetiza entonces con crudeza el final de la relación, suponiendo que Federico, su ex, un día cualquiera de su vida en común «me contempló horrorizado a pesar de yo no tener ninguna

9. «El término lesbiana surge de forma diversa a través de muchas trayectorias discursivas en y entre diferentes comunidades (desde la biomedicina hasta la contracultura homosexual) y es cultural e históricamente contingente en grado extraordinario. Además, es activamente controlado, refutado y sometido a revisión en el interior y por las comunidades lésbicas, así como por las distintas agrupaciones subculturales en su seno» (Wilton 70). 
costra y fin, salió de casa para no volver». Tal deserción no impide que Federico desprecie ahora a Patri, la novia de su ex esposa.

Sofía se presenta ante nosotros en la fecha de su cumpleaños, «justo el día en que Patri me abandona del modo más brutal, como una adolescente, en silencio, sin llamar siquiera». La mujer sufre un dolor anímico insoportable y en varios puntos de la obra exhibe unas emociones desbordadas. Tras una llamada del marido de Patri en la que le anuncia que ha amenazado a esta con suicidarse junto a sus hijos si ella los abandona, Sofía, que ha discutido acaloradamente con su rival, cuelga e implora en vano al aparato: «Llama, Patri. Me muero. Llama con lo que sea. No puedo más. ¡Te quiero, te quiero, te quiero, te quiero, te quiero!». Tras esta explosión de sentimientos se repone y retoma el hilo de su discurso: «¿Por dónde andaba?». La acción dramática continúa, pero el sufrimiento de la enamorada abandonada, Sofía, y el de la amenazada, Patri, atraviesa la escena desde ese instante.

En uno de sus intentos de hablar por teléfono con su amada, Sofía Espíritu formula una pregunta de improviso: «Patri, ¿recuerdas Brokeback Mountain? $»^{10}$. La referencia a esa película trae a la mente del lector/espectador, por un lado, la imagen de un amor homosexual imposible o marcado por la desdicha; por otro, a renglón seguido Sofía saca de una de las cajas «una raída piel de vicuña con la que se arropa después de encamarse». Ese objeto, en el que repara la mujer quizá porque los protagonistas de la película son dos vaqueros, será el que traiga al escenario el recuerdo de la tía Carlota.

Carlota es una de las tres hermanas de la madre de Sofía. Su peripecia vital, en cuya narración pesa más su vida personal que su oficio de actriz, es la última de las que nos cuenta la protagonista, confiriéndole así un lugar privilegiado dentro de la narración. Esta tía materna ejerce una poderosa influencia en la biografía de la sobrina.

La descripción física que se hace de ella difiere de la de los personajes femeninos heterosexuales, es más precisa y significativa: «Carlota poseía una belleza adelantada, moderna, nueva. Labios gruesos, ojos grandes, verdes... Y cuando algo no le gustaba de su cuerpo, lo variaba, para sentirse siempre bien...». A diferencia de otras familiares bellas etiquetadas por Sofía como «antiguas», Carlota se proyecta hacia el futuro ya desde su apariencia, y se siente dueña de sí misma incluso frente a las imposiciones de la naturaleza sobre su anatomía.

10. Brokeback Mountain es un largometraje estadounidense dirigido por Ang Lee en 2005. En los años 60, dos jóvenes vaqueros aceptan un trabajo para cuidar ganado en la montaña Brokeback; entre ambos surge una amistad que deriva hacia una relación íntima. Cuando acaba el verano, deben abandonar Brokeback y regresar a sus respectivas vidas.

Feminismo/s 30, diciembre 2017, pp. 69-92 
Tras esta presentación, la sobrina enfatiza la «adoración» que sentía Carlota por su hermana Felicia, muerta a los veintiún años (comenzaba a despuntar como actriz de cine mudo en París) cuando aquella tenía quince. Sofía considera que esa muerte fue el primer hito del camino que condujo a Carlota al lesbianismo; dicho itinerario continuó con una iniciación sexual con un hombre impregnada de violencia y, a partir de ese momento, una evitación de las relaciones heterosexuales:

A esa edad son muy importantes las transferencias y al parecer Carlota se quedó colgada de la muerta. Después Carlota estuvo enamorada de uno que se portó muy mal con ella, la desvirgó de un modo brutal, sórdido, sin placer, sin gracia, y desde entonces nunca volvió a encontrarse del todo con los hombres. Desde entonces tuvo varios novios con los que jamás se acostó. [...] Y así hasta que Carlota se hizo homosexual, amó a las mujeres.

Este trayecto hasta el lesbianismo, condicionado por la veneración a la hermana muerta y por experiencias negativas con hombres, correspondería a una concepción de la opción sexual lesbiana como automodelación:

El paradigma posmoderno de la automodelación, producido por una cosificación más general del yo, del cuerpo, del deseo y (sugeriría) el propio género [...], da lugar a una descripción de la sexualidad lésbica como elección individual motivada por un interés racional por una misma. (Wilton 65)

El amor lesbiano es presentado por Emma Cohen desde una perspectiva de absoluta normalidad, sin dejar traslucir que las relaciones lésbicas tengan nada de peculiar o anómalo respecto a los amores heterosexuales que desfilan por la obra. Por ello, una vez ubicada Carlota en su opción homosexual, el texto expone su vida amorosa con un enfoque y un tono análogos a los empleados para los personajes heterosexuales. Cuando tomó a la sobrina Sofía bajo su tutela andaría Carlota por la treintena y ya vivía con su pareja más estable, tita Pato. A causa de la convivencia con ambas la jovencísima Sofía creció con ideas particulares sobre el amor:

Yo pensaba que el amor natural, el normal, el amor amor, era entre mujeres, que las que se juntaban con hombres lo hacían por conveniencia, sobre todo para tener hijos. (Sofía ríe) Creía en el amor que constataba a mi vera, en el amor de tita Carlota y Pato. Creía en dos mujeres que se amaban gozosamente y sin violencia ${ }^{11}$.

11. La ausencia de violencia dentro de una pareja formada por dos mujeres contrasta, para Sofía Espíritu, con su experiencia respecto a la relación de sus padres, puesto que su progenitor era alcohólico y violento. 
Hay una parte de Araña en bañera que constituye un alegato de Cohen a favor de la normalización de la homosexualidad. La protagonista extrae de una caja una extensa carta manuscrita; cuando la lectura concluya sabremos que fue Carlota quien la escribió. La misiva se abre así: «Madre, madre querida, para que deje de llamarme putalesbiana le envío estos párrafos de El banquete de Platón». Mientras Sofía lee la carta, del espejo que hay en escena surgen, proyectados, tres «seres esféricos» como los descritos por Platón ${ }^{12}$. En las letras se explica que Zeus (Júpiter en el original) decidió, para evitar que estos seres escalaran al cielo y combatieran a los dioses, separarlos en dos, y desde entonces

...las mujeres que provienen de los andróginos aman a los hombres. Pero a las mujeres que provienen de la separación de las mujeres primitivas no les llaman la atención los hombres y se inclinan más a las mujeres. En tiempos presentes, al deseo y persecución de ese antiguo estado se da el nombre de AMOR.

La carta se cierra retomando el inicio: «Ya está, madre, fin de los párrafos referentes a los esféricos descritos por Platón y elegidos por mí con la intención de que deje de llamarme putalesbiana. [...] se despide su hija que la quiere y respeta, Carlota». La muchacha acude a un texto clásico para hacer que su madre asuma la naturaleza de sus sentimientos y deje de dirigirse a ella con términos insultantes. Se produce un choque entre la sensibilidad de la hija, que apela a la filosofía, y la ignorancia e insensibilidad de la madre.

Patri es la tercera lesbiana de la pieza. Sin estarlo físicamente, durante toda la obra está presente, puesto que a través de las llamadas telefónicas y de las palabras de Sofía el lector/espectador va componiendo su retrato, más borroso que el de las otras dos protagonistas y, por ello, sugestivo. Cuando arranca el monólogo solo sabemos que ha abandonado a Sofía de modo súbito e inexplicable. Hacia la mitad del texto, una llamada de su marido nos descubre el motivo inmediato, si bien seguimos sin conocer sus verdaderos sentimientos; Sofía se indigna al escuchar las palabras del esposo de su amante: « $i$ Que le has jurado a Patri que si ella se va conmigo tú te tiras con los chicos por la ventana?». En este instante, la historia ofrece un giro inesperado, y Patri pasa de ser un personaje negativo a la víctima de un espantoso chantaje. Con todo, cuando la protagonista, ya bastante avanzado el texto, llama por accidente a la casa de su novia, esta parece ajena a su angustia: «SOFÍA: ¿Rara?, ¿la voz rara? Desde hace un rato toda yo estoy rara. (Pausa) ¿Qué piensas hacer? (Pausa) ¿No puedes hablar? (Pausa) [...] ¡PATRI!». Se trata de un personaje en apariencia

12. En el discurso de Aristófanes de El banquete se dice que en un principio eran tres los sexos, masculino, femenino y andrógino. Estos seres tenían forma circular, cuatro manos, cuatro pies y dos rostros (Platón).

Feminismo/s 30, diciembre 2017, pp. 69-92 
pasivo o apocado, si bien su valentía será la que propicie el positivo final. Es una mujer que sufre maltrato psicológico por parte de su marido y este hecho determina su conducta.

El desenlace, en el que todo se soluciona felizmente, es inesperado. A lo largo de la obra se nos proporcionan pistas falsas para embaucarnos, todo parece encaminarse hacia el suicidio de la protagonista, porque ella, como el receptor, cree que el abandono de Patri es irreversible. Cuando vemos a Sofía abrazar a la araña y danzar con ella como asumiendo su destino, nos asombra que irrumpan en escena los dos hijos de Patri. Llegan como emisarios de su madre y anuncian a la protagonista que desean vivir con ambas. La araña, metáfora de la muerte, se desvanece en ese instante: «...los chicos no la veían y entonces la araña se ha ido». Patri entra poco después en la casa y las amantes se abrazan. La última acotación se regodea con humor en lo almibarado de este final feliz: «Del telar caen confetis multicolores ignifugos». Mientras las dos mujeres se abrazan suena el tango Volver, cuyas notas se funden con las de El día que me quieras.

\subsection{Terraza de café por la noche: el cuadro de Van Gogh y su materialización dramática ${ }^{13}$}

La relación de Emma Cohen con esta obra y con la figura de su autor comienza en su infancia y se prolonga en el transcurso de los años:

En 1958, cuando tenía 12 años, nos cambiamos de casa en Barcelona. Mis padres me dieron a elegir reproducciones de cuadros para decorar los huecos de un armario. Ahí encontré el lienzo por primera vez. Fue emocionante tener día tras día frente a mí la obra de este maestro que buscaba el interior de la belleza. [...] En 1990, durante una Feria del libro en El Retiro, mientras mi compañero Fernando [Fernán-Gómez] firmaba ejemplares, yo me hacía con

13. En la página web del Museo Kröller-Müller, donde se expone el cuadro, se encuentra esta valiosa información sobre las circunstancias en que se pintó y las observaciones del autor sobre su trabajo: «Van Gogh had intended to make a nocturnal painting for some time. And not one in the conventional manner, in shades of black and grey, but actually with an abundance of colours. Equally unconventional is that he paints this gas-lit terrace of a café in Arles in situ and in the dark, because colours have a different appearance during the day than by night. [...] The most eye-catching aspect is the sharp contrast between the warm yellow, green and orange colours under the marquise and the deep blue of the starry sky, which is reinforced by the dark blue of the houses in the background. Van Gogh was pleased with the effect: 'I believe that an abundance of gaslight, which, after all, is yellow and orange, intensifies blue.' [...] He writes to his sister Wil: 'I enormously enjoy painting on the spot at night.' The fact that he observes keenly is borne out by later astronomical research. He painted the constellations precisely as they appeared on the night of 16 or 17 September 1888» (Kröller-Müller Museum). 
un calendario de reproducciones de Van Gogh y apareció otra vez el cuadro. [...] Coloqué la lámina en el váter porque pensé que la vería la gente al menos una vez. Está claro que fui yo quien más tiempo la observó. (Méndez)

A pesar de que este texto teatral merece un estudio pormenorizado por su complejidad, proponemos aquí un breve examen de dos de sus aspectos más relevantes: el lenguaje y el tema de los sueños.

Se ha de prestar especial atención al lenguaje empleado por la dramaturga porque, como subraya Sheklin Davis, en el teatro surrealista este no sirve para recrear lo real, sino que

...las palabras crean, hacen posible lo imposible, hacen real lo irreal. El lenguaje del teatro surrealista es un lenguaje simbólico de "origen oscuro de índole poética», según Pérez Minik y, según Salvador Dalí, es «el único lenguaje realmente universal... ya que [...] reposa en la consciencia misma de las grandes constantes vitales: el instinto sexual, el sentimiento de la muerte, la noción física del enigma del espacio, etc.» (342)

Conocedora de estas premisas, Emma Cohen crea en esta «peripecia» nuevas e insólitas realidades mediante un uso peculiar de la lengua. En los diálogos encontramos combinaciones de palabras que resultan en imágenes chocantes: «Libélula absorta» (13), «pirámides menguantes abrazadas al viento» (14), «Bosques pelirrojos» (15) o «Relámpago en flor» (15). Las acotaciones contienen en ocasiones especificaciones enigmáticas ( La terraza se difumina a trompicones», 38) o esperpénticas («PETER BLUE pellizca al SONANTE en el pene», 27). En ciertas intervenciones de los personajes el lenguaje versa sobre la pintura con apreciaciones a la vez penetrantes y divertidas: «FIGURA EN NEGRO. - [...] Las figuras en negro sobre negro vivimos en un caos irregistrable. De todos modos sabido es que pintar las figuras en negro roba menos tiempo» (34-35). Por otra parte, en varios pasajes los diálogos toman la forma de enumeraciones caóticas que sumergen al espectador/lector en la sensación de desorden propia de lo onírico.

En Terraza de café, como ocurre a menudo en el teatro surrealista, el registro varía sin razón aparente. En distintos fragmentos predominan el poético, el coloquial, el culto e incluso el científico, o todos ellos se funden en diálogos en los que la combinación de ciertos términos causa un efecto estridente cercano al del teatro del absurdo:

SOÑANTE.- ¡Anhelo bondad!

HOMBRE CON SOMBRERO.- Deje de provocar. Deje de provocar o cambie de sueño. [...]

SOÑANTE.- Busco trabajo.

HOMBRE CON SOMBRERO.- Y dale. En ese caso conteste, empecinado:

¿Seremos inmortales? 
SOÑANTE.- Usted, ustedes, todos los plasmados en esta terraza nocturna de Vicent Van Gogh, en cierto modo ya lo son.

HOMBRE CON SOMBRERO.- Me refiero a una inmortalidad común y plena. SOÑANTE.- Factores de crecimiento, algunas proteínas y antioxidantes parecen tener mucho que ver con el envejecimiento. Tengo entendido que dicha inmortalidad se alcanzará tras una revolución biomédica, cuando podamos inducir la regeneración de órganos en seres humanos [...] (17)

Ni siquiera falta en el texto una incursión en la ruptura total con el lenguaje que propugnaron algunas de las corrientes de las vanguardias; en la réplica de Peter Blue la reprimenda coloquial seguida de la mención al museo donde se exhibe Terraza de café por la noche producen un efecto risible:

ANDARINA YELLOW.- [...] Chst. Catikatú, catikatá, flipgonká tiang kai moai.

PETER BLUE.- (Se vuelve hacia ella) Me repatea que hables así fuera del Rijkmuseum Kröller-Müller.» (27-28)

La dramaturga pone especial cuidado en la escritura de las abundantes y a menudo extensas acotaciones, que son minuciosas al explicar cómo es el espacio escénico y de qué forma se distribuyen y actúan los personajes en él. Se logra así que el lector visualice el montaje de un texto cuya puesta en escena entraña dificultades:

De las quince ventanas con luz pintadas en Terraza de café por la noche por Van Gogh surgen sábanas color esmeralda retorcidas y anudadas. Por ellas se descuelgan varios ESPERANZADOS [...] El COCHERO hace restallar su látigo, el CABALLO cobra movilidad, avanza hasta que la portezuela del carruaje quede a la altura del cuerpo humeante del CAMARERO/A, el COCHERO lo introduce en el vehículo y acto seguido (el humo rojizo fluyendo a través de las ventanillas) mueve al caballo hacia atrás, hasta recalar en la posición inicial. (36-37)

En Terraza de café... la sustancia onírica del surrealismo está muy presente. García Lorca, en El Público, expresó esta cualidad de forma espléndida: «El público tiene sagacidad para descubrirlo todo [...] Romeo puede ser un ave y Julieta puede ser una piedra. Romeo puede ser un grano de sal y Julieta ser un mapa. ¿Qué le importa esto al público?» (478). En efecto, con el surrealismo se desvanecieron los límites entre los sueños y la realidad. En el caso que nos ocupa, una ambientación onírica es óptima para que una pintura cobre vida. El mundo de los sueños anula las reglas lógicas y la autora hace uso de esta licencia para dar libertad a la imaginación. Los ejemplos abundan. Hallamos objetos corrientes que cambian de tamaño y se transforman en entes temibles:

HOMBRE CON SOMBRERO ha desaparecido. De él, sobre la mesa que ocupaba, solo queda su SOMBRERO, igual y distinto: el SOMBRERO ahora es grandísimo. 
MUJER Y NIÑA. - (Semicubiertas por el SOMBRERO GIGANTE, al unísono)

¡Me ahogo! ¡Socorro! (20)

$\mathrm{O}$ un personaje ofrece a su interlocutor que elija a su antojo su género (en el lienzo de Van Gogh no se aprecia si se trata de una figura masculina o femenina):

SOÑANTE.- ¿Eres camarero o camarera?

CAMARERO/A. - Lo que usted prefiera.

SONANTE.- Camarero, prefiero camarero.

CAMARERO/A.- Vale. (20-21)

El Soñante se permite incluso permutar los colores originales de Terraza de café..., una aberración tan inaceptable que acaba con una disculpa:

...se produce un oscuro celérico seguido por un encadenado con trastoque colorístico: donde antes estaban los azules ahora están los amarillos y viceversa. Mismo empedrado. SOÑANTE contempla (desde el suelo) la terraza azul, el cielo amarillo. [...]

SOÑANTE.- Perdón, fue un impulso irresistible. (40)

Hemos señalado que en este texto ninguno de los numerosos personajes es protagonista, ni siquiera Van Gogh; como sucede a menudo en el teatro surrealista, el ambiente, lo que Sheklin Davis denomina «la atmósfera espiritual» de la obra, es el protagonista (331). De todos modos, si alguno de los seres pintados en Terraza de café por la noche actúa como hilo conductor, es aquel al que la dramaturga bautiza como «Soñante Impactado», a cuyos sueños parece pertenecer cuanto vemos en escena ${ }^{14}$. Uno de los personajes lo reconoce expresamente:

PETER BLUE.- ¿¡Qué haces!?

ANDARINA YELLOW.- [...] Hago lo que él sueña que hago. (26)

La complejidad espacio-temporal de la obra es asimismo posible por su carácter onírico: el espacio en el que transcurre la acción es la tela de Van Gogh, como algo atemporal, que pertenece al tiempo en que fue creada, a los años transcurridos desde entonces y a nuestro presente; pero las acciones suceden también en el tiempo y el espacio en los que fue pintado el cuadro.

14. Cohen desveló en una entrevista el origen del personaje y cómo este fue el detonante de una creación que tenía en mente desde mucho antes: «Me pasaba todo el tiempo en casa y entré en el cuadro, a analizarlo y a entenderlo. Me di cuenta de que el muchacho del centro llevaba un casco o de que allí estaban las chicas del can-can, los cafetines, la mesa para esperar a Gauguin e, incluso, el estudio de Van Gogh. [...] Iba un día en metro y en el trayecto Plaza de Castilla-Sol un chico me comentó sus ansias de trabajar. Se me ocurrió incluir a ese muchacho dentro del cuadro y surgió la trama. Parto de que tiene un accidente de bicicleta, aterriza en el lienzo y comienza a pedirles trabajo a los personajes. Claramente surrealista.» (Méndez)

Feminismo/s 30, diciembre 2017, pp. 69-92 


\section{CONCLUSIONES}

Como objeto de investigación, la creación dramática de Emma Cohen supone un reto. La ausencia de bibliografía y la desaparición física de la autora multiplican las dificultades, pero también la curiosidad de quien se acerca a su particular concepción teatral. La dramaturga conoce el mundo del teatro desde dentro, y construye sus textos activando resortes que garantizan tanto la empatía del receptor hacia los personajes como una puesta en escena acorde con su proyecto dramático. Es una mujer de cultura vasta y heterodoxa que ha vivido intensamente, y dispone, por un lado, de un conocimiento sobre corrientes estéticas que le permite crear un texto dramático surrealista, Terraza de café por la noche, al que dota de su sello personal; por otro lado, posee una sabiduría sobre la condición humana que plasma en Araña en bañera en personajes cuya autenticidad emana de su intensa forma de entristecerse o disfrutar en función de los avatares de sus vidas. Los asuntos principales o secundarios de su creación dramática (el arte, el amor, la soledad, la libertad o los sueños) son tan universales y atemporales que cualquier espectador/a se sentirá concernido/a por ella.

\section{REFERENCIAS BIBLIOGRÁFICAS}

Alegre, Luis. «Muere la actriz Emma Cohen a los 69 años». El País, 15 julio 2016. <http://cultura.elpais.com/cultura/2016/07/11/actualidad/1468270314_935058.html>, consultado el 10-03-2017.

Aranda, Francisco. El surrealismo español. Barcelona: Editorial Lumen, 1981.

Artaud, Antonin. Van Gogh, el suicidado por la sociedad. Colegio de Bachilleres (Gobierno de México). <https://www.cbachilleres.edu.mx/Bibliowiki/libros/A/ Artaud\%20Antonin\%20Van\%20Gogh\%20\%20el\%20suicidado\%20por\%20 la\%20sociedad.pdf>, consultado el 12-05-2017.

Artezblai. «Lectura de Araña en bañera de Emma Cohen». Artezblai, 14 noviembre 2008. <http://www.artezblai.com/artezblai/index.php?option=com_content\& Itemid $=53 \&$ lang $=$ es $\&$ limit $=20 \&$ limitstart $=9400 \& v i e w=$ archive $>$, consultado el 12-04-2017.

Bugallal, Isabel. «Me pasé quince años gorda para no hacer cine y cuidar a Fernando». La Nueva España [Oviedo], 25 febrero 2012. <http://www.lne.es/ cultura/2016/07/11/pase-quince-anos-gorda-cine/1955116.html>, consultado el 20-04-2017.

Cohen, Emma. La libreta francesa. Mayo del 68. En Dossiers feministes 12 (2008). Mayo del 68: revolución y género. <http://www.e-revistes.uji.es/index.php/dossiers/article/view/647>, consultado el 27-02-2017. 
Cohen, Emma. Terraza de café por la noche. Tenerife: La Página, 2011.

Cohen, Emma. Araña en bañera. Inédito.

Dalmaroni, Miguel Ángel. «Sacrificio e intertextos en la poesía de Alejandra Pizarnik». Orbis Tertius 1 (1996): 1-17. <http://www.orbistertius.unlp.edu.ar/ article/download/OTv01n01a07/4298/0>, consultado el 14-05-2017.

Dufour, Nuria. «Talento natural». AISGE Noticias, 12 julio 2016. <http://www. aisge.es/muere-emma-cohen>, consultado el 4-01-2017.

García Lorca, Federico. El Público. En Obras completas. Vol. 2. Madrid: Aguilar, $1974^{18} .461-487$.

Garrido, Benito. «Entrevista con Emma Cohen: Terraza de café por la noche». Culturamas, 10 junio 2011. <http://www.culturamas.es/blog/2011/06/10/ entrevista-con-emma-cohen-\%E2\% 80\% 9 Cterraza-de-cafe-por-lanoche $\%$ E2\%80\%9D/>, consultado el 4-08-2017.

Guggenheim Bilbao. «Louise Bourgeois. Estructuras de la existencia: las celdas». $<$ https://www.guggenheim-bilbao.eus/guia-educadores/mama/>, consultado el 17-04-2017.

Hernández, Patricio. «El surrealismo español entre la recuperación y la marginación». Cuadernos del Marqués de San Adrián: revista de humanidades 1 (2001): 163-170. <https://qinnova.uned.es/archivos_publicos/qweb_paginas/4469/ revistalarticulo9.pdf>, consultado el 31-07-2017.

Kröller-Müller Museum. «Caféterras bij nacht (Place du Forum)». <http://krollermuller.nl/en/vincent-van-gogh-terrace-of-a-cafe-at-night-place-du-forum-1>, consultado el 15-02-2017.

Llanos, Helena de. (2016) «¡Feliz cumpleaños, Emma!». El asombrario \& Co. 21 noviembre 2016. <http://elasombrario.com/feliz-cumpleanos-emma/>, consultado el 1-05-2017.

María, Daniel. «Para la libertad: la literatura de Emma Cohen». La Galla Ciencia, 13 marzo 2016. <http://literaturaycine.lagallaciencia.com/2016/03/recomendacion-61-la-literatura-de-emma.html>, consultado el 10-01-2017.

Méndez, José D. «Emma Cohen elige la Escuela de Actores para representar su nueva obra». El Día [Tenerife] 6 mayo 2011. <http://web3.eldia.es/2011-05-06/ cultura/cultura2.htm>, consultado el 11-08-2017.

Morris, Cyril Brian. El surrealismo y España. 1920-1936. Madrid: Espasa Calpe, 2000.

Platón. Diálogos: Fedón, o de la inmortalidad del alma; El Banquete, o del amor; Gorgias, o de la retórica. Alicante: Biblioteca Virtual Miguel de Cervantes, 2005. (Edición digital basada en la 18. ${ }^{a}$ edición de Madrid: Espasa Calpe, 1975) $<$ http://www.cervantesvirtual.com/obra/dialogos-fedon-o-de-la-inmortalidaddel-alma-el-banquete-o-del-amor-gorgias-o-de-la-retorica--0/>, consultado el 11-05-2017.

Feminismo/s 30, diciembre 2017, pp. 69-92 
Sheklin Davis, Bárbara. «El teatro surrealista español». El surrealismo. Ed. Víctor García de la Concha. Madrid: Taurus, 1982. 327-351.

Wilton, Tamsin. [Des]orientación sexual. Género, sexo, deseo y automodelación. Barcelona: Bellaterra, 2005. 


\title{
DRAMATURGAS ACTUALES Y TEATRO ESCRITO A PIE DE ESCENA EN ESPAÑA: EL MEU AVI NO VA A CUBA, DE VICTORIA SZPUNBERG ${ }^{1}$
}

\author{
CURRENT WOMEN PLAYWRIGHTS AND STAGE-SIDE \\ WRITTEN THEATRE IN SPAIN: EL MEU AVI NO VA A CUBA, \\ BY VICTORIA SZPUNBERG
}

\author{
Luisa GARCÍA-MANSO \\ Universiteit Utrecht \\ m.l.garcia-manso@uu.nl \\ orcid.org/0000-0002-2236-0977
}

\section{Resumen}

Desde la llegada de la democracia se han producido cambios en el sistema teatral que han afectado a las formas de entender la autoría dramática. En el caso concreto de las dramaturgas, es posible observar que las generaciones nacidas a partir de 1960 cuentan con una mayor formación y profesionalización escénica que sus predecesoras y compaginan la escritura con la dirección de escena, la interpretación y/o la producción teatral. Una de las peculiaridades de los nuevos modelos de autoría teatral reside en la interacción entre la labor de escritura y la creación escénica, que se ha visto promovida por iniciativas como el Projecte T6 del TNC, el ETC de la Sala Cuarta Pared o «Escritos en escena» del CDN. Como ejemplo de este modelo de escritura escénica, analizo El meu avi no va a Cuba, de Victoria Szpunberg, en el contexto de un teatro transcultural y de indagación ética y formal.

Palabras clave: drama, escena, memoria, identidad, transcultural.

1. Este artículo forma parte del proyecto de investigación nacional en I+D+i Escrituras, Imágenes y Testimonio en las autoras hispánicas contemporáneas (FFI2015-63745-P), financiado por el Ministerio de Economía y Competitividad. 


\begin{abstract}
Since the arrival of democracy, changes on the theatre system have affected the way we understand theatrical authorship in Spain. In the case of women playwrights, it is possible to observe that the generations who were born after 1960 have a deeper scenic education and professionalisation than their predecessors and combine writing with their work as directors, actors and/or production managers. One of the peculiarities of the new model of theatrical authorship lies in the interaction between the dramatic writing process and the stage, which has been promoted by initiatives such as the TNC's Projecte T6, the ETC of the Sala Cuarta Pared or «Escritos en la escena» of the CDN. As example of this model of stage-side writing, I analyse El meu avi no va a Cuba, by Victoria Szpunberg, in the context of a transcultural theatre of ethical and formal inquiry.
\end{abstract}

Keywords: drama, stage, memory, identity, transcultural. 


\section{LAS ÚLTIMAS GENERACIONES DE AUTORAS DE TEATRO EN ESPAÑA Y SU PROYECCIÓN ESCÉNICA}

Desde que Patricia O'Connor publicara su emblemático estudio sobre las Dramaturgas españolas de hoy (1988) hasta el presente, se han ido incorporando nuevas promociones de autoras a la escena española. Escribo «escena» y no «teatro», en general, o «literatura dramática», porque se trata, en efecto, de una incorporación de las creadoras a los escenarios, llevada a cabo gracias al afianzamiento y el desarrollo de una serie de estrategias de profesionalización e imbricación en el ámbito escénico que ya se venían anunciando en las generaciones de las décadas precedentes. O'Connor aludía a los problemas que las autoras del momento encontraban a la hora de estrenar sus textos, entre los que destacaba sus dificultades para convencer a las compañías teatrales y a los empresarios (O'Connor 22) y lo que la investigadora denominó la «segunda fase de la composición teatral»: «responder a multitud de peticiones de cambios de actores, directores, técnicos, figurinistas, escenógrafos, etc.», un arduo proceso que, según afirmaba, habría también «desanimado a más de un dramaturgo masculino» (23). No obstante, estas condiciones han ido mutando al calor de las transformaciones que han tenido lugar en la gestión teatral de la España democrática y, en la actualidad, es difícil concebir la escritura dramática sin tener en cuenta, de antemano, los límites y las potencialidades materiales y humanas que conlleva la puesta en escena de un texto. A partir de los años 90, en efecto, se hace evidente «el destacado protagonismo» de los directores de escena, la frecuente colaboración de autores y directores e, incluso, «la conversión de los autores en directores de sus propios espectáculos para poder sobrevivir mejor» (Vilches de Frutos 1997, 158). Cada vez resulta menos extraño que en el teatro se compaginen varias facetas artísticas: dirección, dramaturgia, interpretación, producción y gestión, escenografía... Esta tendencia, a pesar de no ser nueva -el teatro ha contado desde siempre con profesionales polifacéticos-, se ha convertido en condición sine qua non para lograr el acceso y la continuidad en los escenarios actuales y es especialmente perceptible en el caso de las creadoras. Tal y como señalaba Vilches de Frutos en 1994: 
Sólo los que hayan logrado adaptarse a las nuevas tendencias de la escena contemporánea, al integrar en ellos mismos la figura del dramaturgo, director de producciones e incluso escenógrafo, o los que hayan 'sucumbido' a los planteamientos del teatro más comercial, lograrán sobrevivir como creadores dramáticos. [...] Los demás probablemente irán perdiéndose en el lento gotear de montajes esporádicos en centros públicos y circuitos alternativos, y escasas publicaciones que sólo se conocerán en círculos casi endogámicos. (286)

Las autoras recogidas en el estudio de O'Connor pertenecían a cohortes nacidas antes de 1960. Entre las más jóvenes destacan nombres como el de Pilar Pombo (1953-1999), Paloma Pedrero (1957), María Manuela Reina (1958), Marisa Ares (1958) y Yolanda García Serrano (1959). De estas autoras, la que una mayor relación con las tablas ha tenido y mantenido hasta hoy es, sin lugar a dudas, Paloma Pedrero, quien, además de escribir textos, ha trabajado como actriz y directora. Otras autoras nacidas antes de los 60 que compaginan la escritura con la dirección escénica y la gestión y la producción teatral son Margarita Borja (1942), Antonia Bueno (1952) y Margarita Reiz (1956), todas ellas comprometidas con asociaciones que pugnan por la visibilización de las mujeres en el teatro y las artes como Clásicas y Modernas-Asociación para la igualdad de género en la cultura-, DONESenART -Dones de l'escena valenciana associades- y Asociación de Mujeres en las Artes Escénicas de Madrid-Marías Guerreras, respectivamente. De las generaciones precedentes, cabe recordar a Maria Aurèlia Capmany (1918-1991) y Ana Diosdado (1938-2015), cuyo teatro surge también de un contacto directo con los escenarios y de su implicación en otras actividades como la dirección, la producción o la interpretación.

Pero es especialmente con la generación de autoras nacidas en los años 60 que esta interrelación entre escritura dramática y escena se convierte en norma. Me refiero a autoras como Lluïsa Cunillé (1961), Beth Escudé (1963), Laila Ripoll (1964), Yolanda Pallín (1965), Angélica Liddell (1966) e Itziar Pascual (1967), que comenzaron a presentar sus obras al público en los años 90. A diferencia de las autoras de otras generaciones, estas se educaron durante la democracia y cuentan con una formación específica dentro del área de las Artes Escénicas ${ }^{2}$. Además, cuentan con compañías teatrales propias o se han integrado en colectivos y asociaciones que les ha permitido gestionar su obra y

2. El desarrollo del Estado de Autonomías, unido a la nueva organización de las enseñanzas artísticas, implicó que se generasen Escuelas de Arte Dramático en las diferentes Comunidades Autónomas, contribuyendo así a la diversificación geográfica del panorama teatral español y sus protagonistas, que en la actualidad pueden formarse y desarrollar su trabajo en ciudades y provincias más allá de los núcleos tradicionales del teatro. Las enseñanzas de Arte Dramático en España fueron reconocidas como enseñanzas artísticas superiores y equiparadas a las titulaciones universitarias de licenciatura en 1990, con la 
representarla con asiduidad ${ }^{3}$. Es posible afirmar, por lo tanto, que es con estas dramaturgas con quienes se consolidan un conjunto de estrategias de acceso a los escenarios basadas en la profesionalización escénica y la autogestión:

Esta formación explícitamente teatral ha sido fundamental para la consolidación de un perfil autorial adaptado a los nuevos tiempos, cuya incidencia en el producto final va más allá de la creación textual, dado que se presta a la intervención activa del autor o la autora en la práctica escénica, a través de su integración en compañías de teatro -muchas de ellas fundadas por las propias autoras- y la frecuente compaginación de la autoría «textual» dramática con la dirección de escena, la interpretación, la gestión teatral, etc. (García-Manso 121-122)

A partir de los años 2000, comienzan a sumarse a los escenarios las autoras nacidas en la década de los setenta y, acto seguido, las nacidas en la primera mitad de los ochenta. Son las últimas promociones de dramaturgas que han llevado sus textos a escena en España, un nutrido grupo en el que se cuentan nombres como el de Pilar Campos Gallego (1973), Eva Hibernia (1973), Gracia Morales (1973), Diana de Paco Serrano (1973), Victoria Szpunberg (1973), Aurora Mateos (1974), Marilia Samper (1974), Vanessa Montfort (1975), Blanca Doménech (1976), Marga Llano (1977), Marta Buchaca (1979), Vanesa Sotelo (1981), Zo Brinviyer (1982), Diana I. Luque (1982), Lola Blasco (1983) y María Velasco (1984), entre otras. Casi todas ellas se han formado en Escuelas de Arte Dramático, cuyos estudios ofrecen desde 2006 una rama de especialización en Dirección escénica y Dramaturgia. La integración de los estudios en Dramaturgia y Dirección en una misma especialización, unida a la tendencia de combinar ambas facetas observable en el presente, ha promovido que se prepare y forme a los autores y autoras dramáticos para una comprensión global del hecho teatral en su doble vertiente de creación textual y escénica, lo que les

promulgación de la Ley Orgánica 1/1990, de 3 de octubre, de Ordenación General del Sistema Educativo (LOGSE) (García-Manso 122).

3. Laila Ripoll es autora, adaptadora, directora de escena y fundadora -junto con Mariano Llorente, José Luis Patiño y Juanjo Artero- de Producciones Micomicón (1992); Angélica Liddell dirige y funda con Gumersindo Puche Atra Bilis Teatro en 1993, compañía con la que ha estrenado únicamente textos propios implicándose no solo en la dirección sino también en la escenografía y la interpretación; Lluïsa Cunillé fundó la Hongaresa de Teatre (1995) con Lola López y Paco Zarzoso, y La reina de la Nit (2008) con Xavier Albertí, compañías para las que escribe textos y adaptaciones; Yolanda Pallín ha estrenado con la compañía Noviembre Teatro textos propios y adaptaciones del teatro clásico; Itziar Pascual es socia fundadora de la Asociación de Mujeres en las Artes Escénicas de Madrid (AMAEM) «Marías Guerreras» (2001); y Beth Escudé participó en la fundación de Projecte Vaca, la Associació de Creadores Escèniques (1998), y ha escrito dramaturgias para La Fura dels Baus y Nats Nus.

Feminismo/s 30, diciembre 2017, pp. 93-110 
permite desarrollar ambas actividades de forma competente. Comparten con la generación anterior una forma integradora de entender el teatro, en la que los vínculos del proyecto creativo con la escena son estrechos. Sin lugar a dudas, se han beneficiado de la experiencia y los avances de las generaciones previas, en las que pueden encontrar modelos y referentes profesionales femeninos.

En la antología Dramaturgas del siglo XXI, editada por Francisco Gutiérrez Carbajo, las autoras de estas últimas generaciones se refieren a la autogestión y la dirección escénica no solo como una estrategia para estrenar los textos propios, sino también como una vía de experimentación teatral ${ }^{4}$. Según Gracia Morales, «en España, pocas compañías se arriesgan a apostar por el teatro más reciente y contemporáneo y los dramaturgos y dramaturgas nos estamos dando cuenta de que es necesario asumir ese reto de formar parte de una compañía que lleve a escena los textos propios» (Gutiérrez Carbajo 313). Lola Blasco afirma que asumió «la producción, la gestión y la dirección» de Pieza paisaje en un prólogo y un acto "porque no podía esperar a que alguien se decidiera a montar» un texto suyo, y que se trató en todo caso de un proceso enriquecedor, en cuanto que le permitió «avanzar en la escritura dramática» (Gutiérrez Carbajo 142). En este sentido, se puede afirmar que para este grupo generacional la profesionalización escénica ha alcanzado un punto culminante, puesto que su actividad creativa viene acompañada del desarrollo de otras facetas, como la dirección o la interpretación, y cada vez es más habitual que las autoras se involucren en los procesos de creación escénica, produciendo obras de teatro innovadoras en el plano formal, que indagan en nuevos lenguajes expresivos, para los cuales las nuevas tecnologías de la información y la comunicación resultan especialmente relevantes.

Resulta halagüeño observar que esta última generación no solo ha logrado estrenar sus obras a una edad temprana, sino que además lo ha podido hacer en teatros públicos y salas alternativas de larga tradición. El acceso a los espacios escénicos y editoriales depende también en gran medida de su habilidad para captar los intereses de las salas e instituciones que costean sus proyectos escénicos. Eso les hace ser una generación muy atenta a las nuevas tecnologías y a los medios de comunicación de masas, que domina no sólo las formas tradicionales de información -prensa, televisión, cine, cultura popular...-, sino también las de la era de la globalización -internet, redes sociales, blogs, páginas web...-, que utilizan tanto para promocionar sus creaciones como para reflexionar sobre sus procesos creativos.

4. Gutiérrez Carbajo realiza un cuestionario para recabar opiniones de las autoras antologadas en el que plantea el siguiente tema: «La labor de las creadoras como gestoras y como productoras de sus propias obras» (110). 


\section{UN TEATRO ESCRITO A PIE DE ESCENA}

La interacción entre escritura dramática y creación escénica se ve favorecida por la creciente proliferación de una serie de programas teatrales que algunas instituciones, escuelas y salas de teatro convocan periódicamente con el fin de promover la investigación en el ámbito escénico. Son los laboratorios teatrales en los que normalmente el compromiso ético con la realidad, las temáticas actuales y de gran impacto social, van de la mano de la indagación formal y la experimentación con nuevas técnicas expresivas. Las generaciones más jóvenes de autores encuentran además en estos programas una vía para la visibilización de su obra, pues les permite acceder a teatros de titularidad pública y a salas como la Cuarta Pared en Madrid o la Beckett en Barcelona. Por otra parte, estos programas responden a una de las demandas de los autores y autoras de teatro que más ha persistido en el tiempo: que las instituciones públicas se impliquen en la promoción del teatro español escrito por autores vivos.

En este sentido, destacan las iniciativas que algunos teatros públicos y salas alternativas, con apoyo del Estado, las Comunidades Autónomas o los municipios, han puesto en marcha en los últimos años. Entre los que han dado cabida a la participación de autoras jóvenes, se hallan el Projecte T6 del Teatre Nacional de Catalunya (TNC), el Espacio de Teatro Contemporáneo (ETC) de la Sala Cuarta Pared (Madrid) y «Escritos en Escena» del Centro Dramático Nacional (CDN). Estos programas, además de brindar a sus participantes los medios económicos y recursos humanos necesarios para el desarrollo de sus proyectos, constituyen una vía significativa para la promoción de su obra y de su trayectoria dramática.

El Projecte T6 se generó en la temporada teatral 2002-2003 como un programa de promoción de la escritura teatral que pretendía «combatir el aislamiento creativo de los autores dramáticos» y asegurarles el acceso a los escenarios $^{5}$. En la última y $6{ }^{a}$ edición del programa, que tuvo lugar durante las temporadas de 2011-2013 $3^{6}$, los organizadores aludían, asimismo, a su apuesta por «una autoria global de l'espectacle, que inclou la direcció escènica com una faceta més del treball d'autor $»^{7}$. De esta manera, se promovía la conjunción de las dos principales actividades creativas del teatro: la textual y la escénica, potenciando que los autores y autoras participen plenamente en la realización

5. Dosier de prensa de la quinta edición (2009-2011) del Projecte T6, https://www.tnc.cat/ uploads/20090722/dossier_T6_5a_ediciA_cat.doc, consultado el 29-05-2017.

6. En enero de 2013 se anunció, junto con otras medidas, la cancelación del Projecte T6, debido a la necesidad de hacer ajustes presupuestarios frente a los recortes en la financiación del TNC (Redacció).

7. Dosier de prensa del Projecte T6. Sisena edició 2011/2013.

Feminismo/s 30, diciembre 2017, pp. 93-110 
del espectáculo. En los últimos años, el programa priorizó la participación de las más jóvenes generaciones, brindándoles la oportunidad de acometer un proyecto escénico en unas buenas condiciones de producción. A lo largo de sus seis ediciones, el Projecte T6 ha contado con la participación de las autoras Victoria Szpunberg (1973) -en la primera edición-, Gemma Rodríguez (1973) e Isabel Díaz (1971) -segunda edición-, Beth Escudé (1963) -tercera edición-, Àngels Aymar (1958), Eva Hibernia (1973) y Mercè Sarrias (1966) -cuarta edición-, Cristina Clemente (1977) y Marta Buchaca (1979) -quinta edición-, y Helena Tornero (1973) y Marilia Samper (1974) -sexta edición-.

El programa ETC de la Cuarta Pared comienza en octubre de 2007 con la finalidad de promover «la investigación y desarrollo de nuevos lenguajes escénicos que, en colaboración con el Ayuntamiento de Madrid y el Ministerio de Cultura, facilita a los profesionales de las artes escénicas realizar las búsquedas que no son posibles en las producciones habituales $»^{8}$. Para ello se ofertan becas con planteamientos temáticos y enfoques que van variando en cada convocatoria, con las que se invita a profesionales de las Artes Escénicas a participar y presentar sus propuestas innovadoras. De esta forma se pretende favorecer la colaboración y comunicación entre los diversos agentes de teatro para indagar en los nuevos lenguajes expresivos sin la presión que conlleva habitualmente la preparación de un montaje. Una de las peculiaridades de este programa es que no conlleva necesariamente la puesta en escena de los proyectos desarrollados. No obstante, la Cuarta Pared generó las iniciativas «Impulso ETC» y «Proyecto ETC» con el fin de apoyar, respectivamente, la realización de montajes independientes y su producción por parte de la Compañía Cuarta Pared. Entre las autoras que han participado en los laboratorios ETC de años recientes se hallan las ya mencionadas Lola Blasco, María Velasco y Zo Brinviyer. Todas ellas han sido seleccionadas, asimismo, para desarrollar un proyecto escénico en el programa «Escritos en la escena» del Centro Dramático Nacional.

«Escritos en escena» forma parte del «Laboratorio Rivas Cherif», un programa de proyectos y actividades que el CDN puso en marcha en la temporada 2012-2013. A 1 igual que las iniciativas anteriormente descritas, se pretende «crear un espacio de libertad creadora exento de la presión que supone la dinámica profesional al uso, con su apremiante exigencia de resultados inmediatos $»^{9}$, tal y como expresa su principal impulsor, Ernesto Caballero, quien asumió la dirección del CDN en 2012. Tiene como uno de sus fines promover:

8. http://www.cuartapared.es/investigacion/que-es-etc/, consultado el 29-05-2017.

9. http://cdn.mcu.es/laboratorio-rivas-cherif/, consultado el 29-05-2017. 
Un modelo de escritura dramática a pie de escenario: partiendo de un primer borrador, el autor desarrolla y finaliza el texto en el ámbito escénico, trabajando estrechamente con un grupo de intérpretes durante un tiempo determinado. El objetivo de este programa es llegar a elaborar textos dramáticos viables y aptos para ser exhibidos, en la línea de los semimontados, susceptibles de prorrogar su vida y desarrollo en otros ámbitos ${ }^{10}$.

La selección de los proyectos se efectúa por convocatoria pública y, aparte de las representaciones escénicas que se realizan en el Teatro Valle-Inclán, el CDN lleva a cabo la edición del texto a través de su editorial. Hasta el momento, las autoras que han participado en las sucesivas ediciones de este programa son: Lola Blasco, María Velasco, Verónica Fernández (1971), Blanca Doménech, Diana I. Luque y Lucía Carballal (1984). En la temporada actual -2016-2017-, Nieves Rodríguez Rodríguez (1983) está preparando la puesta en escena de Por toda la hermosura y, recientemente, se ha anunciado que entre los seleccionados para 2017-2018 figura una propuesta de Zo Brinviyer titulada La fiebre.

\section{MEMORIA, IDENTIDAD Y ESCRITURA ESCÉNICA: EL MEU AVI NO VA A CUBA, DE VICTORIA SZPUNBERG}

La autora Victoria Szpunberg (Buenos Aires, 1973) constituye un buen ejemplo de la interacción entre escritura dramática y creación escénica comentada más arriba. Licenciada en Dramaturgia y Dirección por el Institut del Teatre de Barcelona, ha participado en la Residencia Internacional del Royal Court Theatre (2000) y en el Projecte T6 (2003), y ha obtenido becas de creación dramática en el TNC (2004) y en Iberescena (2008). En la actualidad, compagina su faceta creativa con la docencia en Artes Escénicas. Es profesora de Dramaturgia en el Institut del Teatre y en la Escuela Superior de Coreografía de Barcelona, ha impartido talleres de escritura teatral en el Obrador de la Sala Beckett y en otros espacios, ha dirigido y realizado la dramaturgia de varios montajes y coreografías y ha escrito cuentos sonoros para la radio.

Como hija y nieta de exiliados, que ha vivido en Cataluña tras abandonar Argentina con sus padres para evitar la represión política cuando tenía cuatro años (Szpunberg 2016), Szpunberg ha dedicado una buena parte de su obra a reflexionar sobre la construcción de las identidades nómadas y transculturales. En su Trilogía sobre la fragilidad de la memoria, «un trabajo de introspección sobre su propia historia y la de su familia» (Castro), la autora combina discursos metamnemónicos y metateatrales en torno a la (im)posibilidad de

10. http://cdn.mcu.es/laboratorio-rivas-cherif/escritos-en-la-escena/, consultado el 29-05-2017. 
dramatizar «un hecho abismal: el del exilio y la última dictadura argentina» ${ }^{11}$. Las tres obras, que juegan con distintas estéticas y formas dramáticas, tienen como hilo conductor los retazos de la memoria de una mujer que estuvo a punto de ser secuestrada o chupada por las fuerzas represivas durante la dictadura de Videla. Gracias a una llamada de aviso y al error de quienes iban a detenerla, que la confundieron con su vecina, se salvó de la reclusión ilegal en uno de los muchos centros de detención que se ocultaban en Buenos Aires y de lo que podría haber sido una muerte segura. Sin embargo, su historia aparece siempre relatada o representada a través de voces que se distancian de los hechos a través de la memoria -sea esta personal o mediada, en el contexto de la ficción dramática-. Cada texto de la trilogía -El meu avi no va a Cuba, La marca preferida de las hermanas Clausman y La memoria de una ludisia-cuenta con unos personajes que transmiten imágenes y recuerdos tamizados por la distancia de los años y de un tipo de discurso metarreferencial. En El meu avi, porque la encargada de narrar es una actriz andaluza del presente que ha sido seleccionada en un casting para interpretar el papel de Ana, la mujer argentina exiliada, en una película. En La marca preferida..., porque son Sara y Valentina, las hijas de una exiliada muy parecida, quienes se encargan de dramatizar a modo de juego la escena, tal y como ellas la imaginan a partir de lo que les han contado. Y, en La memoria de una ludisia, porque es la propia protagonista de los hechos quien permite, involuntariamente, que sus dolorosos recuerdos afloren en una entrevista. Las tres obras se estrenaron en años consecutivos: El meu avi no va anar a Cuba (els meus pares si) en la sala Beckett el 21 de diciembre de 2009, La marca preferida de las hermanas Clausman en el Teatre Tantarantana el 2 de abril de 2010, y la pieza sonora La memoria de una ludisia en COM Radio, en agosto de 2008 ${ }^{12}$. En 2011 se mostraron en la sala Cuarta Pared como trilogía.

11. Las tres obras de la trilogía se enmarcan bajo el título «La fragilidad de la memoria (Cómo narrar un hecho abismal: el del exilio y la última dictadura argentina)».

12. Fueron originariamente escritas en catalán y en español, pero para las citas me sirvo únicamente de la traducción al español depositada en la base de textos dramáticos Catalandrama. En el caso de El meu avi..., el título fue simplificado a El meu avi no va anar a Cuba y traducido en su versión castellana como El meu avi no va a Cuba. Tal y como indica la autora en una nota que antecede al texto dramático, con el título se hace referencia a una habanera catalana («El meu avi va anar a Cuba» / «Mi abuelo se fue a Cuba»), pero la modificación de la autora conlleva un giro cómico al hacer referencia al hecho de que, en este caso, son los padres los que se fueron a Cuba, aunque no en 1898, sino décadas después, en la época en la que la isla se convirtió en un lugar de peregrinación y formación para los militantes latinoamericanos de izquierdas. Sobre el humor como instrumento crítico en la trilogía véase el estudio de Pérez-Rasilla. 
Szpunberg explora en la trilogía, por lo tanto, cómo llevar a cabo la dramatización de recuerdos fragmentarios, transmitidos a través de su familia, heredados de una realidad histórica que marcó su vida, pero de la que no pudo ser protagonista, debido a su corta edad. La creación surge de la necesidad de reflexionar sobre ese pasado. La autora cuestionaba en una entrevista: «icómo puede ser posible que con la edad que tengo no supiera nada de todo lo que pasó?» (Gázquez 80). En este sentido, cabe interpretar la trilogía dentro de un contexto más amplio, el de la literatura de los hijos de la dictadura argentina, en el que convergen numerosas obras artísticas producidas por autores y autoras que en aquel momento eran tan solo unos niños. En dichas obras, los autores indagan en el pasado familiar como un medio para construir su propia identidad. Según Szpunberg explicó en una entrevista, a ella no le interesaba hacer una obra histórica sino «hablar, por ejemplo, de los hijos, que es mi caso: ¿qué hacen con la historia de sus padres?» (Gázquez 80).

Dado que los creadores de esta literatura de hijos crecieron y se educaron en tiempos de dictadura o en el espacio del exilio, sin ser protagonistas o agentes activos de las luchas de los adultos, se revela a menudo la dificultad de rememorar y de reconstruir los recuerdos propios o heredados. Por ello, los textos tienden a la fragmentación y a incluir reflexiones autoficcionales, metaliterarias y metamnemónicas. Estas técnicas revelan cierto extrañamiento ante los hechos vividos y una necesidad de distanciarse y revelar los mecanismos de la ficción. Tal y como afirma Drucaroff en relación con la narrativa argentina, «en todas estas obras lo que insiste es el trauma porque se descubre, finalmente, qué estaba pasando mientras los escritores eran niños y jugaban» (177). La perspectiva de los hijos se hace patente también por su tendencia a cuestionar la actitud adoptada por los padres y por la generación de los padres ante la dictadura ${ }^{13}$. En la trilogía de Szpunberg, de hecho, se producen a menudo confrontaciones de carácter generacional o incluso cultural, como ocurre cuando la Actriz de El meu avi... se compara con Ana, la mujer a la que tiene que interpretar en la película ${ }^{14}$, o en La marca preferida... cuando Sara

13. Gino Luque señala que existe una distancia con respecto a los hechos, que le permite a la autora adoptar una mirada crítica con respecto a la generación anterior.

14. «MARTA-ACTRIZ: Ella, a mi edad, sabía usar una Browning 9 milímetros, vivía lejos de sus padres, vivía clandestina, pasaba días sin ver el sol, militaba, formaba parte de un grupo, de un ideal colectivo, sabía cómo hacer una bomba... Yo soy pop, no puedo negarlo... Ella, a mi edad, dirigía un grupo entero de alfabetización, de manera voluntaria, gratuita, solidaria, desinteresada, altruista, no cobraba nada, ni un céntimo, nada... Yo soy posmo, no puedo negarlo» (Szpunberg 2008, 17). 
imita a su madre y muestra cómo esta les ha reprochado alguna vez la falta de compromiso e implicación política ${ }^{15}$.

En este contexto global en el que una obra puede responder a distintas realidades transnacionales, cabe establecer asimismo una relación con la escena española para la que se escribió la trilogía, en la que se producen con frecuencia espectáculos en los que se reflexiona sobre el proceso de hacer memoria y sobre los componentes traumáticos que comporta. El discurso metamnemónico se plantea a menudo a través de personajes cuyo criterio se pone en duda debido a que hay algo que desconocen o, simplemente, porque no pueden recordar. Un ejemplo claro se halla en La mujer burbuja (1998), de Juan Margallo y Petra Martínez, y en Jaula (2003), de Itziar Pascual, obras en las que uno de los protagonistas ha perdido la memoria o padece Alzheimer, representando la desmemoria colectiva a través de la desmemoria individual. Este enfoque dramático suele aparecer vinculado a procesos individuales y colectivos de construcción identitaria, como observamos en relación con la literatura de hijos. Existe una necesidad de reubicarse en relación con el pasado y de hacer algo con las memorias heredadas. Por ello, proliferan las obras en las que se indaga sobre la historia familiar, normalmente protagonizadas por personajes jóvenes, los nietos y descendientes de los protagonistas históricos del suceso recordado. Estos textos saltan de lo privado a lo público debido a las características de las experiencias recuperadas, imbricadas en procesos históricos que han conformado traumas colectivos: guerras, dictaduras, exilio, represión política... Así ocurre en La indiana (2007) y Solavaya (2010), de Àngels Aymar, Père Lachaise (2003), de Itziar Pascual, Santa Perpetua (2011), de Laila Ripoll, y, más recientemente, en La armonía del silencio (2016), de Lola Blasco.

Por otra parte, la indagación identitaria que se lleva a cabo a nivel de contenido, encuentra su réplica en la exploración y la experimentación que se produce en el plano de lo formal en la trilogía de Szpunberg. La autora recibió en la convocatoria de 2007-2008 una ayuda de Iberescena para la creación dramática por su proyecto sobre La marca preferida de las hermanas Clausman, que dio lugar a la creación de la trilogía (Corcuera y Gázquez 79). Cada una de las tres obras responde a distintos modelos de creación y, aunque están conectadas por su contenido y por los paralelismos entre sus personajes, son muy diferentes entre sí. Mientras que El meu avi... y La memoria de una ludisia son textos fragmentarios, que se completan con la puesta en escena y con la

15. «SARA: [...] yo a la edad de ustedes ya había alfabetizado tres barrios enteros y vivía clandestina, militaba a la edad de ustedes, me jugaba la vida, quería cambiar el mundo... No como ustedes, que están siempre preocupadas por las marquitas, las marquitas y las boludeces... Mirá a Sara, parece una retrasada con tanta marquita» (Szpunberg 2010, 37). 
configuración sonora, La marca preferida... es un texto más clásico, en el que la acción se sucede en orden lineal y se concentra en un espacio único y en unos pocos personajes.

El meu avi... responde, por lo tanto, al modelo de creación escénica que describí más arriba. La obra toma forma a partir de las reuniones de la dramaturga con la cantante Sabina Witt y el músico Lucas Ariel Vallejos, quienes actuaron en la puesta en escena junto con Marta López, encargada de hacer el papel de la Actriz y de Ana -la mujer exiliada- y las voces en off del Director y de la Periodista, interpretadas por Francisco Baglietto y Judit Porta, respectivamente. La propia Szpunberg dirigió el montaje. Según declaraciones de la autora en una entrevista, «cada uno hizo lo que sabía hacer. Lucas es batería y sonidista, y en la primera pieza se reconocen las batucadas y los movimientos de H.I.J.O.S. con el tambor, por ejemplo. Trabajaba con el equipo, me iba a casa, escribía, volvía, probaba, reescribía. Fue una escritura escénica más que una escritura de autor» (Corcuera). En otra entrevista, añade:

Como tenía tanto material decidí reunirme con gente con la que compartía una gran complicidad porque habían tenido una vivencia similar a la mía, entre ellos, mi propia hermana, que es cantante; mi compañero Lucas, que también es hijo de exiliados... Con ellos empecé a esbozar un material de un modo totalmente abierto, es decir, que se concreta escénicamente; a diferencia de Las Clausman, que se cierra más como obra dramática en la propia escritura. La memoria de una ludisia, que es una pieza sonora para la radio, cronológicamente aparece como la tercera, pero la escribí entre las dos. [...] Tenía tanto material que decidí jugar con tres formatos diferentes. (Gázquez 79)

En efecto, si comparamos los textos dramáticos de las tres obras y sus puestas en escena, el primer texto de la Trilogía, El meu avi..., responde a ese modelo de escritura escénica fácilmente reconocible por la importancia que ganan las canciones, el espacio sonoro y la interpretación de los actores -e incluso su identidad real- en la configuración del drama. En una nota introductoria al texto dramático, Szpunberg se refiere a su componente metateatral, performativo y autobiográfico, aduciendo que «los intérpretes hacen muchas veces de ellos mismos» $(2008 a, 4)$. En su reseña sobre el montaje, Carnevali observa que el público es "consciente de ver a un músico, a una cantante y a una actriz que cambia de papel en virtud del rol que se le reserva en la realidad así como en la ficción». No se halla muy distante, en este sentido, de otros textos dramáticos que en los últimos años se han construido desde la escena con la participación de los intérpretes, quienes se representan a sí mismos y se refieren a su propia biografía. Sobre una temática similar cabe destacar el emblemático espectáculo Mi vida después [2009] (2016), de Lola Arias (Buenos Aires, 1976), una obra construida a partir de los testimonios de hijos 
de detenidos-desaparecidos e hijos de represores de las juntas militares. Los actores intervinieron directamente en la elaboración del texto dramático aportando sus historias y anécdotas familiares. En la obra, los intérpretes-personajes reconstruyen la juventud de sus padres a través de antiguos objetos: ropa, cartas, grabaciones de sus voces... Se trata de una representación que ha ido mutando con sus protagonistas, quienes, en la larga vida del espectáculo, han ido aportando nuevos datos y referencias biográficas sobre sus padres conforme las han ido conociendo.

En El meu avi... podemos diferenciar distintos nudos de acción que se superponen a lo largo de las tres partes y el prólogo que conforman el drama. Por un lado están la Cantante y el Sonidista, que, aparte de encargarse de la música y el sonido a lo largo de la obra, intervienen en ciertos momentos en la acción principal, aunque solo la Cantante tiene texto. La Cantante actúa como Narradora en varias ocasiones para explicar las acciones y sentimientos de la Actriz, rompiendo así con la ilusión dramática. También ofrece las claves de la trilogía al comienzo de la segunda parte del drama, cuando lee unos breves fragmentos o «intervalos» que reflexionan sobre la fragilidad de la memoria ${ }^{16}$, explican el trasfondo real de la historia -revelando los paralelismos con la biografía de la familia Szpunberg-Witt-, y critican veladamente la sociedad de consumo actual -un aspecto en el que se profundiza en La marca preferida...-.

Como parte central del drama, se halla la grabación de una película testimonial sobre la dictadura argentina. El Director, al que nunca vemos ${ }^{17}$ pero sí escuchamos a través de una voz en off, celebra una audición a la que se presenta Marta-Actriz, quien logra conseguir el papel secundario de Ana, la mujer exiliada. Tras los primeros momentos de euforia por parte de la novel actriz, se nos muestra su decepción ante la decisión de eliminar su escena de la película, paliada por su creciente obsesión por la persona real que se esconde tras su personaje, a quien desea conocer. A pesar de que Marta-Actriz insiste en las diferencias que la separan de la joven militante de los 70, especialmente en cuanto a su falta de compromiso social y político, encuentra un motivo

16. El fragmento sobre la fragilidad de la memoria se repite en los intervalos 1 y 5: «Las palabras que decimos aquí no son del todo fieles a la realidad. Nunca las historias narradas son del todo fieles a la realidad. La fragilidad de la memoria dispersa los hechos, los hace vulnerables... El lenguaje, la imaginación, el discurso... manipulan los hechos. Y nada es tal y como pasó» (Szpunberg 2008a, 11 y 13). El mismo fragmento se incluye en la Nota que precede al texto de La marca preferida... (Szpunberg 2010, 3).

17. En uno de los momentos más cómicos de la obra, los intérpretes se sientan en una mesa como si estuvieran en una rueda de prensa y miran hacia la silla vacía desde donde se escucha la voz del Director, quien responde a las preguntas de la Periodista -también en off-. 
de afinidad en la identidad transcultural de ambas. Para la actriz andaluza, la definición de los acentos es fundamental, pero su importancia va más allá de la habilidad de mímesis actoral y encierra también el deseo de tener una identidad y unos orígenes reconocidos: «Me imagino con otro acento. La pulcritud de un acento bien definido, ser de aquí y solo de aquí, de una buena familia de aquí, estudiando arte dramático, [...] Y luego imagino un acento sin rumbo, el teléfono» (Szpunberg 2008a, 15). De igual manera, uno de los rasgos con los que el personaje de Ana, ya adulta, se autodefine, es su «acento sin rumbo», una marca de su falta de pertenencia y de su sensación de «estar fuera de cuadro» (Szpunberg 2008a, 25).

Por último, está la historia de Ana, militante en los años 70 y exiliada en la actualidad. Conocemos los detalles de su huida de la represión a través de los ensayos de Marta-Actriz y de las llamadas de teléfono que alertan sobre la cancelación de una cita que ha sido interceptada por los militares e informan sobre la detención de Enrique y de Raúl. El motivo del teléfono es esencial en las dos primeras obras de la trilogía. Como explica Sabina-Narradora en uno de los intervalos que abren la segunda parte, fue gracias a una llamada que sus padres pudieron salvarse, razón por la cual «a lo largo de los años, esta llamada milagrosa ha pasado de ser un recuerdo a ser un mito» (Szpunberg 2008a, 12). En La marca preferida..., el sonido del teléfono es la seña con la que las hermanas dan comienzo a su juego, mientras que en El meu avi... tiene la función de interrumpir la acción y retrotraerla a los años $70^{18}$. En todo caso, estas escenas se producen siempre en un nivel metateatral, a lo que contribuye también -en las dos primeras obras de la trilogía- el uso de las pelucas rubias, con las que se identifica a la joven militante de los 70. Al final de El meu avi..., la propia Ana -representada por la misma intérprete que hace el papel de la Actriz- hablará sobre el persistente dolor del recuerdo, la culpa por haberse salvado en lugar de su vecina y de sus compañeros muertos, y criticará el carácter melodramático y morboso de la película del Director.

Para terminar, quisiera reflexionar brevemente sobre la cuestión esencial que Victoria Szpunberg plantea con su trilogía: «cómo narrar un hecho abismal: el del exilio y la última dictadura argentina». La actitud de la autora se asemeja a la de sus protagonistas en el hecho de que todas ellas buscan, cuestionan y ensayan maneras de acercarse a ese hecho abismal. Se podría decir que comparten el pudor del superviviente o el testigo que no se siente del todo

18. También Marta-Actriz hace llamadas a amigos y familiares para contarles que ha conseguido un papel en la película y que va a hacerse famosa. Se produce un contraste entre estas llamadas superficiales y las referentes a los años 70 , similar al que perturba a Marta-Actriz cuando se compara a sí misma con Ana, la militante a la que interpreta. 
legitimado para dar testimonio de la muerte. Las tres mujeres exiliadas que aparecen en las obras de la trilogía cargan con la culpa de haber sobrevivido. Pero también los demás personajes muestran sus reticencias y la presencia de un sentimiento de culpa. El Director argentino de El meu avi... se responde a sí mismo con un rítmico "yo no estuve allí» a cada pregunta que le asalta en torno a su propia creación (Szpunberg 2008a, 16). Las generaciones jóvenes de las tres obras, por su parte, se sienten sobrepasadas por el relato heroico de la generación precedente, hasta el punto de que la Joven de La memoria de una ludisia se reconoce incapaz de enfrentarse al dolor de su madre y a su historia ${ }^{19}$. Como señalaba al principio del análisis, subyace en esta trilogía la idea de la indagación, tanto a nivel formal y creativo, como a nivel ficcional. A modo de tanteo, Victoria Szpunberg propone con su trilogía tres maneras de acercarse al relato de la dictadura y el exilio.

\section{CONCLUSIÓN}

A partir del año 2000 coinciden en los escenarios distintas promociones de autoras españolas que se han ido incorporando progresivamente a la actividad teatral. Al contemplar sus trayectorias individuales es posible observar un paralelismo entre las transformaciones que han tenido lugar en el sistema teatral español y la tendencia, cada vez mayor, hacia la profesionalización escénica. Así pues, las autoras que se formaron durante la etapa democrática han ido adoptando facetas como la dirección de escena, la gestión y la producción teatral que van más allá de la escritura dramática y que les permiten estrenar sus textos y tener una mayor proyección escénica de la que alcanzaron sus predecesoras. Este modelo de autoría escénica se ha visto implementado también en los últimos años por el surgimiento de iniciativas institucionales que ofrecen los recursos necesarios para que los dramaturgos trabajen directamente con otros profesionales del teatro en la construcción escénica del texto. Dichas iniciativas se han convertido en un importante laboratorio de creación teatral y de innovación escénica.

El perfil y la dramaturgia de la autora Victoria Szpunberg se corresponden con esta forma de entender la escritura dramática hoy. En su trilogía sobre la fragilidad de la memoria, iniciada gracias a una ayuda de Iberescena, ensaya distintas formas dramáticas de aproximarse a la representación de la dictadura

19. «[...] pienso que debería volver más pronto a casa, la soledad le hace daño, sobre todo por la noche, tendría que pasar más rato con ella... Pero no puedo, sencillamente no me lo banco, no puedo con su dolor y aún menos con su felicidad. No puedo con su historia... No puedo con su acento sin rumbo...» (Szpunberg 2008b, 6). 
argentina y de su consecuente exilio, entendidos como un hecho abismal. En este sentido, la obra puede imbricarse dentro del contexto de la literatura de hijos de la dictadura argentina y en un teatro de discurso metamnemónico, frecuente en la escena española actual. La primera obra de la trilogía, El meu avi no va a Cuba, responde a un modelo de escritura escénica que avanza al calor de las reuniones y conversaciones de la autora con su equipo de intérpretes. Como resultado, la obra presenta un fuerte componente metateatral y performativo, que conjuga la reflexión formal con la indagación en torno al deber de memoria.

\section{REFERENCIAS BIBLIOGRÁFICAS}

Arias, Lola. Mi vida después y otros textos. Buenos Aires: Reservoir Books, 2016.

Carnevali, Davide. "El meu avi no va anar a Cuba (els meus pares sí), de Victoria Szpunberg». Pausa. Quadern de teatre contemporari 34. http://www.revistapausa. cat/el-meu-avi-no-va-anar-a-cuba-els-meus-pares-si-de-victoria-szpunberg/, consultado el 29-05-2017.

Castro, Julio. «Victoria Szpunberg despierta la memoria de los muertos con su Trilogía». La República Cultural. 26 de marzo de 2011. http://www.larepublicacultural.es/article4026.html, consultado el 29-05-2017.

Corcuera, Laura. «Otra mirada que cuenta el exilio». Periódico Diagonal, 20 abril 2011. https://www.diagonalperiodico.net/culturas/otra-mirada-cuenta-exilio. html, consultado el 29-05-2017.

Drucaroff, Elsa. Los prisioneros de la torre. Política, relatos y jóvenes en la postdictadura. Buenos Aires: Emecé, 2011.

García-Manso, Luisa. Género, identidad y drama histórico escrito por mujeres en España (1975-2010). Oviedo: KRK, 2013.

Gázquez, Ricard. Escrituras performativas de autora en la escena catalana contemporánea. Nuevas dramaturgias no convencionales en la primera década del siglo XXI. Universitat Autònoma de Barcelona, 2011.

Gutiérrez Carbajo, Francisco (ed.). Dramaturgas del siglo XXI. Madrid: Cátedra, 2014.

Luque, Gino. «La memoria es de un dolor muy agudo». Pausa. Quadern de teatre contemporari 34. http://www.revistapausa.cat/410/, consultado el 29-05-2017.

O'Connor, Patricia W. Dramaturgas españolas de hoy. (Una introducción). Madrid: Fundamentos, 1988.

Pérez-Rasilla, Eduardo. «La fragilidad de la memoria. El humor como instrumento crítico para recordar la represión». Estreno 37.2 (2011): 2-6.

Redacció. «La sala Tallers del TNC tancarà durant dos anys a partir del 4 de març». Televisió 3. 25 de enero de 2013. 
Szpunberg, Victoria. El meu avi no va a Cuba. Catalandrama. Teatre català contemporani en altres llengües (2008a). http://www.catalandrama.cat/obres/ el-meu-avi-no-va-anar-a-cuba.htm, consultado el 29-05-2017.

Szpunberg, Victoria. La memoria de una ludisia. Catalandrama. Teatre català contemporani en altres llengües (2008b). http://www.catalandrama.cat/autors/ szpunberg-victoria.htm, consultado el 29-05-2017.

Szpunberg, Victoria. La marca preferida de las hermanas Clausman. Catalandrama. Teatre català contemporani en altres llengües (2010). http://www.catalandrama. cat/autors/szpunberg-victoria.htm, consultado el 29-05-2017.

Szpunberg, Victoria. «El acento de mi abuelo». Pausa. Quadern de teatre contemporari 37 . http://www.revistapausa.cat/el-acento-de-mi-abuelo/, consultado el 29-05-2017.

Vilches de Frutos, María Francisca. «Perspectivas del teatro español para el año 2001: un enfoque sociológico». Siglo XX / 20 th Century 12, 1-2 (1994): 277-290.

Vilches de Frutos, María Francisca. «El teatro español de los 90. Algunas claves para su comprensión». Hispanistica XX 15 (1997): 151-158. 
Para enlazar con este artículo / To link to this article:

http://dx.doi.org/10.14198/fem.2017.30.06

Para citar este artículo / To cite this article:

Jódar Peinado, Pilar. «En defensa y Canícula, de Lola Blasco: la revolución hecha teatro». En Eva García-

Ferrón y Cristina Ros-Berenguer (coords.), Dramaturgia femenina actual. De 1986 a 2016. Feminismo/s, 30

(diciembre 2017): 111-128, DOI: 10.14198/fem.2017.30.06

\title{
EN DEFENSA Y CANÍCULA, DE LOLA BLASCO: LA REVOLUCIÓN HECHA TEATRO
}

\author{
EN DEFENSA AND CANÍCULA, BY LOLA BLASCO: \\ REVOLUTION TURNED INTO THEATRE
}

\author{
Pilar JÓDAR PEINADO \\ IES (Puente de San Miguel, Cantabria) \\ mpjodar@gmail.com \\ orcid.org/0000-0001-6287-5388
}

\section{Resumen}

En defensa... y Canícula son dos obras de la dramaturga alicantina Lola Blasco que representan su teatro político y comprometido. Como integrante de la dramaturgia emergente en España, heredera del feminismo y del teatro de la revolución -fenómenos de finales del siglo $\mathrm{XX}-$, su obra pretende dar respuesta a conflictos históricos y sociales, como el $15 \mathrm{M}$ y la crisis económica, utilizando para ello recursos metateatrales, metáforas o símbolos; y, por otro lado, modalidades como la dramaturgia del yo y el teatro documento.

Palabras clave: Lola Blasco, teatro revolucionario, teatro feminista, dramaturgia emergente.

\begin{abstract}
En defensa... y Canícula are two works by playwright Lola Blasco that represent her political and committed theater. Coming from Feministand the theater of the revolution, and as a member of the Emergent Dramaturgy in Spain-movements from the late nineties-, her work aims to respond to historical and social conflicts, such as the $15 \mathrm{M}$ and the economic crisis, using metatheatrestrategies, metaphors or symbols; and, on the other hand, theatre of the self and the theater document.
\end{abstract}

Keywords: Lola Blasco, revolutionary theatre, feminist theatre, emerging playwrights.

Feminismo/s 30, diciembre 2017, pp. 111-128

Los contenidos de la revista se publican bajo una licencia de Creative Commons Reconocimiento 4.0 Internacional (CC BY 4.0) 



\section{INTRODUCCIÓN}

Este trabajo, que se sitúa en el marco de la atención que está teniendo la dramaturgia femenina en este principio del siglo XXI -a partir de su gran presencia en la escena española hacia los años noventa del pasado siglo- pretende estudiar algunos de los aspectos que determinan la singularidad de la obra de Lola Blasco, galardonada con el Premio Nacional de Literatura Dramática 2016.

Aunque parte de un contexto dramatúrgico ligado al compromiso con las circunstancias históricas, sus particulares soluciones dramáticas a los conflictos sociales y políticos que han asolado el país la hacen representante de un teatro comprometido, que destaca por su intención de influir en la capacidad crítica de la audiencia espectadora.

Por ello, estudio en este trabajo cómo se articulan las preocupaciones de Blasco para conseguir este discurso con el que apelar a la participación del público, a partir del análisis de dos obras representativas de su teatro político, En defensa... y Canícula. Con este propósito, analizo algunos de los elementos que forman parte del contexto de creación, como el metateatro, el teatro documento y el teatro de la revolución, para plantear cuestiones relacionadas con la verdad y la realidad, así como el empleo de mitos y símbolos para indagar en el origen de esta insatisfacción social y existencial.

\section{MARCO BIBLIOGRÁFICO}

La dramaturgia emergente española, nacida alrededor de los ochenta, tiene en Lola Blasco una de sus representantes más destacadas, debido, fundamentalmente, al Premio Nacional de Literatura Dramática que obtuvo en 2016.

El estudio de las dramaturgas españolas está teniendo gran repercusión entre investigadoras e investigadores, como una forma de paliar su secular invisibilización, según afirma Diana I. Luque (44). De este interés por el teatro actual escrito por mujeres dan cuenta las antologías de Francisco Gutiérrez Carbajo (ed.) y Raquel García Pascual (ed.), además de una importante sección dedicada a «Las dramaturgas y el SELITEN@T» (Romera Castillo 2011), en el Centro de Investigación de Semiótica Literaria, Teatral y Nuevas Tecnologías de la UNED, dirigido por el profesor José Romera Castillo, quien promovió, 
asimismo, la conformación del proyecto Dramaturgae, en el que participan, además del citado Centro de Investigación, la Universidad de Toulouse (Francia) y la de Giessen (Alemania), y de donde surgen, respectivamente: Dramaturgias femeninas en la segunda mitad del siglo XX: espacio y tiempo (Ed. Romera Castillo 2005), El personaje teatral: la mujer en las dramaturgias masculinas en los inicios del siglo XXI (Ed. Romera Castillo 2009), Transgression et folie dans les dramaturgies féminines hispaniques contemporaines (Eds. Garnier/ Roswita 2007) y Dramaturgias femeninas en el teatro español contemporáneo: entre pasado y presente (Ed. Floeck y otros 2008). Del mismo modo, habría que mencionar los monográficos de diversas revistas, como el 21 (2012) de Signa (cuyo «Estado de la cuestión I» versa «Sobre lo grotesco en autoras teatrales de los siglos XX y XXI»; el 28 (2012) de Acotaciones (con una parte dedicada a «Teatro breve de escritoras jóvenes»), o el Extra, n. ${ }^{\circ} 1$ (2016) de Las puertas del drama, titulado Mujeres que cuentan; el proyecto 365 Women a Year (pról. Yolanda García Serrano); o el grupo Liga de las Mujeres Profesionales del Teatro (dir. Beatriz Cabur).

\section{LOLA BLASCO Y LA DRAMATURGIA EMERGENTE}

La denominada dramaturgia emergente engloba a un grupo de autoras y autores teatrales -31 y 63, respectivamente, según la nómina establecida por Diana I. Luque (48-54)-, nacidos en torno a los años ochenta del siglo pasado, con gran variedad de lenguajes y temas, como señala, entre otros, Eduardo Pérez Rasilla ${ }^{1}$.

No obstante, podríamos decir que a todas y todos los integrantes les une su compromiso social y político. De hecho, la propia Lola Blasco habla de su obra como un arma de activismo político, en una entrevista al citado investigador teatral, Pérez Rasilla: «Lo que más me interesa del teatro es que es un espacio de compromiso. A día de hoy, es una forma de hacer política [...]. Mi palabra es una palabra que entiendo como acción y es una palabra poética» (2012).

Este interés político revolucionario es evidente en En defensa (Un concierto de despedida) (2011) y Canícula (2016), objeto de estudio de este trabajo; pero también en la galardonada con el Premio Nacional, Siglo mío, bestia mía (2015), Pieza Paisaje en un prólogo y un acto (Premio Buero Vallejo, 2009), Proyecto Milgram (2012), Los hijos de las nubes (2012) o, la más reciente, La armonía del silencio (2017), que, además, investigan en cuestiones que tienen que ver con la memoria histórica y algún tipo de reivindicación feminista.

1. Mientras reviso estas líneas, se anuncia la publicación por parte de la editorial Antígona de Nosotros no nos mataremos con pistolas, de Víctor Sánchez, que analiza esta dramaturgia nacida en los 80 . 
La vertiente política-histórica vincula a la dramaturga alicantina con otras y otros integrantes de su generación, como María Velasco, con Los perros en danza (2010); Paco Bezerra, con El señor Ye ama los dragones (2013); Diana I. Luque, con La imagen de los sometidos (2014); Antonio Rojano, con La ciudad oscura (2015); o Alberto Conejero, con La piedra oscura (2016), por nombrar algunos ejemplos. En estas obras, el retrato de un país en crisis se mezcla con la revisión de momentos de la historia reciente de España y de Europa -el 23F, en el caso de Rojano; la guerra de Irak, en la obra de Diana I. Luque; la crisis económica española, en el texto de Bezerra²; o la Guerra Civil, en María Velasco y Alberto Conejero-.

El interés por dar testimonio del crítico momento del mundo globalizado se interrelaciona con la reivindicación feminista presente en obras como Canícula (2016), Ni mar ni tierra firme (Tres monólogos sobre La tempestad) (2014), La armonía del silencio (2017) o Pieza paisaje en un prólogo y un acto (2009), donde se trata la segregación sexual del trabajo -referido, fundamentalmente, a la atribución de los trabajos de cuidados al género femenino-, la violencia de género y la incorporación de la voz femenina a la corriente dominante de pensamiento.

La imbricación de feminismo y compromiso social y político, en realidad, es una manifestación del posfeminismo que, a partir de la segunda mitad del siglo $\mathrm{xx}$, se ha dedicado, fundamentalmente, a la lucha contra la violencia de género y contra las desigualdades en el ámbito laboral y público en general. Por ello, investigadores como Gutiérrez Carbajo, Romera Castillo (2007) o Wilfried Floeck (2007) relacionan a nuestras dramaturgas con las reivindicaciones propias de la tercera ola del feminismo, a partir del momento de irrupción de las dramaturgas en el teatro español desde los años noventa del siglo Xx, hecho señalado asimismo por César Oliva (55), Virtudes Serrano (96) o José Romera Castillo $(2007,23)$. Estos investigadores afirman que el feminismo, lejos de relegar a las mujeres creadoras en ámbitos marginales, las conecta con las grandes preocupaciones del mundo globalizado, cuestiones a las que ha de responder el feminismo actual, según la gran activista y escritora Lidia Falcón:

Las feministas tienen la obligación de elaborar una ideología que no sólo defienda los intereses de las mujeres sino que plantee también la transformación del mundo. Han de manifestarse en contra del pensamiento único, de la dominación capitalista e imperialista que se ha impuesto y que encubre sus propósitos depredadores. (211)

2. Se pueden consultar las páginas correspondientes en Metateatro español: estudio del concepto y de su presencia en cien textos teatrales de los siglos XX y XX (Jódar Peinado 2016), o Metateatro español en el umbral del siglo XXI (Jódar Peinado 2016). 
El sesgo feminista de las obras de Lola Blasco, por tanto, emparenta a esta con la especificidad de la dramaturgia femenina de finales del siglo Xx y principios del $\mathrm{XXI}^{3}$, de la que se pueden citar ejemplos como Paloma Pedrero (La llamada de Lauren o El color de agosto, por citar algunas), Carmen Resino ( $A$ Arriba la Paqui!, A vueltas con los clásicos), Lidia Falcón (No moleste, calle y pague), Itziar Pascual (Las voces de Penélope, Pared, Variaciones sobre Rosa Parks) y Angélica Liddell (Lesiones incompatibles con la vida, Y como no se pudrió... Blancanieves). Y, citando algunos ejemplos de la generación emergente: María Velasco, con Los perros en danza (2010); Vanessa Montfort, con Las variaciones del golpe (2012); Vanessa Sotelo, con Kamouraska (2010) o Nome: Bonita (2014); Laura Rubio Galletero, con Mi agravio mudó mi ser (2016) o Techo de cristal (2017); Mar Gómez Glez con Fuga Mundi (2008) o Bajo el agua (2013); Beatriz Cabur, con Nefertiti y PIIII (2016); o Pilar Campos Gallego, con Selección natural (2007).

El feminismo en Lola Blasco lo encontramos, por ejemplo, en el monólogo de Miranda de Ni mar ni tierra firme (Tres monólogos sobre La tempestad) (2014), donde la hija de Próspero aprovecha para denunciar, sobre el cadáver de este, determinadas situaciones de desigualdad que quieren erigirse en representativas del género femenino. Miranda le echa en cara a su padre que siempre ha sido ella la que se ha encargado de cuidarle, como si fuera un trabajo únicamente femenino: «Y ¡claro!, lo normal es lavar al muerto, asearlo y vestirlo para la ocasión. [...]. Limpiar mierda siempre ha sido, por costumbre, un trabajo femenino» (150).

Esta misma denuncia o protesta la encontramos en Canícula, donde uno de los hermanos piensa que el trabajo de cuidados es una cuestión de género: «El Mayor: Las mujeres tenéis mano para estas cosas. [...] La Otra: ¿Mano para qué? / El Mayor: Ya sabes. [...] Los enfermos, los niños y los ancianos son un trabajo femenino. [...] el sacrificio es un vicio femenino. Estáis preparadas para usar las rodillas» (41). A lo que La Otra responde de este modo, usando las rodillas y sus palabras: «(La Otra se acerca para darle un rodillazo, se asustan). Que os den por el culo, cobardes de los cojones. Que sepáis que apesta, vuestra cobardía» (42).

Del mismo modo, Lola Blasco denuncia la invisibilidad de las mujeres en el ámbito público, otra de las reivindicaciones del feminismo actual y de las

3. Para cuestiones relacionadas con el feminismo en el teatro español del siglo XXI, se puede consultar mi trabajo «Igualdad, representación y violencia de género: el feminismo en las dramaturgas del siglo XXI» (Pilar Jódar Peinado, Signa. Revista de la Asociación Española de Semiótica, 27, 2018, en prensa). 
dramaturgas españolas, lo que podemos ver, precisamente, en la estructura patriarcal de esta familia de cinco hermanos, gobernada por el mayor de ellos: «Soy el mayor y nadie me dice qué es lo que tengo que hacer [...]. Soy el patriarca» (14-15), lo que provoca que no tenga en cuenta la opinión de las hermanas, quienes, además, permanecen apartadas de sus tres hermanos: «La Una: Nunca se dirige a nosotras. No nos tiene en cuenta» (82).

Las hermanas se quejan de su invisibilidad, del mismo modo que la Miranda de Ni mar ni tierra firme, que se preguntaba por la escasez de representación femenina en la literatura: «No, no hay historias de princesas así en tu biblioteca. Siempre hemos existido pero nunca hemos hablado. Las historias de príncipes que se rebelan a sus padres, que destronan a sus padres son muchas, pero princesas... princesas deseantes...» (155).

\section{EL TEATRO COMO ARMA POLÍTICA: METATEATRO, DRAMATURGIA DEL YO Y TEATRO DOCUMENTO}

Las reivindicaciones feministas no son más que una manifestación del compromiso con la realidad que persigue la obra de nuestra dramaturga. Como queda dicho más arriba, ella misma asume que su teatro es un arma política, «una forma de hacer política» (Pérez Rasilla, 2012), que podría emparentar a la autora alicantina con el denominado, por Robert Brustein, teatro de la revolución. Este autor, en el libro del mismo título, explica que, a mediados del siglo Xx, había surgido en Europa una serie de autores que cultivan este tipo de teatro en el cual unos personajes deciden rebelarse contra una situación injusta y que, sin embargo, son incapaces de culminar satisfactoriamente la revolución emprendida debido a sus limitaciones intelectuales o materiales. Brustein cita a autores como Genet (con El balcón), Pirandello, Brecht, Chéjov o Ibsen, por nombrar algunos, quienes encarnarían en sí las contradicciones de la revolución, sus propias desconfianzas o escepticismo (Jódar Peinado 2016, 23).

Esta modalidad teatral tiene su reflejo, en la escena española del último cuarto del siglo xx, en obras que presentan personajes miserables que no consiguen resolver satisfactoriamente la revolución que han empezado, originada por una situación de desigualdad insoportable. Me refiero, por citar algunos ejemplos, a un grupo de obras que englobé, en mi Tesis de Doctorado, bajo el título «Una revolución dentro de una obra de teatro», dentro de las que podía citar ¡Viva el duque nuestro dueño! (1975), de José Luis Alonso de Santos; Los figurantes (1989), El cerco de Leningrado (1994), ¡Ay, Carmela! (1986) y El Retablo de Eldorado (1985), todas de Sanchis Sinisterra; El Nacional (1993), de 
Albert Boadella; Céfiro agreste de olímpicos embates (1981), de Alberto Miralles; o Los enanos improvisan su comedia (2002), de Antonio Martínez Ballesteros ${ }^{4}$.

Por su parte, Lola Blasco parece recoger esta tradición de teatro revolucionario que es consciente de sus limitaciones formales para representar adecuadamente una realidad inaprehensible como es la crisis originada por el mundo globalizado. Aparte de estas limitaciones representacionales, el teatro revolucionario desconfía de sí mismo como arma de intervención social, de ahí que Blasco nos presente a unos personajes que se debaten entre la resistencia o la revolución, en En defensa; y otros personajes que, directamente, se han abandonado a la corriente dominante de pensamiento, en Canícula, autoconvenciéndose de que no se puede luchar contra la situación de desigualdad, ya que esta es necesaria para que el statu quo se perpetúe.

En defensa, después del prólogo metateatral, nos presenta a un Hombre y a una Mujer que están despidiendo a los jóvenes que están abandonando el país (al que se alude con la metáfora del barco que se hunde) obligados, más bien expulsados, por la falta de trabajo. Estos personajes, por tanto, son testigos de la situación de crisis económica que asola a España y han de debatirse entre huir-hacer la revolución- o permanecer -resistir a la tiranía de la inacción del gobierno-. Por su parte, la farsesca Canícula nos muestra una familia de cinco hermanos, divididos en tres hermanos y dos hermanas, que se encuentran en un hospital asistiendo a la transformación en cabra de un sexto, el representante de cierta esperanza de cambio o renovación, de discurso alternativo que, sin embargo, se ahoga en sus propias contradicciones.

Ambas obras obedecen a la intención que manifiesta la propia dramaturga acerca de alcanzar el origen y las causas de la crisis: «Estoy un poco cansada, la verdad, de ver cómo se multiplican las obras de teatro que hablan de la crisis pero que no parten de la crisis profunda» (Manola 2014, 114). En defensa parece suponer el inicio de esta búsqueda de un teatro revolucionario que constituya en sí mismo una rebelión, cuya forma sea generadora del cambio de conciencia; mientras que en Canícula, seis años después del estallido del 15M, cuando la realidad ha enterrado cualquier conato de cambio, Blasco asume el fracaso de la revolución y nos muestra un retrato caricaturizado, casi valleinclanesco, de una familia que bien pudiera representar el sentir de un país que no está preparado para un nuevo horizonte.

Lola Blasco, por tanto, pretende hablar y hacer la revolución con su teatro, creando un tipo de arte escénico radical en el sentido de pretender averiguar la raíz de la crisis española: «Un teatro político revolucionario es un teatro

4. Pueden consultarse las páginas correspondientes a las citadas obras, en: ver nota 2. 
que habla, fundamentalmente, de la revolución. [...] Que es la revolución en sí mismo. Radical es la palabra, al fin y al cabo, ser radical no es otra cosa que irse a las raíces» («Diálogo para un teatro político revolucionario», En defensa $a^{5}$. En definitiva, el teatro revolucionario es un arma política porque se utiliza para dilucidar el origen de la desigualdad, para interpretar la realidad y poder abordarla. Para ello, la dramaturga alicantina concibe un tipo de teatro que aúna el teatro documento, la dramaturgia del yo y el metateatro.

La propia autora se adscribe a la corriente teatral de la dramaturgia del yo, característica de la generación de las y los nacidos alrededor de los ochenta, y que se basa, fundamentalmente, en la construcción de un sujeto colectivo, pasando del yo al nosotros, lo cual se percibe en las revueltas del $15 \mathrm{M}$ y la Primavera Árabe. Los personajes, por tanto, no son entes individuales sino que se construyen en referencia a la colectividad:

En la dramaturgia del yo se cuestiona el principio fundamental de la imitación, y la identidad ya no se cimenta en el interior del sujeto sino en la relación del sujeto con el mundo. El yo dramático que se expone ante el público no se da entero y acabado; se erige en el propio acto de la enunciación y en su recepción. Son, por tanto, dramaturgias en las que la identidad del sujeto de la enunciación queda instalada en las fronteras persona/personaje. (Blasco 2014, 95)

Esta dramaturgia del yo es ya revolucionaria porque está en proceso, por tanto, está incompleta. Esto la vincula con las estrategias metateatrales que pretenden evidenciar la naturaleza esencialmente ficticia de lo que estamos presenciando. De este modo se representa una realidad esencialmente problemática, a punto de estallar a causa de la crisis social, que necesita del ejercicio crítico de la colectividad.

Este tipo de teatro llama, así, la atención sobre sí mismo, pero con voluntad de referirse a una realidad que es imposible abordar sin una postura reflexiva. Esto es: la metateatralidad tiene evidentes implicaciones extraliterarias, como la de hacer referencia, a través del tamiz del propio teatro, a una situación histórico-política compleja, de lo cual hay evidentes ejemplos en el teatro europeo (Jean Genet, con El balcón o Günter Grass, con Los plebeyos ensayan la rebelión), y en el español (¡Ay, Carmela! o El Retablo de Eldorado, de Sanchis

5. Acerca de esta obra, no consignaré los números de página, ya que tan solo una parte está publicada en el número 28 de la revista Acotaciones, de manera que las referencias a otras partes del texto se deben a una aportación personal de la autora, Lola Blasco, a quien agradezco encarecidamente su colaboración para este artículo.

En defensa fue estrenada en la sala Cuarta Pared, en 2013.

Mientras reviso estas líneas, la propia autora anuncia en su página de Facebook la publicación de esta obra en Ediciones Invasoras, junto con Fuegos... (o el hígado de Prometeo) (20 de noviembre de 2017). 
Sinisterra; Los enanos improvisan su comedia, de Antonio Martínez Ballesteros; Céfiro agreste de olimpicos embates, de Alberto Miralles; ¡Viva el duque, nuestro dueño!, de José Luis Alonso de Santos; o El Nacional, de Albert Boadella) (Jódar Peinado 2016, 20).

En defensa (Un concierto de despedida) cuenta con mecanismos metateatrales como su estructura de mise en abyme, de obra encuadrada o, simplemente, de teatro dentro del teatro, en la que voy a considerar como obras marco el «Diálogo para un teatro político revolucionario» y el «Prólogo En defensa», que englobaría el Concierto de despedida que, a su vez, acogería el Coro de sirenas ${ }^{6}$. En realidad, como afirma la propia autora en correspondencia personal, este primer «Diálogo» ficticio con Alfonso Sastre pertenece a una versión anterior de la obra, que derivó en otro diálogo con los personajes Miquel Insúa y Lola Blasco: el «Prólogo En defensa». De este modo, por las evidentes implicaciones que los conceptos allí expresados tienen sobre la acción que se desarrolla en el Concierto de despedida y, aunque no se encuentren publicadas conjuntamente ya que pertenecen a dos momentos de elaboración de la pieza, me parece interesante considerar estas dos piezas como una obra marco conjunta, más teniendo en cuenta que ese proceso de construcción se hace explícito, por lo que puede considerarse parte de la obra misma.

Comenzando por la obra marco, los ficticios Alfonso Sastre y Lola Blasco mantienen un diálogo autorreferencial muy iluminador sobre conceptos como el teatro documento, el teatro revolucionario o la distancia entre la realidad y la verdad. Cuando estos términos son utilizados por los protagonistas de El concierto de despedida -la obra inserta- adquieren su significado completo:

Si con la primera historia, el diálogo entre Alfonso Sastre y yo, se enmarca la obra, se van dando en la misma algunas claves para comprender la segunda historia: El concierto de despedida. Que a su vez actúa como reflejo de la primera, pero el punto de partida de este relato es ya la ficción y la palabra esencialmente dramática. (Blasco 2011)

Dado que las ideas de la obra inserta encuentran su reflejo en la obra marco, el teatro dentro del teatro cumple, de este modo, la función de descubrir una verdad dentro de la ficción. En definitiva, como asegura la propia Blasco, la única verdad representable es la exhibición de la propia obra como constructo ficticio: «Sólo se habla de la verdad cuando queda claro que lo que estamos viendo es ficción». Tanto estas ideas como la estructura en abismo de la propia obra son explicadas en el blog «En defensa de un teatro político revolucionario», donde se hace explícito el proceso de creación y las reflexiones previas a

6. Según explica la autora en su blog: http://teatropoliticorevolucionario.blogspot.com.es/. 
la construcción de esta primera versión de la obra. Este hecho puede considerarse ya metateatral, por cuanto el propio proceso de creación forma parte de la obra misma, y más en este caso en el que ese proceso de escritura trasciende los límites de lo ficcional para incorporarse a la realidad en forma de página electrónica.

Por tanto, este diálogo autorreferencial L.B-A.S. (En defensa) hace explícito el acto de creación o hace aparecer el tópico de la obra que se desarrolla al hilo de la escritura (Jódar Peinado 2016, 347), del mismo modo que en Canícula, donde el personaje de La Una, que es escritora, declara que va escribiendo la historia de su familia: «La Una: Escribo. / La Otra: ¿El qué? / La Una: Nuestra historia» (26). A esta puesta en evidencia del acto de la escritura le sigue la manifestación de la autoconciencia de los personajes, tanto en En defensa - «L. B.: Aunque estemos hablando de forma ficticia, me pone usted nerviosa. [...] Pero si le he convocado, aunque sea de forma ficticia, es para hablar de teatro»-, como en Canícula-«La Una: ¿A ti qué te pasa? [...] Es que llevas dos monólogos que...» (55); «El Tercero: ¿En qué tiempo estoy? Este escenario, este lugar, parece el solar de una batalla» (61)-.

Los mecanismos metaficcionales exploran esa brecha entre la realidad y su representación, esto es, entre la realidad y la ficción, oposición que equivale a otras que, del mismo modo, vertebran estas dos obras de Blasco, como: teatro documento/fábula, realidad/mito, realidad/verdad y revolución/resistencia.

Por un lado, el teatro documento, donde la autora sitúa su texto como punto de partida, utiliza testimonios de la realidad para concienciar o reflexionar sobre una situación histórica o social problemática (López Mozo). La cuestión central está en cómo se elaboran esos documentos procedentes de la realidad y cuánto porcentaje de fabulación del escritor o escritora permite el teatro documento. En el caso que nos ocupa, la autora quiere explorar la crisis española y, concretamente, la situación de las y los jóvenes españoles exiliados por el paro. Se trata de un momento real de gran contundencia y dureza, de gran carga de realidad, que dificulta la visión de la verdad. La diatriba que se plantea es cómo dar cuenta de una realidad tan apabullante, «excesiva» (Blasco 2011) como es la de la crisis económica española, de modo que Blasco decide centrarse en un momento determinado del $15 \mathrm{M}$ que sirva para reflejar el complejo constructo que llevó a esta revuelta: «Puesto que la realidad de los acontecimientos era excesiva, no podía meterla en una obra ni en un teatro, opté por lo que Benjamin denomina como contar la historia a contrapelo, y rescaté ese pequeño momento documental» (Blasco 2011). Blasco se refiere a un momento ocurrido durante el $15 \mathrm{M}$, que explica justo antes de estas palabras: 
Me centré en el momento en que una multitud de jóvenes en la puerta del Sol se sube a una ballena de cristal. En ese momento, alguien gritó por un megáfono: ‘ßBájense de la ballena que puede ceder!’. La posibilidad de la catástrofe comprendía, no sólo la realidad de ese instante, sino también la economía española y europea en general. (2011)

La realidad, por tanto, se interpreta y esta elaboración ficticia, este pacto, constituiría la verdad: «La idea de la Verdad, diferenciando esta de la realidad (la verdad como pacto, como algo ficticio) ${ }^{7}$. No en vano, las estrategias metateatrales vienen a afirmar que la única verdad que se puede verificar es que la obra es una ficción. Así pues, esta discusión sobre la verdad será el asunto central del «Prólogo» a En defensa, constituido por otro diálogo ficticio, esta vez, entre los personajes Miquel Insúa y Lola Blasco. Estas ideas sobre la relación entre verdad/realidad y la búsqueda de una forma dramática adecuada para representarlas que conjugue la metateatralidad, la dramaturgia del yo y el teatro documento, sirven de marco a la obra inserta, Un concierto de despedida, en la que los personajes del hombre, la mujer y las sirenas nos trasladarán una realidad compleja tomando partido de los presupuestos anteriormente explicados en las obras marco.

\section{MITOS, METÁFORAS Y SÍMBOLOS PARA DESVELAR LA VERDAD}

Uno de estos presupuestos era el hallazgo de la verdad dentro de la ficción, lo cual, además de con la estructura de la obra encuadrada, se lleva a cabo con la utilización de mitos o símbolos que trasciendan la pura anécdota, que lleguen el origen, a la raíz, verdadera esencia del teatro radical, revolucionario. Los mitos de los que se sirve Lola Blasco son Ulises, Ovidio, Virgilio, Sócrates y las sirenas, en En defensa; y Jesucristo, o el diablo, en Canícula: «L.: Ulises para hablar de los jóvenes que se van, y... y... Ovidio, Ovidio para los intelectuales que son expulsados, para los exilios forzosos y Sócrates para los exiliados en su propia patria. [...]. Las sirenas para hablar de la verdad» («Prólogo En defensa», Blasco 2011).

Las sirenas son las que ofrecen el concierto de despedida a las y los jóvenes que se van de España, funcionando como un coro griego que resume, sintetiza, critica esa situación. Así, hablan en su canto de generación mutilada: «El suicidio / de una generación / esta / MI GENERACIÓN [...] que atraviesa las Universidades aprendiendo desvarío de latas de basura [...] mi vasta cultura / la tortura bajo el sol de una España de fosas comunes»; de la fuga de cerebros: «Vamos / ven aquí, que voy a hablarte de la Verdad / de la desgracia / y del

7. Correspondencia personal, 5 julio 2016.

Feminismo/s 30, diciembre 2017, pp. 111-128 
sufrimiento / Y de lamentos / y de intelectos enteros vomitados al mar»; así como del gobierno tiránico: «Voy a quejarme en la amargura de mi alma / por esta tiranía / por esta Democracia».

Siguiendo con esta utilización del lenguaje poético como modo de conocimiento, de llegar a la verdad, nos encontramos con los símbolos, de entre los que destacaría el del barco que se hunde como representación del país en quiebra, pero un barco que es saboteado, hundido deliberadamente por el gobierno:

Hombre: Estamos aquí reunidos para dar un concierto.

Para todos aquellos, jóvenes y no tan jóvenes, que abandonan el barco.

$[\ldots]$

Los jóvenes sin trabajo y la chusma política que ha movido el bote, sí, ha movido bien el bote para ver si se hundía y ahora dice:

Mujer: No fui yo.

Así, la consigna de abandonar el barco se refiere a una forma de huida, de revolución, mientras que quedarse en el país se considera una forma de lucha más efectiva, de resistencia ante la tiranía de la inacción del gobierno: «Ellos no van a hacer nunca nada para que nosotros resistamos porque la resistencia consiste precisamente en (Ríe) que ellos no hacen nada y nosotros resistimos».

En Canícula, los personajes ya han abandonado el barco, la lucha, la resistencia, y han adoptado una forma de vida acrítica. De esta manera, la representación de lo diferente, de la disidencia, se realiza a través del símbolo de la cabra que alude, a su vez, al diablo. En Canícula, ni siquiera el disidente o revolucionario tiene entidad, ya que es caricaturizado en el Tercero, que se encuentra en el hospital porque está sufriendo un proceso de transformación en cabra, fruto de la marginación que sufre por parte de sus hermanos y de la falta de sustento ideológico a sus propuestas revolucionarias. Por ello, cuando este personaje caricaturizado profiere alguna de sus consignas, como «Lograremos nuestra libertad luchando. ¡Rebelión!» (37), los hermanos y hermanas responden ridiculizando: «Voz del hermano: «Amo a todo el mundo, a todo el mundo». / La Otra: Lo han tenido que drogar. / El Menor: Yo quiero que me den lo mismo» (38).

Casi como a Los figurantes, de Sanchis Sinisterra, a los personajes de Canícula les falta complejidad crítica para impulsar un cambio, de manera que se convierten en portavoces de los lemas de la ideología dominante que perpetúa la situación de crisis y desigualdad. Por tanto, estos cinco hermanos serían el contrapunto al coro de sirenas que, por su interpretación de la realidad, profieren un discurso que difiere esencialmente del que realizan los personajes 
de En defensa. De este modo, queda comprobado que, como afirmaba la autora, la verdad es un pacto, es un concepto, una realidad que se acuerda y a la que nos acogemos para vivir de acuerdo a nuestras inquietudes. En el caso de la Mujer y el Hombre, su fin es resistir porque su concepción de la realidad, de la verdad, es esencialmente conflictiva para ellos; en el caso de los hermanos, fundamentalmente, de los varones, la realidad es amenazante para quienes detentan los valores sobre los que se asienta la sociedad actual globalizada.

Por ejemplo, los personajes actores de Miguel Insúa-el Hombre y Lola Blasco-la Mujer tratan de analizar las causas de la crisis española y hablan de la fe en el progreso como una idea fascista: «L.: Al progreso de la humanidad, esas declaraciones son fascistas, esa clase de cosas se dicen en los fascismos. Siempre que creas en el progreso vas a estar esperando a que llegue, como esperando a Godot. La fe en el progreso es la gran falacia». En cambio, para los hermanos de Canícula, la confianza en este progreso que se alcanza con trabajo y sacrificio es la idea que alienta sus vidas: «No se habla, en nuestra familia, se trabaja día y noche y cuando no se trabaja se pone la tele. Así es como son las cosas. En nuestra familia no se habla, ni nadie se siente indispuesto» (14). Este tipo de pensamiento que supedita la felicidad común al sacrificio y abnegación individual es el que sustenta el clima de crisis.

El autosacrificio común para procurar el bien individual provoca una insatisfacción que no se sabe cómo gestionar: «El de en Medio:... y venga sol, y más sol. [...] Y venga turistas, y más turistas, todos rojos [...]. Y los que estamos aquí, nos quedamos aquí, porque los que estamos aquí no tenemos vacaciones. Aquí nunca tenemos vacaciones» (12). No obstante, esta abnegación les legitima como individuos de referencia, de manera que se sienten con libertad para hacer cualquier tipo de afirmaciones y juicios:

El de en Medio: ¡Qué vergüenza!

El Menor: ¡Cómo está el país!

El Mayor: La gente no quiere trabajar.

El Menor: No quieren trabajar.

El de en Medio: No quieren, no.

El Mayor: Hablan y hablan, pero no hacen nada. (39)

Esta seguridad en sus convicciones, que les protege de cualquier fracaso, les lleva a conclusiones tan descabelladas que no pueden ser tratadas sino con el sarcasmo que atraviesa todo este texto: «El Mayor: Entonces la igualdad no existe. Hay clases. Yo lo que tengo muy claro es que no le voy a dejar mi sitio en el sofá a ningún jodido negro, porque yo me he ganado mi sitio en el sofá trabajando» (74). Esta epidemia de juicios sin fundamentar es denunciada por la Mujer y el Hombre de Concierto de despedida, quienes alertan de la dificultad 
de discernir la verdad de entre las proclamas: «Mujer: No hay nada más peligroso que un cretino con un micrófono, se prima la opinión desaforada frente a la información contrastada».

Este pensamiento acrítico con las personas verdaderamente responsables de la crisis favorece la perpetuación de un sistema profundamente desigual, derivado de la globalización:

La Otra: Por favor, no te hagas la víctima, porque sólo porque tú lo permites, sólo porque permites que te traten como a un perro, que no te traten como a un ser humano, existen las injusticias del mundo. Siempre hay gente como tú, en todas partes y por eso existen las injusticias del mundo. Las tiranías suceden porque siempre hay alguien que las permite. (54)

Y precisamente es esta tiranía de un gobierno elegido en las elecciones contra la que protestan Miquel Insúa-Hombre y Lola Blasco-Mujer, en el Prólogo: «Y ahora tenemos unos tiranos elegidos democráticamente».

La decepción en cuanto a la eficacia de una acción revolucionaria es evidente en las palabras de estos dos personajes: «Aceptemos que estamos desanimados, aceptemos que no somos capaces porque a lo mejor no somos valientes, porque, vamos a decirlo ya, es que no creemos en la revolución». Por ello, mientras los hermanos de Canícula son esperpentizados por perpetuar un sistema que engendra desigualdad y violencia, los protagonistas de En defensa reflexionan acerca del modo en que hacer frente a la crisis y al exilio de las y los jóvenes, concluyendo que es necesaria una nueva acción adaptada a los nuevos tiempos: la resistencia.

\section{CONCLUSIONES}

Canícula y En defensa (Un concierto de despedida) son dos muestras del teatro político de Lola Blasco, un tipo de teatro que define buena parte de su obra y que, junto con el feminismo, la emparenta con las aspiraciones de la dramaturgia emergente, generación a la que se adscribe. Su vertiente feminista, asimismo, procede de las reivindicaciones de las que se hicieron eco las dramaturgas que protagonizaron el desembarco de la escritura femenina en el teatro español, a finales del siglo XX.

En En defensa, Lola Blasco explora la vía hacia un teatro de la revolución, a medio camino entre el teatro documento y el mito o la metáfora, que reflexione sobre la distancia entre la realidad y la verdad, esto es, entre la realidad y la ficción. Esta obra, de 2011, podría considerarse una precursora de Canícula, de 2016, donde se muestra a unos personajes que han decidido convivir con la crisis o autoconvencerse de que una revolución es inadecuada o inútil. Por tanto, podríamos decir que ambas piezas constituirían una muestra del teatro 
revolucionario de Blasco en las que se observa una evolución: desde la resistencia como acto revolucionario consciente ante la tiranía de la inacción del gobierno, hasta la convicción de que el orden establecido no se puede cambiar.

Esta falta de confianza en un cambio, esta peligrosa aceptación de las desigualdades que origina la globalización, emparenta a esta autora con el teatro de la revolución de mediados del siglo xx europeo que se continúa en el teatro español de finales del siglo pasado, que pretendía reflexionar sobre las contradicciones que engendran las revoluciones y provocan el fracaso de estas. Estas actitudes son las que caracterizan a los protagonistas de En defensa, que se manifiestan desconfiados con la capacidad de una revolución para procurar un cambio, así como a los hermanos de Canícula quienes, directamente, se muestran reacios a protagonizar o ser testigos de la transformación de su cómoda realidad.

Del mismo modo, comparte con el teatro de la revolución el empleo de recursos metateatrales con el fin de hacer reflexionar sobre la distancia entre la realidad y la ficción o la realidad y la verdad, compartiendo, asimismo, las pretensiones extraliterarias de influir en la realidad, de crear, por tanto, un teatro como «arma política». A su vez, estos mecanismos metaficcionales -entre los que se encuentran el teatro dentro del teatro, la autoconciencia del personaje o los diálogos autorreflexivos- junto con otras estrategias de la dramaturgia del yo y el teatro documento, configurarían algunas de las técnicas principales del teatro de la revolución de Lola Blasco.

\section{REFERENCIAS BIBLIOGRÁFICAS}

Blasco Mena, Lola. En defensa (Un concierto de despedida). 2011. Inédita.

Blasco Mena, Lola. Un concierto de despedida. Acotaciones 28 (2012): 91-102, $<$ http://www.resad.es/acotaciones/acotaciones28/blasco_unconciertodespedida.pdf>, consultado el 15-06-2017.

Blasco Mena, Lola. «En defensa de un teatro político revolucionario», <http:// teatropoliticorevolucionario.blogspot.com.es/>12-12-2011, consultado el 11-06-2017.

Blasco Mena, Lola. Ni mar ni tierra firme (Tres monólogos sobre La tempestad). Dramaturgas del siglo XXI. Ed. Francisco Gutiérrez Carbajo. Madrid: Cátedra, 2014, 143-162.

Blasco Mena, Lola. Canícula (Evangelio apócrifo de una familia, de un país). Alicante: Instituto Alicantino de Cultura Juan Gil-Albert, 2016.

Blasco Mena, Lola. «Sobre el yo generacional en algunas muestras del teatro español actual».Creadores jóvenes en el ámbito teatral (20+13=33). Ed. José Romera Castillo. Madrid: Verbum, 2014, 93-105. 
Brustein, Robert. The Theatre of Revolt. Boston: Little, Brown, 1964.

Central European Time. «Lola Blasco, Premio Nacional de Literatura Dramática 2016». El Cultural. El País, 9 noviembre 2017. <http://cultura.elpais.com/ cultura/2016/11/08/actualidad/1478608820_376148.html>, consultado el 15-06-2017.

Falcón, Lidia. «Feminismo en tiempos de crisis». Miradas multidisciplinares para un mundo en igualdad. Ponencias de la I Reunión Científica sobre la Igualdad y Género, Coord. María Josefina Clavo Sebastián y Goicoechea María Ángeles. Logroño: Universidad de La Rioja, 2014, 205-215.

Floeck, Wilfried. «Entre locura y transgresión: el convento, lo imaginario y la brujería como espacios femeninos en el drama histórico español a finales del siglo XX». Transgression et folie dans les dramaturgies féminines hispaniques contemporaines. Ed. Emmanuelle Garnier / Roswita. Carnières-Morlanwelz (Bélgica): Lansman Éditeur, 2007, 21-36.

Floeck, Wilfried, Herbert Fritz y Ana García Martínez. Dramaturgias femeninas en el teatro español contemporáneo: entre pasado y presente. Hildesheim, Alemania: Olms, 2008.

García Pascual, Raquel (ed.). Dramaturgas españolas en la escena actual. Madrid: Castalia, 2011.

Garnier, E. / Roswita. Transgression et folie dans les dramaturgies féminines hispaniques contemporaines. Carnières-Morlanwelz (Bélgica): Lansman Éditeur, 2007.

Gutiérrez Carbajo, Francisco (ed.). Dramaturgas del siglo XXI. Madrid: Cátedra, 2014.

López Mozo, Jerónimo. «Mapa del teatro documento en los albores del siglo XXI en España». El teatro como documento artístico, histórico y cultural, en los inicios del siglo XXI. Ed. José Romera Castillo. Madrid: Verbum, 2017, 23-41.

Luque, Diana Isabel. «Reflexiones sobre la dramaturgia emergente en España: visibilidad y supervivencia en el contexto de las crisis actuales (más una nómina de jóvenes dramaturgos españoles». Creadores jóvenes en el ámbito teatral (20+13=33). Ed. José Romera Castillo. Madrid: Verbum, 2014, 34-53.

Manola, Giovanna. «Lola Blasco Mena y María Velasco: la escena da nueva voz a la historia contemporánea y a sus personajes». Creadores jóvenes en el ámbito teatral (20+13=33). Ed. José Romera Castillo. Madrid: Verbum, 2014, 106-120.

Jódar Peinado, María del Pilar. Metateatro español: estudio del concepto y de su presencia en cien textos teatrales de los siglos XX y XXI. (Tesis Doctoral). Dir. Emilio de Miguel Martínez. Salamanca: Universidad, 2016. http://hdl.handle. net/10366/128346, consultado el 15-05-2017.

Jódar Peinado, María del Pilar. Metateatro español en el umbral del siglo XXI: el mundo del teatro y el teatro del mundo. Madrid: Academia de las Artes Escénicas de España. UNIR (Universidad Internacional de La Rioja), 2016. También en <http://academiadelasartesescenicas.es/revista/13/ 
ii-premio-de-investigacion-de-la-academia-metateatro-espanol-en-el-umbraldel-siglo-xxi/>, consultado el 15-06-2017.

Jódar Peinado, María del Pilar. «El metateatro como testimonio del quehacer dramatúrgico y escénico en siete textos teatrales del siglo XXI». El teatro como documento artístico, histórico y cultural, en los inicios del siglo XXI. Ed. José Romera Castillo. Madrid: Verbum, 2017, 230-241.

Oliva, César. «Informe básico sobre la escena española en el siglo XXI». Los cuadernos de Thalía. Perspectivas del teatro español actual. Ed. Emilio de Miguel Martínez. Gijón: Cátedra Miguel Delibes. Libros del Pexe, 2006, 45-66.

Pérez Rasilla, Eduardo. "Breve entrevista a una serie de dramaturgos emergentes. Entrevista con Lola Blasco». Don Galán. Revista de investigación teatral 2, 2012. <http://teatro.es/contenidos/donGalan/donGalanNum2/video. php?vol=2\&doc=3_4>, consultado el 15-06-2017.

Pérez Rasilla, Eduardo. «Notas sobre la dramaturgia emergente en España». Don Galán. Revista de investigación teatral 2 (2012). <http://teatro.es/contenidos/ donGalan/donGalanNum2/pagina.php?vol=2\&doc=1_6\&pag=1 >, consultado el 15-16-2017.

Pérez Rasilla, Eduardo. «Siete textos breves de siete dramaturgas jóvenes. Imágenes de una sociedad violenta». Acotaciones 8 (2012): 77-89 <http://www.resad.es/ acotaciones/acotaciones28/rasilla_teatrobrevejovenesescritoras.pdf>, consultado el 22-07-2017.

Romera Castillo, José. «Estado de la cuestión: siglos XX y XXI las dramaturgas y el SELITEN@T». En Pautas para la investigación del teatro español y sus puestas en escena, 381-411, Madrid: UNED, 2011.

Romera Castillo, José. «A tantas y a locas... de amar (Algunos ejemplos en la dramaturgia femenina actual)». En Transgression et folie dans les dramaturgies féminines hispaniques contemporaines. Ed. Emmanuelle Garnier / Roswita. Carnières-Morlanwelz (Bélgica): Lansman Éditeur, 2007, 21-36.

Romera Castillo, José (ed.). Dramaturgias femeninas en la segunda mitad del siglo XX. Madrid: Visor Libros, 2005.

Romera Castillo, José. El personaje teatral: la mujer en las dramaturgias masculinas en los inicios del siglo XXI. Madrid: Visor Libros, 2009.

Serrano, Virtudes. «El espacio y el tiempo de la mujer en la dramaturga femenina finisecular». Dramaturgias femeninas en la segunda mitad del siglo XX. Ed. José Romera Castillo. Madrid: Visor Libros, 2005, 95-108. 


\title{
DESMONTANDO CLICHÉS O LA EVOLUCIÓN DE LOS MODELOS DE FEMINIDAD Y MASCULINIDAD EN LOS ESCENARIOS
}

\author{
DEBUNKING CLICHÉS OR THE EVOLUTION OF MODELS OF \\ WOMANHOOD AND MANHOOD ON STAGE
}

\author{
Maribel MARTÍNEZ LÓPEZ \\ Universidad de La Rioja \\ maribel.martinez@unirioja.es \\ orcid 0000-0003-4466-1962
}

\section{Resumen}

El teatro puede ser entendido como un laboratorio de estudio de las inquietudes sociales de cada época y desde él se reflejan y se constatan unas realidades que representan a la sociedad en la cual los textos nacen. Pero a la vez, las obras dramáticas, desde el texto, pero especialmente desde su puesta en escena, ayudan a entender los conflictos que presentan y a avanzar en el camino que se quiere recorrer para su solución. En este sentido, en el teatro español actual descubrimos la presencia y la transformación de las identidades de género. Desde el acercamiento a algunos textos de autores españoles, descubriremos cómo los escenarios muestran los modelos de feminidad y de masculinidad vigentes, así como los pasos hacia la normalización social de las diferentes identidades sexuales. Un estudio comparado de las obras permite obtener un diagnóstico certero de la evolución de modelos en la sociedad de principios del siglo XXI.

Palabras clave: teatro español actual, identidad de género, feminidad y masculinidad, conflictos sociales.

\begin{abstract}
Theater plays can be understood as a laboratory of study of the social concerns belonging to each period and from it, some realities are both reflected and verified, which represent the society in which the texts are born. But at the same time, the dramatic works, from the very same text but especially from its staging, help understand the
\end{abstract}


conflicts they present and advance to carry on down the path that is necessary to go for its solution. In this sense, in the current Spanish theater, we discover the presence and the transformation of gender identities. From the approach to some texts by Spanish authors, we will discover how these stages show the female portray model and masculinity in force, as well as the steps towards the social normalization of the different sexual identities. A comparative study of the plays allows us to compile an accurate diagnosis of the models in society at the beginning of the 21st century.

Keywords: current spanish theater, gender identity, female portray model and masculinity, social conflicts. 


\section{TEATRO: PULSIONES SOCIALES}

Cuando estudiamos aspectos relacionados con la presencia y el tratamiento de cuestiones de género en el teatro español contemporáneo nos encontramos con un amplio muestrario de todas las fotografías sociales que conforman nuestro día a día y sobre las que se construye nuestra ideología, nuestros comportamientos y nuestra educación sentimental. En este sentido, el tratamiento de cuestiones de identidad de género está en relación con el planteamiento de las identidades así como con las conductas sociales de cualquier grupo. Por ello, la reflexión sobre las nuevas feminidades y las nuevas masculinidades no puede abstraerse de aspectos como las relaciones de pareja, la asunción de roles en la familia, la educación de los hijos, las relaciones interpersonales y, en este ámbito, el uso de las redes como forma de interacción social, así como otros múltiples factores que constituyen nuestra cotidianidad y se plantean en los textos teatrales.

El teatro actual refleja la evolución tanto en las identidades como en las normas y en las características de género que presentan los modelos actuales de masculinidad y feminidad en obras como Hojas de algún calendario ${ }^{1}$ y Whatsapp ${ }^{2}$, ambas de Juana Escabias, que escenifican las relaciones interpersonales a través de las redes; o trata problemas como el ciberacoso en textos como Mr Hitchcock vs Carolinal6, de Paco Bezerra, que presenta la extorsión de un hombre adulto a una chica adolescente. También en Etiopía, de Yolanda Dorado, se trata otro tema como el de la anorexia y el intento de suicidio de una adolescente cuya madre, profesional de éxito, trabaja tanto que no tiene tiempo para ver los problemas de su hija, planteando así la situación de esos

1. Hojas de algún calendario presenta a Raúl (19 años) y Rita (17) en un cibercafé. Él acude allí con el objetivo de conocer a gente. Ella va para chatear y escribirse con Capitán Lunar (que es Raúl). Cuando él le confiesa su identidad, ella se enfada porque prefiere que la relación entre ellos sea a través de la pantalla, donde todo es más fácil e idílico.

2. En Whatsapp JuanaEscabias presenta a una adolescente de 16 años que el día de su cumpleaños prefiere no salir a celebrarlo con sus amigas y chatear por whatsapp con su novio solo porque él, que no la trata muy bien, siente celos de que se divierta con ellas. 
hijos que tienen la vida que los padres han soñado para ellos, pero al mismo tiempo del precio que todos ellos, padres e hijos, pagan por alcanzarla ${ }^{3}$.

En lo relativo a los paradigmas de género, y dentro de ellos, a aspectos todavía controvertidos para la sociedad, como la identidad sexual o la intolerancia en las relaciones amorosas «no ortodoxas» en las que los roles se invierten, el texto dramático, por su concepción dialógica y su efecto espejo, es una importante herramienta didáctica y de lucha. En el texto y sobre el escenario se presentan los modelos y las formas de conducta que son producto, por un lado, de los cambios en la sociedad, pero al mismo tiempo aceleran el proceso incidiendo en los cambios de mentalidad del espectador o de la espectadora, en sus gustos y en sus formas de concebir el mundo y moverse por él.

\section{PRESENCIA Y TRATAMIENTO DE IDENTIDADES DE GÉNERO EN EL TEATRO. PASOS HACIA LA NORMALIZACIÓN SOCIAL DE LA HOMOSEXUALIDAD}

En la década de los 90, en España se produjo cierta visibilidad de la literatura homosexual tanto en lo referente al reconocimiento de los autores o a la presencia temática de esta realidad, como al apoyo de editoriales y premios a las publicaciones. Antes de esa época, la tendencia era o bien ignorar el tema de la homosexualidad o bien representarlo de forma negativa. En el campo teatral uno de los dramaturgos que trataron la temática gay fue Rafael Mendizábal, autor con grandes éxitos de taquilla en la década de los 80. En 1994 estrenó Feliz cumpleaños, señor ministro, texto que presentaba la homosexualidad y la transexualidad. Y en 2003 se estrenó su obra más importante sobre la homosexualidad: Madre amantísima, en la que ofrece una reflexión desde presupuestos ideológicos conservadores y burgueses sobre el conflicto que crea la homosexualidad para la sociedad.

Nos referiremosaquí a textos y espectáculos escritos y estrenados en España entre 2012 y 2017 que cuestionan los esquemas de roles, normas y características de género, en los que se presenta de manera natural o conflictiva la homosexualidad con el objeto de ayudar a su normalización en nuestra sociedad.

Comenzamos citando Mis padres no lo saben, una obra de teatro dirigida por Javier Corral en el año 2012 que, basada en el libro homónimo de Marce Rodríguez y Mariola Cubells, presenta a través de doce monólogos el difícil conflicto de reconocer la homosexualidad ante la familia y en el entorno social.

3. Hojas de algún calendario, Mr. Hitchcock vs Carolina16 y Etiopía están incluidas en la colección El tamaño no importa. Textos breves de aquí y de ahora, editada por la AAT. 
En ella se suben al escenario testimonios reales para mostrar fotografías de vidas de personas de carne y hueso que sufren porque su condición sexual les hace la existencia un poco más difícil que a otros ${ }^{4}$. Las historias reflejan que queda todavía mucho por hacer para la normalización de las diferentes identidades sexuales, cuya aceptación es necesaria para una transformación real de los roles de género.

Frente a este acercamiento a un conflicto real, La Vida es Bell@, espectáculo de Carlos De Matteis ${ }^{5}$, plantea una historia sobre el amor, la vida y la muerte en la cual se profundiza en la esencia del ser humano y sus sentimientos más profundos, y en la que el conflicto no reside en la identidad sexual. Basada en la obra teatral Los días contados, de Franklin Rodríguez, la puesta en escena de Carlos De Matteis presenta el mismo diálogo interpretado por tres parejas diferentes, una lesbiana, una gay y otra heterosexual, para mostrar que los conflictos del amor o del desamor y las relaciones de pareja no residen en la inclinación sexual de sus componentes, sino en sus identidades personales y en las relaciones entre personas, independientemente de sus sentimientos de género.

Por último, Cállate y bésame, también de Carlos De Matteis, plantea los conflictos de pareja entre Lola y Renata, cuya turbulenta relación muestra que no pueden estar juntas, pero tampoco separadas. Sus problemas de pareja no están vinculados con su orientación sexual, sino con sus relaciones interpersonales. Cállate y Bésamees una divertida comedia romántica que habla del amor, de los enredos en las relaciones de pareja y de la fidelidad, de cuántas maneras hay de ser infiel, y si debe perdonarse una infidelidad o si existe un manual para ser el perfecto amante. Se trata de un texto dramático que puede ser encarnado por una pareja gay o una heterosexual, defendiendo, desde la afirmación de rasgos individuales y no de paradigmas sociales, la lucha por la normalización y la libertad de identidad sexual, y la ruptura de características de género, así como de sus roles y normas.

\section{MODELOS DE FEMINIDAD Y MASCULINIDAD: AVANCES Y RETOS ${ }^{6}$}

Tras estos tres textos, reflejo real de un clima social y del deseo de avanzar en la lucha por la igualdad de género, vamos a centrarnos en el modo en el que el

4. Podemos encontrar información sobre este montaje en <http://mispadresnolosaben. blogspot.com.es/>.

5. Podemos encontrar información sobre este autor y director teatral argentino, y sus textos y montajes en <http://www.alternativateatral.com/persona39338-carlos-de-matteis>.

6. Los textos a los que me referiré en este apartado no están aún publicados aunque sí estrenados -excepto uno-. A través de la base de datos www.contextoteatral.es se accede 
teatro español contemporáneo ayuda a entender y a construir las feminidades y masculinidades, nuevas y tradicionales, en el siglo XXI.

En los textos dramáticos encontramos ya de forma habitual, incluso mayoritaria, protagonistas femeninas fuertes, racionales, emancipadas, mujeres activas y muy competentes personal y profesionalmente, junto a hombres que son ahora mucho más sensibles y espirituales, sin perder por esto ni ellas ni ellos otros rasgos definitorios de su género. Entre ambos sexos se establece, como vemos en los escenarios, una relación igualitaria, alternante, donde los valores, actitudes y características de ambos consiguen un equilibrio y se fortalecen mediante el intercambio en una fructífera relación de camaradería y amistad que no excluye una posible atracción física. Comportamientos y actitudes que antes parecían destinados a los varones, ahora se hacen extensibles a las mujeres y, en menos casos, se produce el fenómeno a la inversa ${ }^{7}$.

No obstante, la igualdad no se ha conseguido, pese a que sea indiscutible que se ha producido un cambio en los modelos de feminidad y masculinidad actuales respecto al siglo XX. Los datos económicos y laborales más actuales muestran que los antiguos roles de género todavía no han sido desterrados del mundo del trabajo y que la maternidad no ha dejado de ser aún uno de los principales motivos de abandono del mercado laboral. En estos años de crisis las estadísticas han reflejado una y otra vez que los hombres siguen acaparando los nuevos empleos, frente a la calidad del trabajo femenino cada vez más deteriorada, o que el porcentaje de hombres que piden excedencias para el cuidado de los hijos es casi inexistente. Todo ello supone una enorme presión para la mujer, como plantea en tono de comedia Mercé Sarriás Forner en Hazme una perdida (2014). Esta obra es un alegato en contra del concepto de superwoman, parejo a la emancipación laboral de la mujer, que se localiza y se dota de significados desde la década de los 90 del siglo XX y que cobra matices negativos en el siglo $\mathrm{XXI}^{8}$.

a una breve sinopsis de cada obra, además de que se facilita el poder contactar con los autores. En mi caso he tenido acceso a los textos gracias precisamente a la amabilidad de los dramaturgos que me los proporcionaron.

7. Ver «Algo se consigue», de Lourdes Ortiz, donde la autora reflexiona sobre ello a partir de varios ejemplos de populares series americanas de televisión.

8. Antes de que se conceptualizara ese rol, la historia y la literatura ofrecen muchos ejemplos de mujeres que han tenido que luchar para sobrevivir y para sacar a sus familias adelante, ocupando todo su tiempo en el trabajo. Así, por ejemplo, Alfredo Sanzol dedica su obra Delicadas a su abuela y las hermanas de esta. Delicadas es un título irónico porque trata de mujeres a las que no les dejaron serlo, pues les tocó vivir la guerra y la posguerra y eso les hizo ser fuertes, trabajando duramente para sacar a sus familias adelante. Fuera de la mirada social negativamente evaluadora del triunfo profesional de la mujer y el éxito de 
Hazme una perdida es una comedia en clave de musical, cargada de ironía, que cuenta las aventuras y desventuras de una mujer arquitecta que, intentando sobrevivir al trabajo y la familia, se despierta un día triplicada para poder sobrellevar la peor semana de su vida, en la que confluyen la ausencia de un marido fotógrafo en viaje laboral, el mal ambiente en el trabajo donde nadie entiende que haya pedido jornada reducida, y el cuidado de sus dos hijas pequeñas. Según indica la autora, la obra nace de un encargo de tres actrices que querían explicar su situación después del nacimiento de sus hijos, la dificultad de llevar una vida normal, sin agotamiento, ni descontrol, en un mundo que no está pensado para que la maternidad y la paternidad se vivan de manera relajada, y en el que las mujeres se han llevado la peor parte en su deseo de conciliar el cuidado de los hijos pequeños con la persecución de sus otros sueños.

Y yo que siempre pude con todo, porque me creí lo de la superwoman y pensé que realmente podía criar hijos, trabajar, realizarme y viajar y depilarme, todo al cien por cien, peté. Peté totalmente. Y en la explosión salí convertida en tres. Me tripliqué. Eso sí, mi vida se fue al carajo igual. (2-3)

A lo largo de quince escenas, tres actrices, que representan a una misma protagonista y a la vez encarnan todos los personajes de la obra, reproducen momentos cotidianos reconocibles para la mayoría de los espectadores: desde el ajetreo en los desayunos cualquier día laboral hasta la dependencia de niños y madres del ibuprofeno infantil como solución para casi todo; la lucha contra los piojos en el momento más intempestivo; la inoportuna llamada del colegio en mitad de una importante reunión de trabajo; la frecuencia y facilidad del marido para realizar sus viajes por trabajo y sus negativas consecuencias para la mujer, permanente e injustamente recriminada y ninguneada por el jefe, incluso cuando se le reconoce su alta cualificación y competencia profesional; la espera diaria para acostar a los hijos y seguir trabajando un poquito más; la necesidad de abuelas canguro para cumplir las exigencias del trabajo... Y, en definitiva, las dificultades para las mujeres de armonizar la vida laboral con la familiar y la casi imposibilidad de conciliar el éxito profesional con la satisfacción maternal para la mayoría:

Es mentira, pero en el trabajo conviene no decir nunca que vas a hacer algo relacionado con el hecho de que eres madre. Es muchísimo mejor decir que eres tú la que tienes la gripe, que confesar que tu hija está enferma y tienes que cuidarla. Así se preocupan por tu salud y te consideran una profesional cualificada con gripe, no una madre abnegada y flojeras que prefiere quedarse a sacarle los mocos a su hija que ir a trabajar. (23)

la conciliación familiar, que responde a ese rol de superwoman, no existe la satisfacción o la frustración que el intentar serlo lleva aparejado. 
La conclusión de la obra es el despido de la protagonista, y que se siente sola y con ganas de abandonar, pero no lo hará, se levantará de la caída y se reinventará para luchar hasta vencer, por ella y por sus hijas.

La obra de Mercé Sarriás muestra el nuevo modelo de familia, en el cual la mujer, ahora liberada de su subordinación al marido, trabaja, triunfa y es independiente económicamente. Sin embargo, sabemos que a pesar de todo ello es, con excepciones, el modelo que menos ha cambiado en las últimas décadas, pues la mayor parte de las obligaciones y responsabilidades domésticas siguen recayendo sobre la mujer, y porque el conflicto de la conciliación laboral y familiar sigue siendo una cuestión casi exclusivamente femenina.

En la misma línea nos sitúa la obra Femenino singular, espectáculo coral de Inconstantes Teatro (2015) escrito por sus propios intérpretes: cuatro actrices y un actor. La obra, que escenifica las dificultades cotidianas de las cuatro mujeres, es una comedia sobre la vida que pretende reflexionar sobre las mujeres hoy, desde sí mismas, con los hombres como telón de fondo. Transcurre durante una noche en la que ellas se han liberado de sus responsabilidades familiares y las han delegado momentáneamente en sus parejas, exparejas, abuelos o hermanos, con la precaución de haberles dejado todo preparado y con las instrucciones bien detalladas. Las mujeres han decidido hacer un encuentro entre viejas amigas, con la peculiaridad de que este se va a realizar en un teatro. Allí resulta ser espectador inesperado un técnico de sonido que, de alguna manera, comparte el recorrido de las cuatro mujeres, un tipo que las observa mientras ellas cuentan sus partos, sus relaciones, sus separaciones, sus terapias de pareja, su felicidad, sus infidelidades, sus sueños y sus ilusiones rotas, y que parece esperar pacientemente su turno para contar también su historia9.

Muy interesante es el texto Cama, de Pilar G. Almansa $(2015)^{10}$, una obra cargada de resonancias líricas que presenta la historia de una pareja desde sus primeras citas hasta su divorcio, con custodia compartida del hijo tenido en común. Como señala la autora, su objetivo es explorar los diferentes estadios emocionales dentro de la relación de una pareja de hoy en día que, sin quererlo, reproduce la dinámica de una pareja tradicional, pasando del apasionado enamoramiento inicial al sentimiento de decepción final. Se muestra, desde la perspectiva de las implicaciones que el feminismo tiene actualmente en las relaciones amorosas, el paso de una relación sin compromisos a la adquisición de las obligaciones dentro de la organización cotidiana de una familia con

9. Información sobre este montaje en <http://joomlal.inconstantes.com/index. php?option=com_content\&view=article\&id $=51 \&$ Itemid $=81>$.

10. En 2016 la obra recibió el primer premio en el III Certamen de Nuevos Dramaturgos Lanau Escénica. 
hijos, en la cual los dos miembros de la pareja trabajan. Pilar G. Almansa logra presentar de manera poética a la vez que totalmente realista cómo se ocultan los micromachismos en relaciones de aparente igualdad de género:

ELLA.- ¿Estará ya la lavadora?

ÉL.- ¿No tenías que ponerla tú?

ELLA.- ¿No quedamos en que yo bajaba a comprar lo de la pasta mientras tú ponías la lavadora?

ÉL.- (Bailando.) ¿No quedamos en que yo haría que te sintieras viva?

ELLA.- (Sin bailar.) Necesitaba esa falda para mañana, joder...

ÉL.- $i$ Te acuerdas de que en la hoja de ruta, yo me encargaba del paisaje? ¿De que nunca habría nubes, porque no te gustan los cumulonimbos?

ELLA.- Si la pongo ahora, igual le da tiempo...

ÉL.- ¿Te acuerdas de la oxitocina, de todas las hojas que nunca han caído de ninguno de los árboles que simplemente hemos esbozado? ¿Te acuerdas de tus cenizas y las mías?

ELLA.-Ahora no...

EL.- ¿Cuánto tiempo hace que no te limpias la cerilla de los oídos? ¿Hay alguna pista que me indique cómo se encuentran tus sinapsis? ¿Has visto lo simpáticos que se ponen mis bíceps cuando te huelen? ¿Apagas tus los terremotos internacionales o los apago yo? (pausa.) ¿Ya no quieres acordarte de lo que va a suceder?

Ella.- Lo que va a suceder es que como no consiga mañana ese trabajo, no podremos seguir pagando...

Pausa. Suena el llanto de un bebé.

ÉL.- ¿Te acuerdas de que siempre me querrás? ¿De que hace mil segundos solo uno? ¿De pasta, miedo, estrellas, aguarrás?

Ella.- Desde hace dos segundos, solo uno, te quiero, pero ya no puedo más. (25)

Si en Cama, Hazme una perdida y Femenino singular las protagonistas son las mujeres que encarnan el nuevo modelo de feminidad predominante tras el que se dibuja el paradigma de masculinidad, en otras obras encontramos planteamientos desde protagonistas masculinos, con el resultado del cuestionamiento de los rasgos psicológicos y las normas de género atribuidas tradicionalmente al hombre y que todavía hoy es necesario combatir.

El dramaturgo y actor Alejandro Butrón en Ser un hombre (2017) plantea una reflexión, en clave de humor negro, sobre el concepto de virilidad y sobre todos aquellos supuestos que se adhieren al género masculino desde la infancia, y también, especialmente, sobre la educación y el machismo, así como sobre las críticas antifeministas enunciadas por parte de un sector que se escuda en creer en la igualdad de género y no en feminismos y del que salen en ocasiones ideas sobre el hembrismo o las feminazis. La obra relata la relación de Pepe con su hijo Jorge, que se encuentra en plena pubertad, y del que espera que sea futbolista 
profesional y que se comporte como «un verdadero hombre», siguiendo el mismo esquema en el que Pepe fue educado por su padre y teniendo en cuenta también el ejemplo que ve en casa. Pepe, que perdió su virginidad obligado por su padre en un prostíbulo, se reafirma constantemente como macho. Está dispuesto a enderezar cuanto antes el camino de su hijo, cuya masculinidad es puesta en duda por los amigos de Pepe, como ya le sucediera a él mismo de adolescente con esos mismos amigos a raíz de una anécdota ambigua. En una escena que presenta un flashback de Pepe con quince años, la acotación resume la acción: «Pepe y Luis forcejean y se revuelcan en el suelo, riendo. Finalmente, queda uno sobre el otro. Se miran. Dejan de reír. Se besan. Al cabo de unos segundos, Luis, agitado, se separa de Pepe y se marcha. Pepe queda solo, turbado» (38).

Junto a Pepe, de manera sumisa, aparece María, con la que se casó apresuradamente y cuando apenas se conocían, porque ella se quedó embarazada. Y también de soslayo está el personaje de Silvia, la hija de seis años a la que se educa de manera diferente a Jorge, y con la cual el padre mantiene una canónica conversación sobre la malignidad perpetuada de la mujer desde el pecado de Eva y la manzana. El texto recorre el pensamiento del protagonista para cuestionar qué hace a Pepe pensar de la forma en que lo hace. Jorge, el hijo, se niega a seguir el modelo del padre y se muestra orgulloso de no parecerse a él. Pero tanto Pepe como Jorge son víctimas de un modelo de masculinidad que les asfixia. La obra, en esta concepción de la literatura como espejo de las pulsiones sociales, se escribe desde la emergencia de valores igualitarios que exigen la ruptura de moldes y patrones discriminatorios heredados y la creación de alternativas más acordes con la sociedad actual.

Un segundo ejemplo de lucha por el avance en los modelos de masculinidad trata la presencia todavía hoy de roles machistas encarnados por un personaje tan idealizado como nuestro famoso don Juan Tenorio, que Maykol Hernández reinventa en Desmontando a don Juan (2011) con el objetivo de criticar su ultrajante comportamiento hacia la mujer. La obra presenta al don Juan Tenorio de Tirso de Molina enfrentado en un juicio con el don Juan Tenorio de José Zorrilla. El primero (condenado al infierno en la obra del siglo XVII) decide denunciar a la Justicia Divina por considerar un fraude la sentencia a favor del segundo (cuya alma se salva gracias al amor de doña Inés en la obra del siglo XIX), argumentando que ambos merecen el mismo castigo tras haber llevado la misma vida disoluta. Así pues, ambos personajes, acompañados de sus respectivas enamoradas doña Ana y doña Inés, se ven las caras en un nuevo juicio en el que se rechaza la violencia machista y se desmonta el romántico 
mito del donjuanismo, contra el que argumenta vehementemente la protagonista femenina de la obra de Tirso:

Si perdonamos su conducta simplemente por haberse enamorado de vos o por pedir disculpas justo antes de morir, estamos abriendo una puerta para que todo aquel que decida burlar, ultrajar, o incluso golpear a una mujer, pueda ser absuelto ante este tribunal y rehuir así el castigo que se merece.(23)

[...] ni amando ni sin amor, ningún agravio, violación o agresión debe quedar impune.(24)

En esta parodia, el Divino Juez dicta sentencia a favor de los desenlaces ya elegidos por los autores de ambas obras, si bien concluye que

[...] ambos destinos son inamovibles ya que [...] son personajes que pertenecen al universo literario [...] No obstante, sirva esta farsa para que todos los presentes condenemos el comportamiento de los donjuanes de carne y hueso que solo tratan de probar su virilidad y atractivo.(28)

\section{MUJERES FUERTES / HOMBRES SENSIBLES}

Otro mito se desmonta en Nueve mujeres infieles, obra de Juana Escabias (2013) que propone una revisión de la infidelidad femenina desde una perspectiva que huye de toda crítica moralista. Las protagonistas, insatisfechas con sus relaciones de pareja, buscan el amor en otros hombres como escape previo a poner fin al lastre de sus vidas e iniciar una existencia nueva ${ }^{11}$. Hasta ahora el hombre era el personaje infiel y la esposa tenía que resignarse ante una situación aceptada por la sociedad. Pero en esta obra la mujer es un personaje dinámico y seguro que engaña a su pareja con otros hombres para sentirse liberada de toda opresión o infelicidad. Nueve mujeres infieles está compuesta por trece escenas independientes, algunas relacionadas entre sí, que abordan el tema de la infidelidad femenina desde perspectivas unas veces cómicas y otras dramáticas y crueles. Así, nos encontramos con la esposa que se acuesta con el hermano de su marido; con la que, siendo ella la infiel, echa a su marido de casa y se queda con todo (bienes materiales, pensión y custodia de los niños),

11. Juan Escabias planteó este tema igualmente en su libro de relatos Adúlteras. En otra obra, Crimen imperfecto, recogida en la colección Cuatro obras políticamente incorrectas, esta misma autora presenta el monólogo de una mujer que se justifica a sí misma, torturándose, porque salió corriendo de casa con sus dos hijas y no despertó a su marido cuando en mitad de la noche la avisaron de que había un escape de gas y debían abandonar el edificio de inmediato. Tuvo varias oportunidades de salvarle y no lo hizo, acogiéndose a una excusa diferente cada vez, todas triviales. Su estado de nerviosismo la lleva a ser tratada por los psicólogos, que creen que no acepta la realidad, pero lo cierto es que la muerte de él ha sido toda una liberación para ella. 
y aun así se siente la víctima de la situación; con la amante que, cansada de serlo, llama a la esposa cornuda para que descubra a su marido con ella en la habitación del hotel donde se encuentran; con la que acude a un intercambio de pareja anónimo mientras su marido se queda en casa con los niños para que ella haga un recado; con la que fue casada sin amor, empujada por sus padres, y acaba siendo asesinada cuando su marido descubre que le es infiel; y otros ejemplos que presentan un variado muestrario de situaciones.

Estas protagonistas representan mujeres de edades, condiciones sociales e intereses personales diferentes, pero que comparten el mismo deseo de alcanzar unos derechos irrenunciables: la independencia económica, el desarrollo profesional y la libertad de movimiento y pensamiento. Su autorrealización personal está vinculada, según la propia autora, con una interacción sobre su entorno cargada de elementos ideológicos progresistas, que tiene como finalidad la revisión de los tradicionales modelos patriarcales y el deseo de derribarlos. Desde esa concepción de la mujer, y del papel de la misma en la sociedad y en el teatro, estas protagonistas son definidas por Juana Escabias como «malas», entendiendo por tal el ser transgresoras, a veces mujeres defensivas, incluso agresivas si es necesario, como respuesta a la hostilidad de un entorno en el que siguen siendo el «segundo sexo» (Escabias 2014, 219-228) ${ }^{12}$.

Si por un lado se presenta la evolución del paradigma femenino en su aspecto moral, por otro, a través de tres generaciones, Juana Escabias en Interiores (obra estrenada en 2008) muestra la contraposición entre modelos de mujer vanguardista y otros caducos, resaltando la repetición de ciertos esquemas emocionales. En Interiores el conflicto se plantea en tres actos divididos en varias secuencias. Los personajes son tres mujeres (Carla -madre-, María -su hija- y Carla -hija de María-) y tres hombres (Fernando -ex marido de María-, Miguel -marido de la joven Carla-y Santiago -padre de Miguel-). El acto primero nos sitúa en la década de mil novecientos sesenta, y en él vemos a Carla, nacida en los años cuarenta y modelo de buena mujer según los cánones de esa época, recién abandonada por su marido y con una hija de once años, María. Carla es víctima de una educación que le ha enseñado a tener miedo a la independencia y que la ha preparado para el matrimonio y, dentro de él, para que su marido e hija alcancen una autorrealización que ella nunca logrará:

Yo tenía preparada la maleta, escondida debajo de la cama, la tomé y salí a la calle, hacia el autobús de línea. Temblaba de expectación, iba a conocer el mundo, sería libre. No subí al autocar, me quedé en la esquina, observando

12. Para un acercamiento previo a la lectura de los sketches que configuran Nueve mujeres infieles, ver la reseña a la obra de Teruel Martínez. 
la parada. Sentí miedo. ¿Sería capaz de administrar mi propia vida? [...] Durante un tiempo dejé de tener sueños, nadie se percató. (Pausa). Cuando papá enfermó vinimos a vivir a la ciudad. Era maravilloso, coches, tranvías, riadas de gente, ruidos, tiendas... Yo ya tenía veinticuatro años. Me gustaba ir al trabajo, era el único momento en que podía conversar con otros seres humanos sin tener que preocuparme de que alguna amenaza cayera sobre mi honra. Era la dependienta más eficiente de todas, luego regresaba a casa y la vida continuaba siendo una prisión. [...] Creí que casándome escaparía de aquella falta de movimiento, de ese letargo que devoraba mis días. A veces pienso que mi vida no ha sido más que un muro frente a mí. (53-54)

Tras su separación, aparece un antiguo pretendiente con quien puede empezar una nueva vida, pero el rechazo de María, que no quiere compartir a su madre con nadie, hace que se aleje de él. En el mismo acto, en un salto temporal, años más tarde y con María adulta, la relación entre ambas es conflictiva, y la hija hará su vida sin agradecer a Carla su total entrega durante tantos años, «ejemplificando lo que la vida depara como pago a quienes sacrifican su felicidad por complacer a los demás»(Escabias 2014, 224).

No me trates como a una niña, tengo treinta y un años. [...] Esta mañana he alquilado un apartamento, mamá. Me marcho de casa. Necesito hacer mi vida, tienes que comprenderlo. [...] Compórtate como una adulta. Baja a la realidad. (Pausa). Probablemente me case en el verano. Antonio y yo lo hemos planificado todo en Nueva York. Ya conocerás a Antonio, te lo presentaré mañana mismo. [...] Hemos decidido que viviremos solos. Tú te vales por ti misma, cocinas, te desenvuelves... ¡Eres independiente! [...] No me mires con esa cara, si no te casaste con Eduardo fue porque no querías.(62)

Madre e hija componen una dualidad enfrentada de forma irremediable. El personaje de María se contrapone al de su madre, reclamando su proyección personal como derecho que cree le corresponde por nacimiento y anteponiendo su vida pública y profesional a las obligaciones familiares.

El acto segundo transcurre en la década de mil novecientos noventa. Aquí María es una mujer que amaba a su marido de una forma dependiente y posesiva, ahora separada de él, con una hija adolescente y una mala relación con su ex marido, y que chatea con hombres a través de la red para llenar su soledad. A lo largo del acto también se irán sucediendo los saltos temporales, a través de los cuales se mostrará la relación conflictiva entre madre e hija, y entre esta y su padre.

El acto tercero transcurre ya en el siglo XXI. La joven Carla acaba de ser madre. Aquí la voz protagonista es la de su pareja, Miguel, que con veintiocho años y un bebé recién salido del hospital, proyecta en su hijo la relación que él ha tenido con su padre. El progresista Miguel se niega a que su hijo conozca a Santiago, su abuelo paterno, porque, tras muchos años de matrimonio, este ha 
abandonado a su mujer por otro hombre. Santiago aparece e intenta explicar a su hijo cómo sacrificó su vida por no defraudar a su familia y cómo luego, por sus hijos y por respeto a su esposa, que sabía toda la verdad, necesitó vivir guardando las apariencias. Miguel le asegura que su rechazo se debe a que haya vivido una mentira toda su vida y no a su homosexualidad, pero un comentario irónico de Santiago sobre su homosexualidad y el bebé provoca la angustia de Miguel, que cierra la obra preguntando entre sollozos «No me engañes, dímelo, ¿también será maricón?» (85).

SANTIAGO.- (Observa a su nieto). Este niño está mirándome con complicidad. Parece que se alegra de que su abuelo sea ma-ri-ca. (Estupor de Miguel, que se asoma al cochecito para examinar a su hijo). Compruébalo por ti mismo, está haciéndome guiños.

Miguel.-(Observa al bebé. Solloza). ¿Crees que será maricón?

SANTIAGO.- No te lo tomes en serio, hijo mío, ha sido una chiquillada por mi parte.

MigueL.- Míralo bien. Sé sincero. Tú entiendes de esas cosas. ¿Tiene ojos de maricón?

SANTIAGO.- (Iniciando su salida de escena). Solo era una broma, vamos, tranquilízate.

Miguel.- (Persigue a su padre, que huye). Vamos, dime la verdad. ¿Crees que será maricón? Míralo bien. (84-85)

Como en Ser un hombre, la obra de Alejandro Butrón, pero también como en las otras donde la figura del varón aparece en un plano de mayor igualdad entre ambos sexos, Juana Escabias ofrece aquí la visión de que, si bien socialmente se ha avanzado en el camino por la emancipación femenina y en el lugar que ocupa la mujer en la sociedad, sin embargo queda todavía mucho por hacer para cambiar los patrones masculinos, cuyo pensamiento social y, sobre todo, cuya evolución emocional, se mantienen en un estadio arcaico.

Vamos a referirnos, por último, a la transformación de las identidades de género a través de un argumento que trata sobre la superación del dolor provocado por el desamor y abordado sin prejuicios desde distintas formas de amar y desde la desestructuración del mito del amor romántico. Lo hace el dramaturgo Alfredo Sanzol en su comedia La respiración (2016), una metáfora del bienestar emocional que ofrece diferentes perspectivas del amor a través de seis personajes enamorados los unos de los otros. Esta obra, escrita como autoterapia a partir de la separación real del autor de su pareja, con la que tenía un hijo, habla del amor en diferentes edades, de una manera intergeneracional, y lo hace mediante el acercamiento a diferentes tipos de relaciones, todas ellas poco ortodoxas. La obra escenifica cómo Nagore, la protagonista divorciada hace un año y con una hija pequeña, se reinventa en su necesidad de recuperar 
la respiración calmada, y con ella la autoestima que perdió al separarse. Incapaz de asumir su nueva situación, al principio su respiración es siempre ansiosa y a menudo se desmaya (cita 1) hasta que logra aceptar su nueva realidad (cita 2):

(CITA 1) NAGORE.- [...] ese hueco, ese silencio en el que solo me oigo a mí misma con la respiración ansiosa, entrecortada, es el reflejo exacto de cómo me encuentro. Soy una especie de náufraga en mi propia cama.(18)

(CITA 2) NAGORE.- [...] Os quiero agradecer muchísimo todo lo que me habéis hecho disfrutar durante esta fantasía, y es perfecto que se acabe. Las cosas no pueden durar siempre, aunque algunas veces nos gustaría.(155)

El espacio en el que todo transcurre es la casa de Nagore, porque toda la historia es, en realidad, una fantasía imaginada por ella a partir de un consejo que le da su madre: la ficción es el mejor entrenamiento para la realidad. Los personajes son tres hombres y tres mujeres. Los masculinos son sensibles emocionalmente y tienen oficios relacionados con la salud (Andoni es profesor de yoga; Íñigo es fisioterapeuta, y Mikel es preparador físico), y los femeninos están liberados sexualmente y sus trabajos pertenecen al ámbito de la justicia (Maite es una jueza jubilada, Nagore es una abogada de familia y Leire está recién licenciada en derecho). En tono amable, el texto reflexiona sobre el carácter incierto, posesivo $\mathrm{y}$, muchas veces, también caprichoso del amor, y la necesidad de quienes han sufrido un desengaño o una ruptura amorosa de adaptarse a la nueva situación ${ }^{13}$ :

LEIRE.- ¿Cuál es el problema aquí? (Pausa). ¿Que nos queremos los tres? $¿$ Ese es el problema? ¿Que yo os quiero a vosotros tres y que vosotros tres me queréis a mí? ¿Que Maite os quiere a los tres y los tres queréis a Maite? ¿Ese es el problema? (122)

En esta obra se anulan los patrones de feminidad y de masculinidad (lo cual es ya un rasgo de la evolución de los modelos anteriores), pues el objetivo es explorar la construcción de la autoestima en torno al amor y reflexionar sobre las relaciones amorosas sin distinción de género o de sexo. Al igual que en las primeras obras a las que nos referimos arriba, protagonizadas por personajes homosexuales, La respiración ofrece un muestrario de emociones en el que los rasgos psicológicos de cada personaje y su percepción o sus necesidades afectivas dentro de las relaciones interpersonales nada tienen que ver con patrones sociales de género, sino que dependen de la identidad individual de cada uno.

Otras de las obras que hemos comentado, sin embargo, sí se centran en los modelos de feminidad y masculinidad vigentes. En aquellas que se construyen

13. Ver reflexiones del autor sobre el proceso de creación y el significado de la obra en varias entrevistas en prensa con referencia en la bibliografía final. 
en torno al rol de la mujer madre o de la mujer trabajadora, se perciben los cambios de ambos paradigmas en el siglo XXI, dejando constancia a la vez del camino que todavía queda por recorrer. Respecto al rol masculino y sus normas de conducta social, se incide en que todavía parecen requerir importantes esfuerzos para su evolución.

En conclusión, el teatro lleva a escena personajes y argumentos con los que busca ofrecer un nuevo marco conceptual donde puede ser explorado lo femenino y lo masculino en su condición histórico-cultural. En las obras aludidas, los autores presentan a personajes, la mayoría de ellos héroes y heroínas vanguardistas; otros, por el contrario, antagonistas de los nuevos modelos y paradigmas, que actúan como espejos de la realidad que pretenden transformar para lograr, a través de la contraposición, que su mensaje cale en el receptor. En cierto modo, todas esas obras realizan pequeños análisis y su estudio comparado permite obtener un diagnóstico certero de las preocupaciones e inquietudes vitales y sociales latentes en la sociedad de principios del siglo XXI.

\section{REFERENCIAS BIBLIOGRÁFICAS}

AA.VV. El tamaño no importa (18). Textos breves de aquí y de ahora. Madrid: Asociación de Autores de Teatro, 2011.

Bravo, Julio. "Alfredo Sanzol estrena en La Abadía La respiración, una comedia romántica terapéutica».ABC Cultura, 14 de enero de 2016. <http://www.abc. es/cultura/teatros/abci-alfredo-sanzol-estrena-abadia-respiracion-comedia-romantica-terapeutica-201601142044_noticia.html>, consultado el 20-10-2017.

Butrón, Alejandro. Ser un hombre, inédito. Documento recibido del propio autor a través de <http://www.contextoteatral.es/serunhombre.html>, consultado el 20-10-2017. Año de escritura: 2017.

Corral, Javier. Mis padres no lo saben. Montaje teatral.<http://mispadresnolosaben. blogspot.com.es/>, consultado el 20-10-2017.

Escabias, Juana. Interiores. Madrid: Huerga y Fierro editores, 2010.

Escabias, Juana. Nueve mujeres infieles. Madrid: Ediciones Irreverentes, 2011.

Escabias, Juana. «Malas y más que malas, por supuesto: Breve alegato sobre la necesidad de ir contra corriente». Malas. Eds. Margarita Almela, María García Lorenzo y Helena Guzmán. Madrid: UNED, 2014. 219-228.

Escabias, Juana. Cuatro obras políticamente incorrectas. Madrid: Esperpento ediciones, 2015.

G. Almansa, Pilar. Cama, inédito. Documento recibido de la propia autora a través de < http://www.contextoteatral.es/pilargalmansa.html>, consultado el 20-102017. Año de escritura: 2015. 
Hernández, Maykol. Desmontando a don Juan, inédito. Documento recibido del propio autor a través de <http://www.contextoteatral.es/desmontandoadonjuan.html>, consultado el 20-10-2017. Año de escritura: 2011.

Matteis, Carlos de. La Vida es Bell@. Montaje teatral. <http://www.alternativateatral. com/persona39338-carlos-de-matteis>, consultado el 20-10-2017.

Matteis, Carlos de. Cállate y bésame. Montaje teatral. <http://www.alternativateatral.com/persona39338-carlos-de-matteis>, consultado el 20-10-2017.

Ortiz, Lourdes. «Algo se consigue». Malas. Eds. Margarita Almela, María García Lorenzo y Helena Guzmán. Madrid: UNED, 2014, 485-494.

Resino de Ron, Carmen. «Buenas y malas». Malas. Eds. Margarita Almela, María García Lorenzo y Helena Guzmán. Madrid: UNED, 2014, 495-498.

Rodríguez, Marce y Mariola Cubells. Mis padres no lo saben. Barcelona: Plaza\&Janés, 2009.

Sanzol, Alfredo. La respiración. Madrid: Ediciones Antígona, 2016.

Sarriás Forner, Mercedes. Hazme una perdida, inédito. Documento recibido de la propia autora a través de <http://www.contextoteatral.es/hazmeunaperdida. html>, consultado el 2-06-2017. Año de escritura: 2014.

Teruel Martínez, Susana. «Mujeres infieles». El Kiosko teatral. De aquí y de ahora. Teatro Español Contemporáneo, n. ${ }^{\circ}$ VI. <http://www.aat.es/elkioscoteatral/ leer-teatro/leer-teatro-6-sumario/no-6-de-aqui-y-de-ahora-1-6-teatro-espanolcontemporaneo/>, s.a., consultado el 2-06-2017.

Valle, Emilio de, Jorge Muñoz, Marta Belenguer, Rosa Manteiga, Carolina Solas y María Vázquez. Femenino singular. Montaje teatral. <http://joomlal.inconstantes.com/index.php?option=com_content\&view=article $\&$ id $=51 \&$ Itemid=8>, consultado el 20-10-2017.

Vicente, Álvaro. «La Respiración de Alfredo Sánzol. Entrevista».Godot 60, añoVII (2016): 22-24. <http://www.escenagodot.com/entrevistas/80-La-Respiracinde-Alfredo-Sanzol>, consultado el 2-06-2017.

Vila, José-Miguel. «La respiración y la adversidad. Reseña». Diariocrítico.com, 28 de enero de 2016. <https://www.diariocritico.com/la-respiracion-alfredo-sanzol>, consultado el 2-06-2017. 



\title{
STRAWBERRY JAM AND ROASTED CHICKEN: GENDER, CORPOREALITY, AND IDENTITY FORMATION IN MARILÓ SECO'S MERMELADA DE FRESA (1999)
}

\author{
MERMELADA DE FRESA Y POLLO AL HORNO: GÉNERO, \\ CUERPO E IDENTIDAD EN MERMELADA DE FRESA, DE \\ MARILÓ SECO (1999)
}

\author{
Nina NAMASTE \\ Elon University, North Carolina \\ nnamaste@elon.edu \\ orcid.org/0000-0003-3694-2019
}

\begin{abstract}
Mariló Seco's one-act play, Mermelada de fresa (1999), employs particular items of food to portray the difficulties that can arise in the process of navigating both society's and an individual's expectations. Generational differences about the role of women, plus the mix of traditional and contemporary values in 1990s Spanish society create an overabundance of behavioral expectations for Ella. Her coping mechanisms, displayed by the strawberry jam ritual, turn out to be dysfunctional because she focuses only on the physical representation of the female role (beauty, sexual activity) to the detriment of the psychological self. The contested roasted chicken echoes men's consumption of women because it represents another commodity or object of gratification for the men. Culinary imagery and metaphors in Mermelada de fresa expose the mounting demands and complexity in satisfying an escalating number of often contradictory roles that exist for any individual, but particularly for women, in a pluralistic society.
\end{abstract}

Keywords: gender identity, culinary imagery, social expectations, corporeality, role conflict. 


\section{Resumen}

La obra de teatro de un acto Mermelada de fresa (1999), de Mariló Seco, específicamente usa comida para representar las dificultades que pueden resultar del proceso de navegar las expectativas sociales e individuales. Diferencias generacionales sobre el rol de las mujeres, más una combinación de valores tradicionales y contemporáneos en la sociedad española de los años 90 , crean una abundancia de expectativas para la protagonista, Ella. Sus maneras de lidiar con los problemas, ejemplificadas por su ritual de mermelada de fresa, resultan ser inefectivas porque solo se enfocan en el aspecto físico del rol de ser mujer (belleza, relaciones sexuales, etc.), lo cual perjudica su estado mental. El pollo al horno representa el consumo masculino, figurativo y literal, de mujeres, ya que es otro objeto de gratificación. La comida y las metáforas de consumo en Mermelada de fresa exponen las dificultades para cumplir las normas sociales, roles y expectativas, que son frecuentemente contradictorias para cualquier individuo, pero particularmente para las mujeres, en una sociedad plural.

Palabras clave: identidad, comida, expectativas sociales, cuerpo, conflicto. 
The «nutritional arts,» to use Michel de Certeau's term, form a nexus of the complex social and cultural issues related to food, eating, and cooking. These arts encompass the physical, physiological, and affective activities related to production (shopping, cooking, combining ingredients, presenting, and serving meals) and consumption (food taboos, social interactions, tastes, and the acts of digestion and excretion $)^{1}$. Whether a solitary or social act, eating in any society has codes or behaviors that promote social, cultural, and historical mores. Gender roles and definitions of masculinity and femininity are reinforced by cooking practices, household management, and delineated spaces. In addition, relationships of control and power dictate the time, place, quantity, and quality of foods people eat. Self-destructive diseases, such as bulimia and anorexia, manifest a struggle between the body, the mind, and perceived notions of an ideal. The sensorial and often the sensual nature of eating reveals its relationship to sexual appetite. Furthermore, issues of socio-economic class distinctions, affective attachments through memory and nostalgia, geographic and cultural markers, as well as struggles between public and private spheres all demonstrate the multi-faceted, polemical connections between food and society.

The plastic, performative, and literary arts present, for a distinct purpose, the politicized and transgressive nature of food. In literary works, allegorical uses of eating, devouring, and cannibalism often expose structures of power. For instance, tropes of consumption, either of items or of people, represent an extreme capitalistic, consumer driven economy so as to demonstrate social inequalities and imbalances. Symptoms of excess associated with hunger and gluttony metaphorically stand for the extravagances of a society or a political regime. Through the deliberate inclusion of allegoric food-related references, authors frequently imbed a discourse of critique and transgression into their works. Consequently, the varied representation of the «nutritional arts» within literary texts becomes a mechanism to discuss the negotiation of culture.

1. The growing consumer market for cooking utensils, food-related television programming, diets, cookbooks, and products that promise professional results at home illustrates the fashions and fads to which even culinary topics are susceptible. 
Specifically in twentieth-century Peninsular drama, significant socio-historic, political, and cultural aspects of identity formation are explored through gastronomic imagery. The appearance or lack of food is not simply mentioned in passing, but is rather a means for the authors to process the country's socio-historical and political struggles. The presence of culinary images in works of literature is far from mere costumbristic detail but, rather, is a means of describing the individual and structural forces that contribute to identity struggles in particular moments of socio-historical development.

The death of General Francisco Franco in 1975, who had ruled Spain since 1939, ushered in a gradual transition to democratic rule, and with it came the usual difficulties of a pluralistic society. With the change from a dictatorship to a parliamentary monarchy, the struggle to construct identity shifted from individuals behaving in relation to the government's expectations to behaving in relation to other individuals' expectations. Under the dictatorship, Franco's regime «instructed» the citizens on what roles they were to fulfill and how to enact them appropriately. In contrast, Spain's democratic society grants freedoms, independence, and choices, which in turn increase the total number and sources of codes, rules, expectations, and behaviors. During both dictatorial and democratic times identity is based on roles of social expectations, but it is the type, number and sources of expectations that increase with the development of a pluralistic society. The additional options and possibilities often create a burden of choice because of the numerous and potentially conflicting social expectations.

Spanish society underwent vast political, economic, and social change after the signing of the 1978 constitution, which caused a «confused and confusing hybridity» (Graham and Sánchez 408). For example, the government granted regional control through the establishment of autonomous regions, which allowed for economic and cultural self-determination. Also, economic industrialization leapt forward to attain a level similar to that of the rest of Europe. Yet concurrent with Spain's rapid modernization, outdated forms of male dominance, sexual prejudice, and racism still existed (Graham and Sánchez 408-10; Brooksbank Jones 1995, 390). Therefore, Spanish culture in the 1980s and 1990s encompassed both anachronistic and contemporary characteristics, which may have caused confusion or disorientation at times. Helen Graham and Antonio Sánchez termed it «cultural schizophrenia» so as to define «the disorienting effects on Spaniards' consciousness of the speed and complexity of the changes that have radically altered their society over the last thirty years [1960s-1990s]» (408). Moreover, heterogeneity characterized Spanish society of the late twentieth century, and as Jo Labanyi states, «Spanishness is a shifting 
concept, encompassing plurality and contradiction» (396). Whereas in dictatorial times the regime closed national boundaries to outside influence and attempted to impose the definition of what it meant to be Spanish, in the last two decades of the twentieth century many groups co-existed and competed to define and delineate a Spanish identity, or rather identities.

Questions about fragmentation and exploration of identity form a core characteristic in Spanish drama at the end of the twentieth-century. In fact, «Spanish theatre in the 1990s is interested in the individual, but for an individual that has lost his/her coherence, unity, and autonomy» and «The characters in contemporary theatre encounter not only incoherence and fragmentation of the world in which she/he lives, but also the fragmentation and dissolution of her/his self» (Floek 2003, 48) ${ }^{2}$. Loneliness and the crisis of identity that leads to violence is another central characteristic, yet that violence isn't social or political in nature, but rather entirely personal and interpersonal explosions of violence (Floek 2004, 201). Susanne Hartwig, in her article about fragmentation in contemporary drama states, «Many of the hybrid texts utilize spatial-temporal ruptures and modes that do not affect the coherence of the principal storyline» (228). She goes on to say that the use of fragmentation, though not new, is different in that it doesn't aim to propel audience members to be agents of social change (such as in Brechtian theatre) nor does it connote a nostalgic desire for unity and plentitude (235). Mariló Seco's Mermelada de fresa exemplifies characteristics of drama written during this time period in that the protagonist is in the active process of fragmentation and dissolution, her identity crisis leads to personal violence, and the text itself breaks with linear and chronological time and space.

Though most known for her voice on radio shows (currently Canal Sur Radio Andalucía) and film dubbings, Mariló Seco is nonetheless part of a cohort of young Spanish dramatists writing in the mid -and late- 1990s. Born in 1962, Mariló Seco trained in voice and piano at a conservatory and then went on to get a degree in Dramatic Arts (Ortega 17). Her play PARA. NO. YA (1996) garnered acclaim from the Comisión de Lectura del Centro Andaluz de Teatro in that same year (Ortega 124). The anthology of female Andalucian playwrites, to which Mermelada de fresa pertains, describes the three authors as having their works staged, but not printed, and that the three female dramatists aren't very well known, thus, and precisely thus, their inclusion in the anthology (Ortega 7). María José Ragué-Arias documents well the upsurge of

2. All translations of the referenced scholarly articles, plus the dramatic text itself, are my own. 
women dramatists in the 1990s and their more noticeable and strong presence in the literary world. Seco's drama shares the central tenets of Spanish theatre of the 1990s in that the play Mermelada de fresa presents the struggle for individuality and self-identity in a democratic society and the food items function as a literary device to discuss the creation, negotiation and destruction of individual identities.

Identity, according to leading identity theorists Sheldon Stryker and Peter Burke, is the identification with a perceived role, the subsequent actions a person takes due to these constructed meanings, and the person's resulting concept of self (284). Roles, in sociological terms, are the behaviors and characteristics that fulfill perceived expectations. Social expectations delineate the roles in which people participate, multiple roles come together to create identities, and multiple identities create a total sense of self (Stryker and Burke 284). Relationships between people create expectations of behavior, which then leads to the formation of a self-definition. Socio-historical contexts and agents of socialization, such as family and school, help create the social expectations that become the structure of identity. Noting the constraint imposed on individuals through social roles and expectations of behavior, Karen Cerulo adds that «subjective definitions imprison individuals in spheres of prescribed action and expectation» (388). Though every choice has a social consequence of not fulfilling an expectation, individuals, significantly, choose whether to participate or not in those roles. Most often, social expectations and individual choice are not in opposition, but ultimately role clashes are difficult to escape because whenever a choice is to be made there is the potential for conflict. Individuals must prioritize the multiple expectations they perceive are placed on them, and choose the roles, or behavior, to exhibit. Most often, those unconscious choices are influenced by «master status» identities, or the most salient identities, which impact how the self is constructed. The self can be conceived of as a hierarchical interconnection of identities, with some identities prioritized and more prevalent than others based on the situation and context. Ella, the drama's protagonist, exemplifies the discord that can exist between roles and their, sometimes, conflicting expectations, especially when those expectations are connected to a master status such as gender.

The one-act play Mermelada de fresa, written in 1999 by Spanish dramatist Mariló Seco, exposes the mounting demands and complexity in satisfying an escalating number of, often contradictory, role expectations that exist for women in a pluralistic society and, thus, difficulties in creating a sense of self. Mermelada de fresa employs particular items of food, such as strawberry jam 
and a roasted chicken, to explore the ways in which freedom and increased choices can breed contradiction, confusion, and conflict.

\section{MERMELADA DE FRESA}

This eighteen-scene, one-act play opens with Ella attempting to relax by ritualistically working strawberry preserves into her hair in reaction to remembering an argument at the end of a date. He expects sex, something she does not see as a logical consequence of their date. In the ensuing scenes Ella theorizes that men and women cannot be friends because sex always interferes. Her encounters with men are persistently negative: she verbally spars with former boyfriends, and in a meeting the men organize to «talk» to her, they almost successfully gang rape her. Tension also exists among female relationships: Madre gives her food and questions Ella's ability to care for herself, while her roommate, Amiga, vacillates between consoling her and pointing out that Ella is to blame for her own unhappiness. As a solution to her problems, Ella meets numerous times with a hired hit-man, Asesino, asking him to kill people on a list she gives him. She appears uncertain as to whether the men or the women in her life are the source of her problems, and as a result changes the names on the death list frequently. Ella meets with Asesino one last time and tells him to kill the last person on the list. The play concludes with Ella sitting at the kitchen table spreading strawberry preserves on her hair while Asesino enters through the kitchen door and points a gun at her head.

Désiré Ortega Cerpa states, in the prologue to the drama, that Seco's works routinely have characters who straddle the edge of sanity, resisting, but also ready, to fall off the edge into the abyss of mental illness (18). Since the eighteen scenes frequently leap across linear time and space and present a fragmented, discontinuous reality it is impossible to know if what is happening is real or imagined by a mentally ill person (Ortega Cerpa 19). Thus, Mermelada de fresa infers mental instability through textual fragmentation as well as the main protagonist because of her inability to accommodate social and individual pressures. Yet, the question isn't «is Ella crazy», but rather «why is Ella pushed to the edge of sanity and why doesn't she have a viable, satisfying way to construct her personal identity, particularly a feminine one?» The textual and personal fragmentation fits into dramaturgical trends of the 1990s as noted above; indeed, the fragmentation offers a means to analyze and criticize a society that makes women feel disoriented by the multitude of social expectations, particularly those related to gender. While Ella vacillates on whom to blame as the source of her problems, men or women, the text posits that the 
core problem is the "crazy» society that expects individuals to happily enact restrictive, stereotypical gender roles.

Mariló Seco's Mermelada de fresa demonstrates the nature of constraint on identity. Ella's core problem centers on the demands and complexity of satisfying an increasing number of roles, and the changing expectations that go along with those roles, that exist for any individual in a contemporary, pluralistic society. She does not know which expectations to fulfill in her role as daughter, friend, girlfriend, and «modern» woman because often the expectations from one role contradict the expectations from another role. There are so many conflicting expectations of behavior that Ella is rendered almost «role-less». In fact, the characters' names indicate such in that Amiga (Friend) and Madre (Mother) have names associated with their roles, but Ella (She) is identified by her gender alone. Contrastingly, all the male characters have proper names (Carlos, Roberto, etc.), implying that men aren't defined by their roles, but by their individual personhood. While Ella identifies with being a woman, her «master status» or most prominent identity, the concept and definition of being a woman is in flux for her and for women, socially and historically, in 1990s Spain. Since the definition of woman includes so many disorienting traditional and modern expectations that are constantly being negotiated and defined socially, gender identity isn't something that Ella can use to stabilize her own sense of self. Ella can't delineate what it means for her to be a woman within contemporary Spain, therefore, Ella's sense of self is focused on an identity she can't define. Ultimately, an unstable, undefined, indefinite and unfulfilling sense of self leads to psychological turmoil, which for her leads to suicide. The balance between society's and the individual's expectations of behavior, combined with the increase in available roles a person can fulfill, can lead to an individual's struggle, and, sometimes, an inability to create a cohesive sense of self. Seco presents a decidedly negative potential reaction by an individual to overwhelming and conflicting perceived social expectations, all within a frame of culinary imagery.

The food items in Mermelada de fresa illustrate the protagonist's malfunctioning, unidimensional coping mechanisms, created in reaction to the overwhelming, multidimensional and conflicting social expectations placed on contemporary women. The only thing that provides solace to Ella is the ritual of spreading strawberry preserves on her hair, yet the act, though soothing, does not solve her problems. She states that of all the things she has done over the years to make herself look better, putting the red jam in her hair persists: «seriously, it falls out less and shines much more, on top of that it relaxes me and is very pleasant» (148). Amiga does not agree or share her enthusiasm for 
the product, but Ella appears not to care because it is the only thing that she does purely for her own enjoyment and pleasure, even if it is only temporarily satisfying. Ella applies marmalade to her hair three times: at the start of the drama when she is remembering a heated confrontation she had with her date about sex, after she has a disturbing conversation with Amiga's boyfriend about not making a difference in society, and at the end of the drama when she waits for Asesino to come kill her. In all three instances the ritual calms her agitated emotions, and in essence, serves as her momentary escape after or before an emotionally conflictive situation.

Curiously, what makes Ella feel better is a food item that is not ingested. She does not eat her «comfort food», but rather spreads it onto dead cells (hair), which makes it a purely exterior and superficial act rather than a nutritional one. As a symbol, strawberries, a fruit associated with Venus, the Roman goddess of love, have historically been considered an aphrodisiac due to their heart or V shape. As a visual representation on stage, the strawberry jam, because of its blood-like color, can function as a mechanism of foreshadowing death. In addition, sugary foods, such as jams and cookies, are often associated with child-like innocence and the ritual may indicate her desire to evoke such. In the end, the ritual, even if she were to eat the preserves, cannot remedy her underlying mental anxieties because the strawberry jam remains within the realm of the corporeal and does not address her psychological needs.

Ella acknowledges society's influence in shaping her expectations and the resulting single-minded concern of her physical appearance. Though she admits the ludicrous nature of diets and «helpful hints» that appear in magazines, she nevertheless succumbs:

ELLA: (Reading a magazine.) Listen to this, (She reads.) «...if you really want to slim down, this is the moment, we have great news, a revolutionary method.»

AMIGA: Didn't you read me this last week?

ELLA: No, but it is the same thing; don't eat, exercise, don't smoke, don't drink alcohol, sleep eight hours nightly, use good quality creams and, presto!, the miracle will happen without you even noticing it.

AMIGA: You'll be an irrecoverable anorexic, with a depression as big as a house, but with an enviable figure.

ELLA: I'm fed up with all of it. I will never go on a diet again.

AMIGA: Sure. Until someone tells you about a marvelous new method and you won't be able to resist. Like the one with peaches and hard-boiled eggs. Who the hell thinks of these things, or thinks they work?!

ELLA: I do. I will never eat canned peaches again. I probably won't ever eat canned fruit again. (147) 
Even though Amiga and Ella agree on the destructive nature of these images and ideas, Ella nevertheless admits to having participated in such miracle makeovers and «revolutionary» methods. Ella didn't achieve the euphoria promised, but rather ended up abhorring canned peaches. The magazines, presenting false promises of happiness that center on women's physical looks rather than mental abilities and/or needs, construct and reflect the ways in which society defines women within the narrow realm of the corporeal. Susan Bordo in Unbearable Weight affirms that the body in Western culture has repeatedly been equated with the female while the mind is equated with the male (5). Futhermore, Bordo exposes the rhetoric in diets and food advertisements, which imply that «women's appetites require containment and control, whereas male hunger is legitimated and encouraged» (14). Ella, following society's messages about women's bodies, throughout the drama remains rooted in the physical, to the detriment of the mind and the heart.

The image of a roasted chicken acts as a sexual symbol and as a metaphor of men's consumption of women. Ella visits her mother before going to the party and, before leaving, Madre gives her a roasted chicken. Ella promises her mother she will put it in Roberto's refrigerator so the chicken does not spoil while Ella is at the party. The stuffed chicken becomes a point of contention after Ella escapes the attempted rape:

ROBERTO: Hey! You're forgetting the chicken.

ANTONIO: Don't worry, we'll eat it, toasting to your health. (Everyone laughs.)

ELLA: I hope it rots in your stomach, sons of a bitch! (She slams the door and leaves.) (158)

The image associated with a roasted chicken is that of a cavern; in this case the chicken is stuffed, thus presenting a symbolic doubling of the need for filling in a space. Linguistically, the closeness between pollo (chicken) and polla (slang for penis) also indicates the author's choice in granting a sexual connotation to a chicken. In addition, the image of a cellophane wrapped chicken presents the idea of women (meat) «on display» to be consumed by men. In this scene, the men cannot have Ella so they will use the food as another means of fulfillment. One commodity, woman, is replaced by another, a cooked bird, to be eaten. Women and food appear here to be nothing more than mere objects for the gratification of men's desires.

Along with the image of the chicken Ella describes men in terms of ingestion and expulsion. Ella tells Carlos, «you make me want to vomit» (157), after describing how he used Ella to date her former and present roommates. Since Ella blames the men for her miserable life, she asks Asesino to kill them: 
«They fucked up my life. It is their fault I feel like this. They are the irrefutable proof that my life is shit. I've had relationships with seven-eyed beasts, ready to destroy me, ready to devour me slowly like hungry rats» (159, my emphasis). The images in these scenes are that men devour and expel women, just like any other food they ingest.

Through their words and actions men are connected with both sexual aggression and unassuageable appetite. She complains, «I definitely can't go out with a man, I know or not, without at the end of the night him wanting to sleep with me» and concludes that male friends cannot exist for women (13132). Roberto confirms this notion when, after a date, he suggests they go up to his apartment for sex. In an even worse scenario, Roberto organizes a party for Ella in which he invites only her ex-boyfriends. Carlos, Roberto, Antonio, and Pedro tell her, «we all blame you for something. You are so stuck-up, I don't know who the hell you think you are, but now you are going to explain it to us» (157). Roberto interjects, «You look beautiful. (He caresses her hair.) All of a sudden, after all your rude comments, I think I want to do something other than just talk» (157). Though Pedro does not want to participate, recommending they leave her alone since they are not barbarians, Carlos, Roberto and Antonio attempt to gang rape Ella. The portrayal of men in the drama is decidedly negative; women, like food, are for men's consumption, gratification, and satiation.

The same image of the roasted chicken is used in relation to both females and males. For the men it functions as a sexual referent and a commodity, while for Ella it potentially acts as a punishment, since she wishes the chicken will rot in their stomachs, serving as a means to inflict revenge on her torturers. Moreover, for Madre it symbolizes her daughter's ineptness at providing for herself:

MADRE: Come on, take it. Don't be stubborn.

ELLA: I said no, I don't need it.

MADRE: I know, but it will save you time.

ELLA: You're right, tonight I won't have time to cook and tomorrow I leave early.

MADRE: See? Go ahead and grab it. It is in the fridge. All you have to do is heat it up.

ELLA: $\quad$ Fine. (She goes to the kitchen and returns with a large stuffed chicken wrapped in cellophane.)

MADRE: It will be much better than the one you make, that's for sure. (138)

Madre goes on to insist that Ella put the chicken in the refrigerator wherever she goes and not just leave it in the car. Madre thinks that Ella is incompetent at basic things such as cooking for herself, yet she knows that younger women 
are always in a hurry and pressed for time in work-related activities rather than domestic duties. Via the chicken, Madre concurrently upholds the traditional female role of caring and nurturing for others through food, while also stressing the change in women's roles. For the younger generation, the role of professional worker has replaced the domestic one. However, the young women in this drama are no better off than their mothers, because although conditions have changed and options have expanded, the focus for and by women is still on the physical aspects of their being.

Ella's relationships with women are as conflicted as those with men because Madre and Amiga, just like Ella, concentrate on the corporeal features of the self and defined in relation to food. When Ella visits, Madre comments on her appearance: «Look at you, you are a mess, you look like a licorice stick so dark and sickly» to which Ella responds, «Wow...thanks! So many hours sunbathing and exercising so that your mother sees you as a licorice stick» (138). The connection with candy, which has no nutritional value, is a clear denigration. Both Madre and Amiga treat Ella's angst as nothing more than a temporary phase instead of assessing the serious nature of the situation or helping Ella deal with her troubled mental state. After Ella shares her fears about the extreme emotions she experiences, Amiga retorts that it must be a second adolescence and a bad phase that will pass in due time. Amiga, in a statement reiterated later by Carlos, will even suggest, "What you need is a boyfriend» $(142,154)$ as if males, and by extension sex, were a viable solution to her problems. Amiga has the distance to notice the contorted, negative ideas diets and magazines suggest, but she cannot see that her suggestions of finding a boyfriend and riding out the phase perpetuate the same notions of womanhood rooted in, defined as, and limited by her body. Thus, one criticism in Mermelada de fresa centers on men's inability to treat women as anything other than a commodity, in addition to women's complicity in upholding a system that narrowly focuses on the physical dimension of women's bodies and promotes them as objects for men to enjoy.

The drama's imbedded criticism of the commodification of women connects to Spain's decades-long race for acquiring consumer products. Fueled by a favorable international climate and global economy, increased investments, and a renewed determination to improve living conditions, Spain experienced fifteen years (1960-1975) of unprecedented growth (Grugel 65; Longhurst 20). Once a strong rural economy, Spain in the 1960s became the sixth largest manufacturer of cars, an indication of its level of industrialization. With such an expansion, the acquisition of consumer goods rose dramatically. In 1960 five percent of households had electronic appliances, while sixteen years 
later almost ninety percent owned a television and a refrigerator; by 1976 forty-nine percent of households owned a car (Longhurst 17). The insistence on acquiring goods and consumer culture continued during Spain's transition to democracy; in the drama not only goods are commodified and consumed. Those that don't or can't fit into the social expectations, such as Ella, are made to feel dispensable.

Ella cannot recognize the emotional sustenance, limited as it may be, her female relationships attempt to provide. After Ella explodes during a conversation and lays crying on the couch, Madre consoles Ella by making her an herbal tea, the quintessential «healing» drink, and by holding her hand. Yet despite their outright displays of concern, Ella tells Asesino to kill both Madre and Amiga precisely because of what she perceives to be the smothering effects the women have on her: «Yes, kill them both. That way they'll stop overwhelming me, stop telling me what I should do. Their affections and care suffocate me» (161). Instead of acknowledging Madre and Amiga's attempts at being supportive, even though they, too, are focused on the realm of the physical, Ella is tired of the soothing, nurturing care that the women offer, and, by extension, cannot comfortably inhabit the role of daughter or friend.

Social scientists Richard Ryan and Edward Deci find that identities are adopted to fulfill basic needs, such as connecting with others and experiencing belonging (254). If those identities aren't well internalized, because they don't fulfill basic needs, the less those identities foster mental well-being (Ryan and Deci 254-255). None of the relationships, roles nor expectations that Ella fulfills through those relationships provide connection and since «interpersonal relationships are among the most common constituent parts of the perception of the meaning and purpose of life» (Viewegh 5), Ella lives disconnected, unsatisfied, and confused; food items such as strawberry jam, chicken, licorice, «soothing» tea and metaphors of consumption (digestion and elimination) symbolically display such.

Seco voices, by means of the protagonist's relationship and role conflicts, constantly defined and delineated by food, the crisis many contemporary Spanish (and European) women endured. During the 1960s and after the death of Franco, women helped create the social reforms necessary to increase their presence in society and thus women's roles in Spanish society changed drastically. Women like Lidia Falcón, both feminist activist and playwright, participated in the Women's Liberation Movement to push for legal reforms of divorce, abortion, and contraception (Davies 183). By 1986 women made up over half of the work force, and by 1994 slightly over half of the university students were women (Davies 185), yet Anny Brooksbank Jones also documents 
the persistence of the «double shift» for most working women in the 1980s and 90s because domestic chores still fell primarily on them (1995, 390). According to these findings, contradictory expectations abounded within women's roles in Spanish society of the time. Brooksbank Jones further proposes that in the 1990s, Spanish women felt increased stress because of a value disorientation resulting from the fading traditional beliefs formerly promoted by the church and state $(1995,390)$. Graham and Sánchez posit that the combination of anachronistic and contemporary values creates disorientation due to postmodernity (408). They further note, «We are in a world [in the 1980s and 1990s] where social and national boundaries dissolve or coexist with emerging forms, accentuating the tendency towards cultural and social dislocation» (410).

Ella inhabits this world of the disoriented and dislocated. She describes herself as a confident, modern woman, declaring, "I've always known how to make decisions» (160), yet she changes her mind five times about whom Asesino should kill. Ella strives to epitomize the strong, liberated, determined, young Spanish woman, although she is riddled with self-doubt and continually questions what she wants, should be doing, and/or should have done. At a certain age the ability to go against social norms (work, marriage, home, children, happiness, etc.) becomes increasingly difficult thus often women in their thirties bend towards those social expectations to have career and family. The conflict between traditional and progressive expectations becomes more acute as well as the conflicts within those expectations. Significantly, Ella feels pressure from many sources to look good, to always be happy, to contribute to society in a meaningful way, and to aspire to the traditional female roles of wife and mother. These expectations confuse Ella because she does not know what to believe or seek, particularly because of the perception of herself as a thirty-year-old woman who should know what she desires.

To fulfill the role of sexually liberated and «modern» woman, Ella expresses the need to be sexual, but is detached from the people with whom she is intimate. For instance, she has a random sexual encounter with a stranger in an elevator on the way to meeting an ex-boyfriend. Ella accosts the man, who eventually acquiesces, has sex with him, and then leaves, all without speaking to him. When she arrives late, her excuse consists of «I was delayed in the elevator» (155). In addition, she tells Amiga about her frustration with the fact that in order to spend time with her ex-boyfriends, she has to agree to have sex with them or else they will not meet with her. Ella consents, but she never mentions any enjoyment or fulfillment from her encounters; her frustration signals she wants something more from her relationships but she is unable to reach any other level other than the purely physical. In many ways Ella 
is, to use Judith Butler's term, "performing gender» because she enacts the behaviors she perceives appropriate for a contemporary, urban, economically (and therefore sexually) independent woman. Gender is the social construct that defines appropriate behavior for the sexes and even though the "doer' is variably constructed in and through the deed» (Butler 181), Ella cannot gain satisfaction from fulfilling the role of woman because it only focuses on the physical self, to the detriment of her psychological one.

In addition to all the food-related interconnections with identity, other issues emerge related to forming a sense of identity within an increased world of choices and expanding expectations. The image of the thirty-something professional woman ends up being a false promise for Ella because she feels insecure about the choices she has made. Ella confesses to Amiga that she does not know what to do with her life and that maybe she should get married and have children (148), or in other words, perform the socially acceptable role of womanhood that includes matrimony and child rearing. Amiga asks what is wrong with Ella's life if she has a family that worries about her, various friends, and a job that she likes. Ella responds, "You're right, I shouldn't complain, so what is wrong with me?» (149), but she does not find an answer in herself or in Amiga's situation. Amiga provides the standard measure of success to which the two women aspire when she complains of her own perceived inadequacies:

[AMIGA:] I turned thirty long ago, I have my doubts and I hate to make decisions. I don't want to depend on anyone and my parents are elderly, plus I don't have any children and my job isn't the cure-all I thought it would be. I share an apartment with a neurotic woman, I've only slept with three different men in my life, it has been much too long since someone said «I love you» and my boyfriend is going bald... (149)

Amiga's response shows the disjuncture between expectations and reality: women, she suggests, should be decisive, independent, not need external affirmation, have a family, have a fulfilling job, have stable friends, be sexually adventurous and active, be loved, and, in general, not care about age nor mortality. The role of the professional superwoman is a false promise because it is neither attainable nor truly satisfying. Neither the role of aesthetically pleasurable object, created through beauty regimens or detached sexual encounters, nor the role as independent, decisive, working woman is viable because both roles focus only on the material rather than the mental and emotional aspects of life, plus the definitions of success and happiness are externally defined.

Of note is the way in which social expectations in this drama relate to stereotypes, particularly related to gender. The male characters, which, again, all have first names, are sex-obsessed, violent, and entitled, «devouring» and 
consuming women in their wake. The women, again, named only by their roles (Amiga, Madre), focus on physical appearance and traditionally «feminine» roles of woman, mother, homemaker and friend. Generically named Ella seeks to be the stereotypical modern woman who, literally, embodies it all: a sexually liberated, professional (worker) with an amazing physical appearance who finds meaning and purpose in life and connects with others. She is sexually free, but seemingly gains no pleasure from her heteronormative encounters. While an economically independent middle-class professional, work doesn't provide fulfillment. Her physical appearance is appealing to others, particularly men, but her being objectified and desirable likewise provides no joy or gratification. Her relationships and connections with others are fraught with difficulties, arguments, and strife. The ascribed identity of woman, rooted purely in the physical or corporeal realm, is not a role she can enact precisely because it doesn't meet her emotional and mental needs. In sum, all the gender-related stereotypes that she attempts to inhabit and enact do not work for her, and she has problems with those around her that inhabit equally stereotypical roles and behaviors.

Ella senses that she and the rest of her generation are useless, out of place, and disconnected. She voices her desire to make an impact, to have meaning in her life, and to be a part of history:

ELLA: Have you ever had the feeling that what we do is of no use whatsoever? For example, why are you here? Of what use are you? Throughout the ages there have been people who are useful to society and other useless, burdensome people. In this day and age, the second group far outnumbers the first and, of course, you and $\mathrm{I}$ are in that second group.

CARLOS: We aren't heroes or outstanding, but I'm sure we're doing something useful. Or, maybe, we're the irredeemable links in some human chain.

ELLA: That is it. That is exactly what we are, the stuffing in the chain. Maybe our entire generation is. We're misplaced, the «transition» generation. My parents, for example, talk about the past and they have something to tell: they survived the post-Civil war period. Or the hippie generation, they lived life differently, like they wanted to. (153)

Carlos thinks that Ella is going to drive herself crazy, analyzing everything so much. He suggests she should simply live life and have fun, like he does. Ella accusingly responds, «It is because of people like you that we don't evolve. You will guarantee that our generation passes unnoticed in the History of humanity» (153). According to Ella, the younger cohort lacks the collectivity, fabricated as it may be, that the previous generation experienced. The 
adolescents growing up during the transition period (1975-late 1980s), who later become the thirty-something group members in the 1990s, share the demanding need to adapt and expand social roles. The traditional male and female roles such as husband, father, wife, mother, all vestiges of the Franco regime that «instructed» the citizens on what roles they were to fulfill and how to enact them appropriately, needed to be combined with the progressive roles created during the last years of the dictatorship, transition to democracy and afterwards (educated, independent, female professional, for example). For Ella, the possibility of mediating traditional and contemporary expectations, both founded upon stereotypes, is unattainable.

Ella has moments of lucidity when she observes her own mental instability. In scene after scene, Ella moves from one extreme to the other, which even she alludes to as a sort of schizophrenia, leading her to the conclusion that death is her only viable option. Ella is worried because she has unexplained and drastic changes in emotions: «I haven't known how I truly feel for a long time now. I'm miserable, about to vomit, and the next moment I have a huge, unavoidable smile covering my face like an utter fool» (140). Her self-described Dr. Jeckyll and Mr. Hyde condition leads her to be happy one moment and suddenly have the desire to do harm, to kill someone, to make sure that some people disappear forever (141). After confessing her concerns to Amiga, Ella observes, «I've never really understood what the experts say about the many masks and the many people, within one person, that we are. For awhile now, I believe in schizophrenia, in multiple personalities» (140). The various masks and personalities that she mentions directly refer to the multiple roles, dependent on situations and relationships, which comprise identity. Ella aptly portrays the pendulum-like emotions many women feel when confronted with the multitude of changing, social expectations imposed on the modern, professional, urban, thirty-something woman. Ella, incapable of "playing» the disparate expectations and roles she perceives, finds her solution in contracted, assisted suicide.

Social scientists Richard Holmes and Stephen Holmes in their comprehensive book, Suicide. Theory, Practice and Investigation, discuss the interrelatedness of impulsive and violent behavior towards others and oneself (33). They present various theories regarding suicide, including the three connected dimensions of revenge/hate (a wish to kill), depression/hopelessness (a wish to die), and guilt (a wish to be killed) (34). They also describe common characteristics of suicides, which include unbearable psychological pain, a sense of aloneness and isolation, a growing self-realization that death is the only solution, inflexible thinking and an inability to see or complete solutions to problems, and, 
unmitigated hopelessness (Holmes and Holmes 34-35). In Mermelada de fresa, Ella embodies every one of these characteristics of suicides documented by social scientists. At first, she wanted to destroy the people with whom she had a relationship and, consequently, destroy the expectations she perceives others impose on her in that if she eradicates the relationships, she will abolish the attached social role expectations as well. In other words, if Madre no longer exists, Ella does not have to perform the role of daughter. In the end, she wants to destroy herself through contracted suicide because, if there is no self, there is no «battleground» on which to have to negotiate and live one's own and others' expectations. The uncertainty about how to perform all her roles leads Ella to choose suicide, which will ultimately erase her identity entirely.

Though she questions issues in her life, Ella's attempt at navigating society's mixed messages about young women's roles in society remains within the narrow realm of the physical: she applies strawberry preserves to her hair, subjects her body to extreme tanning and exercise regimens to be attractive to men, and has detached, sexual encounters. Enrique Gil Calvo argues that women use «womanly weapons» (sexual attractiveness, appearance, expression of identity) to control micro-level relationships and gain a sense of power, yet such weapons are useless at the macro-level because those very weapons objectify them via the male gaze. Those private or internal identities constructed on personal relationships with others may carve out some sense of power, but on the larger, social scale women are still dominated by male desires and modes (Gil Calvo 304). Since Ella remained objectified by those very elements that she did to provide her with a positive sense of self (strawberry jam ritual, diet, exercise), Ella cannot find power within the role of woman. Suicide is Ella's last act of control or individual choice and, therefore, an attempted rejection of social expectations, but the solution proves to be an equivalent unidimensional solution -the death of her physical body and the complete elimination of self.

Roles, in sociological terms, are the behaviors and characteristics that fulfill perceived expectations (Stryker and Burke 284). Multiple roles come together to create an individual's identity. Social expectations delineate the roles in which people participate, though there is also individual choice as to whether to participate or not in those roles. Most often, social expectations and individual choice are not in opposition, but ultimately role clashes are difficult to escape because whenever a choice is to be made there is the potential for conflict. Individuals must prioritize the multiple expectations they perceive are placed on them, and choose the roles, or behavior, to exhibit. Shelley Budgeon, in Choosing a Self, discusses the importance of choice in the delineation of an identity: 
Recent arguments have centered upon the assertion that within postmodernity the individual is increasingly freed from the constraints of ascribed identities that once were tightly organized through relations of class, race, sexuality, ethnicity, and gender, and must, therefore, construct his or her own internally referential identity within conditions of expanded choice. Questions surrounding how to live one's life have not only become central to identity, but the process of having to confront increased uncertainty and choice is itself productive of self-identity. (2)

The sense that Ella can enact her right to choose, for instance whom she wants killed, provides her with a sense of power, no matter how limited it may be. The inherent problem is that choice is structured by socio-historic conditions and under a continual state of revision or negotiation (Budgeon 6-7). The drama clearly depicts the lack of neatly discrete identities and the conflicts that can arise when a person feels forced to fulfill mutually competing roles; so too it depicts limiting socio-historic choice that Ella ultimately rejects.

Mariló Seco's Mermelada de fresa employs particular items of food, such as strawberry jam and a roasted chicken, to portray the difficulties that can arise in the process of filtering and prioritizing both society's and an individual's expectations of behavior. The drama exposes the mounting demands and complexity in satisfying an escalating number of seemingly contradictory roles that exist for any individual in a pluralistic society. Mermelada... renders the difficulty of navigating roles and creating an identity when there are so many options available because freedom and increased choices can potentially breed contradiction, confusion, and frustration. Generational differences about the role of women, plus the mix of traditional and contemporary values in Spanish society create an overabundance of behavioral expectations for Ella. The protagonist mixes social expectations with individual choice in an attempt at self-actualization, but the fusion causes a clash resulting in an identity crisis. Ella's coping mechanisms, displayed by the strawberry jam ritual, are dysfunctional because she focuses only on the physical representation of the female role (beauty, sexual activity) to the detriment of the psychological self. The contested roasted chicken echoes men's consumption of women because in the drama it represents another commodity or object of gratification for men. In the end, Ella vacillates between wanting to be an aesthetically pleasurable object and a self-fulfilled, professional woman, both of which turn out to be non-viable, unsatisfying options for her. Seco's protagonist cannot find any other alternatives because she feels the need to inhabit the extreme aspects of stereotypical, gendered behavior, expectations, and roles. The drama, thus, portrays the impossibility of satisfying multiple roles when individuals focus on only one aspect of their identity, particularly the corporeal. In addition, it 
depicts the confusion individuals experience as a result of socially defined roles and expectations that are always in a state of flux. As a result of the character's difficulty with and choices made in prioritizing roles, the dramatist shows the potential withdrawal, dislocation, and isolation of an individual from society, which in this drama leads to death.

After the decline of an oppressive ruler, members of society gain political freedom, but a much less visible and less obvious force governs their freedoms in a pluralistic society. The balance between society's and the individual's expectations of behavior, combined with the increase in available roles a person can fulfill, can lead to an individual's struggle, and, sometimes, an inability to create a cohesive sense of self, particularly when the roles are limited, limiting, and stereotypical. Mermelada de fresa exposes the mounting demands and complexity in satisfying an escalating number of often contradictory roles that exist for any individual in a pluralistic society.

\section{WORKS CITED}

Bordo, Susan. Unbearable Weight: Feminism, Western Culture, and the Body. Berkeley: University of California Press, 1993.

Brooksbank Jones, Anny. «Work, Women, and the Family: A Critical Perspective». Spanish Cultural Studies. Ed. Helen Graham and Jo Labanyi. NY: Oxford University Press, 1995. 386-395.

Brooksbank Jones, Anny. Women in Contemporary Spain. New York: St. Martin's, 1997.

Budgeon, Shelley. Choosing a Self: Young women and the Individualization of Identity. Westport, CT: Praeger, 2003.

Butler, Judith. Gender Trouble. NY: Routledge, 1999.

Certeau, Michel de, et al. The Practice of Everyday Life. Vol 2: Living and Cooking. Trans. Timothy Tomasik. Minneapolis: University of MN Press, 1998.

Cerulo, Karen. «Identity Construction: New Issues, New Directions». Annual Review of Sociology 23 (1997): 385-409.

Davies, Catherine. Spanish Women's Writing, 1849-1996. Atlantic Highlands, NJ: Athlone, 1998.

Floek, Wilfried. «Pérdida y búsqueda de identidad en el teatro de Yolanda Pallín». Identidad en el teatro español e hispanoamericano contemporáneo. Ed. Susanne Hartwig and Klaus Pörtl. Frankfurt: Valentia, 2003. 47-60.

Floek, Wilfried. «Entre posmodernidad y compromiso social. El teatro español a finales del siglo XX». Teatro y sociedad en la España actual. Ed. Wilfried Floeck and María Francisca Vilches de Frutos. Frankfurt: Iberoamericana, 2004. 189-207. 
Gil Calvo, Enrique. Medias miradas. Un análisis cultural de la imagen femenina. Barcelona: Anagrama, 2000.

Graham, Helen and Jo Labanyi, eds. Spanish Cultural Studies. NY: Oxford University Press, 1995.

Graham, Helen and Antonio Sánchez. «The Politics of 1992». Spanish Cultural Studies. Ed. Helen Graham and Jo Labanyi. NY: Oxford University Press, 1995. 406-418.

Grosz, Elizabeth. Volatile Bodies: Towards a Corporeal Feminism. Bloomington: Indiana UP, 1994.

Grugel, Jean and Tim Rees. Franco's Spain. London: Arnold, 1997.

Hartwig, Susanne. "¿Fragmentos, elipsis, huecos textuales? La escritura de los jóvenes autores dramáticos». Teatro y sociedad en la España actual. Ed. Wilfried Floeck and María Francisca Vilches de Frutos. Iberoamericana: Vervuert, 2004. 223-239.

Holmes, Ronald and Stephen Holmes. Suicide. Theory, Practice and Investigation. Thousand Oaks, CA: Sage, 2006.

Jordan, Barry and Rikki Morgan-Tamosunas, eds. Contemporary Spanish Cultural Studies. London: Arnold, 2000.

Labanyi, Jo. «Postmodernism and the Problem of Cultural Identity». Spanish Cultural Studies. Ed. Helen Graham and Jo Labanyi. NY: Oxford University Press, 1995. 396-406.

Labanyi, Jo, ed. Constructing Identity in Contemporary Spain. NY: Oxford University Press, 2002.

Longhurst, Alex. «Culture and Development: The Impact of 1960s 'desarrollismo'». Contemporary Spanish Cultural Studies. Ed. Barry Jordan and Rikki MorganTamosunas. London: Arnold, 2000. 17-28.

Nieva de la Paz, Pilar. «Luces y sombras de la nueva identidad femenina en el teatro español actual». Teatro y sociedad en la España actual. Ed. Wilfried Floeck and María Francisca Vilches de Frutos. Frankfurt: Iberoamericana, 2004. 65-86.

Ortega Cerpa, Désirée. Prologue (Prólogo) to La noche no duerme, Los gordos, Mermelada de fresa, by Mercedes León, Belén Boville Luca de Tena and Mariló Seco. Cádiz: Junta de Andalucía, 65-86, 5-19, 123-124.

Ragué-Arias, María José. ¿Nuevas dramaturgias? Los autores de fin de siglo en Cataluña, Valencia y Baleares. Madrid: INAEM, 2000.

Ragué-Arias, María José. El teatro de fin de milenio en España (De 1975 hasta hoy). Barcelona: Ariel, 1996.

Ryan, Richard and Edward Deci. «On Assimilating Identities to the Self: A SelfDetermination Theory Perspective on Internalization and Integrity within Cultures». Handbook of Self and Identity. Ed. Mark Leary and June Tangney. NY: Guilford Press, 2003. 253-272. 
Sánchez, Antonio. «Postmodernism and the Contemporary Spanish Avant-Garde». Contemporary Spanish Cultural Studies. Ed. Barry Jordan and Rikki MorganTamosunas. London: Arnold, 2000. 101-110.

Seco, Mariló. Mermelada de fresa. In La noche no duerme, Los gordos, Mermelada de fresa, by Mercedes León, Belén Boville Luca de Tena and Mariló Seco. Cádiz: Junta de Andalucía, 1999. 125-167.

Stryker, Sheldon, and Peter Burke. "The Past, Present, and Future of an Identity Theory». Social Psychology Quarterly 63.4 (2000): 284-297.

Valiente, Celia. «An Overview of Research on Gender in Spanish Society». Gender and Society 16.6 (2002): 767-792.

Viewegh, Josef. Suicide and Fiction: On the Concept of the Research into the Interplay Between Them. Brno: Psychologický ústav Akademie věd Ceské Republiky, 1998. 
Para enlazar con este artículo / To link to this article:

http://dx.doi.org/10.14198/fem.2017.30.09

Para citar este artículo / To cite this article:

Nicolau Jiménez, Adriana. «Aspectos de la maternidad actual en El conejito del tambor de Duracell de Marta Galán». En Eva García-Ferrón y Cristina Ros-Berenguer (coords.), Dramaturgia femenina actual. De 1986 a 2016. Feminismo/s, 30 (diciembre 2017): 169-191, DOI: 10.14198/fem.2017.30.09

\title{
ASPECTOS DE LA MATERNIDAD ACTUAL EN EL CONEJITO DEL TAMBOR DE DURACELL DE MARTA GALÁN
}

\author{
ASPECTS OF CURRENT MOTHERHOOD IN THE DURACELL'S \\ BUNNY WITH THE DRUM BY MARTA GALÁN
}

\author{
Adriana NiCOLAU JiMÉNEZ \\ Universitat Oberta de Catalunya \\ anicolauj@uoc.edu \\ orcid.org/0000-0002-1916-3200
}

\section{Resumen}

El objetivo de este artículo es estudiar la visión de la maternidad en la obra teatral El conejito del tambor de duracell de Marta Galán, así como su adaptación y puesta en escena por Marc Martínez. Nuestro estudio se basa en la lectura atenta del texto a partir de un sucinto marco teórico compuesto por aproximaciones feministas de la maternidad -esencialmente Federici, Sau, Badinter y Fernández Pujana- al cual se añade una entrevista personal a la autora. Siguiendo muy de cerca a Federici, el texto de Galán constituye un alegato a favor de la politización de los cuidados y contra la actual devaluación del trabajo reproductivo de las mujeres, bajo la supuesta solución que constituye la conciliación. La obra es sintomática de la aparición de nuevas temáticas en el mundo teatral a causa de la progresiva incorporación de las mujeres en los roles de autoría y dirección, así como su adaptación lo es de las limitaciones que aún siguen imponiendo el establishment y la omnipresente perspectiva masculina.

Palabras clave: Marta Galán, teatro, maternidad, trabajo reproductivo, Silvia Federici.

\begin{abstract}
This article's goal is to study the perspective on motherhood in Marta Galán's play The duracell's bunny with the drum, as well as its adaptation and staging by Marc Martínez. Our study is based on the text's close reading grounded on a succinct theoretical frame composed by feminist approaches on motherhood -essentially Federici, Sau, Badinter
\end{abstract}


\& Fernández Pujana- and a personal interview with the author. Strongly based on Federici's theories, Galán's text builds a claim in favour of a politicization of care, and against the current devaluation of women's reproductive work, under the supposed solution of labour and family conciliation. The play is symptomatic of the emergence of new topics in theatre due to the increasing amount of women in the role of directors and authors. Its adaptation is an example of the limitations that are still imposed by the theatrical establishment and the ubiquitous masculine perspective.

Keywords: Marta Galán, theatre, motherhood, reproductive work, Silvia Federici. 
Nuestra historia actual es la de miles de mujeres que agonizan sobre los libros, el cuadro o la canción que nunca podrán acabar o que ni siquiera pueden comenzar, porque no disponen de tiempo o dinero (Federici 2013, 99).

Marta Galán (Barcelona, 1973) es «autora y directora de proyectos escénicos desde 1999 », tal como se define en su página web personal ${ }^{1}$. Su obra se sitúa en el terreno del teatro postdramático, y propone una reflexión que oscila entre la reivindicación de corte social y la indagación existencial e identitaria. En 2015 escribe El conillet del tambor de duracell [sic] (El conejito del tambor de duracell [sic]), un solo en el que una mujer madre de dos hijos expone sus dificultades prácticas, emocionales y económicas para vivir de manera plena su propia vida, su maternidad y su relación de pareja, al tiempo que elabora una crítica muy explícita y combativa al tratamiento de la maternidad por parte de nuestra sociedad, al modelo de familia heteropatriarcal y al sistema capitalista.

En los últimos años, la progresiva incorporación de las mujeres al mundo teatral en calidad de directoras y autoras ha propiciado la aparición de un número reducido de obras que giran en torno a la maternidad ${ }^{2}$, una problemática que, como otras cuestiones tradicionalmente ligadas a la vida cotidiana de las mujeres, es extraordinariamente reciente en el ámbito del teatro. Por ello, el objeto de nuestro estudio reviste un especial interés, así como por su manera de abordar la maternidad en tanto que cuestión política, y por consiguiente afirmando la necesidad de su reconsideración en los planos político y cultural. Cabe añadir la importancia que la pieza tiene en la trayectoria de la autora, puesto que supone su acceso al gran público: el mismo año de su creación, el texto fue adaptado y dirigido por Marc Martínez y protagonizado por Clara Segura en una puesta en escena que cosechó un gran éxito de público y crítica.

1. <http://www.marta-galan.com/index.php?Mparam=bio-trayectoria>, consultado el 23-05-2017.

2. A manera de ejemplo: Fes-me una perduda, de Mercè Sàrrias, sobre el mito de la superwoman; La lista, de Jennifer Tremblay e interpretada por Laia Marull en el Lliure, sobre la carga mental de las mujeres; o, en el campo del teatro-danza, Mujer embarazada con hoja en blanco, de Constanza Brcnic. 
En este artículo estudiaremos qué concepto de la maternidad moviliza la obra y de qué forma lo articula en relación a una subjetividad a través de la cual se exponen también los sentimientos que puede generar esta experiencia. Para guiar nuestro análisis nos serviremos de una bibliografía reducida de aproximaciones feministas a la maternidad que nos permitirá abordar los aspectos esenciales del texto en relación a esta temática. Asimismo, exploraremos brevemente qué cambios se operan en la adaptación y puesta en escena realizadas por Martínez $z^{3}$.

\section{INTRODUCCIÓN AL CONCEPTO DE MATERNIDAD ACTUAL}

Piezas como la de Marta Galán reflejan la necesidad de iluminar una realidad silenciada en el ámbito de la representación a lo largo de los siglos -como señalara ya Adrienne Rich en Of Woman Born-, y traslucen al mismo tiempo un malestar contemporáneo en relación al espacio de los cuidados en nuestra sociedad. Diversas pensadoras feministas -como Silvia Federici, Elizabeth Badinter, Adrienne Rich o Victoria Sau- han demostrado que la maternidad tal y como la entendemos hoy en día es un constructo cultural producto de las sociedades patriarcales, que encuentra sus fundamentos en la ideología rousseauniana sobre los cuidados (s. XVIII) y en la separación de espacios domésticos y de producción que conllevó la propagación del sistema fabril (s. XIX). Como explica Sau, la madre ha sido tradicionalmente una «función del Padre» (32), mero vehículo para finalidades masculinas que se ha visto obligada a renunciar a sus propios intereses: «la mujer no deja de ser una mujer por el hecho de ser madre; en todo caso, ha adquirido una función más. Pero la cultura patriarcal ha convertido la palabra madre, o sea, la función, en la mujer como totalidad $[. .$.$] » (30). La idea del instinto maternal ha sido fundamental$ para mantener a las mujeres en esta función: se ha instaurado la idea de que la reproducción, «entendida como el complejo de actividades y relaciones gracias a las cuales nuestra vida y nuestra capacidad laboral se reconstruyen a diario» (Federici 2013, 21), es un «atributo natural de nuestra psique y personalidad femenina, una necesidad interna, una aspiración, proveniente supuestamente de las profundidades de nuestro carácter de mujeres» (Federici 2013, 37). Sin embargo, el hecho de que a lo largo de la historia las madres hayan maltratado, vendido, mutilado y asesinado a sus propias hijas (Sau 42), junto con «la imposibilidad de definir un comportamiento maternal propio

3. No puedo dejar de agradecer aquí la ayuda de Marta Galán, por su buena disposición y afabilidad, así como de mi directora de tesis, Teresa Iribarren, y de Joan Pujolar, Marina Massaguer, María Zaragoza y Mireia Manzano. 
de la especie humana» (Badinter 72), ponen en entredicho el concepto del instinto maternal. En la actualidad occidental, la maternidad es el espacio de la vida cotidiana que quizás evidencia de forma más fehaciente la ideología de género, puesto que se promueve un modelo ideal de madre y al mismo tiempo «se obstaculiza un desarrollo armonioso de ese ideal -ya que los cuidados no están en la centralidad del quehacer político e institucional y continúan considerándose un asunto privado de los hogares, y fundamentalmente de las mujeres» (Fernández Pujana 35-36). Además, el modelo que se impone como natural y universal es en realidad clasista y racista, puesto que está ligado a la situación concreta de mujeres blancas, occidentales y de clase media (Esteban 223, citado por Fernández Pujana 22).

\section{TRAYECTORIA DE MARTA GALÁN}

Marta Galán nace en Barcelona y, después de pasar su infancia en Madrid, regresa a la capital catalana para cursar estudios de Filología Hispánica y Artes Escénicas. En 1997 estudia dramaturgia y dirección en la EMAD (Escuela Municipal de Arte Dramático de Buenos Aires). De regreso a Barcelona, en 1998, funda la compañía La Vuelta, con Núria Lloansi, Xavi Bobés, Mireia Serra y otros, con la que estrena Lu Blanc de Lu Groc (1999), Desvínculos (2000, Sala Conservas), K.O.S. Fer-se el mort (Sitges Teatre Internacional, 2001) y Estamos un poco perplejos (Sitges Teatre Internacional, 2002), con la que la compañía se disuelve. A inicios de los años 2000 Galán comienza una nueva etapa de cocreación con el performer y cantante Santiago Maravilla, con quien produce la Trilogía Cínica, formada por Lola (La Poderosa, 2003), Machos (Escena Abierta Burgos, 2005) y El Perro (Festival Panorama de Olot, 2006); Transilvania 187, in memoriam (Ca l’Estruch en Sabadell, 2004) y Melodrama (La Fundición de Bilbao, 2007). También en cocreación, esta vez con Juan Navarro y Núria Lloansi, estrena en el ciclo Radicals Lliure del Teatre Lliure de Barcelona Protégeme, Instrúyeme (2008). A finales de la primera década del nuevo siglo, su interés deriva «a prácticas socioeducativas contextuales» (Gázquez 167): en esta línea se estrenan las Superproducciones postdramáticas de un solo uso (Dark figurantes, Reprise, Madres, tetas y nanas en la Nau Ivànow, 2009; y Morir de amor aquí, CAET de Terrassa, 2011), que involucran a varias entidades y personas de la sociedad civil. Con Morir de amor aquí, y después de años de trabajo precario y auto-gestionado, la autora siente agotarse su «deseo de hacer teatro» (Gázquez 466), lo que la llevará, junto con un traslado de Barcelona al Empordà y las necesidades derivadas de una doble maternidad, a abandonar progresivamente la actividad teatral. Así, habrá que esperar al año 
2015 para presenciar nuevamente en Barcelona uno de sus textos llevados a escena.

Según Cornago, la obra de Galán constituye, junto con las de sus compañeros de generación, el exponente de una sensibilidad del cambio de siglo fundamentada en la duda y el fin de los grandes relatos, que coincide además con un momento de precarización del mercado teatral. Estos autores -Carlos Marquerie, Angélica Liddell, Rodrigo García o la misma Galán, entre otrosproducen discursos confesionales de diversa índole, que a menudo parten del cuerpo como garantía última del yo. Por su parte, Gázquez destaca la importancia de la propia identidad para una generación de autoras españolas nacidas entre 1966 y 1978 que trabajan «con el material autobiográfico para crear piezas coreográficas donde se impone el concepto de auto-ficción» (11) Se trata de "poéticas de la experiencia y de lo personal» que se escenifican a menudo en solos, destilando materiales autobiográficos que sirven para cuestionar «el concepto de identidad» (56). Como Galán, todas ellas comienzan en proyectos grupales que abandonan a inicios del siglo XXI para emprender carreras individuales, desarrolladas mayoritariamente en circuitos alternativos. Salvo excepciones (como las de Juan Domínguez o Sergi Faüstino), estos discursos aparecen más y de manera más profunda en creaciones de autoría femenina, lo cual se debería a que «todas ellas trabajan con el cuerpo plástico y performativo, y este siempre ha sido fuente de conflicto o de exclusión» (17).

De entre todas sus compañeras de generación, destaca Gázquez, Galán es la que confiere una mayor importancia al texto -que decanta casi siempre en versículos libres-y también la que trabaja desde una posición más abiertamente política. Según Cornago, su trabajo «puede entenderse como una búsqueda de una verdad emocional a la que se acerca a la vez desde la experiencia personal y la reflexión en torno a lo social» (169). Su manera de entender la creación teatral, que se enmarca en el campo del teatro postdramático y ha tendido progresivamente hacia lo performativo, propone además «una performance de la narración permeable a la otredad del intérprete» (Gázquez 57): habitualmente, Galán presenta un texto que funciona como punto de partida y que puede modificarse y combinarse con aportaciones de los actores a través de los ensayos. Por lo tanto, sus espectáculos presentan, más que personajes, subjetividades superpuestas; y más que tramas, visiones poliédricas de una determinada problemática, generalmente de forma fragmentaria y mezclando discursos monológicos con acciones físicas, música, vídeos, etc., que

4. Dichas autoras son: «Constanza Brcnic, Paloma Calle, Amalia Fernández, Bea Fernández, Marta Galán, Sonia Gómez, Lidia González-Zoilo (Macarena Recuerda), María Jerez, Loreto Martínez Troncoso, Mònica Muntaner, Victoria Szpunberg y Ada Vilaró» (11). 
configuran una estética voluntariamente excesiva como forma de cuestionar los lenguajes teatrales miméticos.

Galán señala el feminismo como uno de sus grandes temas (Nicolau/Galán) y ha explorado cuestiones de género a lo largo de su carrera: por ejemplo, en Lola y Machos, donde se centra en la construcción hegemónica de la masculinidad; o en Morir d'amor aquí, pieza en la cual reflexiona «sobre la no operatividad del amor en contextos donde se imponen paradigmas patriarcales de violencia y dominación $»^{5}$. Madres, tetas y nanas, la tercera de sus Superproducciones, se centra en el tema de la maternidad, llevando a escena a veinte mujeres con sus respectivos bebés, a los que dan el pecho, y a un grupo de mujeres mayores que cocinan para el público. En la carta de presentación, la autora explica:

Se trata de una propuesta musical y escénica que reflexiona sobre la función de la madre en la construcción de nuevas sociedades pacíficas y cooperantes. Ante la crisis del modelo capitalista y de la razón instrumental, estamos obligados a construir nuevos modelos de relación basados en el amor incondicional y en dinámicas fundamentadas en la cooperación y no en la destrucción. Creación (crianza) es actualmente una palabra radical y subversiva. La transgresión hoy en día está en nutrir, conservar, amar y criar ${ }^{6}$. (2009 s.n.)

Como veremos, este planteamiento no se aleja en demasía del que sustenta El conejito del tambor duracell, que se cierra precisamente con la propuesta de un cambio social que ponga los cuidados en el centro de la actividad política.

\section{EL CONEJITO DEL TAMBOR DE DURACELL}

Este artículo se fundamenta en El conejito del tambor de duracell, una traducción al español realizada por la autora de la versión catalana escrita en $2015^{7}$. El origen de la obra se remonta a un texto de 2006 de igual título ${ }^{8}$, en el cual predominaba una reflexión psicológica de corte existencial y el tema de la

5. <http://www.marta-galan.com/index.php?Mparam=creaciones-2016-1999\&Sparam= morir-damor-aqui-2011>, consultado el 26-05-2017. La traducción es propia (T.P.).

6. T.P.

7. El conillet del tambor de duracell constituye el primer texto de Galán escrito íntegramente en catalán. Tanto esta versión como la española datan de 2015 y pueden encontrarse en la web personal de la autora: <http://www.marta-galan.com/index.php?Mparam=creaciones2016-1999\&Sparam=conillet $>$, consultado el 26-05-2017. Para facilitar la comprensión, en nuestro artículo trabajaremos con la versión española, que difiere del original catalán en algunas modificaciones de estilo de corte menor. Solo anotaremos los cambios sustanciales a nivel de significado y, puesto que el documento no tiene numeración de página, referiremos las citas según su número de sección.

8. No disponible en versión impresa o digital. De esta primera versión surgió también, en 2007, el espectáculo Melodrama, que fue creado junto a Santiago Maravilla y cuyo texto 
maternidad quedaba en segundo plano. El texto de 2015 surge cuando el actor Marc Martínez se interesa por el original de 2006 y le propone a Galán montarlo con Clara Segura, una de las grandes actrices de la escena catalana. Ante la propuesta, la autora siente la necesidad de reescribir la pieza de acuerdo con una situación que la distanciaba sustancialmente de su propio discurso en 2006: había sido madre dos veces. De ello surge en 2015 El conillet del tambor de duracell, una versión más extensa y donde todos los pasajes añadidos contribuyen a politizar la experiencia de la maternidad: así, la figura del conejito de duracell que se queda sin pilas, inicialmente ligada a un cansancio psicológico y profesional (Nicolau/Galán), se convierte en símbolo del agotamiento de las madres en el actual contexto social.

La pieza es un monólogo dividido en 12 secciones de extensión irregular pronunciado por una protagonista sin nombre, lo cual desdibuja al mismo tiempo los límites entre su dimensión ficticia y autobiográfica y entre su propia voz y la de otras muchas madres. La protagonista es una mujer de mediana edad que mantiene una relación heterosexual (no se especifica si está casada o no), de clase media y cultivada, trabajadora y madre de un hijo de ocho años y una hija de cinco. Su monólogo se inicia en presente con un episodio que funciona como la gota que viene a colmar el vaso: la recepción de una carta de la escuela porque su hijo lee sin cesar «todo tipo de libros extraños» y desatiende sus obligaciones $(2)^{9}$. Seguidamente asistimos a la reunión de la protagonista con el tutor del hijo, la vuelta a casa después de las actividades extraescolares y el momento de poner los niños a dormir. El resto de la obra prosigue con el hilo de las reflexiones iniciado en la primera parte para entrar de pleno en consideraciones más amplias que interpelan al público. El monólogo mezcla descripciones realistas con visiones hiperbólicas e hipótesis delirantes que sirven para subrayar el mensaje; alterna tonos cómicos con sarcasmos, pasajes tiernos con tiradas reivindicativas, y momentos de desesperación y rabia con exposiciones mesuradas. Todos sus recursos estilísticos se ponen al servicio de una voz que quiere representar también a muchas otras: la del símil del conejito de duracell, cuya energía dura más que la de cualquier otro, pero a quien, aun así, están empezando a acabársele las pilas.

puede encontrarse aquí: <http://artesescenicas.uclm.es/index.php?sec=artis\&id=74>, consultado el 09-10-2017.

9. Quien explore la obra de Marta Galán se dará cuenta rápidamente de que muchos motivos y pasajes se repiten de una obra a la otra. Conillet no es una excepción y recupera pasajes de Protégeme, instrúyeme (la carta de la escuela), Madres, tetas y nanas (el árbol como compendio de belleza y lugar de disolución), Morir de amor aquí (la sed de ser amada y probar muchos cuerpos) o la alusión al portazo de Nora Helmer (Dark figurantes). 


\subsection{La (im)posibilidad de conciliar trabajo productivo y trabajo reproductivo}

En su entrevista con Óscar Cornago, Galán afirma: «nunca empiezo una nueva creación si no tengo clara una especie de «tesis». Es decir, inicio un nuevo trabajo de creación a partir de una intuición, pero inmediatamente me pongo a buscar materiales teóricos y críticos que puedan dar consistencia a esa intuición» (Cornago 175). En el caso de El conejito..., la fuente más directa (Nicolau/Galán) son los trabajos de María Jesús Izquierdo y de Silvia Federici. Los estudios de esta última demuestran que una de las bases fundamentales del capitalismo es el trabajo no remunerado de las mujeres, que típicamente se han hecho cargo de la reproducción y del bienestar físico y moral de los trabajadores en lo que «siempre ha aparecido como si se tratase de un acto de amor» (62). En la actualidad, las reivindicaciones de Federici no sólo han sido desoídas por las estructuras de poder, sino también por buena parte del movimiento feminista, más ocupado en abrirse camino en el mundo laboral masculino que en reivindicar un cambio de paradigma que proporcione un lugar central a las tareas reproductivas en nuestras sociedades (47). Siempre según Federici, «la ilusión de que el trabajo asalariado podía liberar a las mujeres no se ha producido» $(2014$, s.n.), puesto que la masiva incorporación de las mujeres al mercado laboral (en los países del primer mundo) ha acarreado para ellas la aparición de la llamada «doble jornada» (laboral y doméstica). Y ello es así, en gran medida, porque la incorporación de las mujeres al trabajo remunerado no ha ido acompañada de «la equivalente alza en la proporción de hombres participando en el trabajo no remunerado» (Goñi-Legaz, Ollo-López y Bayo-Moriones 526). En el estado español, solo el 12\% de mujeres afirman compartir con sus compañeros de forma plenamente equitativa las tareas del hogar, mientras que la media europea se sitúa en el $25 \%(526)^{10}$.

En el imaginario social y el discurso político, la doble jornada se ha normalizado y reforzado bajo el término de «conciliación» como la opción de vida más deseable para las mujeres. Tanto Silvia Federici como Elizabeth Badinter argumentan que el mismo concepto es una trampa, puesto que prioriza la tarea

10. T.P. Como explican Goñi-Legaz, Ollo-López y Bayo-Moriones, la tasa de ocupación para las mujeres españolas de entre 16 y 64 años aumenta de un $22.9 \%$ en 1964 a un 53\% en 2009 (516). Sin embargo, su estudio demuestra que incluso en 2010 el reparto del trabajo reproductivo en parejas heterosexuales con dos sueldos continúa siendo profundamente desigual: el $55.22 \%$ de mujeres encuestadas afirman realizar todas las tareas del hogar, frente a un $1.48 \%$ de hombres; el $44.16 \%$ de mujeres declaran compartir las tareas frente al $64.87 \%$ de hombres; y un 33.29\% de hombres declara no realizar ninguna tarea en el hogar, frente al ínfimo $0.61 \%$ de mujeres (521). 
de crianza y la educación de los niños ante las posibles reivindicaciones relativas al bienestar de las madres (Badinter 135), y relega al terreno privado de la organización personal una cuestión profundamente pública (Federici 2013). Además, no debemos olvidar que a estas exigencias tácitas se suman otras, como la exigencia de belleza y de disponibilidad sexual, lo que en conjunto sustenta el mito de la «superwoman».

La protagonista de El conejito... es, en palabras de la autora, «una persona al límite pero que es muy capaz de comunicarnos con claridad y contundencia lo que piensa» (Soler Bort). Así, se declara con sumo sarcasmo orgullosa de haber podido conciliar vida laboral y familiar, añadiendo que ésta debe ser la misión de una mujer, sin esperar que nadie valore su trabajo reproductivo puesto que lo realmente valioso, en nuestra sociedad, es producir:

CONCILIAR./ Hacer compatibles las horas de crianza/ (esas horas muertas, improductivas, irrelevantes)/ con las horas verdaderamente productivas;/ las que cuentan,/ computan,/ las que le van a pagar,/ [...] ¡Estas sí que son horas productivas!/ Pero dar la vida, conservar la vida, iqué idiotez!/ Te jodes y CONCILIAS. (3)

Como mujer, además, debe ceñirse estrictamente a esta doble tarea, bajo riesgo de ser tildada de invasiva si opta por no tener un empleo o de madre demasiado desprendida si dedica poco tiempo a la crianza: «iMe ves a mi cara de conformarme con ser ama de casa/ o atreverme a ser vicepresidenta del gobierno?/ ¡NO!/ YO CONCILIO./ Lo hago todo./ ¡Soy una jodida máquina y puedo con todo./ (No sabéis de qué manera puedo con todo)! (3)». El texto erige la situación de la protagonista en ejemplo de la de muchas otras mujeres, aclarando además que, si son ellas las que se ven obligadas a desdoblarse, es porque ellos no lo están haciendo: «YO CONCILIO/ TÚ CONCILIAS/ ELLA CONCILIA/ NOSOTRAS CONCILIAMOS/ VOSOTRAS CONCILIAIS./ ELLOS NO CONCILIAN» $(3)^{11}$.

En uno de los pasajes más memorables de la pieza, la protagonista explica a qué destina los 1440 minutos de un día tipo ${ }^{12}$. Al final del recuento, revela que solo le quedan 14 minutos de «vida»: «de eso que yo llamo «vida»: el cerebro disponible, las manos desocupadas» (6). El resto los destina a trabajar, limpiar, cocinar, transportar a sus hijos, sacar a la perra y asearse (treinta minutos «nivel usuario: básico» (6)). En su explicación, aclara que los minutos

11. En la versión catalana esta alusión aparece aunque de modo menos explícito: «JO CONCILIO/ TU CONCILIES/ ELLA CONCILIA/ NOSALTRES CONCILIEM/ VOSALTRES CONCILIEU/ ELLES CONCILIEN».

12. El pasaje del cómputo de minutos fue escrito durante el proceso de creación junto a Clara Segura y Marc Martínez, y su autoría es compartida con ellos. 
destinados al trabajo «son los únicos minutos del día/que obtienen remuneración» (6), y siguiendo las tesis de Federici no duda en llamar los 98 minutos de tareas de la casa «TRABAJO DOMÉSTICO»: una "presencia desapercibida», de «cuerpo en acción brutal» (6). En otras palabras, la protagonista trabaja prácticamente todas las horas del día sin contar el sueño, habiéndose visto obligada a renunciar a todo lo que atañe a la vida personal, como «Las cenas con amigos $[\ldots] /$ Los proyectos preciosos $[\ldots] /$ El consumo cultural $[\ldots] / \mathrm{La}$ lectura $[\ldots]$ / Los ratos perdidos mirando el mar $[\ldots] »$, a los que considera, irónicamente, «prescindibles» (3). Por lo tanto, la maternidad la ha llevado a una situación límite en la que el primer tributo que ha tenido que pagar ha sido el de su identidad como mujer independiente y autorrealizada. Como apunta Hays, en una sociedad que exige a las mujeres con hijos que sean a la vez competentes profesionales y madres abnegadas y amorosas, «las complejas estrategias que las madres usan para afrontar estas lógicas contradictorias iluminan el tributo emocional, cognitivo y físico que deben pagar las madres de hoy» (Hays 220 citado por Fernández Pujana 32). No queremos dejar de mencionar que la protagonista subraya su elección de no ceder su «tiempo de crianza/ a una mujer del Ecuador o polaca, rusa, filipina, española, catalana» (3). Con esta alusión se apunta a lo que Federici considera un síntoma de la grave crisis de cuidados que sufre actualmente el mundo occidental: el traspaso de las tareas de cuidado a mujeres más pobres y mayoritariamente inmigrantes, lo cual «solo crea nuevas desigualdades entre las mujeres y alarga la crisis reproductiva» $(2013,180)$.

Al final del pasaje la protagonista arremete contra la película La sal de la tierra de Wim Wenders, un buen ejemplo de narrativa épica contemporánea en la que los arduos viajes del «héroe», el célebre fotógrafo Sebastião Salgado, oscurecen por completo una misión considerada muy menor: la de su mujer Leila, condenada a criar sola a sus dos hijos -uno de ellos con síndrome de Down- y a conciliar vida laboral y tareas reproductivas sin ninguna ayuda. La acusación pone de relieve hasta qué punto la invisibilización de las vidas de las mujeres y de las tareas reproductivas es una herencia aún vigente en la producción cultural de occidente, y evidencia por qué trabajos como la misma obra que la contiene son a la vez necesarios e innovadores.

\subsection{Sentimientos maternos: amor y entrega, pero también culpa y miedo}

Si bien, como argumenta Federici, el patriarcado capitalista ha devaluado siempre la importancia de las tareas reproductivas, no por ello ha dejado de promover un mandato exacerbado de maternidad, sin el cual no podría reproducir su fuerza de trabajo. Según autoras como Sharon Hays (1996) o Elizabeth 
Badinter (2011), la incorporación de las mujeres al trabajo asalariado ha traído consigo un aumento de dicho mandato y de las responsabilidades que lo acompañan. Desde una posición igualitarista, Badinter sostiene que, entre 1980 y 2010, se ha devuelto «la maternidad al centro del destino femenino» (11) gracias a una ofensiva naturalista que con el argumento de «lo natural» insta a las madres a invertir más tiempo en la lactancia y la crianza, bajo la premisa de la centralidad del bebé, ante el cual «la preocupación por una misma debe ceder el puesto al olvido de una misma» (23).

Otras autoras sostienen desde el feminismo de la diferencia que la vuelta a la crianza natural conllevaría, al contrario, la recuperación de una maternidad propia, soterrada bajo el modelo de madre impuesto por el patriarcado. En este sentido, Casilda Rodrigáñez defiende los diferentes estadios de la maternidad biológica como un «estado sexual [que] ha sido robado a la vida sexual de la mujer», en una "dimensión clave del matricidio y de la eliminación de la madre» (25). Según esta tesis, recuperar la naturalidad de los procesos de embarazo, parto y lactancia no iría en contra de la madre, sino que le permitiría acceder a un ámbito de su propia sexualidad que le ha sido vedado bajo las formas represoras del instinto materno -concepto animalizante y patriarcal opuesto al propiamente humano «deseo materno»-. La protagonista de $\mathrm{El}$ conejito... sería más afín a estas posiciones, al igual que su autora, que cita como referente Maternidades subversivas de María Llopis (Galán 2017), una recopilación de entrevistas que, entre otros aspectos, ahonda en las tesis de Rodrigáñez para presentar vivencias de la maternidad que se alejan del «contexto capitalista y patriarcal en el que se desarrolla asexuada, medicalizada, biologizada y desempoderada» (contracubierta).

Las dos corrientes del feminismo coinciden, en cualquier caso, en los resultados nefastos que acarrea una maternidad intensiva desarrollada en el contexto productivo occidental contemporáneo. Badinter los resume en una triple contradicción que aparece plenamente reflejada en la obra de Galán. En primer lugar, social: el ya mencionado choque entre el exacerbado mandato de reproducción y la devaluación de las tareas reproductivas en el imaginario social, que los citados pasajes sobre la conciliación denuncian sin ambages. En segundo lugar, conyugal, ya que «la idea estereotipada de que el hijo refuerza la solidez de la pareja ha fracasado» (180), y la relación de pareja de la protagonista es un ejemplo de ello. Y, finalmente, identitaria, puesto que muchas madres «se sienten divididas entre su amor por el hijo y sus deseos personales» (144), como es el caso de la protagonista, que ha debido renunciar a todos sus deseos personales por amor a los hijos. 
El fundamento del texto que nos ocupa es la tensión entre los sentimientos reales de amor y entrega que unen a la protagonista con sus hijos y el tipo de maternidad a la cual la realidad social la ha conducido. El texto se abre y se cierra con un mismo pasaje, reproducido también en la sección cinco, que funciona como contrapunto al resto de la pieza y simboliza metonímicamente los sentimientos positivos que puede generar una maternidad deseada y gozada: «Estoy aquí./ Sentada./ Paciencia infinita./ Toda tetas./ Toda oídos./ Expuesta./ AMÁNDOTE-AMAMANTÁNDOTE/ Aquí, para ti, como una ofrenda./ Este es mi pequeño secreto:/ existir para ti como una ofrenda» ( 1 y 12). La última línea del pasaje ofrece la clave para entender cómo el deseo de darse a los hijos que siente la protagonista queda pervertido por el modelo de maternidad imperante, que le exige una versión exacerbada de una entrega difícil de sostener a largo plazo. Esta lectura se ve reforzada por un pasaje de la apoteosis final, en el cual la protagonista contrapone las experiencias del parto y de la lactancia, vividas en su caso como una experiencia satisfactoria, algo «sexual, físico, placentero» y que «sólo suma» (10); a los años posteriores de crianza:

Pero criar con presencia, con gratitud, con alegría, serena y firme,

día tras día, año tras año, hasta que pasan tres, cuatro, cinco, trece, dieciséis años,

sin tribu,

sin leyes que nos protejan a las madres,

a los hijos, a las hijas;

a las personas que cuidan, cargan, acarician, cambian pañales, dan de comer, miran a los ojos, dan la mano, escuchan y ponen a dormir, es una EXTORSIÓN y sólo resta. (10)

Esta «EXTORSIÓN» es también la que viven muchas mujeres reales, primeras perjudicadas de las desastrosas consecuencias de las políticas de conciliación y de igualdad en España. En la actualidad, en el Estado español son muy deficientes las bajas de maternidad y paternidad, la cobertura de «centros públicos de educación infantil para niños de cero a tres años», la poca flexibilidad y larga duración de las jornadas laborales y, en un sentido más amplio, el gasto público sobre las familias, insuficiente «para estimular la igualdad de género en los hogares españoles» (Gracia y Bellani 42-43). Y todo ello porque, una década después de su creación, la Ley Orgánica 3/2007 para la igualdad efectiva de mujeres y hombres, pionera en su momento, continúa sin enmiendas y está muy lejos de aplicarse. Dicha situación aboca a muchas madres a criar en una sociedad que da completamente la espalda a los cuidados, lo cual repercute negativamente tanto en sus maternidades como en sus empleos (Gracia y Bellani). Además, la imagen imperante de una maternidad intensiva en la que no tienen cabida los sentimientos negativos inherentes a cualquier relación 
humana y mucho menos las problemáticas propias de la conciliación, convierte a las madres en presas fáciles de la culpa, la desorientación y el miedo. Por ejemplo, varios estudios (Badinter, Imaz) demuestran que las madres trabajadoras se ven a sí mismas como alejadas de un modelo de crianza intensiva que consideran el ideal, incluso reconociendo que éste resultaría «frustrante para su propio desarrollo personal» (Imaz citada por Fernández Pujana, 40). Por otro lado, y como los citados trabajos argumentan, el exacerbado sentimiento de responsabilidad actual para con los hijos es histórico y está ligado a la contemporaneidad occidental, en la que se produce un «incremento de obligaciones con respecto al hijo que se ha escogido dar a luz» (Badinter 11) y del que, por lo tanto, se es especialmente responsable ${ }^{13}$.

En el caso de la protagonista, la actitud que mantiene hacia los hijos pone de relieve lo opresor del modelo de maternidad imperante y los sentimientos negativos que genera. Por un lado, dos o tres actuaciones irreverentes y de claro carácter provocador -como fumarse un cigarrillo a medias con su hijo, discutir con él gritando y agarrándole el brazo o mandar a los dos retoños a la cama sin cenar (la noche en la que asistí a la función se oyeron bufidos de desaprobación en esta escena $)^{14}$ - ponen de relieve hasta qué punto en los últimos años se han vuelto impensables ciertas libertades por parte de las madres, cada vez más obligadas a renunciar a cualquier actividad que pueda perjudicar a sus hijos (Badinter 85). Por el otro, el peculiar «entrenamiento» al que la protagonista somete a sus hijos -buen ejemplo del gusto de la autora por lo excesivo- deja entrever que sus sentimientos maternales son el amor y la entrega, pero también el hartazgo, la culpa y el miedo.

El «entrenamiento» en cuestión es un delirante programa de lecturas de disciplinas diversas y múltiples actividades extraescolares que deben preparar a sus hijos por igual, tanto al niño como a la niña. Dicho programa define a la protagonista, por un lado, como sujeto activo que ejerce un control sobre su prole y la educación a la que la somete, lo cual la aleja de la figura de víctima sin recursos. Por el otro, el entrenamiento constituye una versión hiperbólica del alto grado de exigencia que reviste actualmente la educación de los hijos, y que unida a la ideología de la maternidad intensiva multiplica los deberes de la madre:

13. Una alusión a esta cuestión aparece en la sección 10: «PARTENOGÉNESIS./ Dar la vida por decisión propia, a todo riesgo./ Bajo su única responsabilidad./ PARTIRSE./ Hacerse dos».

14. Representación del 31 de marzo de 2017 en el Ateneo de Cerdanyola del Vallès, en el marco de la gira por Catalunya. 
[los cuidados maternos] ya no se reducen únicamente a los cuidados corporales y afectivos, implican también una atención escrupulosa al desarrollo psicológico, social e intelectual del hijo. La maternidad representa, más que en el pasado, un trabajo a tiempo completo. (Stanworth 1987, 143, citado por Badinter 14)

El erigirse como única responsable de la educación de sus hijos comporta, en efecto, hacerse cargo de todas sus consecuencias, lo cual genera indefectiblemente una carga añadida de culpabilidad y miedo: «Al principio: miedo/ $\mathrm{Al}$ final: miedo igual, pero soportable./ Miedo de cagarla en todos los sentidos./ Que todo te salga mal./ El tiro por la culata./ Criar cuervos» (6). Para esta mujer que dice no poder «imaginar para [su]s hijos ni un segundo de infelicidad» (4), la crianza puede revelarse muy culpabilizadora, a pesar de su programa para que sus hijos devengan autosuficientes.

Esta contradicción arroja luz sobre la perversión que supone minimizar las ayudas a aquellas personas que se ocupan de la crianza al mismo tiempo que se les exigen resultados imposibles. En palabras de Sau, «el orden social moderno pone la infancia en sus manos [las de la madre] a full time y luego le reprocha que sea complaciente, posesiva o demasiado tolerante», criticándola indistintamente por ser demasiado intensiva o por ser «poco cálida, distante, ausente [...] capaz de ser feliz al margen de su maternidad» (35). Por eso la protagonista cada día les dice a sus hijos que les quiere «más que a nada en el mundo» (3), para que no olviden sus sentimientos reales a pesar de que cada vez se sienta con menos fuerzas para continuar:

¿Os he dicho que sois lo más importante que me ha pasado en la vida?

¡La cosa más bella, más perfecta y más alucinante que he hecho en la vida!

Pero a veces las madres necesitan descansar.

Salir a dar un paseo.

Tomar un poco el aire.

$\mathrm{Y}$ a veces las madres se ausentan.

O se mueren, las madres.

A veces también pasa eso: que las madres se mueren.

Y por eso tenéis que ser fuertes como titanes, como leones.

¡Fuertes, imperturbables y felices!

¡ATARAXIA, ATARAXIA! (10)

El pasaje resume la ansiedad que supone para la protagonista darse cuenta de que, a pesar del amor que profesa a sus criaturas, la situación la sobrepasa: finalmente, resulta desolador constatar que aquello que la protagonista desea para sus hijos, la felicidad y la ataraxia -la «imperturbabilidad del ánimo ante la adversidad» (2)-, está lejos de poder ser una realidad para ella, tanto en lo que atañe a su vivencia de la maternidad, como en lo referente a su tiempo personal 
y a su vida afectiva y sexual. Respecto a esta última, la protagonista despliega a lo largo de tres secciones una visión muy desencantada: según explica, en los 14 minutos de «vida» que tiene al día, intenta recuperar algo de la intensidad sexual que la unió a su pareja al inicio, aunque su relación se basa ahora en dinámicas de poder y abuso ${ }^{15}$. Al fin y al cabo, sus deseos profundos-vivir su sexualidad y su afectividad más allá de la monogamia, y reproducirse siguiendo únicamente su deseo de ser madre- quedan muy alejados de su realidad -«Soy una mujer monógama y tengo sólo 2 hijos» $(7)^{16}$. Del mismo modo que el hilo conductor de la pieza se encarga de desmitificar la maternidad, estos pasajes ponen en duda el discurso del amor romántico-«Alguien me debería haber explicado/ [...] que no iba a existir ningún hombre capaz de hacerme feliz./ [...] ¿Por qué alguien no les explica a los niños y a las niñas que el amor romántico es letal?» (7) - y el modelo tradicional de familia junto con el «amor monógamo» (7), problemático tanto para la vivencia de la maternidad como en relación a la pareja: «Crear familias a partir de parejas que follan/ (parejas que durante un tiempo follan y después se cansan, es natural: ¡una mala idea!)/ Tener hijos y criarlos junto al padre biológico: ¡Una mala idea!» (7).

\subsection{Reivindicación de la importancia política y social de los cuidados}

El clímax de la obra se produce en la sección 11 -seguida solo del leitmotiv de la lactancia-, cuando «el conejito del tambor de duracell» anuncia que se le están acabando las pilas, y da a elegir entre una revolución completa en el tratamiento que la sociedad da a los cuidados y el retiro de todas sus ocupaciones, por el que finalmente opta: «Sí, quiero que me dejéis descansar» (11).

En un pasaje previo de la obra, la protagonista presenta su visión sobre el trabajo como algo totalmente utilitario - «Voy, lo hago y cobro el dinero./ Voy, lo hago y me pagan.» (4)-, un punto de vista anticapitalista que va en contra del discurso neoliberal dominante sobre el emprendimiento y la autorrealización a través de la actividad remunerada. El pasaje concluye con la exposición de un deseo -atribuido explícitamente a El intercambio simbólico y la muerte de Baudrillard-: que todos los trabajadores desaparecieran, murieran simbólicamente, como forma de sustraer su producción y su propio cuerpo productor

15. A nuestro parecer, el defecto principal de la pieza -aun teniendo en cuenta que las creaciones de Galán no son tramas cerradas ni con vocación psicológica- sería no problematizar la nula implicación de la pareja en las tareas domésticas.

16. El pasaje que concluye con esta afirmación no aparece en la versión catalana. Se trata de 18 versículos que reproducen parte de un fragmento de Madres, tetas y nanas donde la protagonista declara querer pasar el resto de su vida pariendo y criando, ya que su «cerebro sólo ha encontrado paz en ese estado químico, anímico» (7). 
al capital. La explicación anticipa la resolución final de la protagonista, que una vez más se relaciona también con las ideas de Federici: «Si no hay reproducción, no hay producción. Si ese trabajo que hacen las mujeres en las casas es el principio de todo lo demás: si las mujeres paran, todo para; si el trabajo doméstico para, todo lo demás para» (2014, s.n.). Por eso el deseo de dejarlo todo y el cansancio de la protagonista funcionan metonímicamente como los de todas las mujeres: «¿Sabes por qué tengo que pedirte, por favor, que me protejas de mis deseos?/ Porque son letales./ Porque suponen el fin del amor romántico y de toda esa mierda./ El fin de la reproducción sexuada, del matrimonio, la monogamia... ¡ todo ese tinglado!» $(11)^{17}$.

Los exabruptos de hartazgo y rabia que encontramos a lo largo de la obra culminan en esta sección con una improbable hipótesis: que, de repente, la protagonista deje de interesarse por los que la rodean y se dedique solo a su placer, transgrediendo así el tradicional rol femenino de anteponer siempre el cuidado de los otros a las propias necesidades, y de actuar con discreción para no destacar más que sus homólogos masculinos. Después de lanzar su hipótesis, sin embargo, reconoce que se trata en realidad de una visión exacerbada del miedo y la culpabilidad que siente al imaginar que podría no haber dedicado suficiente tiempo a sus seres queridos: «Tengo miedo de que llegue un momento en el que ya no me interese el mundo./ Ni la gente./ [...] Tengo miedo de no haberles escuchado lo suficiente,/ [...] Tengo miedo de haber vivido sólo y exclusivamente para llamar la atención» (11). La hipótesis sirve para poner en evidencia hasta qué punto la figura de la madre requiere del sacrificio concreto de la mujer -ella sabe que, si se entrega al placer, la llamarán «ególatra, egoísta, putón, mala madre (11)»- y sitúa la obligatoriedad de este sacrificio en el contexto más amplio de una actitud femenina prototípica, evidenciando cómo el género juega en contra de las mujeres.

No obstante, y a pesar de todos sus miedos, la protagonista acaba por declarar su extenuación y amenaza con cesar su actividad si no le traen los medios suficientes para continuar ejerciendo su maternidad dignamente:

Dadme una nueva sociedad donde dar la vida, conservar la vida, estar al cuidado de la vida (de la de los bebés, los niños, los jóvenes, los viejos) con amor, con presencia, día a día, sea alguna cosa que fundamente las estructuras sociales, que condicione los planes económicos, las derivas políticas, las acciones reales. (11)

17. La versión catalana añade: «Perquè suposen la fi del món./ La fi del vostre món». 
A medida que desgrana la lista de médicos, juristas, leyes, medios de producción y otros elementos necesarios para que ello sea posible, una ira creciente impregna sus reivindicaciones, poniendo de manifiesto hasta qué punto la crianza es una actividad invisible que nadie agradece:

¡Dadme las gracias, hijos de puta!

¡Protegedme y dadme las gracias!

¡Ponédmelo más fácil, dadme apoyo!

Estructuras legales en las que ampararme.

¡Más guarderías, Catovit gratis!

¡Hacedme estatuas, bustos, colocadlos en las plazas!

¡Ponedle mi nombre a una calle o a un parque!

¡Yo sola no puedo! (11)

Finalmente se compara con el conejo de duracell, cuya batería es de larga duración y alto rendimiento, pero que incluso así se está quedando sin energía, y pide refuerzos porque: «es muy peligroso que yo me detenga...» (11). Después añade: «Y si no tenéis todo esto que os he pedido,/ TODO, dejadme descansar, por favor». La conclusión, que apunta reminiscencias del famoso portazo de Nora en Casa de muñecas de Ibsen, se cierra con una alusión a unos versos de Alejandra Pizarnik: «Quiero un silencio perfecto, por eso hablo» (11). Esta paradoja resume la lucha de la protagonista: necesita descanso después de un cometido agotador; pero para llegar a él es necesario que hable primero sobre su situación y la de muchas mujeres que son madres en la actualidad, para empezar a sacarla de la invisibilidad social a la que está desterrada.

\section{LA PUESTA EN ESCENA DE MARC MARTÍNEZ Y CLARA SEGURA}

La versión adaptada por Marc Martínez bajo el título Conillet se estrenó en el Festival Temporada Alta de Gerona el 6 de noviembre de 2015. Estuvo un mes en la cartelera del Teatre Lliure de Barcelona (11/11/2015-13/12/2015, con prórroga incluida) y posteriormente se exhibió en el Festival Grec de Barcelona (19-07-2016-05/08/2016) y en una gira por Cataluña (01/04/201607/05/2017). En la dirección, el actor Marc Martínez demuestra su competencia en un terreno que no le es propio y Clara Segura, con su habitual brillantez y amplitud de registros, despliega una energía admirable para representar a la protagonista de la obra, lo cual le mereció el Premio de la Crítica 2015 a la Mejor Actriz Principal y el Premio Butaca 2016 a la Mejor Actriz Teatral. La versión producida por el Lliure y Bitò Produccions está pensada para agradar a un público exigente pero relativamente amplio, y tiene una impronta más refinada y sobria de lo que es habitual en Galán. Como ella misma afirma, escribir para el Lliure supone «un cambio de contexto [...] de estatus» (Gázquez 475) 
y, casi sobra decirlo, de presupuesto. La escenografía, de Alejandro Andújar, se reduce a una gran boca de desagüe que apunta a múltiples simbologías - «ya puede simbolizar un agujero negro, un refugio o una vulva inmensa», interpreta Foguet- con el cual la actriz interactúa a lo largo de la pieza.

La versión de Martínez -primera dirección ajena de un texto de Galántiende a reducir el texto original, lo cual demuestra ser un acierto ante la puesta en escena, con una duración y un ritmo impecables. Sin embargo, la adaptación no solo reduce su duración, sino también su componente subversivo, limando el lenguaje de connotaciones políticas -conciliación, trabajo doméstico, trabajo no remunerado, amor romántico, monogamia...-y menguando el alcance de la reflexión sobre la dimensión política de la maternidad. Así, desaparecen los citados pasajes sobre la conciliación (3) y la reivindicación de los cuidados como centrales para la construcción de una sociedad más justa (11), y con ellos la insistencia en la dimensión política del trabajo de las mujeres y las propuestas políticas que contiene la pieza. Desaparece también la crítica a $L a$ Sal de la tierra y por tanto la metacrítica hacia los productos culturales contemporáneos que reproducen el discurso patriarcal. Asimismo, es eliminado el pasaje sobre la «mala idea» (7) de mezclar sexo, familia y amor, limitando así la deconstrucción de la familia heteropatriarcal, junto con los deseos femeninos que la ponen en duda - ¿hasta qué punto sigue siendo subversiva la expresión de determinados deseos en boca de una mujer ${ }^{18}$ En consecuencia, la protagonista de Martínez tiene un discurso muy similar a la de Galán, pero menos apoyos teóricos y políticos para justificarlo -habiendo quedado difuminado el argumentario de Federici-, y, por lo tanto, menos autoridad, reduciendo su potencial de cuestionamiento y menguando la capacidad para trasladar determinadas ideas al público.

A grandes rasgos, la puesta en escena de Martínez convierte un discurso que tenía mucho de deconstrucción de la figura de la madre, en su reivindicación. Según la autora, el director acerca su personaje a una visión de la madre «más idealizada, este perfil femenino más todopoderoso», en lo que probablemente fuera «un homenaje a su madre» (Galán 2017). El lenguaje no verbal elegido por Martínez va acorde con este carácter de «homenaje» que la autora señala: así, antes del inicio de la función se ve a Segura bailando y

18. Junto con los casos citados, consideramos especialmente significativa la supresión total o parcial de la pelea con el hijo; la alusión a la delegación de la crianza en otra mujer; la referencia a Baudrillard; la designación de los minutos de trabajo del día como los únicos «que obtienen remuneración» (6); la alusión a las tareas domésticas como «cuerpo en acción brutal» pero no como «TRABAJO DOMÉSTICO» ni como «presencia desapercibida» (6); y, finalmente, el pasaje sobre su deseo polígamo y su sed de ser querida. 
haciendo estiramientos largo rato al son de una música electrónica, preludio del fuerte ejercicio físico que realizará durante la función y trasunto material del carácter «todopoderoso» de este animal doméstico que es el «conejito». $\mathrm{Su}$ indumentaria sobria pero atractiva -camisa y americana con deportivas negras, y posteriormente vestido negro- podría ser la de cualquier mujer de clase media hoy y por lo tanto la sitúa más cerca de un perfil medio que de uno más disruptivo respecto al modelo de mujer dominante. Asimismo, Martínez añade una coda en la que Segura saca al escenario una olla de lentejas con chorizo y después de cenar ella misma para «ganar tiempo», invita al público a servirse. Esta conclusión reproduce el final de Madres, tetas y nanas, y va muy acorde con la tónica de Galán, que a menudo termina sus espectáculos en momentos festivos, con bailes, bebida o comida. No obstante, y a pesar de acercar la representación a los códigos habituales de la autora, el cierre no deja de suavizar el contenido reivindicativo del clímax, sustituyéndolo por un tono final más festivo y conciliador.

Algo parecido ocurre con el uso recurrente del humor: si bien en buena parte sarcástico -y subrayado por la magnífica risa sardónica de Segura-, este recurso no deja de aliviar la tensión de la pieza. Por todo ello, adaptación textual y puesta en escena concurren en otra reducción sin duda muy significativa: la del grado de incomodidad que pueda experimentar el sujeto masculino del público.

\section{CONCLUSIONES}

La actual incorporación de las mujeres al mundo del teatro en tanto que directoras y autoras, aunque incipiente, está ya cambiando la idiosincracia del género dramático y poniendo sobre la mesa temas hasta ahora silenciados. Así, las iniciativas escénicas que a día de hoy problematizan la maternidad y la paternidad parten en su mayoría -lamentablemente- de autoras femeninas. La pieza de Marta Galán, junto con su proceso de creación, es un buen ejemplo de ello y de cómo las dinámicas del mundo teatral afectan y distribuyen la presentación de ésta y otras temáticas ligadas a la mujer.

En El conejito del tambor de duracell, Marta Galán propone una reflexión, ligada a su experiencia concreta de mujer heterosexual que ha sido madre (Galán 2017), que cuestiona el modelo de crianza y de familia actual y arroja luz sobre el desamparo emocional, laboral y económico que puede generar la maternidad en nuestra sociedad. Se trata, por lo tanto, de una obra que se inserta en la línea de piezas que destilan materiales autobiográficos que sirven para cuestionar «el concepto de identidad» (Gázquez 56), desde una posición claramente política. En este sentido, la fuerte carga teórica de la pieza cobra 
una vitalidad nueva, al verse materializada en las experiencias reales de una mujer concreta.

El discurso de la protagonista parte de una perspectiva interseccional que aúna anticapitalismo y feminismo de la diferencia. En cuanto a su maternidad, no es de tipo intensivo -puesto que tiene una ocupación remunerada que le ocupa entre ocho y diez horas cada día-, pero sí bastante presente -como la de muchas mujeres que concilian-, al haber elegido no delegar cuidados en otra mujer y al haber renunciado a autorrealizarse a través de actividades personales. La cuestión, casi sobra decirlo, es identificar hasta qué punto se trata de una elección verdadera o bien de una situación forzada por un entorno social que delega enteramente los cuidados en las mujeres. Ella no deja de manifestar esta ambigüedad para defender la posibilidad para «las personas que cuidan» (10) de disponer de tiempo, especialmente para el cuidado de bebés y niños, insistiendo en que la crianza y otras tareas reproductivas constituyen un trabajo no remunerado.

En su puesta en escena, como hemos visto, este conjunto de reflexiones se ve mermado en sus postulados más rompedores. No es baladí que ello coincida con el acceso a la escenificación para un público más amplio que el hasta entonces convocado por Galán: al tiempo que lima las connotaciones políticas de la pieza, la versión de Martínez transforma un texto cercano a lo postdramático en un monólogo tragicómico mucho más tradicional, en el que los cambios bruscos del texto quedan hábilmente solventados. En otras palabras, la producción del Lliure es más conservadora que los trabajos habituales de Galán tanto en su subversión del género como en términos de lenguaje teatral. Por ello el proceso de creación de Conillet, junto con el hecho de que sea esta institución faro del teatro barcelonés quien coproduzca la pieza, no hace sino reafirmar una tendencia general: cuanto más se sube en la jerarquía teatral, menos representación tienen las mujeres y, de manera paralela, más cercanas a un discurso patriarcal son las narrativas que las representan.

A pesar de todo, poner la maternidad en el centro de un objeto cultural, como hace Galán, implica sacarla de su devaluación sistemática para tratarla como «ámbito de oportunidad para conocer y analizar toda su complejidad en lo referente a las relaciones, [...] a las emociones, a las tensiones y contradicciones que genera», pero también como «locus privilegiado para analizar cuestiones como las relaciones de poder» (Fernández Pujana 25). Es decir, darle el estatus que se le ha negado sistemáticamente en la representación cultural occidental: el de una experiencia humana y por lo tanto compleja, diversa y crucial para sus protagonistas. Abordarla en tanto que espacio político 
significa, además, reivindicar su verdadero valor de trabajo, algo estrechamente ligado a la posibilidad de su revalorización simbólica, puesto que

Mientras que el trabajo reproductivo siga devaluado, mientras siga considerándose una tarea privada y responsabilidad exclusiva de las mujeres, estas siempre tendrán menos poder que los hombres para oponerse al Estado, y permanecerán en condiciones de extrema vulnerabilidad social y económica. (Federici 2013,179)

El conejito del tambor de duracell nos interpela, a través de su discurso potente, complejo, anárquico y subversivo, con un mensaje de importancia capital: sin igualdad de oportunidades en el terreno social y sin políticas centradas en la vida cotidiana de las mujeres, no habrá nunca igualdad en el campo simbólico y cultural, que es el que continúa sustentando, como nos recuerda Ana de Miguel, el patriarcado del consentimiento.

\section{REFERENCIAS BIBLIOGRÁFICAS}

Badinter, Elizabeth. La mujer y la madre: un libro polémico sobre la maternidad como nueva forma de esclavitud. Madrid: La Esfera de los libros, 2011.

Cornago, Oscar. Éticas del cuerpo: Juan Domínguez, Marta Galán, Fernando Renjifo. Madrid: Fundamentos, 2008.

Esteban, Mari Luz. «La maternidad como cultura. Algunas cuestiones sobre la lactancia materna y cuidado infantil». Medicina y cultura. Estudios entre la antropología y la medicina. Eds. Enrique Perdiguero y Josep M. Comelles. Barcelona: Edicions Bellaterra, 2000. 207-226.

Federici, Silvia. Revolución en punto cero. Trabajo doméstico, reproducción y luchas feministas. Madrid: Traficantes de Sueños, 2013.

Fernández Pujana, Irati. Feminismo y maternidad: ¿una relación incómoda? Conciencia y estrategias emocionales de mujeres feministas en sus experiencias de maternidad. Vitoria-Gasteiz: Emakunde/Instituto Vasco de la Mujer, 2014.

Foguet, Francesc. «Dones extenuades». El Temps 1642 (1 diciembre 2015): 94.

Galán, Marta. La Corporació/2009: superproduccions postdramàtiques d'un sol ús / un projecte de Marta Galán per a la Nau Ivanow / BCN. Barcelona: Departament de Cultura i Mitjans de Comunicació, Nau Ivanow, Escándalo Films, 2009.

Gázquez Pérez, Ricard. La escenificación del yo en los solos de las nuevas creadoras interdisciplinares en España: 2000-2014. Tesis doctoral de la Universitat Autònoma de Barcelona, 2014. <http://www.tdx.cat/handle/10803/384527>, consultado el 23-05-2017.

Goñi-Legaz, Salomé, Andrea Ollo-López y Alberto Bayo-Moriones. «The Division of Husehold Labor in Spanish Dual Earner Couples: Testing Three Theories», Sex Roles 63 (2010): 515-529. 
Gracia, Pablo y Daniela Bellani. Las políticas de conciliación en España y sus efectos: un análisis de las desigualdades de género en el trabajo del hogar y el empleo. Estudios de progreso 51. Madrid: Fundación Alternativas, 2010.

Hays, Sharon. The Cultural Contradictions of Motherhood. Yale: Yale University Press, 1996.

Imaz, Elixabete. Mujeres gestantes, madres en gestación. Representaciones, modelos y experiencias en el tránsito a la maternidad de las mujeres vascas contemporáneas. Leioa: Universidad del País Vasco, 2010.

Llopis, María. Maternidades subversivas. Tafalla: Txalaparta, 2015.

Miguel de, Ana. «Sobre el patriarcado del consentimiento». <http://www. tribunafeminista.org/2017/05/ana-de-miguel-sobre-el-patriarcado-del-consentimiento/>, consultado el 28-05-2017.

Nicolau, Adriana. «Entrevista a Marta Galán». 25 mayo 2017 (material inédito hasta publicación de tesis doctoral).

Requena Aguilar, Ana. «Entrevista a Silvia Federici. Es un engaño que el trabajo asalariado sea la clave para liberar a las mujeres». El diario, 24 mayo 2014. <http://www.eldiario.es/economia/engano-trabajo-asalariado-liberar-mujeres_0_262823964.html>, consultado el 24-05-2017.

Sau Sánchez, Victoria. Reflexiones feministas para principios de siglo. Madrid: Horas y horas, 2000.

Soler Bort, Soraya. «Entrevista a Marta Galán. Marta Galán, creadora i autora contemporània». Faaan! (2015). <http://faaan.es/people_view.php?i=1506>, consultado el 23-05-2017.

Stanworth, Michelle. Reproductive technologies: gender, motherhood and medicine. New York: Polity Press, 1987. 

Para enlazar con este artículo / To link to this article:

http://dx.doi.org/10.14198/fem.2017.30.10

Para citar este artículo / To cite this article:

Peña Rodríguez, Francisco José. «El teatro de Ana Merino: una propuesta para el siglo XXI». En Eva García-Ferrón y Cristina Ros-Berenguer (coords.), Dramaturgia femenina actual. De 1986 a 2016. Feminismo/s, 30 (diciembre 2017): 193-207, DOI: 10.14198/fem.2017.30.10

\title{
EL TEATRO DE ANA MERINO: UNA PROPUESTA PARA EL SIGLO XXI
}

\author{
ANA MERINO'S THEATER: \\ A PROPOSAL FOR THE $21^{\text {ST }}$ CENTURY
}

\author{
Francisco José PeÑa RodRíGUEZ \\ IES Miguel de Cervantes (Fuenteálamo, Albacete) \\ Universidad Autónoma de Madrid \\ franciscojosepr@yahoo.es \\ orcid.org/0000-0002-1381-1238
}

\section{Resumen}

En este trabajo se analiza, desde una lectura múltiple (textual, lingüística, social), el teatro de la poeta madrileña Ana Merino (Madrid, 1971) como una propuesta dramatúrgica para el siglo XXI. En una etapa de crisis del teatro actual, el análisis de sus piezas teatrales recogido en este estudio muestra su obra como una aportación novedosa en el contexto del teatro femenino español actual.

Palabras clave: España, teatro, poetas, dramaturgas, propuesta teatral.

\begin{abstract}
This article discusses from a multiple reading (textual, linguistic, social) the theatre of the Spanish poet Ana Merino (Madrid, 1971) as a new dramaturgy proposal for 21st century. In context of crisis in the current theatre, the analysis of her theatre's plays collected in this article shows her theatre as a singular contribution in context of the current Spanish female theatre.
\end{abstract}

Keywords: Spain, theatre, poetess, playwrights, theatrical proposal. 



\section{INTRODUCCIÓN}

En la dramaturgia española de los últimos veinte años hallamos una serie de características propias del teatro que acentúan ciertos aspectos críticos: una constante argumentación a favor de una continua crisis escénica posterior a la Transición (1976-1982) y la aparición de nuevos nombres que revitalizan la escena, singularmente comediógrafas nacidas en el tardofranquismo e incorporadas al teatro con el cambio de siglo. En el primero de los casos el profesor José-Carlos Mainer incide en que la crisis teatral es «crónica»-más allá de media docena de propuestas-, quizás por «la omnipresencia de la subvención pública» (210); en el segundo, la escritura de una serie de obras singulares, de la mano de dramaturgas a cuya cabeza el propio Mainer sitúa a Paloma Pedrero y Angélica Lidell (210), aporta una prolongación de la tradición teatral española con dosis de realismo y leve experimentación. En este contexto, otros nombres más allá de las consagradísimas Ana Diosdado o Lourdes Ortiz añaden novedosas visiones teatrales que no se ciñen exclusivamente al teatro convencional que se ha venido desarrollando hasta los años noventa del siglo XX.

El estudio de dramaturgias particulares, basado en el análisis de todos los aspectos intervinientes en la escritura dramática y puesta en escena de la pieza, se nos hace necesario. Así, el propio libreto; el lenguaje, desde el punto de vista denotativo o connotativo, pero también desde su uso social en la obra en relación con el público; la ficcionalidad del universo teatral; la configuración global de la obra como un todo literario; su escenicidad y, además, su valor social. En definitiva, todos los ámbitos formales y estilísticos de la misma se reconocen necesarios para analizar estéticas singulares que puedan añadirse a la tradición teatral de nuestros días.

La exégesis de la obra teatral de Ana Merino permite entender su dramaturgia como una propuesta estética válida y en consonancia con el teatro actual desarrollado por mujeres, tal como se mostrará en adelante. Además, la proyección futura de su obra -todavía en ciernes- permite consolidar las tesis defendidas por críticos que han adelantado en estudios precedentes la obra ya clásica de autoras de nuestros días, como Angélica Lidell e Itziar Pascual, tanto en obras monográficas como en ensayos de conjunto que el lector verá 
citados y encontrará anotados en el apartado bibliográfico. En ese sentido, este trabajo pretende, desde el análisis teatral de Ana Merino, incorporarla al canon de dramaturgas actuales, toda vez que la autora tiene ya tras de sí un bagaje poético singularmente relevante desde mediados de los años noventa.

Así pues, al permanente debate -no siempre clarificador-acerca de la crisis del teatro español y a las originales propuestas teatrales de las nuevas dramaturgas, unidas a los nombres de autoras consagradas como Paloma Pedrero o M. ${ }^{a}$ Manuela Reina, entre otras, se unen nuevas aportaciones como la de Ana Merino (Madrid, 1971), quien se ha sumado a la escritura dramática con tres obras de significativa temática social y, al mismo tiempo, con un marcado propósito experimental desde el punto de vista estético y temático.

Amor: muy frágil (2012), Las decepciones (2014) y La redención (2016) implican, inicialmente, un compromiso social a partir de una profunda mirada hacia problemas y debates actuales, como las relaciones entre personas del mismo sexo, el amor y sus fórmulas en el siglo XXI o la idea de destrucción del planeta a causa de la contaminación y los efectos del calentamiento global. Además, esos temas y la prospección en otros secundarios, la experimentación formal basada en estructuras de cuatro actos (Amor: muy frágil), seis (La redención) o siete (Las decepciones) conllevan una apuesta escenográfica singular, en consonancia con las propuestas innovadoras y vanguardistas del teatro español materializadas desde principios del siglo XX. La propia Merino reconoce que «lo que buscaba era expresar mi universo» ${ }^{1}$ (Peña/Merino 2017).

Hasta bien entrado el último cuarto del siglo XX las propuestas teatrales de la mano de dramaturgas no pasaban de más allá de algún breve epígrafe en los manuales canónicos de la literatura actual, o de esporádicas reseñas en la prensa; análogamente, la singular historia del teatro español -por otra parte excelente en matices, ideas y nombres- se ha centrado en una inmensa mayoría de autores, entre los que se abrieron paso inicialmente nombres como los de María Martínez Sierra (María de la O Lejárraga, 1874-1974), Pilar MillánAstray (1879-1949) o Concha Méndez (1898-1986) a inicios del siglo pasado. No obstante, nuevas visiones de la literatura española actual y, sobre todo, un reconocimiento del papel literario de las comediógrafas en el teatro actual permiten explicar el teatro de los últimos veinticinco años desde autoras como Lourdes Ortiz y Carmen Resino hasta Gracia Morales o la propia Ana Merino. Desde 1980 el teatro español se enfrentó a circunstancias políticas y sociales que, por una parte, facilitaron un replanteamiento de temas, fórmulas y

1. Cita recogida a través de la correspondencia electrónica mantenida con la autora el 30 de octubre de 2017. 
representaciones y, por otra, incorporaron nuevos nombres, entre los cuales se encuentran los ya clásicos de la dramaturgia española actual. De ese modo, con el final de la dictadura los textos hasta ese momento prohibidos o mutilados por la censura pudieron representarse ( $E l$ público, de Federico García Lorca, o El Adefesio, de Rafael Alberti); en consonancia, las propuestas más vanguardistas y revolucionarias, frente al teatro convencional del franquismo (Alfonso Paso, Joaquín Calvo Sotelo), tenían cabida en las salas habituales y no únicamente en los círculos teatrales independientes, casi siempre ligados a estudiantes universitarios. Es en ese momento cuando se da a conocer Lourdes Ortiz con Las murallas de Jericó, obra que había obtenido el Premio Aguilar del año 1978. A raíz de la victoria socialista de 1982, las instituciones públicas recuperan la iniciativa del fomento teatral más allá de las salas de Madrid y Barcelona, de tal modo que diputaciones provinciales y ayuntamientos, conjuntamente con comunidades autónomas, restablecieron espacios y reivindicaron parcialmente nombres silenciados por el franquismo: basta citar el caso de la rehabilitación del Teatro Circo de Albacete (2002) dedicado además a la ópera -género escasamente puesto en escena en esa ciudad-o de la reedición de obras de autoras como la mencionada Concha Méndez, María Teresa León (La libertad en el tejado) o Carlota O'Neill (1905-1990), a quien destaca especialmente el profesor Romera Castillo en un reciente trabajo (228-231).

Por otro lado, Virtudes Serrano sitúa en el año 1983 «el renacer de la dramaturgia femenina en España» (2004, 562-563), explicitando que además de mostrar su trabajo varias autoras, vieron la luz tres significativas obras teatrales: Un olor a ámbar, de Concha Romero; Ulises no vuelve, de Carmen Resino (Premio Lope de Vega, 1974) y El navegante, de María Manuela Reina, que recibió el Premio SGAE. Sea como fuere, en el último tramo del siglo pasado la dramaturgia femenina cobra singular importancia y aparece ligada a la renovación teatral que la Transición y la consolidación democrática posterior permitió en nuestro país, sobre todo porque a la altura de 1990 aún «la presencia de nombres femeninos, tanto españoles como extranjeros, en la nómina de los autores resulta ser bastante exigua. Las mujeres representan sólo el 10,92\% de los dramaturgos que se encuentran en la cartelera madrileña» (Lo Porto 373). Más tarde, el teatro del siglo XXI permitirá verificar la convivencia de varias generaciones de dramaturgas en la publicación de obras y estrenos teatrales.

Como fenómeno análogo a la poesía actual escrita por mujeres o a la narrativa desligada del denominado best seller, el teatro del siglo XXI adquiere un valor temático e interpretativo que, en gran medida, se debe a propuestas de mujeres. Así, a los nombres que despuntaron en los ochenta (Lidia Falcón, Lourdes Ortiz, Helena Pimenta, Paloma Pedrero) se suman las nuevas 
promociones de autoras que, si bien nacen en los últimos años del franquismo, se educan ya en la democracia y toman conciencia social y literaria en los años de consolidación de unas libertades que implican el conocimiento y la formación intelectual más allá de la universidad, además de vivir ligadas a experiencias viajeras en interdisciplinariedad artística o literaria. En definitiva, autoras como Natalia Menéndez, Angélica Lidell, Itziar Pascual, Ana Merino o Gracia Morales desarrollan su textualización teatral en el siglo XXI.

\section{ANA MERINO: ENTRE LA POESÍA Y EL TEATRO}

Ana Merino Norberto nació en Madrid el 25 de junio de 1971 y es hija del escritor y académico de la RAE José María Merino. Se licenció en Historia Moderna y Contemporánea por la Universidad Autónoma de Madrid (1995) y, más tarde, realizó el Doctorado en Estudios Culturales y Transatlánticos (especializándose en Teoría del Cómic) por la Universidad de Pittsburgh (2001). A raíz de la obtención de una Beca Erasmus, a mediados de la década de 1990 residió en Groningen (Holanda), ciudad en la que surgieron algunas de las composiciones de su primer poemario, Preparativos para un viaje, Premio Adonáis de 1994.

La década pasada decide establecerse en Estados Unidos, desempeñando la docencia universitaria en la Appalachian State University (Carolina del Norte, 2001-2003), Dartmouth College (New Hampshire, 2004-2009) y, actualmente, en la University of Iowa, en donde dirige además el MFA de Escritura Creativa.

Merino se dio a conocer en la literatura a partir de la obtención del mencionado Premio Adonáis de 1994. Así, el galardonado Preparativos para un viaje vio la luz en 1995, al que siguieron Los días gemelos (1997) y La voz de los relojes (2000). En 2003 Juego de niños obtuvo el Premio Fray Luis de León de Poesía, concedido por la Diputación Provincial de Cuenca. A esos títulos hay que añadir Compañera de celda (2006), Curación (Visor 2010) y Hagamos caso al tigre (2010). Su poesía ha sido traducida al inglés y al alemán.

Nuestra autora ha alcanzado gran repercusión por sus estudios sobre el cómic, fruto de los cuales son los ensayos El cómic hispánico (2003) y Chris Ware: la secuencia circular (2005). Es colaboradora habitual de la revista española Leer, columnista del diario El País y ha sido galardonada con el Premio Diario de Avisos por sus artículos sobre el cómic.

En el plano teatral, la incorporación de Ana Merino a la escena se produce en la segunda década del siglo XXI. Debuta en 2012 con el estreno de Amor: muy frágil en el Theater Stok de Zúrich bajo su propia dirección, llevando más adelante la obra a teatros de Biel y San Galo (San Gallen), también en Suiza, en el otoño de ese año. Más adelante publica Las decepciones (2014) y La redención (2016); esta última se representó igualmente bajo la dirección de 
la propia Merino, en el Teatro de la Universidad de Iowa en 2017. A su pluma se debe, asimismo, la pieza breve Escenas alrededor de la leyenda de Bernardo del Carpio (2013).

Por añadidura, nuestra autora se ha introducido en el terreno narrativo con la novela juvenil El hombre de los dos corazones (2009) y algunos relatos publicados en obras colectivas.

Sobre el quehacer teatral, desde un punto de vista formal, José Luis Alonso de Santos resalta las pautas clásicas, formales y técnicas en La escritura dramática (1998) que, en esencia, se cumplen a la hora de analizar el teatro de Ana Merino. No obstante, la propuesta teatral de la autora permite establecer una coexistencia entre el planteamiento clásico de la obra, esencialmente en cuanto a la construcción del personaje, sus características y circunstancias, y la recreación de la atmósfera espacial en la que transcurre la acción dramática. Por ello, se puede afirmar que su propuesta dramática combina el teatro convencional con una evidente experimentación escénica -sobre todo- que va más allá del tratamiento temático que se evidencia en sus tres obras iniciales: el amor, el engaño, el sexo, la amistad, la culpa y lo social, entre otros que se matizarán más adelante.

A propósito de su actividad creadora, Ana Merino en 2006 explicaba en una entrevista sobre su formación académica en la Universidad Autónoma de Madrid que:

El trayecto a Cantoblanco, en tren o autobús, es perfecto para las distancias cortas de los cuentos o los poemas. Pero muchos estudiantes no saben lo que significa el placer de la lectura, el placer de abstraerse con una historia o un poema que tienes que descifrar, se conforman poniéndose unos cascos con música y no hacen esfuerzos. Leer significa un esfuerzo y como son «chicos audiovisuales» no saben construir espacios fijos de atención. Esto yo lo veo en España, en México o en Estados Unidos. (Peña 2006, 9)

La idea recurrente del tren como fuente inspiradora se traslada a la creación teatral, de ahí que la autora reconozca la concepción y escritura de Las decepciones en un tren entre San Galo y Zúrich, por los días en que en la primera de estas ciudades se representaba Amor: muy frágil. De este modo, ella misma explica que:

Las decepciones se fueron fraguando en el tren de San Gallen a Zúrich durante todo el otoño de 2012. Viajaba al menos tres veces por semana para ir a los ensayos de Amor: muy frágil, la que fue mi primera obra de teatro que yo misma dirigí y monté con un grupo de actores hispano-suizos. La aventura de ese montaje me hizo adicta a sus sensaciones y me llenó de energía para escribir esta otra pieza. $(2014,9)$ 
Es evidente que esta anécdota no es más que una parte mínima de su labor creadora, a pesar de que la propia dramaturga reconozca que también La redención fue concebida «mientras volaba de Zúrich a Edimburgo a comienzos de abril de 2013» $(2016,7)$. En realidad, la construcción de la obra teatral de Merino en todo su sentido queda explicada, habitualmente, en los prólogos de sus obras, como también hacía, por ejemplo, Enrique Jardiel Poncela.

El proceso ideológico que lleva a textualizar la obra literaria requiere de un proceder formal-estilístico que, como ha estudiado Manuel Pérez Jiménez (2005), configura la obra teatral desde lo ficcional a la escenicidad. En ese sentido, la propia Ana Merino explica la génesis de sus obras desde aspectos sociales y humanos que derivan en materia teatral procedente de la observación o vivencia de lo cotidiano. Así pues, La redención nace de la reflexión personal acerca de que «algún día tendremos que darnos cuenta de que la contaminación es una losa que nos hunde. Es un aura ominosa que está en el aire, el mar y la tierra. Llevamos más de medio siglo contaminando sin parar» $(2016,10)$; una reflexión social que vuelve la vista, como referentes que servirán para configurar la atmósfera distópica de la pieza, hacia Chernóbil y Fukushima y las catástrofes medioambientales que se dieron allí en 1986 y 2011, respectivamente. Esa distopía nace, incluso, de una situación personal en el aeropuerto de Ámsterdam que incidió en el proceso de escritura de la obra teatral.

Por añadidura, la mudanza personal desde Nueva Inglaterra (Darmouth College) al Medio Oeste norteamericano (Iowa), el desencanto y el cansancio que la burocracia universitaria produce en la docente-autora-poeta conlleva una apuesta por el teatro: de esa introspección personal a unas notas de diario y de la imagen difusa de un personaje a la escritura de Amor: muy frágil (Merino 2012, 14-15). Paralelamente, las conversaciones en los ensayos con los actores de esa obra derivaron en la idea central de Las decepciones.

En tanto que dramaturga que, además, ha dirigido los montajes escénicos de sus obras, Merino pasa de lo ideológico a lo formal, a la plasmación de lo espacio-temporal o a la dramatización de personajes y acciones con una ágil discursividad -discursividad alternada-, en consonancia con las líneas dominantes en la dramaturgia actual. Por otra parte, la elección del teatro no es aleatoria, ya que, como ella misma confesará, «el teatro es una apuesta mucho más interesante que la novela súper-ventas» (Peña/Merino 2017).

\section{EL TEATRO DE ANA MERINO}

La trayectoria teatral de Ana Merino es aún reciente, lo cual no le impide aportar una mirada de modernidad dramática -propia de las autoras actuales- en 
consonancia con otras propuestas españolas o americanas como la de la argentina Lola Arias (Buenos Aires, 1976).

Así pues, la concepción dramática de la autora se mueve entre el teatro de síntesis (M. ${ }^{a}$ José Ragué-Arias, Pilar Pombo) y las novísimas propuestas (Yolanda García Serrano, Sara Molina), cuyos comienzos podemos situar a finales de los años noventa e inicios de la década pasada (Prieto de Paula y Langa, 263-275). Asimismo, la tradición clásica -con sus singulares dosis de experimentación- se da cita en el teatro de Ana Merino, ya que, desde mi punto de vista, Benito Pérez Galdós y Antonio Buero Vallejo comparecen tras las temáticas de Amor: muy frágil o La redención. Parece evidente que la pasión lectora de la comediógrafa está presente en el trasfondo de la elaboración de personajes y tramas; no en vano, ella misma confesaba en 2006 su amplio bagaje de lecturas clásicas:

Son muchas las lecturas. Desde los clásicos españoles del Siglo de Oro hasta la generación del 27 al completo, pasando por los ingleses, latinoamericanos, franceses... He tenido la suerte de crecer en una casa con una biblioteca inmensa donde los libros de poesía se leían constantemente. (Peña 2006, 9)

En Amor: muy frágil ${ }^{2}$ el planteamiento temático parte de que dos amigos, Jorge y Matías, comienzan una relación amorosa inserta en un triángulo pasional, ya que el primero de ellos está casado con Ada, con la que se resiste a romper sentimentalmente. Como consecuencia de esos amores casi clandestinos surgen, a su vez, emociones y sentimientos encontrados (el engaño, la amistad, la dependencia afectiva, los hijos...) que llevan a Matías a desarrollar unos intensos celos. La autora verbaliza así un tema candente en España en los años iniciales del siglo XXI, el de las parejas homosexuales -recordemos que en 2005 se produjo la aprobación del matrimonio entre parejas del mismo sexo-. Un debate también abierto en Estados Unidos, país de residencia de la escritora, que aumenta por tanto el valor social del planteamiento teatral.

Ana Merino recupera aquí el tema del ménage à trois de la tradición literaria occidental, pero desde un punto de vista radicalmente diferente y rompiendo el esquema convencional de la mujer atrapada entre dos amores masculinos: en esta obra aparece una pareja masculina en el centro de la relación y la mujer de uno de ellos (Ada) resulta el factor que impide el normal desarrollo de la experiencia amorosa. Este nuevo triángulo amoroso tiene su razón de ser en una sociedad moderna, con planteamientos vitales novedosos pero, igual que

2. La pieza se estrenó a finales de 2012 en el ya mencionado Teatro Stok de Zúrich, bajo la dirección de la propia Merino y con un elenco de actores formado por Alberto Ruano, Sandra Zellweger, Rainer Jutzi, Sandra Vilas, Mireya Sánchez, Sonia Díaz y Carolina Flores. 
en otras obras de similar planteamiento temático, aparece detrás una sociedad con sus convencionalismos- que finalmente impedirá la libre elección de Jorge y Matías. Por extensión, esa atmósfera social, representada principalmente por la familia y los hijos, incide en la imposibilidad de ruptura entre Jorge y Ada, beneficiando así la cohesión familiar. Los elementos espacio-temporales justifican del mismo modo los sentimientos de insatisfacción y frustración que desarrolla el libreto teatral.

Paralelamente, esta obra recuerda, en mi opinión, a La de San Quintín, de Benito Pérez Galdós (1894), cuyo leit motiv es igualmente un triángulo amoroso, cuyo arriesgado planteamiento en la época contó en su estreno con notable polémica. No obstante, Ana Merino matiza que «la verdad es que he escrito de manera muy libre, pero he tenido presente la tradición española del teatro. A Lope, a Cervantes y a Calderón, pero también el teatro de Galdós o Buero. Creo que me he empapado a través de sus obras de esa pulsión literaria que reivindico» (Peña/Merino 2017).

En La redención ${ }^{3}$ un grupo de trabajadores en el tratamiento de residuos (Isabel, Ada, Nicolás, Rodrigo y Jaime) acude a una planta cercana al mar, en un lugar difuso, para tratar de procesar el material almacenado; una vez allí, se recrea una atmósfera cercana a la ciencia ficción (distopía). En ese panorama desalentador se suscitarán sentimientos encontrados entre los personajes, dando lugar a emociones divergentes como el pesimismo, la soledad, la pulsión amorosa o la sensación de abuso de poder. La obra enuncia análogamente algunos de los problemas sociales más acuciantes de nuestro tiempo: la incomunicación en la era de las nuevas tecnologías, las nuevas relaciones laborales que frustran y empobrecen al trabajador -surgidas en la época de crisis económica y social en la que se escribe la pieza teatral- y, al mismo tiempo, plantea a través de los personajes (Ada, Isabel, Rodrigo) estereotipos de ciudadanos competentes cuya psicología se ve transformada por la acción teatral, en función de las circunstancias límite y contradictorias que se producen con el transcurso de los actos que componen la pieza.

A pesar de la singularidad de esta pieza teatral, La Fundación (1974), de Antonio Buero Vallejo, se percibe, de nuevo desde mi punto de vista, tras la línea argumental de esta obra: una «redención» con la que sueñan los protagonistas. En esta obra de Merino las precisas intervenciones de Ada y Rodrigo, sobre todo, irán mostrando la sensación de búsqueda de una salida a

3. Esta obra fue estrenada en mayo de 2017 en Iowa, codirigida por Ana Merino y Taylor Claman. El elenco de actores, procedentes en su mayoría de la University of Iowa, estuvo formado por Karla Álvarez, Beatriz O. Gallardo, Eloy Barragán, Jim Evans, Horacio Olivo y Valeria Amado. 
la inmovilidad de las vidas de los personajes, previa introspección en su pasado y en sus propias pulsiones y sentimientos.

Las decepciones resulta una obra marcada, en diferentes momentos, por una atmósfera metafísica. Está protagonizada por un profesor cincuentón y tres de sus alumnos: Marta, Sara y Mauro. Afectados todos ellos por un atentado crucial en sus vidas, ese hecho desencadena la pluralidad de enfoques y puntos de vista humanos que, del mismo modo que los acerca como amigos, también los aleja. En este drama Merino acude a un tema actual y muy presente en la sociedad occidental, el del terrorismo (11-S, 11-M), para desarrollar la escritura dramática de la obra. La comediógrafa se introduce incluso en las nuevas fórmulas de relación entre profesores y alumnos, surgidas de la evolución de los métodos de enseñanza universitarios occidentales. También aparece el tema de la educación como fórmula de reflexión social o la proyección del mundo universitario como referente desde el que analizar la sociedad en la que viven los protagonistas y plantear soluciones a los problemas sociales. El tema de la educación como superador de las dificultades de la sociedad está muy presente en toda la obra y la ideología de la autora:

Creo firmemente que la educación es la llave fundamental que redime el mundo. Y dentro de ese proceso son clave los maestros y profesores porque son los que nos ayudan a madurar y a crecer [...] Por eso me dedico a la educación, porque creo que la única forma de cambiar el mundo es educando a la gente; enseñarles a pensar y a que aprendan a valorar el mundo que les rodea... a desarrollar su propio criterio ideológico e intelectual respetando siempre a los demás. Pero la educación empieza en las escuelas cuando somos niños y nos enseñan a leer, a valorar la literatura y a imaginar. (Peña 2006, 9)

En líneas generales, el teatro de Ana Merino está concebido con fórmulas «muy directas y expresivas» (Alvar, Mainer y Navarro, 660), propias de la poética de su obra previa. Así, la obra teatral de la autora madrileña está muy ligada a los problemas sociales de su tiempo pero, además, experimenta mediante la construcción de personajes complejos, desde el punto de vista psicológico, cuyos traumas y experiencias personales anteriores a la acción dramática salen a la luz en el contexto del argumento principal. Son, de igual modo, personajes que evolucionan al ritmo de la obra teatral, sin demasiadas acotaciones que especifiquen sus características físicas o psicológicas y que, por extensión, quedan estéticamente a merced de la visión del espectador, en virtud del desarrollo dramático de cada pieza.

Paralelamente, cada obra teatral implica una mirada hacia la sociedad, con una intención didáctica -quizás- que no siempre tiene una lectura lineal debido a la complejidad de los personajes, más allá de la urdimbre textual. En ese sentido, la prospección en las interioridades de Ada o los protagonistas 
masculinos de La redención aportan una visión mucho más compleja de la idea central: la salvación del universo de su propia autodestrucción medioambiental. Si por un lado Jaime llega a decir que «hay esperanza. Los índices de radiación han bajado» (38), por otro, Rodrigo deja de lado ese optimismo para exteriorizar que:

Mi yo anterior retornará. Los rincones de mi existencia consciente pueden volver a mí (suspiros). Todos los días me despierto buscando la clave de mi ser anterior y solo noto cuchilladas clavándose en mi espalda. Puñales de olvido que me atan al espanto de los malos presentimientos. (58)

Es preciso mencionar, en el mismo sentido, que el reflejo de la realidad lingüística de nuestros días es evidente, recogiendo un lenguaje estándar y cotidiano propio de la condición de clase media de casi todos los protagonistas de la dramaturgia de Merino. Esa representación verbal, que implica un entendimiento e identificación del lector-espectador con el personaje, es evidente en Amor: muy frágil o La redención. Desde otro punto de vista, en Las decepciones la autora se permite modular ese lenguaje, ya que el hecho de que tres de sus protagonistas (Marta, Sara y Mauro) sean estudiantes facilita la diversidad verbal en aras de la verosimilitud.

En relación con esta última obra, el cambio de registro entre el profesor y los alumnos es mínimamente perceptible: por un lado el docente mantiene unos parlamentos en consonancia con su posición intelectual y, por otro, los alumnos se permiten expresiones algo más coloquiales o cotidianas, especialmente Sara. Esta protagonista incorpora en sus intervenciones expresiones como «tabletas digitales», «navego por la red», «terminaba enganchando las bragas y los leotardos» (39); o, más adelante, otras como "profe», «jugoso blog» (50) o "ganazas» (67), incluso se permitirá la ironía: «Hay algún que otro chorizo que tiene esas ocurrencias, muy culto sí, pero a base de mangonear...» (61).

Sara es, desde mi punto de vista, el personaje más redondo de la citada obra, como considero que Matías y Ada lo son en Amor: muy frágil y La redención, respectivamente. La estudiante de Las decepciones es, pues, fiel reflejo de alumnos universitarios de hoy -pese al impacto que en ella causa el atentado y sus secuelas posteriores- $y$, como se viene especificando, sirve a la autora para marcar la diferencia, desde el punto de vista del lenguaje teatral, con el resto de personajes en el teatro de Ana Merino. De ese modo, Sara verbaliza parlamentos cargados no solo de cotidianidad, sino también -como se ha vistode humor e ironía: «Parece un pavo real. Qué manera de inflarse (con ironía). Qué satisfacción. Parece que levita, ¿no?» (64). 
Por lo que se refiere a la concepción general de su teatro, Ana Merino no busca la complejidad formal, estética, en cada obra teatral; tampoco hay, en su aún corta trayectoria como comediógrafa, ningún tipo de alarde estilístico o vanguardismo que la aleje de la conexión con el público. Es más, la proyección de toda suerte de sentimientos y emociones -como se ha escrito- busca la comunicación directa con el público que, en cierto modo, se siente identificado o disiente de los planteamientos sobre el engaño, el amor, las relaciones interpersonales, el medio ambiente, el egoísmo, la culpa y un sinfín más de temas y subtemas que subyacen en la confusión vital de los protagonistas.

Simultáneamente, el compromiso social -como hemos visto- no llega necesariamente a un compromiso político, sino a una actitud o mirada crítica que arroje una lectura personal de los problemas colectivos en la actualidad. No hay en sus obras y planteamientos textuales -por el momento- una lectura política, aunque sí un «compromiso con la humanidad» a través de la escritura dramática.

Acerca de la diversidad en actos de su obra, de cómo los tres actos convencionales no le son útiles y los modifica, supeditándolos al discurso teatral, comenta la autora:

De pronto los tres actos se me quedaban cortos. Me gustó mucho adentrarme en la voz literaria de los personajes y eso hace que los actos tengan otra dinámica [...] En Amor: muy frágil lo llevaba a dos casas y pasaba en cuatro actos, en Las decepciones todo se desarrollaba en 7 actos y La redención lo llevo a seis actos. Me gusta que los personajes se muevan en espacios diferentes y marcar las diferencias entre esos espacios, con actos donde hay oscuridad y cambio de escenario. Creo que eso limpia la escena y permite que el espectador respire. Reivindico un teatro de pulsión literaria, ese aspecto me parece importante. Quiero retornar al teatro de actores que interpretan vida y pensamiento. Creo que en los últimos años se ha primado el ritmo de textos breves en cada intervención donde los actores dicen ocurrencias y no se profundiza. Mi reivindicación es la pulsión existencial literaria como expresión teatral [...] Creo en la fuerza del teatro como espacio de reflexión social. (Peña/Merino 2017)

Es por ello que la lectura de cada obra, la comunicación directa con el público, el mensaje claro que transmite cada planteamiento tiene una fuerte dosis de didactismo.

\section{CONCLUSIÓN}

Toda obra abierta -como la de Ana Merino y otras autoras de nuestros díasimplica una conclusión también abierta de ideas acerca de una obra literaria y de su valor en el contexto literario del momento histórico. Por lo que se refiere a este trabajo, con él se ha expuesto una visión muy general de la dramaturgia 
y estética de la autora madrileña en una nueva faceta de su trayectoria literaria; una interpretación textual de sus obras -a excepción de la pieza breve titulada Escenas alrededor de la leyenda de Bernardo del Carpio- que, pese a su edición en España y la puesta en escena de dos de ellas en Suiza y Estados Unidos, aún deben subir a las tablas en nuestro país ${ }^{4}$.

En este estudio se ha mostrado el teatro de Merino como una propuesta que se cimenta en tres aspectos singulares. En primer lugar, en una verbalización que, con un lenguaje estándar cargado de ironía, gira hacia lo coloquial en diversos personajes (Las decepciones) y en torno a temas profundamente sociales, así como con un punto de vista personal que los pone en consonancia con el público. En segundo lugar, una configuración de personajes complejos cuyas emociones y sentimientos no necesariamente se subordinan a la acción principal de la obra. Y, por último, una innovación en cuanto al número de actos, los cuales, como se ha dicho, relacionan a la dramaturga con los experimentos teatrales de inicios del siglo XX. En este último aspecto es reseñable que ninguna de sus obras se ciña a los tres actos convencionales, pese a una extensión del libreto muy similar a la de las obras clásicas 5 .

En cuanto al teatro de nuestros días, parece evidente que su revitalización, innovación y, sobre todo, apuesta escénica se debe en gran medida a las propuestas que vienen de la mano de autoras que tomaron las tablas a principios de nuestro siglo y que arriesgan teatralmente en un momento en el que, parafraseando al profesor Mainer, la crisis crónica del teatro nos permitiría tener esperanza.

\section{REFERENCIAS BIBLIOGRÁFICAS}

Alonso de Santos, José Luis. La escritura dramática. Madrid: Castalia, 1998.

Alvar, Carlos, José-Carlos Mainer y Rosa Navarro. Breve historia de la literatura española. Madrid: Alianza, 2014.

Checa Puerta, Julio. «Mujeres y teatro en la escena actual: Angélica Lidell (1966) e Itziar Pascual (1967)». ALEC 36.2 (2011): 85-112.

García-Pascual, Raquel (ed.). Dramaturgas españolas en la escena actual. Madrid: Castalia, 2011.

4. El académico José María Merino reconoció al autor de este trabajo que «quizás el motivo por el cual aún no se han estrenado en España sea que Ana vive en Estados Unidos y un montaje requiere una presencia constante y de tiempo, sobre todo en los ensayos y en el montaje». (Entrevista en León, 19 de octubre de 2017).

5. Es preciso señalar que Lourdes Ortiz, Carmen Resino, Paloma Pedrero, Lluisa Cünillé o Laila Ripoll, entre otras, tienen piezas de un único acto. 
Lo Porto, Valeria Maria Rita. «Puesta en escena de obras de dramaturgas en la cartelera de ABC de Madrid (1990)». Signa 21 (2012): 369-393.

Mainer, José-Carlos. Historia mínima de la literatura española. Madrid: Turner/El Colegio de México, 2014.

Merino, Ana. Amor: muy frágil. Madrid: Reino de Cordelia, 2012.

Merino, Ana. Las decepciones. México: Consejo Nacional para la Cultura y las Artes, 2014.

Merino, Ana. La redención. Madrid: Reino de Cordelia, 2016.

Nieva de la Paz, Pilar. «Las autoras teatrales españolas frente al público y la crítica (1918-1936)». Actas del XI Congreso de la Asociación Internacional de Hispanistas. Irvine, 1992, 129-139.

Pedraza Jiménez, Felipe B., y Milagros Rodríguez Cáceres. Manual de literatura española. XIV Posguerra: dramaturgos y ensayistas. Pamplona: Cénlit, 1995.

Pedrero, Paloma. Pájaros en la cabeza. Teatro a partir del siglo XXI. Ed. Virtudes Serrano. Madrid: Cátedra, 2013.

Peña Rodríguez, Francisco José. «La obra de Ana Merino: hacia la poesía del siglo XXI». Género y géneros I: Escritura y escritoras iberoamericanas. Ed. Ángeles Encinar, Eva Löfquist y Carmen Valcárcel. Volumen 1. Madrid: Universidad Autónoma de Madrid, 2006, 373-383.

Peña Rodríguez, Francisco José. «La educación es la llave que redime el mundo». Encanto Blanco 37 (octubre 2006): 8-9.

Pérez Galdós, Benito. La de San Quintín. Electra. Ed. Luis F. Díaz Larios. Madrid: Cátedra, 2002.

Pérez Jiménez, Manuel. «Panorama formal-estilístico de la dramaturgia femenina actual». Dramaturgias femeninas en la segunda mitad del siglo XX: espacio y tiempo: actas del XIV Seminario Internacional del Centro de Investigación de Semiótica Literaria, Teatral y Nuevas Tecnologías. Coord. José Romera Castillo. Madrid: UNED, 2005, 509-524.

Prieto de Paula, Ángel L., y Mar Langa Pizarro. Manual de Literatura Española Actual. Madrid: Castalia, 2007.

Romera Castillo, José. Teatro español entre dos siglos a examen. Madrid: Verbum, 2011.

Serrano, Virtudes. «Política, teatro y sociedad: temas de la última dramaturgia española». Monteagudo 2 (1997): 75-92.

Serrano, Virtudes. «Dramaturgia femenina fin de siglo. Estado de la cuestión». Arbor CLXXVII (Marzo-Abril 2004): 561-572. 

Para enlazar con este artículo / To link to this article:

http://dx.doi.org/10.14198/fem.2017.30.11

Para citar este artículo / To cite this article:

Ros-Berenguer, Cristina. «Hacia el horizonte de lo colectivo: la «generación en red» y el teatro político de Lola Blasco». En Eva García-Ferrón y Cristina Ros-Berenguer (coords.), Dramaturgia femenina actual. De 1986 a 2016. Feminismo/s, 30 (diciembre 2017): 209-233, DOI: 10.14198/fem.2017.30.11

\title{
HACIA EL HORIZONTE DE LO COLECTIVO: LA «GENERACIÓN EN RED» Y EL TEATRO POLÍTICO DE LOLA BLASCO
}

\author{
TOWARDS THE HORIZON OF THE COLLECTIVE: \\ THE «NETWORK GENERATION» AND THE POLITICAL \\ THEATER OF LOLA BLASCO
}

\author{
Cristina ROS-BERENGUER \\ Universidad de Alicante \\ Cristina.ros@ua.es \\ orcid.org/0000-0001-8051-2046
}

\section{Resumen}

Los primeros estudios críticos sobre las directrices del teatro español del siglo XXI coinciden en la existencia de una escritura dramática joven con propuestas suficientemente específicas como para hablar de una visión novedosa en el panorama teatral actual. Se trata de una nueva generación en la que el papel cualitativo y cuantitativo de las dramaturgas se considera indiscutible. Entre sus características destaca el retorno a la mirada social y comprometida del teatro. Así, a partir de la revisión de los posicionamientos críticos sobre esta cuestión, el objetivo del presente estudio es mostrar cuál es la postura al respecto de la dramaturga Lola Blasco a través de sus testimonios sobre su teatro político.

Palabras clave: feminismo, teatro siglo XXI, dramaturgas siglo XXI, teatro político, Lola Blasco.

\begin{abstract}
The first critical studies on the guidelines of the Spanish theater of the 21st century coincide in the existence of a young dramatic writing with sufficiently specific proposals to talk about a new vision in the current theatrical panorama. It is a new generation in which the qualitative and quantitative role of dramatists is considered indisputable. Among its features highlights the return to the social and committed look of the theater.
\end{abstract}

Feminismo/s 30, diciembre 2017, pp. 209-233

Los contenidos de la revista se publican bajo una licencia de Creative Commons Reconocimiento 4.0 Internacional (CC BY 4.0) 
Thus, from the review of the critical positions about this issue, the objective of the present study is to show what is the position on the subject of the playwright Lola Blasco through her testimonies about her political theater.

Keywords: feminism, theater 21st century, playwrights XXI century, political theater, Lola Blasco.

Feminismo/s 30, diciembre 2017, pp. 209-233 
«La repulsa de lo trágico no es otra cosa que la incapacidad para permanecer esperanzados después de asomarse al espectáculo total de la vida y sus derrotas».

A. Buero Vallejo

\section{INTRODUCCIÓN}

Iniciados los análisis sobre las directrices del teatro español del siglo XXI, las primeras aproximaciones críticas que hacen balance de estos últimos quince años parecen coincidir en la existencia de una generación - «promoción», en opinión de Pérez Rasilla (2011, 14) - que ha traído consigo propuestas nuevas suficientemente específicas como para poder sustentar una visión novedosa sobre el panorama teatral español en la actualidad. Se habla, así, de un grupo de autores jóvenes cuya producción dramática comienza con el nuevo siglo y a la que se le otorga crédito gracias a la existencia -entre otras-de novedades formales y temáticas que suponen una revisión o distanciamiento más o menos rupturista respecto a los paradigmas establecidos en el siglo anterior. Dentro de esta misma generación, buena parte de la crítica especializada se detiene en concreto en los textos y las representaciones de las dramaturgas españolas jóvenes como parte destacada de esta, haciendo visible y reconociendo de este modo el papel fundamental -cualitativo y cuantitativo- de las mujeres en la escena actual.

Estos primeros estudios sobre las últimas propuestas dramáticas destacan entre sus características una que consideramos clave para la definición del teatro del siglo XXI: la revinculación de este con la realidad, su evidente compromiso con la Historia y con el sujeto que la sufre, y, en consecuencia, la concepción del teatro de nuevo como reflexión y actuación sobre las raíces políticas y sociales que sustentan nuestra vida actual. Un discurso que también pertenece a la escritura de las mujeres, cuya interpelación a la época que nos ha tocado vivir es una constante que vincula de alguna forma su última producción dramática y que la liga a su responsabilidad social y a su sentida obligación del compromiso (Pérez Rasilla 2012a, 79). 
A partir de la revisión de los posicionamientos críticos sobre esta cuestión, el objetivo del presente estudio es mostrar cuál es la postura al respecto de Lola Blasco, una de las dramaturgas más personales y prometedoras de la actualidad, y el de hacerlo no ya a través de su producción dramática (propósito de un ensayo ya realizado con anterioridad ${ }^{1}$ ), sino a través de sus testimonios, ya se incluyan en algunas de sus entrevistas -incluidas las últimas concedidas a raíz de la obtención del Premio Nacional de Literatura Dramática 2016 por su obra Siglo Mío, bestia mía-; ya sea a través de artículos en los que la propia autora construye una visión acerca de su producción dramática o sobre lo que es/debería ser el teatro actual; o bien a partir de sus reflexiones sobre el hecho teatral publicadas en el volumen de Francisco Gutiérrez Carbajo Dramaturgas del siglo XXI.

\section{MÍNIMA RETROSPECTIVA}

El seguimiento de las posturas críticas que defienden la existencia de un nuevo teatro joven de propuestas estética e ideológicamente sólidas, lo iniciamos con una revisión de los paradigmas ya establecidos, es decir, planteando una mínima retrospectiva que nos sitúe y nos recuerde a un tiempo de dónde proceden las voces que estamos escuchando ahora mismo sobre nuestras tablas y hasta qué punto estas resultan rupturistas o continuadoras de las que las precedieron. Tarea en sí misma reduccionista, pues a partir de ahora nuestra mirada está enfocada a trazar un orden dentro de la complejidad de lo real, a lo que además sumamos la propia insularidad de la situación socio-política española.

Ese recorrido de la contemporaneidad comienza, como sabemos, a partir de las últimas décadas del siglo pasado, en esos últimos años de la dictadura que suponen una época de apertura y de búsqueda de nuevas formas expresivas en la producción dramática, y que desembocarán en la ruptura con tabúes sociales y morales apostando, de nuevo, por tendencias «no-realistas» y por una diferente concepción estética del teatro. Nuestras tablas conocerán entonces diferentes propuestas de percepción de lo real que convivirán con otras miradas de tendencia «realista ${ }^{2}$ y que abrirán paso a lo que Lehmann definió como «teatro posdramático» (2013). Este calificativo, en ocasiones

1. Ver Cristina Ros Berenguer, «Siglo mío, bestia mía, de Lola Blasco». Actas del XXVI Seminario Internacional del SELITEN@T sobre «Teatro y marginalismos por sexo, raza e ideología en los inicios del siglo XXI». Madrid: 2017. En prensa.

2. Seguimos en este punto la opinión de Francisco Ruiz Ramón de considerar ambos grupos, los «realistas» y los «anti-realistas», como poseedores de una misma actitud ética ante la realidad y la finalidad del teatro, con una idéntica experiencia de la marginación y con similar estructura de percepción de lo real, pero con la diferencia del tratamiento de la 
considerado demasiado amplio y, por ende, superficial, quizá en nuestro caso sea el más acertado, pues englobaría una gran variedad de formas teatrales que iniciaron en ese momento el camino hacia procesos artísticos sin pretensiones imitativas, con una escritura dramática en la que la ilusión del espectador no era el referente fundamental de la propuesta escénica, pero que tampoco renunciaba al compromiso con la situación social y política del país.

En esas últimas décadas del siglo XX, ante la constatación de que la manera de analizar y pensar la realidad era realmente diferente, es cuando se comenzó a hablar en España del paso de la Modernidad a ese otro momento artístico, la Posmodernidad, cuyo pensamiento había empezado a impregnar Europa y el mundo occidental a partir de los años 50, anunciando «la liquidación de los valores progresistas que, desde la Ilustración, habían animado los procesos revolucionarios burgueses» (Pérez Jiménez 2). Un nuevo orden sociopolítico y una diversidad de factores culturales, tecnológicos, sociales y económicos habían formado una sensibilidad y una respuesta artística más acordes con la fragmentación y el individualismo que con la simetría y la dimensión colectiva de decenios pasados.

En el caso español, centrándonos en la esfera teatral, el nuevo camino que se abría en aquellos días a través del contacto con la práctica escénica de fuera de nuestro país resultó rico e interesante, incluyendo los propios análisis críticos de las circunstancias que en nuestro caso hacían ciertamente peculiar dicho proceso: desde aquellos que analizaron el momento en que las innovaciones estéticas del teatro internacional -así como el desencanto político e ideológico que las vertebraba- coincidieron finalmente con la situación de desilusión y desengaño que vivió buena parte del mundo teatral español durante la transición política (la fundación en 1977 del «Teatro Fronterizo» por José Sanchis Sinisterra se considera el hecho fundamental para el verdadero surgimiento de «una dramaturgia experimental que iba a romper definitivamente los moldes antiguos, a crear un nuevo paradigma y a alinearse mediante una confrontación fecunda en los terrenos de la llamada creación posmoderna» (Garnier 17)) hasta los que se centraron en examinar de qué modo y en qué medida la escena

misma: frente a mantener el sistema de relaciones entre el mundo dramático y el mundo real de los primeros, la destrucción de este en los segundos (490).

3. Hay quienes consideran a su vez el año 1986 (año en que España ingresa en la entonces denominada Comunidad Económica Europea) como el de la superación de ese «muro» metafórico que impedía la incorporación real de nuestro país a Europa, y con el cual, en opinión de Wndy-Llyn Zaza, «la nueva era sociopolítica en España también abraza el inicio de la posmodernidad, sin que dicho paso excluya ni la tradición ni la modernidad» (142). 
española entroncó realmente con los nuevos modelos de concepción dramática del mundo occidental.

Esta última cuestión, la que plantea cierta peculiaridad «intrínseca» del teatro español posmoderno, ofrece a nuestro parecer reflexiones interesantes por lo que respecta a la construcción dramática del texto y a su aspecto referencial. En este sentido citamos la opinión de Wilfried Floeck, para quien las categorías que el investigador Alfonso de Toro había establecido en los años noventa como modelo del teatro posmoderno internacional (Toro, 1990; citado en Floeck 2002, 48) no se ajustaban exactamente en todos sus términos a la escena española, de modo que acerca del carácter antimimético, autorreferencial, antitextual, multimedial y deconstruccionista que albergaba el concepto de posmodernidad, Floeck opinaba que «en el teatro español actual estas características se advierten igualmente, pero solo en parte y raramente de forma radical. Sobre todo las categorías de la antitextualidad y de la autorreferencialidad se observan solo de manera bastante atenuada» $(2002,48)$. El crítico alemán habla de un teatro español en el que se mezcla el realismo mimético con técnicas deconstruccionistas y anti-ilusionistas, y donde la autorreferencialidad implica solo en casos muy excepcionales una ruptura total con la realidad extraliteraria y extrateatral, convirtiéndose en un teatro «de textualidad literaria y teatralidad multimedial, de autorreferencialidad y compromiso ideológico» (48). Más tarde, manteniendo que el teatro español de los años noventa se podía integrar sin problemas en la corriente internacional del teatro posmoderno, Floeck insistiría en que en nuestro teatro se da «la particularidad de que en él postmodernidad y compromiso político forman una unión coherente» $(2004,50)^{4}$.

Como vemos, dicha afirmación vinculaba claramente esa autorreferencialidad «atenuada» de la escritura y práctica teatral españolas con una función denunciadora y crítica. De este modo, si esa marca intra-teatral fuera considerada como el elemento plenamente caracterizador de la creación posmoderna (Pérez Jiménez 6), en el teatro español esta aparecería condicionada -en mayor o menor medida- por el compromiso del autor, quien, siguiendo la estela de las propuestas estéticas, técnicas y formales del posmodernismo, no abandona la explícita referencia extrateatral, la cual entendemos como un elemento

4. Floeck insiste en que las nociones de posmodernidad y compromiso no se excluyen mutuamente, y que con esta tendencia el teatro español no se opone al teatro internacional, sobre todo en lo que se refiere a los grandes modelos: Heiner Müller para el teatro alemán, Michel Vinaver y Bernard-Marie Koltés para el francés o Eduardo Pavlovski para el argentino. En el caso español, se trataría de un enfrentamiento con la realidad social contemporánea constante e inmediata desde el inicio de la posmodernidad (2004, 50-51). 
evidente de resistencia y de deber con la realidad que se está viviendo durante la última década del siglo XX.

En este sentido se preguntaba María José Ragué-Arias cuando en el año 2000 planteaba hasta qué punto se podía hablar de «nuevas dramaturgias» en los autores de fin de siglo y, aunque su estudio se circunscribía al teatro catalán, valenciano y balear, bien se podían extrapolar sus conclusiones al conjunto del teatro nacional:

Algunos de nuestros autores utilizan «falsillas poéticas» que pueden asfixiarles y no permitirles escribir desde su realidad inmediata. Pero la mayoría, con humor e ironía, con fragmentación y silencio, con estructuras formales que juegan con la simetría, con enigmas o con anécdotas, con nuevas o con clásicas estructuras dramáticas, son autores que nos hablan de una realidad próxima, una realidad que como ya se ha dicho a menudo provoca angustia, sensación de soledad y deseos de huida. $(2000,158)$

El mundo del que se deseaba huir era precisamente el del desencanto y el nihilismo que había conducido a la posmodernidad, un mundo en quiebra donde, debido en gran parte a las crisis ideológicas, ya no existen las verdades indiscutibles y que imposibilita, por ello, las miradas compactas, seguras, unitarias, y en el que, lejos de cualquier desenlace «conclusivo», no hay más que preguntas, vacíos, desalientos y perplejidad (Ragué-Arias 2000, 157). Se vive en un contexto relativista, en el que el individuo ya no se reconoce en ningún tipo de rigidez, incluida la rigidez del pensamiento racional, la rigidez social o la histórica -«muerte del sujeto, muerte de la razón, muerte de la metafísica, muerte de la totalidad», lo define con cierta ironía Celia Amorós (23)-, y donde el «todo vale» sustituyó en algún momento a los futuros posibles, optimistas, totales y resolutivos de la modernidad, y lo abocó a él, al individuo, al retorno a su único destino: ante lo imprevisible, el presente del aquí y el ahora, y, por lo tanto, la plenitud del instante y el elogio del goce frente a la fatalidad, a lo efímero 5 .

No obstante, al llegar a este punto, surge la siguiente pregunta: ¿es en ese mundo fragmentado, plural, indecidible, donde ha muerto el sujeto sobre el que se vertebraba todo el proyecto de la modernidad? $i \mathrm{O}$ realmente el teatro español posmoderno, que es el que nos ocupa, desde el inicio y debido a circunstancias propias, expresó su necesidad de reflexionar, y, por lo tanto, de revisar el proyecto inacabado de la época moderna, de forma que «de algún modo vuelve [el sujeto] a través de ciertos discursos y teorías - muy a pesar de los apocalípticos- a tratar de construir un nuevo escenario para que ese

5. Ver Michael Maffesoli, El instante eterno. El retorno de lo trágico en las sociedades postmodernas. 
«sujeto en crisis» no se disuelva al igual que las representaciones modernas» (Hernández Enríquez 59-60)? Por lo que hemos visto hasta el momento, la «unión coherente» entre posmodernidad y compromiso político apuntada anteriormente parece refrendar la existencia de ese sujeto en crisis que pugna por continuar a pesar de la radicalidad de la época en la que vive.

Este es un tema, además, que adquiere nuevas e interesantes perspectivas desde la óptica de la teoría y crítica feminista, puesto que tales reflexiones teóricas acerca de la existencia, subsistencia o muerte del sujeto abrió un sugestivo debate en este ámbito en el que se cuestionó desde el comienzo tanto la naturaleza de ese sujeto como la idoneidad final de incluir el discurso feminista dentro de la teoría posmoderna ${ }^{6}$.

En cualquier caso, sin poder ahondar en estas páginas sobre la posible existencia o no de un feminismo posmoderno, dicho debate podría aportar sin duda ideas enriquecedoras -y quizá fundamentales- al análisis del teatro español actual. Lo que sí podemos hacer es afirmar que, con lo referido hasta ahora, en buena parte del teatro español posmoderno el sujeto de la razón ha seguido existiendo, buscándose, reinterpretándose a través de esas nuevas formas de discurso teatral propias de la deconstrucción y el palimpsesto posmodernista; que, derivado de ello, sería muy interesante saber qué peso tienen las dramaturgas femeninas desde los años noventa -como mínimo- en tal persistencia, vinculando sus problemas identitarios con la característica que desde un principio hemos tratado como la que singulariza de algún modo nuestra producción teatral de esa época: la presencia constante de alguien con actitud de compromiso consigo mismo y con la sociedad en la que vive.

La profesora e investigadora francesa Emmanuelle Garnier en su libro Lo trágico en femenino también afirma, en la línea de Floeck, que «la realidad extraliteraria y extrateatral ocupa un lugar importante entre los temas transmitidos por las obras del teatro español posmoderno» (20). Garnier centra su estudio en la producción teatral de las mujeres, y refiriéndose sobre todo a la «generación de los 90» (donde incluye a Lluïsa Cunillé, Beth Escudé, Laila Ripoll, Yolanda Pallín, Mercè Sarrias, Angélica Lidell, Itziar Pascual, Gracia

6. En 1995 Celia Amorós plantea lo que ella considera el problema clave para el feminismo con la siguiente pregunta: « ¿muerte o redefinición del sujeto de la modernidad?» (36), y con ello está mostrando la importancia de la postura feminista ante la conceptualización de la posmodernidad y su consiguiente rechazo del discurso ilustrado, que ella interpreta, por ende, como la muerte del sujeto político. El hecho de que la filósofa española considere peligroso el acercamiento del feminismo al posmodernismo se debe a que teme una desactivación de las ideas-fuerza del primero; así, se cuestiona finalmente: « ¿puede la posmodernidad, a condición de politizarse, adaptarse a estas necesidades del proyecto feminista?» (36). 
Morales y Diana de Paco Serrano), nos habla de una dramaturgia posmoderna en los siguientes términos:

Así, en una dramaturgia cuyas formas no dejan de evolucionar, las escritoras se plantean con vigor cuál es el lugar del individuo -fundamentalmente femenino- en la colectividad y cuál es la naturaleza de esa misma colectividad, en la que el hecho teatral se transforma, de facto, en un acto político. (35)

Siendo esa una dramaturgia alejada del carácter más realista y militante de su predecesora (nos referimos al teatro cuyo primer referente sería Lidia Falcón), Garnier sostiene incluso que en el panorama teatral español las dramaturgas de la citada generación de la democracia constituyen un grupo aparte, «el que se caracteriza por un fuerte retorno al compromiso político, alimentado por una búsqueda formal constantemente innovadora» $(35)^{7}$. Acto seguido, para explicar que ambos aspectos de la dramaturgia posmoderna femenina -exploración formal y posición social o política- no compiten entre sí, sino que «provocan una resonancia dialéctica profunda», escribe:

Todo transcurre como si los avatares de la estética posmoderna fueran cómplices de un compromiso político underground, asfixiado desde siempre, y que las mujeres llevasen oculta bajo sus faldas una bomba de relojería, una granada de fragmentación. Desde los silencios de la poética minimalista de Lluïsa Cunillé hasta los chorros de bilis negra de la poética del fracaso de Angélica Lidell, es el mismo grito sordo, trágico, que, lanzado desde lo más profundo de aquellos vientres de mujeres, impone sucesivamente a los espectadores de teatro una confrontación intensa primero con la insufrible condición de la mujer frente a lo masculino dominante, después con la impotencia social frente a los poderes económicos, con la negación individual frente al diktat de lo político y por último con la dificultad en resistir el peso aplastante de la Historia. (36)

\section{DEL TEATRO DE LA CONTINUIDAD AL HORIZONTE DE LO COLECTIVO}

Tras todas estas reflexiones, nos adentramos en el siglo XXI con el objeto de analizar si en estos momentos, pasados más de quince años del nuevo siglo,

7. Garnier apuesta por ampliar así el número de grupos de dramaturgos españoles que los investigadores Candyce Leonard y John P. Gabriele proponen en su Panorámica del teatro español actual publicado en 1996. En ese volumen se habla de cuatro grupos: el de los autores que proceden de la época franquista, los realistas, cuyo compromiso político ya no responde a las expectativas del público; el de aquellos marginalizados de los lugares de teatro cuyas obras carecen de envergadura universal; el de los innovadores, que buscan nuevas formas dramáticas; y, finalmente, el de los de la democracia, que son los que ya no tienen ninguna relación con el franquismo y que plantean nuevas concepciones en la relación de texto, actuación e imagen. A ellos Garnier añadiría las citadas dramaturgas, las cuales constituirían el quinto grupo (35). 
es posible hablar de una nueva mirada, superadora, trasgresora, rupturista o continuadora en relación al teatro posmoderno: ¿existe, pues, una nueva generación/promoción que ha sabido ver y tratar la realidad de una manera diferente? Contemos, en primer lugar, con que la realidad no es simplemente otra, sino que es peor, que la historia se ha superado a sí misma en sinsabores, brutalidades, injusticias, y que el orden sociopolítico y económico mundial difiere en grado del siglo anterior por la mayor manipulación y el enorme desequilibrio que se ha creado entre personas y entre países.

En segundo lugar, respecto al teatro, la cuestión es que si no existe retorno posible a la mímesis aristotélica, entonces, ¿ hasta qué punto podemos afirmar en el momento actual que la posmodernidad ha sido superada o transformada en algo diferente?

En este sentido, era el mismo William Floeck quien a principios del siglo XXI observaba ya signos de superación de la posmodernidad en el teatro español a partir de un proyecto realizado por José Ramón Fernández, Yolanda Pallín y Javier García Yagüe titulado Trilogía de la juventud (2001), donde, según el crítico alemán, se evidenciaba cierto resurgir de la coherencia temporal y dramática, junto con una mayor referencia extrateatral que parecía otorgar una nueva oportunidad a la historia y al propio idioma como medio de acceder a la verdad $(2004,59-60)^{8}$; contrariamente, por cierto, a lo que opinaba el propio José Sanchis Sinisterra, para quien el proceso del posmodernismo escénico debía todavía llegar a su punto culminante, el cual se daría con la deconstrucción total a través de estructuras opuestas al discurso logocentrista de la claridad, a la renuncia a la omnisciencia autoral y, sobre todo, al cuestionamiento final del idioma como herramienta de comunicación y percepción de la realidad (citado en Floeck 2004, 59-60).

Años más tarde, concretamente en 2011, verá la luz un artículo de carácter panorámico sobre ese último teatro español publicado por Eduardo PérezRasilla bajo el título de «La escritura más joven. Algunas notas sobre la

8. Según Floeck, en la obra Las manos, perteneciente a la citada trilogía: «Lo novedoso es que la realidad histórica se presenta mediante una mezcla de acción dramática narrada y dialogada con una coherencia cronológica y espacial [...]. La acción dramática es comprensible; los personajes llevan nombres y están ligeramente individualizados; el trasfondo social y político, cuya reconstrucción se basa en una cuidadosa documentación de los autores y actores, se ilustra en una forma comprensible. [...] Los personajes se acercan en la obra al pasado más reciente desde la más pura curiosidad frente a una época histórica que es parte de sus historias familiares y personales, para de este modo entender mejor su propia identidad y las raíces de su propia vida. El éxito de la obra muestra que la confianza en el idioma y la razón como medio de percepción de la verdad y representación de la realidad parece de nuevo aumentar» (2004, 59-60). 
literatura dramática emergente en España». En esta publicación se afirma por vez primera de manera contundente que «la negación de una escritura dramática joven solo puede responder a la ignorancia o a la desidia», constatando que «existe una literatura dramática joven abundante y de calidad en el teatro español contemporáneo» (13-14). Pérez-Rasilla habla ahí de una promoción de autores y autoras, cercanos todos ellos a la treintena -nacidos, pues, a partir de 1975-, que han hecho públicos sus trabajos en el primer tramo de este siglo, y aunque con preferencias estéticas y temáticas diversas, advierte en el conjunto de su producción algunas líneas dominantes, a saber: en primer lugar, el gusto común de todos estos autores por la elaboración formal, el cual se traduciría en un uso elaborado y cuidado del lenguaje, donde además se evidencia una intención poética e intelectualmente ambiciosa. Se citan, asimismo, los numerosos referentes e influencias que se perciben en los textos, convirtiendo la escritura actual en documentos dependientes de otras voces, escrituras y construcciones intelectuales y culturales, al tiempo que muestran un afán claro por expresarse de manera original y diferente. Por último, a este cierto carácter paradójico Pérez-Rasilla suma el deseo por convertir el texto dramático en un espacio de una experimentación constante, de ensayo, de revisión, de superposición de planos, en definitiva, de experimentación formal, aunque en realidad, en su opinión, «pocos son los dramaturgos que rompen radicalmente con los moldes clásicos y optan por un teatro que pueda calificarse de vanguardista» $(13)^{10}$.

Por su parte, en lo referente a temas y motivos abordados en este llamado teatro emergente, se mencionan la ciencia, la historia, el lenguaje y el propio teatro. Se advierten, asimismo, actitudes cercanas a las corrientes irracionalistas de las últimas décadas de la cultura contemporánea, y la perspectiva autobiográfica desde la que muchos de ellos emprenden la reflexión sobre las

9. En esa lista abierta Pérez-Rasilla incluye a Marc Angelet, Paco Bezerra, Lola Blasco, Marta Buchaca, Marco Canale, Jordi Casanovas, Alberto Conejero, Carlos Contreras, José Cruz, Blanca Doménech, Aleix Duarri, Joen Espasa, Darío Facal, Ózkar Galán, Juan Pablo Heras, Pablo Iglesias, Irene Mazariegos, Josep María Miró, Rosa Molero, Vanessa Monfort, José Manuel Mora, Antonio de Paco, Emiliano Pastor Steinmayer, Mar Plá, Antonio Rojano, Juan Alberto Salvatierra, Vanesa Sotelo, Begoña Tena, compañía La Tristura (compuesta por Celso Giménez, Pablo Fidalgo, Itsaso Arana y Violeta Gil), María Velasco, Néstor Villazón y Zo Brinviyer (2011).

10. Acerca de esta última afirmación, Pérez-Rasilla comenta: «Los dramaturgos más jóvenes practican con asiduidad el ejercicio de las variaciones sobre el mismo tema o el juego de la mirada diversificada sobre el mismo fenómeno. Ensayan con complejas estructuras que alternan con las percepciones convencionales del tiempo y el espacio. Sienten predilección por el experimento. Recurren a la elipsis, fragmentan, ocultan, practican la recurrencia, diseminan los componentes que previsiblemente tendrían una relación de contigüidad, establecen puentes entre escenas o unidades estructurales alejadas en la composición del texto, etc.» $(2011,16)$. 
relaciones interpersonales. A su vez, la mirada violenta de la sociedad a la que se mira proviene de una reflexión profunda sobre las raíces políticas y sociales que sustentan la actual condición humana, de ahí su cercanía a temas como la guerra, el exilio forzado, el capitalismo brutal, las dictaduras contemporáneas, la pobreza, la marginalidad social, el desarraigo y también la reflexión sobre los problemas relacionados con la identidad, ya sea colectiva o individual (PérezRasilla 2011, 17).

A todas estas características formales y temáticas sobresalientes del teatro último, habría que sumar, lógicamente, el resto de cambios acaecidos en todos los espacios de la creación escénica, lo cual aportaría una visión completa del fenómeno que sí podría representar en su conjunto la existencia de una nueva realidad teatral. Nos referimos a la importancia de tener en cuenta aspectos tales como los nuevos conceptos de autoría de la obra artística, la redefinición de las relaciones jerárquicas dentro del equipo creativo, los nuevos espacios teatrales fuera de las consabidas salas de teatro alternativas que proliferaron durante el siglo XX, los nuevos conceptos de recepción, la llegada de nuevos espectadores, la implantación de recorridos de Dramaturgia y Dirección en las Escuelas Oficiales de Teatro, o los cambios evidentes en los modelos de gestión, producción o distribución ${ }^{11}$.

Ante todo este panorama es cuando Pérez-Rasilla afirma concluyente que en las actuales manifestaciones teatrales existen novedades relevantes que «configuran un paisaje teatral que muestra significativas diferencias con el que se divisaba en el siglo anterior», independientemente de su valoración estética, ética o política $(2012 \mathrm{~b}, 1)$.

A nuestro parecer, es indudable que existe una generación más joven que muestra rasgos específicos del siglo XXI, sobre todo en lo referente, por una parte, al compromiso con la creación escénica, el cual se realiza en varios o

11. En este sentido, acerca de los nuevos modelos de producción y distribución del teatro español en el siglo XXI, es interesante consultar el artículo de Robert Muro «Crear y mostrar en el siglo XXI. Mirando al futuro sin ira. La producción y la exhibición de las artes escénicas en España», donde el autor revisa los modelos por los que se regía el arte y la industria teatral en el siglo XX para a continuación analizar los rasgos diferenciales que configuran el marco de funcionamiento de la creación y exhibición de las artes escénicas durante el siglo actual (2011, 33-54). Por otro lado, respecto a los nuevos procedimientos compositivos contemporáneos, al cambio en las nociones de participación y autoría social de la obra artística y, en general, a todo lo que se desprende de la verdadera crisis del concepto de director en España, es recomendable el artículo de Ana Contreras titulado «Líneas emergentes en la dirección escénica durante el siglo $\mathrm{XXI}$ ». Este último artículo resulta especialmente interesante, además, por contar con un último epígrafe en el que se analizan las aportaciones propiciadas por la reciente y significativa incorporación de la mujer a la profesión escénica $(2011,55-82)$. 
muchos de sus campos (ya sea la autoría, la dirección, la gestión, la interpretación, la escenografía,...); por otra parte, en las posibilidades de acceso a la formación -e información- que ha sido, como mínimo, más amplia y profesionalizada. Por último, en el hecho de ser hija de una nueva situación social, política y económica -así como puramente teatral-, y el pertenecer a otra realidad más global, tecnológicamente conectada, en la que vive naturalmente y con la que se siente identificada y comprometida.

Parece esta una generación que refleja de algún modo un cambio de pensamiento, en el sentido de que el concepto de relatividad del ser y del mundo tan propio de la posmodernidad, y por el cual se cuestionan los valores absolutos, la verdad, y el individuo, en fin, se estuviera diluyendo en pos de una nueva reflexión sobre la identidad, sobre la posición del sujeto en el mundo, junto al Otro, y, por lo tanto, con la opción de darle una nueva oportunidad a la Historia. Pensar la Historia, aunque esta caiga como un peso enorme sobre nuestros hombros, analizarla, supone otorgar al sujeto de nuevo el poder de intervenir en ella, aunque sea, eso sí, eso siempre, desde el trágico presente.

En cuanto a ese teatro emergente caracterizado a grandes rasgos por el profesor Pérez-Rasilla, lo que se nos presenta como más interesante es precisamente el apunte sobre su carácter paradójico. Nos referimos, primero, a ese paradójico autor teatral que se desvanece entre una pluralidad de modelos y paradigmas, y que, al mismo tiempo, busca de nuevo la originalidad para diferenciarse. Así entenderíamos el afán por crear una escritura propia de referentes amplios y personales, una escritura que proviene, además, de un trabajo laborioso con el lenguaje, y cuyo tamiz autobiográfico guía muchas de las propuestas dramáticas. Resulta contradictoria, asimismo, esa predilección por el experimento formal, por las secuencias fragmentadas y deconstruidas, y su convivencia con propuestas en las que casi nunca se llega a rupturas totales, y donde la variedad de la configuración formal y el respeto a los paradigmas clásicos se representan por igual.

Si hablamos sobre el tratamiento del tiempo, es paradójico que, superado el concepto lineal y de progreso de la época moderna, alcanzado el no tiempo, la fractura total -coincidente con la sensación de vivir en el final de la Historia-, observemos a la vez que el tiempo existe, que se le da categoría de existencia. La falta de soluciones con la que vive la posmodernidad, sus construcciones aporéticas, han conducido a otro tiempo, trágico también si se quiere, pero que plantea maneras diferentes de aprehender la realidad: la oscuridad existe tanto como el sinsentido de la vida, pero ello no justifica que ante la contemplación de la amargura y la conciencia de la muerte no haya que mostrar una actitud valerosa. El teatro no debe ser el reflejo de un «pensamiento débil», 
sino un «agente» de la época contemporánea. El tiempo existe porque existe la Historia y el autor dramático vuelve a apelar a él, a pertenecer a él, a adherirse y a increparlo. "Contemporáneo es aquel que percibe la oscuridad de su tiempo como algo que le incumbe y no cesa de interpelarlo, algo que, más que cualquier luz, se dirige directa y singularmente a él», comenta el filósofo italiano Giorgio Agamben $(2011,22)$. Es esa manera de interpelar la propia contemporaneidad lo que, a nuestro juicio, puede definir la dramaturgia más interesante del siglo XXI.

Con todo ello no queremos decir que tales características o actitudes sean ni mayoritarias ni absolutamente novedosas, sino, más bien, que lo novedoso radica en la convivencia entre las propuestas dramáticas más interesantes del siglo XX y la mirada que sobre ellas lanza un autor o autora que pertenece a otra generación, que es víctima de su propia época y, al mismo tiempo, heredera de los replanteamientos fundamentales que sobre la vida y el arte se realizaron en el pensamiento occidental en el siglo pasado.

De hecho, el esquemático recorrido que hemos iniciado a partir de las últimas décadas del siglo XX y que hemos hecho desembocar en el teatro posmodernista español es suficiente para evidenciar el enorme legado del que parte nuestro teatro actual y, al mismo tiempo, para relativizar asimismo la trascendencia que pudiéramos otorgar a estas novedades del teatro último: «la actual dramaturgia emergente es heredera de las sucesivas corrientes renovadoras y vanguardistas que han ido desarrollándose a lo largo de estas tres décadas», insiste, de hecho, Pérez-Rasilla (2012c, 2).

A este respecto, en una entrevista realizada a Lola Blasco por José Romera Castillo en junio de 2017, la actriz, directora y dramaturga respondía a su pregunta sobre la presencia de los lenguajes de vanguardia en el teatro español actual con las siguientes palabras:

A mí lo que me interesa es que, como diría Ortega y Gasset, hay un teatro de continuidad. Es un teatro que ha asumido la tradición clásica, no la rechaza, pero que también asume la vanguardia y las formas de hacer de ese teatro que se ha denominado posmoderno, en los años noventa, y lo que hace es una fusión, una mixtura de lenguajes que en mi opinión responde a eso, a un teatro de continuidad en el que no es que quepa todo, pero sí que no se rechaza nada, y eso me parece que es muy enriquecedor.

Lola Blasco, dramaturga nacida en Alicante en 1983, forma parte de esa promoción emergente de la que hablaba Pérez-Rasilla en 2011, donde la incluía junto a otras doce autoras y veintidós autores. Un año después, en 2012, uno de sus textos teatrales integrará también el número complementario que la revista Acotaciones publicó con la intención de dar a conocer obras breves de alguno 
de esos treinta y cinco dramaturgos mencionados con anterioridad. El hecho fue que con el fin de mostrar una representación de diferentes concepciones de la joven escritura teatral, Francisco Doménech, director de la revista, y el propio Pérez-Rasilla decidieron entonces que esta relación estuviera compuesta solo por autoras, justificando tal selección de dramaturgas «como expresión de reconocimiento hacia un fenómeno que no debe pasar inadvertido» (PérezRasilla 2012a, 77). Los textos ahí incluidos corresponden a las autoras Marta Buchaca, Blanca Doménech, Diana I. Luque, Vanessa Monfort, Vanesa Sotelo, María Velasco y la citada Lola Blasco, todas ellas dramaturgas del siglo XXI avaladas por cierta trayectoria y con una sólida formación tanto intelectual como propiamente escénica.

Con unas palabras más que optimistas sobre la situación de visibilidad con que la mujer dramaturga afronta la escena española en el presente siglo, los responsables de esta publicación comentaban el proceso de selección con las siguientes palabras:

Las posibilidades eran abundantes, puesto que, felizmente, se ha hecho realidad en el teatro español contemporáneo la deseable circunstancia de que las mujeres ocupen un territorio equiparable al de los hombres, no solo en lo que atañe al número de autoras o a la calidad de sus textos, algo que en este momento no puede ya discutirse, sino también a su visibilidad y a su presencia en los escenarios, en las publicaciones o en los premios. (77-78)

A continuación, se realizó un somero análisis de las autoras y de los textos publicados en el monográfico, insistiendo en que estos presentaban una serie de rasgos comunes. Se habla, así, de una misma preocupación formal, de un lenguaje preciso y elaborado, y de un idéntico sentido de la responsabilidad social que les lleva a una escritura decidida y resuelta, comprometida:

Por esta razón, me parece revelador que en todos los casos las dramaturgas hayan adoptado una actitud crítica y una reacción airada antes las injusticias, las estupideces y las lacras de una sociedad -la suya y la nuestra- ante la que se sienten responsables y obligadas a adoptar un compromiso, a dar una respuesta. Los motivos concretos son diferentes, aunque próximos unos a otros, y los estilos son diversos, acordes con la personalidad estética de cada una de las creadoras, pero el estado de ánimo que podemos inferir desde la lectura de sus obras es semejante. Todas parecen haber sido escritas desde la rabia, desde la disconformidad que produce dolor, y también desde la necesidad de actuar sobre esa sociedad que causa indignación. Este sentimiento inspira una escritura contundente y audaz, sin miramientos ni timideces, notas que pueden aplicarse sin excepción a todas las obras que ahora se publican. En todas ellas advertimos también una experimentación con el lenguaje dramático, una búsqueda formal exigente y arriesgada. (79) 
Se trata de rasgos compartidos con los que no tratamos en estos momentos de singularizar la dramaturgia femenina como tal ( $i$ El teatro que escriben las mujeres contiene su identidad?», tal y como lo formula Ragué-Arias (1997, 227)), sino simplemente de resaltar preocupaciones, necesidades y actitudes comunes en un grupo de dramaturgas actuales que se reflejan a través de propuestas y lenguajes dramáticos muy próximos.

Dos años después, en 2014, será Francisco Gutiérrez Carbajo el que, en su edición a la antología Dramaturgas del siglo XXI, apuntará esa misma existencia de características comunes:

Las dramaturgas actuales, junto al papel de representación, subrayan de manera especial el valor de la palabra, del texto. En este sentido, una de las características que las singulariza es su preocupación por el lenguaje, a la vez que adoptan una clara actitud de compromiso, y sus textos se erigen en «una respuesta significativa a una situación particular», como diría Lucien Goldmann. (61)

Llegados a este punto, la precisión obligada es que en el presente estudio no pretendemos entrar en disquisiciones -que las hay muchas y encontradassobre si existe una dramaturgia femenina diferenciada de la masculina ${ }^{12}$, sino que preferimos dejarnos guiar en esta cuestión por la posición de la profesora Meri Torras, para quien esta reflexión no es la mayor contribución de los feminismos con la teoría teatral, sino que la verdadera importancia recae en todo lo que de ella se ha derivado. En su opinión:

La contradicción radical -de raíz- presente en el feminismo, la necesidad y, a la vez, la imposibilidad de definir su categoría fundacional de estudio y reivindicación y, por consiguiente, el requerimiento igualmente inalcanzable de

12. Baste citar como ejemplo sendos artículos publicados en un mismo volumen que muestran posiciones contrarias. Por un lado, el de José Luis García Barrientos, quien, a raíz de un estudio sobre la dramatología del tiempo en la obra de cinco autoras españolas de la segunda mitad del siglo XX, sostiene que «la dramatología, la teoría del drama, ya se refiera al tiempo o a cualquier otro elemento, es o debe ser una», para seguidamente afirmar de manera contundente: "no creo en una dramaturgia femenina, en una única y diferenciada práctica del drama por parte de las mujeres, presuntamente opuesta a la de los hombres». Lo cual no es óbice para que el autor del artículo reconozca la necesidad de un discriminación positiva a favor de las dramaturgias femeninas ante la constatación de que en el grueso de los estudios académicos estas siguen estando injusta y desproporcionalmente desatendidas (44). Por otro lado, el de Virtudes Serrano, titulado «El espacio y el tiempo de la mujer en la dramaturgia femenina finisecular», donde mantiene la opinión de que la incorporación de las mujeres al teatro ha favorecido una nueva visión del mundo, «una mirada distinta que, al proceder de una cosmovisión y experiencia diferentes, percibe la realidad con unos matices que no son habituales para el canon establecido", siendo el suyo un teatro que nace de la identidad y del momento en que la mujer se inserta en el mundo (96). 
determinar una estética teatral femenina/feminista, ha conferido una dinámica expansiva a la concepción de texto teatral o de teatro, tout court. Dicho de otro modo, la convergencia con el feminismo -entre otros factores- ha acentuado el movimiento de considerar el teatro como un ámbito más amplio que el estricto texto dramático; más cerca de una forma cultural. (349)

Sobre dicha forma cultural es adonde hemos dirigido la mirada que la mujer dramaturga joven ha podido aportar. Una mujer inserta en el siglo XXI que, sin duda, es una mujer distinta, en el sentido de que es una mujer formada en otras condiciones y con vivencias y experiencias comunes a toda una generación de autores que, como veremos, la misma Lola Blasco calificará de «generación en red» $(2014,97)$. La suya es una dramaturgia inspirada por otro tipo de identidad, en cualquier caso afín con la identidad social propia de su época, esa que se muestra a través del compromiso ante un mundo injusto y una sociedad indigna, característica que, como hemos visto, la crítica apunta como rasgo común de ese grupo de creadoras que constituye muestra y ejemplo de calidad y representatividad en la escritura teatral española del nuevo siglo. Podemos decir, incluso, que el suyo es un teatro que supone un nuevo enfrentamiento con la Historia, y que pone sobre el escenario ideas y actitudes que comparten buena parte de los escritores de esta última generación.

Este nuevo concepto de la identidad, esa nueva reflexión sobre el lugar del sujeto en el mundo, en el que el Otro es pieza fundamental, que está más lejos de la sublimación del individuo y más próxima al ser social, es en la que nos detenemos ahora a través del teatro político de Lola Blasco.

\section{LOLA BLASCO: DEL YO AL OTRO}

Dentro de ese grupo de dramaturgas que Pérez-Rasilla presentó en Acotaciones en 2012, Lola Blasco es la autora que de una manera más decidida ha hablado siempre de su voluntad de escribir teatro como un acto político, ostentando una posición crítica y un discurso claramente comprometido.

Todo arte es política, ciertamente, pero no todo se crea con el fin de apelar a la sociedad y de «ejercer con él un ejercicio activo de la ciudadanía» (Blasco 2017), como es el caso. Si hacemos recuento de su producción dramática ${ }^{13}$, es evidente que esta desvela desde el principio su interés por temas relacionados

13. Acerca del conjunto de su producción dramática -iniciada con Pieza paisaje en un prólogo y un acto (Premio Buero Vallejo, 2009), distinguida con el Premio Nacional de Literatura Dramática por Siglo mío, bestia mía (2016), y concluida, a día de hoy, por La armonía del silencio (2016) - ver Cristina Ros Berenguer «Siglo mío, bestia mía, de Lola Blasco» y Julio E. Checa Puerta «Dramaturgas españolas del siglo XXI: Lola Blasco (1983), del ditirambo al rap». 
con la historia contemporánea, por acontecimientos que han marcado el siglo y que han definido la vida de miles de personas. Así, su teatro trata las consecuencias de la Historia a través de los desposeídos, los excluidos, los desesperanzados, los obligados al éxodo y los marginados, las víctimas, en fin; pero también nos muestra la actitud de los callados, los que observan, los que acatan, los que se dejan llevar y finalmente son llevados. Para todos ellos debe trabajar el teatro como si de una labor memorialista se tratase.

Uno de los críticos que más se ha acercado a la obra de Lola Blasco, Julio Enrique Checa, sintetizaba en 2012 su producción dramática con estas palabras:

En todos ellos [los textos de Lola Blasco] se detecta un marcado interés por la Historia del siglo XX, así como por sucesos de extraordinaria relevancia en el presente; también por la reflexión -la voluntad de llevar pensamiento a la escena- sobre los mitos contemporáneos y por la protesta vehemente contra la injusticia y la violencia gratuitas. No se queda al margen de otras preocupaciones, como pueden ser las relaciones entre los intelectuales y el poder o la participación de la ciencia en la destrucción masiva de inocentes. (359)

Conociendo mínimamente las dificultades intrínsecas de la labor del autor teatral para poner en escena sus propuestas -condicionadas por el propio sistema y por la eterna crisis en la que sobrevive el arte teatral-, podemos suponer, además, las que de manera extrínseca se han sumado en el caso del teatro de Lola Blasco, no solo como «autora joven contemporánea», sino sobre todo como autora de unas propuestas de teatro político cuyo interés general sobre las tablas es mínimo. Podemos insistir por ello en que el camino creativo de Lola Blasco no ha sido fácil. De hecho, a raíz de la obtención del Premio Nacional de Literatura Dramática 2016 ella confiesa: «Yo en estos momentos me estaba planteando si el camino que estaba siguiendo en mi creación era el adecuado y este premio de alguna forma lo confirma» (UC3M Magazine). Observación con la que Lola Blasco se muestra plenamente consciente de lo marginal de sus propuestas y del enorme esfuerzo que ha dedicado durante todos estos años a la construcción de un teatro político.

En el año 2011 la autora definía lo que era para ella el verdadero sentido del teatro con estas palabras:

Creo que el teatro es de los pocos espacios donde todavía se establece un diálogo real. Y se necesita de cuerpos para estar ahí. [...] No basta con la literatura, el teatro en sí mismo, es verdad que es literatura, pero hay que encarnarlo, representarlo. Y creo que es importante hacer justicia a través de los cuerpos, así que creo que el teatro, aunque obviamente no es una manera de hacer justicia (y es muy pequeño lo que podemos hacer porque viene muy poca gente), menos es nada. Y me parece que, dependiendo qué tipo de 
teatro, se producen cosas en el «aquí y ahora» y ese diálogo que se establece es importante. (Castro)

Su tipo de discurso comprometido y crítico la situaba entonces, como hemos dicho, al margen de casi todas las tendencias teatrales, pues en estas no se daba ese tipo de interpelación a la realidad, esa mirada directa frente a determinados acontecimientos históricos. Sobre la situación teatral en aquellos días, la opinión de Lola Blasco era la siguiente:

Creo que [el teatro actual] no es crítico de ninguna manera, porque por un lado hay gente que está instalada en los espacios públicos, que no hacen discurso crítico [...], y luego está el teatro alternativo, en el que la línea dominante tampoco es la crítica. En los últimos años la tendencia va más hacia lo estético y no hacia el discurso más comprometido o más político. Hay excepciones, como Angélica Lidell [...] o Marco Canale [...] Creo que también María Velasco... Pero llevarlo al panorama general sería falso, y ahora se tiende mucho hacia la danza y la performance con la cultura de la imagen, que se ha impuesto (antes era una alternativa y ahora está en todo) y se ha dejado de lado el texto y el discurso. Y a lo mejor yo no quiero hacer «cosas bonitas», aunque a veces, el hecho de poner cosas horribles en el escenario puede resultar muy hermoso. (Castro)

Bajo el significativo título de «Lola Blasco Mena y María Velasco: la escena da nueva voz a la historia contemporánea y a sus personajes», Giovanna Manola publicaba en 2014 un artículo en el que reconocía el aire novedoso que la dramaturgia más joven aportaba al panorama teatral español, mostrando un enfrentamiento ante la complejidad social a través de los más delicados temas del presente y del pasado histórico: «Vuelven a acercarse a ese «teatro comprometido», permitidme el término, donde la Historia asume un rol central, vista y analizada con ojo crítico y novedoso, sin dejar atrás el necesario aspecto cautivador que hace acudir a la gente al teatro» (106).

Acerca de la presencia de esos componentes históricos y simbólicos en el teatro actual, Lola Blasco la considera reflejo de la existencia de una clara voluntad social por «hacer memoria» como forma de avance social, anhelo que tiene de esta forma su propia representación en el lenguaje teatral del momento. Si los hechos históricos pasados se reflejan en la cultura contemporánea como modelos de comprensión del actual momento histórico, la dramaturga concluye: «En el caso del teatro, por el lenguaje que le es propio, estos hechos históricos suelen reflejarse como símbolos en el afán de dar cuenta de la realidad concreta» (Gutiérrez Carbajo 140-141). Y a ello añade:

En mi opinión, estos rasgos del teatro actual nos hablan de un cambio hacia un teatro cada vez más comprometido. Si en los noventa la introspección y la conquista del sujeto parecía ser la norma, ahora, en pleno siglo XXI, el teatro 
parece abrirse hacia los demás para compartir un mensaje que es importante que llegue al público. Sin renunciar, por ello, a la intención poética o formal que venimos heredando de finales del siglo pasado. (141)

Ante la duda de que tales propuestas teatrales resulten verdaderamente innovadoras en el teatro contemporáneo y, por lo tanto, estén alejadas de los códigos clásicos, Manola defiende, por su parte, una vía intermedia: «una herencia [la clásica] que los jóvenes no rechazan del todo y a menudo proponen transformándola, reelaborándola con su personal estilo»(107-108). Esta actitud de asunción y superación de las formas clásicas, en opinión de Lola Blasco conformaría una especie de «teatro defectuoso» que aúna tradición y vanguardia, buscando el pasado para proyectarlo hacia el futuro (Manola 108).

En relación con este carácter integrador de los más recientes discursos dramáticos y aquellos que los precedieron, reproducimos unas palabras de Lola Blasco publicadas en su ensayo «Sobre el yo generacional en algunas muestras del teatro español actual», donde acerca del concepto de identidad en la última dramaturgia española comenta: «No obstante, esta generación de los [nacidos en los] años ochenta no es una generación que rompa con los modelos inmediatamente anteriores. De hecho, y en esta inclinación hacia la primera persona del plural, se puede decir que la generación de los ochenta no rompe con ningún modelo» $(2014,96)$. Es evidente, pues, que Lola Blasco, en su intento de definir esa nueva generación de autores del siglo XXI, subraya el que se trate de una cuestión generacional, y, por lo tanto, de una evolución natural hacia la voluntad de los autores más jóvenes de asumir una identidad colectiva: de la introspección y la conquista del sujeto del teatro de los años 90 a un teatro que tiene su centro de interés en el horizonte de lo colectivo, «en abrirse hacia los demás para compartir un mensaje que es importante que llegue al público» $(2014,141)$ :

En primer lugar, y a través de ese nosotros, podemos decir que existe la idea de pertenencia a una generación. Si en las promociones anteriores, atravesadas por la postmodernidad, asistíamos a la sublimación del individuo como puerta de acceso a la verdad y al mundo, el lugar de posicionamiento de los dramaturgos jóvenes se instala directamente en su yo social, en su ser en grupo. $(2014,97)$

Nuestra autora acuña entonces la citada etiqueta de «generación en red» como aquella que les es propia, cuyo lema, «me comunico, luego existo», contribuye a ese sentimiento de pertenencia a una comunidad, un sentimiento unitario que va íntimamente ligado a un nuevo concepto de la identidad, la identidad social.

Un año más tarde, en un artículo de 2015 titulado «Sentido de los códigos musicales en la actualización del teatro político», Lola Blasco reflexiona sobre 
su proceso creativo y sus constantes intentos por renovar este tipo de teatro, cuestionándose los alcances de la verdad, preguntándose si verdad y realidad son términos intercambiables e intentando averiguar cuál es la función última del teatro político: «¿Un teatro político que quiera cantar las verdades ha de dar cuenta de su realidad histórica?» (42). Su conclusión es la siguiente:

La verdad no es otra cosa que un pacto al que se llega a través del diálogo con los demás y que permite desvelar lo oculto y sacarlo a debate. Y en ese sentido es que considero que todo teatro político se ocupa de la verdad. Todo teatro político anhela la verdad. El teatro político no es teatro social. El teatro social se limita a dar cuenta de la realidad circundante. El teatro político habla de una actitud ciudadana, de un estar en la polis generando debate, diálogo, pactos. (43)

Como vemos, de nuevo es el yo social el que habla, y lo hace para que el público pueda aproximarse a la verdad y al mundo por sí mismo, solo con la mediación del diálogo y del debate.

En ese esfuerzo constante por la construcción de un teatro político nuestra autora ha llegado finalmente hasta el concepto de fábula política, defendida por Lola Blasco al considerar que las fábulas y las metáforas de su teatro -y con ello recuerda a Alfonso Sastre- «no tienen que ver con la mentira, con la falsedad; el hecho de que algo no haya ocurrido en la realidad es, simplemente, una irrealidad dialéctica» $(2015 a, 42)$. De este modo, a partir de ellas, a partir de la autonomía poética de la forma, es cuando esas fábulas y diálogos ficticios permiten, en último término, el desvelamiento de la realidad:

Yo hablo de fábula política. Hago un teatro que atiende al interés por la tragedia y por la renovación de los mecanismos utilizados tradicionalmente en el teatro político. Me interesa la palabra poética entendida como acción, como construcción del mundo. Busco en mis obras la belleza como consuelo ante la verdad. (UC3M Magazine)

Este concepto de la palabra poética como algo útil, como una herramienta equiparable a la acción, le permite reflexionar sobre acontecimientos históricos extremos a través de la imaginación y la metáfora, creando «fábulas necesarias para no envenenarse de odio» (UC3M Magazine). El material histórico se maneja, además, a través de un tiempo propio, único, que acerca la fábula al carácter circular de la tragedia, y es donde sus personajes, desprovistos de nombre, nos muestran una y otra vez la imagen terrible del hombre moderno (Checa Puerta 359). Nuestro existir trágico -abocados, como estamos, a todo tipo de crisis- muestra nuestra caída concentrada en un instante, y el tiempo que se presenta en escena no parece fluir de forma lineal, sino que sobre las tablas todo parece suceder a la vez, dando la sensación de que nada avanza, 
sino que todo se repite, de manera circular y eterna: «la forma de construir es rizomática y no hay un centro claro», declara la autora (Pérez Rasilla 2012d).

A grandes rasgos podemos concluir diciendo que en el teatro político de Lola Blasco, la reconstrucción ritual de los acontecimientos históricos, la compleja red alegórica que proponen todos sus textos y la metáfora como recurso expresivo fundamental en la concepción poética del drama constituyen señas de identidad fundamentales. A lo que unimos, finalmente, la apuesta personal de la dramaturga por desarrollar un teatro político cada vez más próximo a la denominada «dramaturgia del yo», caracterizada, en general, por construir la identidad del sujeto que está sobre la escena en el momento de la enunciación, de forma que lo que muestra de sí mismo, su mundo interior, sus obsesiones, sus dudas, tienen un punto de partida en el yo y un punto de llegada en el otro, mostrándose, pues, inacabado. Tratándose de una fábula de concepción abierta, esta acaba de construirse en cada uno de los receptores, y en ella «la identidad ya no se cimenta en el interior del sujeto sino en la relación del sujeto con el mundo» (Blasco 2014, 95). Son discursos, en definitiva, que suelen estar próximos a la confesión, que suponen nuevos modos de subjetivismo alejados de elementos naturalistas y cuyo interés reside en los mecanismos que subyacen en los ejercicios de las confidencias o testimonios públicos. Dice Lola Blasco: «[...] me interesa la confesión en cuanto construcción y mejora de la identidad y en cuanto construcción y mejora del entorno» (Montero). Así, bajo el recurso de la confesión pública, y en busca de una construcción identitaria, las obras se convierten en claras propuestas éticas: el Yo que construyo y que muestro ante los demás se crea tanto en relación con ese Otro/s como con el enfrentamiento o la sumisión ante la realidad.

Eso significaría, en último extremo, entender el espacio dramático como aquel donde trabajar un teatro de dimensión política, social, e, inexorablemente, identitaria, existencial.

En respuesta a Romera Castillo sobre si el activismo político ejercido a través de su teatro se ha mantenido desde sus inicios o si es resultado de una trayectoria última, la autora comenta en junio de 2017:

Yo hago teatro porque me gusta compartir. Y además quiero contar o transmitir un mensaje a cuanta más gente mejor. Entonces, desde el principio he querido contar historias que hablaran de las injusticias, que tuvieran ese sentido casi de redención «benjaminiana» de volver a recuperar esas injusticias para redimirlas de alguna forma, y que... por qué no decirlo, que también denunciaran aspectos del presente.

«Estoy escribiendo la historia de un viaje. Mi viaje. Mi siglo. Mi bestia. Es la historia de un viaje y también un alarido, un desamor, una derrota» (Blasco 
2015b, 25). Estas palabras forman parte de uno de los tres fragmentos que constituyen el Cuaderno de Bitácora, texto que, a modo de soliloquio, intercala la pieza Siglo mío, bestia mía. Son palabras que rememoran el poema «El Siglo» del malogrado poeta ruso Osip Mandelstam, cuya referencia se relaciona con que ambos autores realizan un viaje a través de sí mismos identificándose con una época a la que intentan mirar cara a cara, y porque, como indica Lola Blasco, «Mandelstam habla en ese poema de la fractura, del dolor, pero también de la esperanza en el futuro» (Muro 2017).

Creo que es importante mirar al pasado, concebirlo en la línea de Benjamin como un pasado abierto que nos interpela de forma directa negando el tiempo como algo progresivo, puesto que la historia la han hecho los vencedores, no los vencidos, y por tanto nuestra historia está manchada con la sangre de todos los que perecieron. Creo que existe la posibilidad de redención en el presente, y que le futuro está también ahora en nuestras manos. Comprender esto puede darnos una posibilidad. (Montero)

\section{REFERENCIAS BIBLIOGRÁFICAS}

Agamben, Giorgio. Desnudez, algunos ensayos. Barcelona: Anagrama, 2011.

Amorós, Celia. «Feminismo, Ilustración y Posmodernidad». Diálogos sobre filosofía y género. México: UNAM, 1995, 23-39.

Blasco, Lola. «Sobre el yo generacional en algunas muestras del teatro español actual». Creadores jóvenes en el ámbito teatral $(20+13=33)$. Ed. José Romera Castillo. Madrid: Verbum, 2014, 93-105.

Blasco, Lola. «Sentido de los códigos musicales en la actualización del teatro político». Teatro y música en los inicios del siglo XXI. Ed. José Romera Castillo. Madrid: Verbum, 2015a, 41-59.

Blasco, Lola. Siglo mío, bestia mía. Madrid: INAEM, 2015b.

Castro, Julio. La República Cultural.es (23 de marzo de 2011). https://larepublicacultural.es/article4014.html, consultado el 22-03-2017.

Contreras, Ana. «Líneas emergentes en la dirección escénica durante el siglo XXI». Acotaciones 27 (julio-diciembre 2011): 55-82.

Checa, Julio E. «Dramaturgas españolas del siglo XXI: Lola Blasco (1983), del ditirambo al rap». Imágenes femeninas en la literatura española y las artes escénicas (siglos XX y XXI). Eds. F. Vilches de Frutos y P. Nieva de la Paz. Ohio: Society of Spanish and Spanish-American Studies, 2012, 353-367.

Floeck, Wilfried. «iJuego posmoderno o compromiso con la realidad extraliteraria?: el teatro de José Sanchis Sinisterra». Teatro contemporáneo español posfranquista: autores y tendencias. Eds. Herbert Fritz y Klaus Pörtl. Berlín, 2001, 47-54. 
Floeck, Wilfried. «El teatro actual en España y Portugal en el contexto de la postmodernidad». Iberoamericana IV, 14 (2004): 47-67.

García Barrientos, José Luis. «Dramatología del tiempo y dramaturgias femeninas (Diosdado, Ortiz, Pedrero, Reina, Resino)». Dramaturgias femeninas en la segunda mitad del siglo XX. Espacio y tiempo. Ed. José Romera Castillo. Madrid: Visor Libros/Seliten@t (UNED), 2015, 43-66.

Garnier, Emmanuelle. Lo trágico en femenino. Bilbao: Artezbai, 2011.

Gutiérrez Carbajo, Francisco (ed.). Dramaturgas del siglo XXI. Madrid: Cátedra, 2014.

Lehmann, Hans-Thies. Teatro posdramático. Tr. Diana González Martín. Murcia: EPR Murcia Cultural, 2013.

López Antuñano, José Gabriel. «Teatro del siglo XXI. Presentación versus representación». Nueva revista de política, cultura y arte 140 (septiembre 2012): 1-9. http://www.nuevarevista.net/articulos/ teatro-del-siglo-xxi-presentacion-versus-representacion

Maffesoli, Michael. El instante eterno. El retorno de lo trágico en las sociedades postmodernas. Barcelona: Paidós, 2001.

Manola, Giovanna. «Lola Blasco Mena y María Velasco: la escena da nueva voz a la historia contemporánea y a sus personajes». Creadores jóvenes en el ámbito teatral (20+13=33). Ed. José Romera Castillo. Madrid: Verbum, 2014, 106-120.

Montero, Paula L. Revista digital RITMOS XXI de información cultural (2015). http:// www.ritmos21.com/13579/una-vida-sin-examen-no-merece-ser-vivida.html, consultado el 08-10-2016.

Muro, Javier. «Mujeres en el arte». SPOONFUL. Magazine de Cultura, Ocio y Deporte (marzo-abril 2017). http://spoonful.es/noticia/cultura/libros/al-teatro-se-va-acompartir'_20161117083156.html, consultado el 02-05-2017.

Muro, Robert. «Crear y mostrar en el siglo XXI. Mirando al futuro sin ira. La producción y la exhibición de las artes escénicas en España». Acotaciones 27 (julio-diciembre 2011): 33-54.

Pérez Jiménez, Manuel (1996). «La posmodernidad como categoría en literatura y teatro». Contribución al Seminario «Las artes escénicas europeas: renovación y transgresión como espíritu de modernidad». Universidad de la Laguna, 1996, 1-14. http://hdl.handle.net/10017/19970

Pérez-Rasilla, Eduardo. «La escritura más joven. Algunas notas sobre la literatura dramática emergente en España». Acotaciones 27 (julio-diciembre 2011): 13-32.

Pérez-Rasilla, Eduardo. «Siete textos breves de siete dramaturgas jóvenes. Imágenes de una sociedad violenta». Acotaciones 28 (enero-junio 2012a): 75-176.

Pérez-Rasilla, Eduardo. «El teatro español en el siglo XXI. Presentación». Don Galán. Revista de investigación teatral (2012b): 1-3. http://teatro.es/contenidos/ 
donGalan/donGalanNum2/pagina.php?vol=2\&doc=1_0\&pag=1, consultado el 02-05-2017.

Pérez-Rasilla, Eduardo. «Notas sobre la dramaturgia emergente en España». Don Galán. Revista de investigación teatral (2012c): 1-6. http://teatro.es/contenidos/donGalan/donGalanNum2/pagina.php?vol=2\&doc=1_6, consultado el 02-05-2017.

Pérez-Rasilla, Eduardo. «Breve entrevista a una serie de dramaturgos emergentes». Don Galán. Revista de investigación teatral 2 (2012d). http://teatro.es/contenidos/donGalan/donGalanNum2/video.php?vol=2\&doc=3_4, consultado el 02-05-2017.

Ragué-Arias, María José. «La obra de algunas autoras españolas contemporáneas desde la perspectiva de la teoría teatral feminista». Reescribir la escena. Ed. Laura Borrás. Madrid: Fundación Autor, 1998, 227-236.

Ragué-Arias, María José. ¿Nuevas dramaturgias? (Los autores de fin de siglo en Cataluña, Valencia y Baleares). Madrid: CDT, 2000.

Romera Castillo, José. «Lola Blasco dialoga con José Romera Castillo» (30 de junio de 2017). http://www.rtve.es/alacarta/videos/uned/uned-06-10-17/4249916/, consultado el 25-07-2017.

Ruiz Ramón, Francisco. Historia del teatro español Siglo XX. Madrid: Cátedra, 1995.

Serrano, Virtudes. «El espacio y el tiempo de la mujer en la dramaturgia femenina finisecular». Dramaturgias femeninas en la segunda mitad del siglo XX. Espacio y tiempo. Ed. José Romera Castillo. Madrid: Visor Libros/Seliten@t (UNED), 2015, 95-108.

Toro, Alfonso de. «Hacia un modelo para el teatro posmoderno». Semiótica y teatro latinoamericano. Buenos Aires: Galerna/IITCTL, 1990, 13-42.

UC3M Magazine (2016). http://uc3m-magazine.uc3m.es/index.php/2016/12/19/ entrevista-a-lola-blasco, consultado el 20-01-2017.

Vilches de Frutos, Francisca. «Representaciones de género en el teatro español contemporáneo. La igualdad en la construcción del espacio cultural europeo». ALEPH 24 (2010): 9-28.

Zaza, Wendy-Llyn. Mujer, historia y sociedad: la dramaturgia española contemporánea de autoría femenina. Barcelona: Reichenberger, 2007. 



\section{EN PRIMERA PERSONA: ENTREVISTAS A CUATRO VOCES \\ DE LA DRAMATURGIA FEMENINA ACTUAL}





\section{LOLA BLASCO}

Alicante, 1983. Comienza sus estudios de interpretación en la escuela de Cristina Rota y posteriormente en el estudio de Jorge Eines, al tiempo que ingresa en la Real Escuela Superior de Arte Dramático, en 2005, para cursar la carrera de Dramaturgia. Es Máster de Humanidades por la Universidad Carlos III de Madrid, donde ejerce la docencia. En 2009, recibió el Premio Internacional Buero Vallejo por su obra Pieza paisaje en un prólogo y un acto y en 2016 el Premio Nacional en Literatura Dramática por Siglo mío, bestia mía. En 2009 fundó la compañía teatral Abiosis, para la que dirigió sus primeros espectáculos además de participar como actriz. Además de las citadas, entre sus textos teatrales destacan Foto Finis (2009), Oración por un caballo (2009), Los hijos de las nubes (2011), Un concierto de despedida (2011), En defensa de un teatro político-revolucionario (2011), Proyecto Milgram (2012), Las tres murallas (2013), Ni mar ni tierra firme (2014), Artículo 47 (2014), Canícula (2015), La confesión del Quijote (2015), Teme a tu vecino como a ti mismo (2015) y Canción de cuna (2016).

1. ¿Cuáles son sus razones para dedicarse al género dramático? ¿Complementa su actividad dramatúrgica con alguna otra profesión teatral (interpretación, dirección, producción, gestión pública o privada...)?

Yo empecé estudiando interpretación. Adoro el teatro desde que tengo uso de razón, pero en mi época de estudiante y tras mis primeros trabajos como actriz, me di cuenta de algo: no me sentía representada con ninguno de los papeles que tenía que abordar. Una vez le dije a mi profesor de entonces, Jorge Eines, que yo quería ser Ricardo III. Un par de años antes había hecho de Lady Ana en una escuela, pero yo quería ser Ricardo III. Ese era el personaje verdaderamente interesante para mí. Ricardo III es una bestia, un seductor estratega, pero ese tipo de papeles no están destinados a las mujeres y menos aún si son jóvenes. Luego me di cuenta de que el panorama para las mujeres maduras era todavía más desolador, si cabe. Desde siempre he sentido mi cuerpo, mi género, como un estorbo. Yo pensaba que el teatro era el lugar donde uno 
podía ser otro. Yo pensaba que, en el teatro, podría hacer de un joven perdido, de un viejo agotado, de una vieja con ganas de dominar el mundo, de un niño que se enamora... Yo pensaba que, en el teatro, podría saltarme los estrictos corsés que la sociedad nos imponía y luego me di cuenta de que no, de que el teatro era representación de la realidad, mímesis.... En ese momento, me di cuenta de que había que contar nuevas historias, crear nuevos roles para las mujeres con la esperanza de que, al cambiar la representación, cambiara también el mundo. De ahí que me pasara de la interpretación a la dramaturgia. La dirección vino más adelante, cuando vi las dificultades que, como mujer, tenía para ser representada. En el 2009 formé una compañía y tuve que encargarme durante algunos años de la producción. En estos momentos estoy retomando de nuevo mi faceta como actriz.

2. ¿Cuáles diría que son los rasgos más llamativos e interesantes del teatro escrito por mujeres en la actualidad?

Creo que la autoría femenina está en un momento maravilloso. Somos muchas y eso hace que también haya mucho más teatro de calidad. Uno de los rasgos que observo es que las mujeres, al haberlo tenido más difícil y haber sido menos representadas en teatros importantes y, por tanto, también al haber estado menos sometidas a la dictadura de la producción, hemos sido más libres para desarrollar nuestro propio lenguaje. Los textos firmados por mujeres asumen, a mi modo de ver, mayor riesgo y compromiso político.

3. ¿Qué aspectos sobre temas de género tratados por otras dramaturgas le interesan especialmente?

En estos momentos estoy muy interesada en la violencia de género. A veces parece que vamos hacia atrás en algunos aspectos...

4. En las últimas décadas han surgido en España numerosas agrupaciones de mujeres vinculadas a las artes escénicas (Asociación de Dramaturgas Españolas, Asociación de Mujeres en las Artes Escénicas de Madrid, Federicas, Projecte Vacas y Margaritas, etc.). ¿Conoce la labor de estos colectivos? ¿Qué papel considera que han jugado en la dramaturgia femenina de estos años?

Creo que las asociaciones son importantes y que las mujeres debemos asociarnos. Con compañeras el camino se hace menos arduo, y nos necesitamos las unas a las otras si queremos cambiar nuestra situación de desigualdad frente a los hombres. 
5. Describa cómo son sus personajes femeninos y valore si su relevancia o protagonismo es mayor que el de los masculinos en el conjunto de su producción.

No me gusta tanto medir a los personajes por cantidad como por calidad. En mis obras no necesariamente hay más mujeres que hombres (aunque en los últimos años cada vez la presencia femenina sea mayor), lo importante es qué clase de mujeres aparecen. Ellas mueven acción y son portadoras del discurso, eso es lo importante.

6. ¿Qué aspectos que atañen específicamente a las mujeres considera que es más importante o urgente abordar desde el teatro?

De nuevo, la violencia. Pero me refiero a esa violencia cotidiana, la que casi no queremos ver...

7. ¿En qué cree que se diferencia más ostensiblemente la literatura dramática escrita por mujeres y por hombres?

En nada. Como decía, debido a que hemos tenido más dificultades hemos experimentado más, pero no sólo nosotras... Cuando leo un texto no soy capaz de diferenciar si es de una mujer o de un hombre.

\section{DIANA M. DE PACO SERRANO}

Murcia, 1973. Es Doctora en Filología Clásica (Universidad de Murcia) y Licenciada en Filología Italiana (Universidad de Salamanca). En la actualidad es Profesora Titular de Filología Griega en la Universidad de Murcia. Ha investigado sobre literatura griega, en especial sobre el teatro griego y su influencia en la cultura contemporánea y sus trabajos han sido publicados en diversas revistas y libros, entre los que figura La tragedia de Agamenón en el teatro español del siglo XX (2003). Desde 1998 ha publicado y estrenado diversos textos teatrales como Eco de cenizas (1998), Accésit al Premio de Teatro Universidad de Sevilla 1998; Polifonía (2001), finalista del Premio Calderón de la Barca 2000; Lucía. La antesala (2002), premio al mejor libro murciano 2002 en la modalidad de teatro; Su tabaco, gracias (2004); Obsession Street (2009), Premio de Teatro Ciudad de Palencia; PCP (2010), De mutuo acuerdo o el concierto de un hombre con un abrigo pegado a la piel y otras obras Menudas (I Premio Irreverentes de Comedia, 2015) y el volumen Casandras (2016) que incluye cinco textos: Polifonía, Espérame en el cielo o...mejor, no, África L., Morir de amor, Casandra. 


\section{1. ¿Cuáles son sus razones para dedicarse al género dramático?}

Desde mi infancia he tenido una estrecha relación con el teatro. Mis padres, Virtudes y Mariano, han dedicado sus investigaciones al teatro español de los siglos XX y XXI y, por ello, la relación con este género ha sido muy cercana, muy vivida. La biblioteca de mis padres es un sueño para los amantes del arte dramático. Junto a colecciones de revistas desde sus primeros números, como Estreno o Primer Acto, se reúnen centenares de publicaciones de obras teatrales de todos los tiempos y autorías y, en particular, un enjundioso catálogo de obras contemporáneas. La lectura de los textos siempre ha estado al alcance de la mano y recuerdo que, en ocasiones, yo podía hojear incluso las pruebas de imprenta que llegaban a casa de las ediciones de los autores del momento y hasta colaborar en su corrección. Aproveché esta oportunidad para acercarme a este género que poco a poco me cautivaría. Con mis padres, mis hermanos Mariano, Miguel y yo hemos ido al teatro en muchas ocasiones en Murcia -recuerdo las citas veraniegas en el Festival de San Javier o las representaciones en el Teatro Romea- y en otras ciudades; hemos visitado el Festival de Teatro de Almagro y hemos acudido al teatro romano de Mérida... Guardo en mi memoria con emoción y todo lujo de detalles -incluido el atuendo que lucí ese día y el mágico momento en que Javier Escrivá me firmó un autógrafo: «Buena suerte»- el estreno de Lázaro en el Laberinto de Antonio Buero Vallejo en el teatro Maravillas el 18 de diciembre de 1986. Quedé impresionada con la obra y me prometí que, algún día, yo escribiría también teatro. La relación de amistad que mis padres entablaron con Antonio Buero Vallejo nos permitió a mis hermanos y a mí acompañarlos y encontrarnos también con él y con Victoria Rodríguez en diversas ocasiones, muchas de ellas en Murcia, otras en su casa de Madrid, charlar con él, entrañable y cercano siempre. Su palabra sabia y las hermosas dedicatorias manuscritas en sus libros eran, sin duda, un tesoro para una aspirante a dramaturga.... Durante mis años de estudiante tuve la oportunidad de conocer a otros autores en la casa familiar o en encuentros teatrales a los que acompañaba a mis padres y así conocí a Alfonso Sastre, Domingo Miras, Paloma Pedrero, Carmen Resino, Alberto Miralles, Jerónimo López Mozo..., y yo quería hacer como ellos y escribir teatro y crear historias en papel que subieran a un escenario.

Siempre me ha gustado escribir y el género dramático era mi preferido. En ocasiones lo hacía como un desahogo, una especie de terapia que, aún ahora, me resulta efectiva, pero con el tiempo escribir teatro significó mucho más. Los textos que había escrito para mí me pedían salir del cajón. Mi madre leía mis obras y me las corregía -todavía hoy es mi primera lectora y, además, he tenido el feliz honor de que ella, una de las más destacadas investigadoras del 
teatro español escrito por mujeres, que además ha tenido (sin remedio) que leer mis obras desde que empecé a escribir, prologue mi último libro, Casandras-, después ella se las pasaba a mi padre, como también ocurre hoy, y luego llegaban las críticas de ambos. En alguna ocasión me los guardé para mí, textos secretos que un día verían la luz. Al mismo tiempo, mi hermano Mariano, que hoy es director teatral, era actor en el Teatro Universitario. Yo intenté subir a un escenario una o dos veces. No sabía. Yo quería ser dramaturga.

Un día vi un anuncio de un concurso de textos teatrales, el premio era en metálico, en pesetas, no recuerdo cuántas porque no lo gané, pero «arreglé» mi primera obra de teatro para presentarla en sociedad y la envié ilusionada a este concurso. Desde entonces sigo escribiendo teatro. Esa obra era Eco de cenizas (1998), que poco después ganaría el Accésit de los premios teatrales de la Universidad de Sevilla. La dediqué a mi abuela María, luz de amor inspirador en mi vida, y también a mis queridos padres.

El género dramático es un género mágico que permite crear una realidad y llevarla a la escena para establecer un diálogo con el público, como ocurrió desde sus orígenes en Grecia. El teatro entraña la belleza y el compromiso de crear un mundo alternativo que cobrará vida cada vez que se lea o se represente y que permite crear en él caracteres y situaciones que agiten, al menos un poco, las almas de todos los que participamos en el hecho teatral; que nos haga pensar sobre el mundo en que vivimos, de modo más o menos consciente y sobre otros mundos posibles; que plantee preguntas, que remueva, que despierte emociones, que nos lleve a disfrutar y sufrir a la vez en un acto de arte y de realidad, jugando con el tiempo y el espacio a través de la creación de un universo simbólico que en cada lectura o cada representación comienza y termina en un movimiento circular de infinitas posibilidades. El «drama», etimológicamente, es actuación y a través de ella tenemos la posibilidad de indagar sobre el ser humano, la sociedad que nos envuelve, el mundo que conocemos y el que no, plantear preguntas a través del humor y el llanto, el absurdo y la poesía, en definitiva, crear, observando el trocito de universo en que vivimos e imaginando el resto y reflexionando sobre él de todas las maneras posibles.

\section{2. ¿Complementa su actividad dramatúrgica con alguna otra profesión teatral?}

Ocasionalmente he coproducido alguna de mis obras. La primera vez fue con la compañía Espacio Imaginado, junto a Mariángeles Rodríguez y Jorge Fullana, en el montaje de Espérame en el cielo o...mejor, no (2012). También tuve que participar en la distribución del mismo. En la época en la que vivimos, si quieres ver una obra propia sobre la escena y no encuentras quien la produzca -algo 
habitual-, hay que armarse de valor y lanzarse a ello. Eso fue lo que a mí me ocurrió. Fue una experiencia muy hermosa y agotadora. Me impliqué mucho en el proceso de ensayos y en la producción. Así pasó también con la siguiente obra, De mutuo acuerdo o el concierto de un hombre con un abrigo pegado a la piel (2015).Después ya no he hecho otra cosa sino escribir y reescribir, según las necesidades: en Polifonía, dirigida por Miguel Cegarra, retoqué el texto siguiendo sus indicaciones para ponerla en escena.

Durante casi dos años, hasta este mes de septiembre, me encargué de la Coordinación del Servicio de Cultura de la Universidad de Murcia en el que está incluida el Aula de Teatro, por lo que participé directamente en la gestión de la actividad teatral: la producción de montajes y lecturas dramatizadas (se realizó una lectura la última semana de cada mes con participantes con y sin experiencia teatral en el marco del Festival Deletreartes. Encuentros de Cultura UMU), la programación de la sala de teatro con obras propias y externas, la organización de talleres de teatro bilingüe, teatro musical, infantil, etc. Fue una experiencia muy enriquecedora.

3. ¿Cuáles diría que son los rasgos más llamativos e interesantes del teatro escrito por mujeres en la actualidad? ¿Qué aspectos sobre temas de género tratados por otras dramaturgas le interesan especialmente?

Las autoras estamos conquistando, finalmente, un espacio propio dentro del panorama teatral que había sido silenciado o ignorado a lo largo de la historia y que cada vez es más significativo. La reivindicación de este espacio en las publicaciones teatrales de autoras contemporáneas -gracias a la labor de editoriales dedicadas al teatro que, cada vez más, se interesan por nuestras obras-se ha unido, a su vez, a la mayor presencia de nuestras obras en los escenarios, gracias a los logros que vienen impulsados por el enérgico esfuerzo realizado por las autoras, las críticas y las estudiosas a lo largo del siglo XX y, en especial, a partir de la llegada de la democracia, desde la década de los 80 .

Resultan imprescindibles a este respecto los estudios y ediciones de investigadoras como Patricia W. O'Connor, Pilar Nieva de la Paz, María José Ragué o Virtudes Serrano, quienes centran sus trabajos en este teatro español escrito por mujeres. Esta empresa de recuperación de la voz teatral femenina desde entonces es cada vez más efectiva y a ella se unen autoras y autores, investigadoras e investigadores año tras año. Muestra de ello, afirma Virtudes Serrano, («Dramaturgia femenina fin de siglo. Estado de la cuestión, Arbor, CLXXVII, p. 563), son los catálogos de autoras de la ADE que vieron la luz en los años noventa y las publicaciones dedicadas a dramaturgas españolas, siendo pionero el número monográfico sobre estas de la revista Estreno (1984), 
dirigida entonces por Patricia W. O'Connor, cuya encomiable labor a través de ediciones, estudios, antologías y traducciones, llevó la dramaturgia femenina española a Estados Unidos y contribuyó a darle visibilidad en España (yo misma tengo el honor de aparecer en Mujeres sobre mujeres en los albores del siglo XXI (Fundamentos, 2006) y de contar con la traducción de Patricia W. O'Connor de mi obra Espérame en el cielo...o, mejor, no (Wait for me in Heaven...or, maybe not) publicada en Estreno Plays, 38, junto a la obra de Juana Escabias La puta de las mil noches (The Hoocker of a Thousand Nights), por lo cual aprovecho la ocasión para expresar mi agradecimiento sincero a esta magnífica mujer, entusiasta e incansable estudiosa de nuestro teatro). A ello se unen, además, las más recientes antologías, como la realizada por Francisco Gutiérrez Carbajo, quien nos ha dedicado numerosos trabajos, entre ellos su volumen Dramaturgas del siglo XXI (Cátedra 2014), en el que he tenido la fortuna de ser incluida junto a autoras tales como Lola Blasco, Antonia Bueno, Juana Escabias, Beth Escudé, Aizpea Goenaga, Diana I. Luque, Gracia Morales, Itziar Pascual, Carmen Resino y Vanesa Sotelo. Se trata de una antología donde podemos comprobar rasgos destacados de esta sólida dramaturgia femenina, tal y como subraya el autor en el prólogo de esta edición.

Aunque los temas y planteamientos en el teatro actual escrito por mujeres resultan de lo más variado, así como las estéticas y propuestas, considero que uno de los rasgos más definitorios de esta dramaturgia es la fuerza y el compromiso con el que se abordan los temas sociales, con especial interés en aquellos relativos al abuso de poder, el maltrato y la injusticia ejercida sobre las mujeres de cualquier tiempo y procedencia y la insistencia en la necesaria rebelión de las mujeres frente a estas situaciones dramáticas. La indagación en el alma femenina, la reflexión sobre las relaciones humanas, la incomunicación y la incapacidad de entendimiento son también motivos recurrentes en nuestros textos.

Se trata, sin duda, de un teatro comprometido, de denuncia, que muestra de manera caleidoscópica un entramado de temas y situaciones a través de los que reflexionar y actuar sobre el presente. En este sentido, me resultan especialmente interesantes todas las miradas femeninas y todos los aspectos tratados en los textos.

Las dramaturgas, tras un primer impulso a principios del siglo XX, comienzan a ganar parte de un espacio necesario con obras de Ana Diosdado -ya en los 70- o, en los 80, con Concha Romero, Lidia Falcón, María José Ragué, Carmen Resino o Paloma Pedrero, quien, recordemos, agitó la escena española con $\mathrm{La}$ llamada de Lauren. Los textos de estas y otras autoras de la época constituyen la sólida raíz del teatro español contemporáneo escrito por mujeres. Gracias a 
esta labor constante de autoría y crítica, hoy en día, los textos publicados por mujeres son cada vez más numerosos, por lo tanto, a las autoras consagradas que continúan publicando, debemos unir nuevas voces cuya lectura resulta imprescindible para adentrarse en el universo de la literatura dramática de nuestro siglo.

En cuanto a los temas de género, considero que todos los aspectos tratados por otras dramaturgas entrañan un gran interés y están escritos desde una postura conscientemente comprometida: el abuso y la marginación, la prostitución y la explotación de mujeres y niños, la violencia machista y la discriminación social, laboral o económica por razón de sexo, y la repercusión de todos estos elementos en la vida privada y pública de los personajes femeninos, junto a la rebelión de ellas frente al elemento opresor: la lucha por la libertad y la igualdad de derechos.

Los tratamientos históricos o mitológicos de las heroínas y protagonistas femeninas, frecuentes en la literatura dramática actual escrita por mujeres, resultan también muy interesantes a la hora de abordar estos temas, merced a su carácter simbólico y universal, como también lo son las historias que están encuadradas en el momento presente y aquellas que mezclan diferentes planos históricos, mitológicos y cronológicos jugando con el presente, el pasado e, incluso, el futuro.

4. En las últimas décadas han surgido en España numerosas agrupaciones de mujeres vinculadas a las artes escénicas (Asociación de Dramaturgas Españolas, Asociación de Mujeres en las Artes Escénicas de Madrid, Federicas, Projecte Vacas y Margaritas, etc.) ¿Conoce la labor de estos colectivos? ¿Qué papel considera que han jugado en la dramaturgia femenina estos años?

Sí, conozco estas asociaciones, desde la primera Asociación de Dramaturgas Españolas que surge en 1986 y se da a conocer en 1987, hasta las más recientes, como la AMAEM (Marías Guerreras), Federicas, Projecte Vacas, Margaritas... Considero que la unión de las mujeres relacionadas con las artes escénicas es fundamental para reivindicar y dar visibilidad a la actividad dramatúrgica femenina y contribuir «a la integración cultural de las mujeres dedicadas a las artes escénicas a través del teatro», como recordaba Carmen Resino, primera presidente de la Asociación de Dramaturgas Españolas, en el año 1987.

En los últimos años, las redes sociales también se convierten en una plataforma con esta finalidad, así a través de ellas se puede dar impulso a las agrupaciones y asociaciones de mujeres relacionadas con las artes escénicas, como ocurre, por ejemplo, con la Liga de las Mujeres Profesionales del Teatro 
que nació en España en 2016, a la que llegué a través de Facebook y en la que se realiza un intenso trabajo de difusión, apoyo e impulso colectivo de la labor de las mujeres en el ámbito de las artes escénicas.

No hay que olvidar la presencia de publicaciones centradas en el estudio y la palabra de las dramaturgas que cada vez cobran más fuerza, como este número dedicado a la última dramaturgia femenina española -mi agradecimiento a las editoras por realizarlo y por contar conmigo-; el Extra n. 1 de Las puertas del drama coordinado por Yolanda Dorado y dedicado a «Mujeres que cuentan [Especial Autoras]», donde junto a la voz de las autoras se publica una sección en la que los autores y críticos hablan de las dramaturgas -Francisco Gutiérrez Carbajo me dedica sus reflexiones-, y otra que se ocupa de asociaciones de mujeres; los encuentros y seminarios de SELITEN@T dirigidos por José Romera Castillo en el marco de los cuales se ha otorgado un papel protagonista a las dramaturgas; proyectos como DRAMATURGAE que implica diferentes universidades europeas en el estudio del teatro escrito por mujeres y su difusión; encuentros teatrales en diferentes festivales de teatro dedicados a las figuras femeninas y a las autoras; jornadas como las organizadas este año por la Asociación Clásicas y Modernas; premios de investigación dedicados a la dramaturgia femenina, como el III Premio de Investigación José Monleón «La mirada femenina en la dramaturgia española del siglo XXI»... Son todas ellas iniciativas que sirven como ejemplo de las muchas existentes y que muestran cómo se contribuye desde muy diversos ámbitos al impulso y a la visibilidad de las dramaturgas en el panorama teatral español, lo cual no es óbice, por otra parte, para que insistamos en lo necesario de seguir trabajando para alcanzar nuevos y más espacios de desarrollo y reivindicación de las obras y las figuras de las dramaturgas españolas contemporáneas.

\section{Describa cómo son sus personajes femeninos y valore si su relevancia o protagonismo es mayor que el de los masculinos en el conjunto de su producción.}

Voy a detenerme en el último libro que he publicado, Casandras (Esperpento ediciones teatrales, 2016), que contiene cinco obras cuyas protagonistas son todas mujeres, pese a que también anteriormente, como mencionaré, algunas de mis obras presenten igualmente protagonistas femeninas.

En Casandras se presenta un grupo de protagonistas femeninas: distintas edades, procedencias, épocas y características pero, pese a todo, entre ellas existe una sólida conexión. En palabras de Virtudes Serrano en el prólogo del libro, las protagonistas de las cinco obras «son diez figuras femeninas, reunidas para contar sus historias que es la historia de las mujeres de antaño y de las 
actuales. Son relatos que tienen en común a sus protagonistas, mujeres y niñas sometidas por unos sistemas que las privan de la voz, que les impiden, hasta con la muerte, hablar de lo que han sido, son o quieren ser en el mundo». La solidaridad femenina frente a la agresión externa es un motivo imprescindible y recurrente en estas obras. Aparece claramente en Polifonía y en Espérame en el cielo o mejor no y también en un monólogo breve, Hermíone o la guerra sin nombre, obra que publicará la revista Estreno este mismo otoño en un monográfico coordinado por Lourdes Bueno y Juana Escabias, y que incluirá mi monólogo junto a otras 49 obras de autoras y autores españoles que abordan la temática del maltrato.

He tenido el enorme privilegio de que las obras del volumen Casandras hayan sido prologadas por prestigiosas hispanistas, destacadas estudiosas de la dramaturgia femenina contemporánea como Virtudes Serrano (Casandra), Helen FreearPapio (Polifonía), Iride Lamartina-Lens y Susan Berardini (Espérame en el cielo...o, mejor, no), Greta Trautmann (África L.), Rossana Fialdini-Zambrano (Morir de amor).Se trata de un volumen dedicado a las mujeres y realizado por mujeres. Con Casandras he querido representar el drama de la mujer sabia y silenciada, a la que no se escucha porque no conviene, a la que se maltrata para apartarla. Una mujer que se rebela ante estos ataques y alza su voz para enfrentarse a su destino. La obra se estrena el 2 de junio en Sevilla en el Teatro Távora, con la compañía Tríade Teatro, dirigida por Miguel Cegarra.

En obras anteriores también aparecen protagonistas femeninas: la Lucía protagonista de la obra homónima publicada en 2002, la Berenice de la obra $P C P$, publicada en Estreno en 2010, y la recreación de la figura de Medea en El canto póstumo de Orfeo. Monólogo de tres almas, del año 2009.

Si hago un repaso de mi producción, en mis obras es evidente que el protagonismo del universo femenino es mayor que el del masculino, aunque siempre, presentes o ausentes, están los varones como contrapunto de muchas de las historias. Algunas de mis obras tienen protagonistas masculinos muy marcados como en Eco de Cenizas (Universidad de Sevilla, 1998), pero en muchas otras ocasiones comparten escena con las figuras femeninas, como en el caso de Obsession Street (Huerga y Fierro, 2010) o De mutuo acuerdo o el concierto de un hombre con un abrigo pegado a la piel (Ediciones Irreverentes, 2015), donde se trata la situación de un hombre manipulado por dos ex mujeres y atrapado en una situación de indefensión que no sabe manejar. También los niños son protagonistas en mis textos: el hermano desaparecido de Aisha, Hamed, el gemelo al que le gustaba «vestirse con sus ropas» y que, al ser descubierto vestido de niña, fue hecho desaparecer tal y como emotivamente cuenta 
la hermana en Espérame en el cielo...o, mejor, no, o el pequeño protagonista -inspirado en el niño que viajó en una maleta desde Costa de Marfil- de la obra El viaje de Abdou, incluida en la antología Los mares de Caronte. Diecisiete calas dramáticas sobre migraciones (Madrid, Fundamentos, 2016). En la última obra breve, En blanco, publicada en la antología La paradoja del dramaturgo (Esperpento ediciones teatrales, 2016) personajes masculinos y femeninos de mis propias obras se confabulan para sabotear el trabajo de la autora...

Si bien es cierto que siento la necesidad de tratar temas femeninos que me inquietan y cuya problemática deseo y considero muy necesario recrear en escena, también lo es que me interesa indagar sobre todo tipo de situaciones y personajes, el ser humano en acción, las relaciones interpersonales y las conexiones de las mismas con el mundo en que vivimos.

\section{6. ¿Qué aspectos que atañen específicamente a las mujeres considera que es más importante o urgente abordar en el teatro?}

Es necesario continuar abordando todos los temas relativos a la mujer y a nuestra situación en la sociedad actual. Como leía hace unos días en el ensayo de Chimamanda Ngozi Adichie, Todos deberíamos ser feministas, «si hacemos algo una y otra vez, acaba siendo normal. Si vemos la misma cosa una y otra vez, acaba siendo normal», el silencio contribuye a esa consideración de «normalidad» de la que es necesario huir, y el teatro es un medio extraordinario para romper con ese silencio y denunciar a través de las historias dramatizadas las injusticias y las desigualdades que se dieron y que se siguen dando en muchos casos en la actualidad. El teatro puede servir para romper la idea de que «eso ya no pasa» porque no se ve, porque no se escucha. Para combatir contra ello, todos deberíamos ser feministas.

Continuemos escribiendo, autoras y autores, sobre mujeres luchadoras, conocidas o no, reales o ficticias, que se han enfrentado al elemento opresor, que han dicho «no» a las prohibiciones y a la violencia, que han combatido y combaten con la palabra, con la ciencia, con la humanidad, con la razón y con la inteligencia, con la solidaridad y con el apoyo mutuo. Existen generaciones de niñas que están sufriendo la violencia física y psicológica, la negación de los derechos básicos... Una cantidad de barbaridades irracionales que debemos frenar intentando, como también ellas hacen en el momento en que les es posible -pensemos en Malala-, enfrentarnos, mujeres y hombres, unidos para que la historia no siga repitiéndose, desde todos los lugares del mundo, a estas incomprensibles y repugnantes amenazas. A través del teatro tenemos que romper fronteras y mirar más allá de nuestro entorno, con el fin de gritar 
no a la violencia en cualquiera de sus manifestaciones, unirnos para ganar la apuesta por la libertad y la igualdad de derechos.

7. ¿En qué cree que se diferencia más ostensiblemente la literatura dramática escrita por mujeres y por hombres?

En la actualidad creo que las diferencias entre la literatura dramática escrita por mujeres y hombres se han acortado en lo que respecta a los temas que se tratan, aunque la mirada sí puede ser distinta en cada caso, el enfoque o la inquietud desde la cual se aborda la temática.

Centrándonos en el protagonismo femenino en los textos, los hombres, a diferencia de lo que podría ocurrir en décadas pasadas, se acercan cada vez con más frecuencia a los temas que atañen directamente a la mujer. Autores españoles contemporáneos dan prueba de ello y, con seguridad, el número irá creciendo con el tiempo. Afortunadamente, el esfuerzo que las dramaturgas realizaron durante el siglo XX por dar a conocer sus textos y representar en ellos una temática femenina, esfuerzo que continua vivo en la dramaturgia femenina del siglo XXI y en los estudios de la misma, ha dado su fruto también en el teatro escrito por hombres. Por supuesto en las décadas precedentes hay distinguidos ejemplos de dramaturgos que abordan personajes femeninos (Buero Vallejo, Domingo Miras o, posteriormente, Jerónimo López Mozo...) desde una perspectiva de reivindicación de estos perfiles, pero esta línea ha ido en aumento a lo largo de los años hasta hoy y todavía se debe nutrir más en el futuro.

\section{BEGOÑA TENA MOYA}

Castelló de la Plana, 1978. Realiza estudios de Historia del Arte y Arte Dramático en la ciudad de Valencia, donde desarrolla su carrera como actriz, cantante, directora y dramaturga. Sus primeros trabajos se centran en el campo de la performance y creación sonora experimental con el dúo Antorcha Amable. Posteriormente realiza estudios de escritura dramática con el autor Paco Zarzoso y centra su actividad en la dramaturgia. En el 2007 consigue el accésit del Premio Internacional para Autoras Dramáticas María Teresa León, convocado por la Asociación de Directores de Escena de España, con la obra Acuática. Ha trabajado como actriz con las compañías Teatro de la Resistencia, Cía Hongaresa, Patrícia Pardo, Sala Escalante, La Zafirina, Pot de Plom, Teatrencompanyia, La Familia Política, Bramant... Como autora ha 
colaborado en proyectos comunitarios (Zero responsables, 2010, con P. Zarzoso; Valèntia, 2012, con Colectivo Veus); piezas cortas para festivales de teatro próximo (Volcán azul, 2014; Els senyors de la terra, 2016) musicales de gran formato (Invisibles, 2016, con el compositor Luis Serrano), dramaturgias y textos para otros creadores (Kòktel Molotov para Pep Ricart; Gorgona para Eva Zapico; Silurs para la productora Scura) y piezas que dirige en su propia compañía (Hambre, 2014; Mambo, 2013; Acapulco, 2012). Ha publicado las piezas infantiles El último parque y El bosque tiene voz (Aula Editorial), Acuática (ADE) y el díptico con Xavier Puchades I tornarem a sopar al carrer i Una indígena ens va guiar a través de les muntanyes (Alupa Editorial).

1. ¿Cuáles son sus razones para dedicarse al género dramático? ¿Complementa su actividad dramatúrgica con alguna otra profesión teatral (interpretación, dirección, producción, gestión pública o privada...)?

Comencé a escribir obras a raíz de estudiar interpretación en una escuela de teatro, donde me formé como actriz. Anteriormente había escrito poesía y relatos, pero es en la literatura dramática donde hallo mi espacio para combinar acción y poesía, un espacio donde poder trabajar la ficción y el trabajo en presente con el encuentro, el encuentro con el público. Al principio, no podía separar la escritura de la interpretación, ya que mis primeros textos son piezas que yo misma represento. Posteriormente iría trabajando para otros actores, actrices y compañías, realizando piezas de pequeño y gran formato. Actualmente combino la escritura con la interpretación y dirección de escena, en proyectos propios y encargos para otras compañías.

2. ¿Cuáles diría que son los rasgos más llamativos e interesantes del teatro escrito por mujeres en la actualidad?

No soy una estudiosa ni poseo la información suficiente para hacer una valoración global sobre el teatro que escriben las mujeres en la actualidad. Conozco la obra de algunas mujeres y puedo decir que es muy heterodoxa, con temáticas y tratamientos muy distintos.

3. ¿Qué aspectos sobre temas de género tratados por otras dramaturgas le interesan especialmente?

Me interesan aquellas autoras que trabajan la memoria histórica desde un punto de vista de género. Me interesa ver cómo rescatan personajes femeninos, mujeres silenciadas en la gran historia. Me interesa ver cómo se expone y denuncia la cosificación de la mujer. Me interesa ver cómo autoras más jóvenes que yo 
presentan y desarrollan otras educaciones/realidades sentimentales y sexuales. Otras formas de interrelacionarse.

4. En las últimas décadas han surgido en España numerosas agrupaciones de mujeres vinculadas a las artes escénicas (Asociación de Dramaturgas Españolas, Asociación de Mujeres en las Artes Escénicas de Madrid, Federicas, Projecte Vacas y Margaritas, etc.). ¿Conoce la labor de estos colectivos? ¿Qué papel considera que han jugado en la dramaturgia femenina de estos años?

Conozco la labor de algunas de estas asociaciones y creo que tienen una gran importancia para visibilizar y posicionar a las autoras y denunciar la falta de paridad en nuestro sector. Creo que seguimos sufriendo una clara desventaja respecto a los autores. Nuestras obras, y las obras de dramaturgas del pasado, siguen sin publicarse, estrenarse ni producirse tanto como las de nuestros compañeros. Y un autor o autora es invisible si su obra no llega a los escenarios.

Desde la asociación de la que formo parte, AVEET (Associació Valenciana d'Escriptores i Escriptors Teatrals), desarrollamos una labor de seguimiento y presión a las administraciones y entidades culturales para conseguir un trato paritario en sus programaciones, ayudas y producciones. Y creo que esta labor, que es llevada conjuntamente a cabo tanto por autoras como por autores, con todas las críticas internas que pueden producirse, es muy positiva y nos lleva a conseguir a las autoras una mayor presencia pública y artística, reivindicando un espacio de igualdad real como creadoras.

5. Describa cómo son sus personajes femeninos y valore si su relevancia o protagonismo es mayor que el de los masculinos en el conjunto de su producción.

Es muy difícil valorar cómo son mis personajes femeninos porque son muy distintos y numerosos, pero podría decir que no son clichés, son poliédricos y activos, son los protagonistas de la acción. Cuando comencé a escribir desarrollaba más personajes femeninos que masculinos por la simple razón de que los tenía que interpretar yo. Y, cuando eres actriz, te encuentras ante una cantidad abrumadora de personajes masculinos protagonistas, algunos protagonistas femeninos y clichés que reducen a la mujer a madre-hija-amante-anciana. Yo quería escribir personajes amplios, que escaparan de los estereotipos tanto masculinos como femeninos y que, en el caso de los femeninos, fueran los motores de la acción y la trama. Con sus luces y sus sombras. Intensos. 
6. ¿Qué aspectos que atañen específicamente a las mujeres considera que es más importante o urgente abordar desde el teatro?

Me preocupa mucho el machismo y sexismo que hay en los adolescentes, especialmente en las relaciones sentimentales, en el ámbito privado y doméstico. Advierto y me horroriza ver cómo no se han superado esquemas de relación no igualitaria y sexistas que empiezan desde bien pequeños. Creo que el teatro tiene en este público, la infancia y adolescencia, un gran terreno donde abordar esta realidad tan grave.

Otro tema, que padezco y veo en muchas compañeras, es la dificultad en la conciliación laboral y familiar, un tema que no afecta a las mujeres en exclusiva sino a toda la sociedad. Se generan muchas frustraciones y tensiones tanto en aquellas mujeres que no siguen con sus carreras profesionales porque no pueden u optan por la crianza y cuidado de sus hijos, como en aquellas que deciden priorizar sus carreras profesionales frente a otras facetas y en aquellas que intentan realizar ambas. Ser madre y trabajadora en este país es una auténtica batalla, donde parece que la mujer nunca esté realizando bien ninguna actividad, ni la profesional ni la personal. Veo muchas mujeres equilibristas haciendo frente a situaciones de gran estrés familiar, personal y profesional. Y la situación empeora según baja el poder adquisitivo de las mujeres.

Me preocupa y ocupa hablar de las mujeres más pobres, de las migrantes, de las indígenas, de las mujeres activistas que denuncian el expolio de las grandes multinacionales sobre los recursos naturales de los pueblos.

Me interesa hablar de la tradicional función del cuidado que han ejercido las mujeres en el pasado (el cuidado de los débiles, de los niños, enfermos, ancianos) y sobre quién lo está realizando (o no) ahora y cómo se lleva a cabo en las sociedades blancas del primer mundo, sociedades cada vez más individualistas donde prima la productividad de las personas sobre casi cualquier otros aspecto.

Me interesa escuchar la vejez y cómo se enfrentan a ella las mujeres.

7. ¿En qué cree que se diferencia más ostensiblemente la literatura dramática escrita por mujeres y por hombres?

Creo que las diferencias entre hombres y mujeres van disminuyendo en el terreno de la escritura dramática actual. Sí creo que hubo un período donde las mujeres trataron temas más relacionados con la intrahistoria, con lo oculto, con la recuperación de la memoria, con la reivindicación de realidades silenciadas porque no eran las predominantes (masculinas). Pero no creo en una literatura femenina y otra masculina. Creo en una literatura que abarque la globalidad, porque tenemos derecho a hablar de lo que queramos, sin límites, sin etiquetas, 
sin género. Esa es la literatura que me rodea. Por eso puedo hablar de autoras y autores en particular. $\mathrm{Y}$ a mi alrededor, los escritores y escritoras de mi generación hablamos y tratamos temas muy parecidos, compartimos estilos y enfoques que no puedo diferenciar por el género. Y si ahora tuviera que hacer un análisis sobre las diferencias entre ambos, solo podría hablar de estereotipos. Creo que es una pregunta para especialistas, yo solo puedo hablar desde mi experiencia y aventurarme sin tener un conocimiento profundo.

\section{MARÍA VELASCO}

Burgos, 1984. Doctora en Comunicación Audiovisual por la Universidad Complutense de Madrid. Estudió dramaturgia en la Real Escuela Superior de Arte Dramático y es Máster en Práctica Escénica y Cultura Visual. Ha escrito los textos para teatro Los perros en danza (Accésit Marqués de Bradomín, 2010), Manlet (2011), Lorca al vacío (2012), La ceremonia de la confusión (Centro Dramático Nacional, 2013), Infamia (2014), Líbrate de las cosas hermosas que te deseo (2015), Si en el árbol un burka (2016) y Fuga de Cuerpos (2017). Algunos de ellos fueron traducidos al euskera, al francés y al italiano. Ha dirigido dos de sus obras: Günter (2014) y La soledad del paseador de perros (2016), que fueron estrenadas en la Sala Cuarta Pared. También ha protagonizado dos acciones: Los dolores redondos (2013) y Damasco Mashup (2016) en Teatro Pradillo. Ha escrito teatro infantil y una obra para adolescentes, Triple Salto, que fue nominada al Max al Mejor Espectáculo Revelación en 2015. Es dramaturga para la compañía de danza contemporánea Kor'sia, liderada por bailarines de la Compañía Nacional de Danza, y próximamente estrena su última pieza, Escenas de caza, con la compañía Malditos y dirección de Alberto Velasco.

1. ¿Cuáles son sus razones para dedicarse al género dramático? ¿Complementa su actividad dramatúrgica con alguna otra profesión teatral (interpretación, dirección, producción, gestión pública o privada...)?

No es algo que haya racionalizado fríamente, dedicarme a un género. Primero, para mí, fue la necesidad de anclar la experiencia por medio de la escritura: recrearla y, a veces, crearla; luego, de que esa palabra se «incorporase» y fuese promiscua (para con la danza, la música, la plástica...). Para paliar esta necesidad, y a falta de que alguien confiase en mí, he sido también, accidentalmente, productora, directora, incluso performer... Y, de una manera casi inconsciente, todo eso se ha convertido en mi oficio, o bien en lo único que sé hacer. 
2. ¿Cuáles diría que son los rasgos más llamativos e interesantes del teatro escrito por mujeres en la actualidad?

No diría que haya un teatro escrito por mujeres con una idiosincrasia definida. Sería empobrecedor, sería dar por sentado que más de la mitad de la población mundial tiene mucho más en común que una raja entre las piernas. Es lo mismo que opino de «trampas teóricas» como las generaciones. Siempre cito a Derrida, que dice que incluso para los que parecen "pertenecer a una misma época, delimitada en términos de datación histórica o de horizonte social, sería fácil demostrar que sus tiempos son infinitamente heterogéneos y, a decir verdad, sin relación entre ellos». Creo que cada individuo no es una isla, pero sí una selva. Para mí lo más llamativo e interesante es que, en la actualidad, se hable de «teatro escrito por mujeres», porque este fenómeno responde, obviamente, a una discriminación positiva, una deuda histórica con las mujeres y asimismo con los hombres todos; pero también a una estrategia.

3. ¿Qué aspectos sobre temas de género tratados por otras dramaturgas le interesan especialmente?

Las dramaturgas no me interesan por los aspectos de género que tratan. Una poética me subyuga siempre de una manera más misteriosa. Hice una tesis doctoral sobre el teatro de Angélica Liddell, porque quería ser capaz de explicarme la atracción y repulsión que sentía por sus representaciones. He querido aprender de la mano de creadoras escénicas como Claudia Faci, que tienen una visión personalísima de la escena (era como aprender otro idioma). Si quiero leer sobre género, leo a Paul B. Preciado, aunque no sé si es hombre, mujer, o todo lo contrario. Ahora que lo pienso, me gustan los autores que también hacen una dramaturgia de su género, de sus personas (soy fan de Gertrude Stein, Violette Leduc, Lucía Berlín, Virginie Despentes...).

4. En las últimas décadas han surgido en España numerosas agrupaciones de mujeres vinculadas a las artes escénicas (Asociación de Dramaturgas Españolas, Asociación de Mujeres en las Artes Escénicas de Madrid, Federicas, Projecte Vacas y Margaritas, etc.). ¿Conoce la labor de estos colectivos? ¿Qué papel considera que han jugado en la dramaturgia femenina de estos años?

Conozco algunas. Las respeto y las considero necesarias (como decía, para mí es incuestionable e indiscutible, en términos sistémicos y sociológicos, la necesidad de la discriminación positiva y la aplicación de la famosa Ley Orgánica de Igualdad). Pero yo no participo de ellas. Porque mi manera de militar, según lo 
entiendo, es otra. Yo he decidido hacer activismo a través las representaciones de la realidad. No quiero confundir un deber político y social con mi poética, porque entonces seguiría debajo del «zapato» del patriarcado.

5. Describa cómo son sus personajes femeninos y valore si su relevancia o protagonismo es mayor que el de los masculinos en el conjunto de su producción.

Me planteo muchas veces que da igual si el trato que reciben mis personajes es masculino o femenino; que lo importante es que, en muchos casos, me sería indiferente el género de quién los interpretase, porque el teatro te da esa capacidad de «ser otr@», porque no hay hombres ni mujeres biológicos sobre escena. No es casual que en mis primeras obras haya personajes transexuales o travestis, que se buscan a través de su sexualidad; ya entonces estaba la idea de que el género es una construcción fundamentalmente cultural. A veces me han reprochado que en un dramatis personae hubiera más nombres de varón los mismos empresarios culturales que se encargan, vía castin tipo Lo que el viento se llevó, de asignar los personajes femeninos a mujeres de edad muy joven o que la aparentan gracias a la cirugía. Por todo lo anterior, cada vez prefiero más escribir para una persona, un intérprete en concreto: su cuerpo, su voz... su carisma.

6. ¿Qué aspectos que atañen específicamente a las mujeres considera que es más importante o urgente abordar desde el teatro?

Para mí es imperioso que una mayoría adquiera conciencia de que los clichés sexuales del heteropatriarcado nos han oprimido a todos (vía religión y no solo) y han impedido en muchos casos nuestra realización personal, la de nuestros ascendientes, que nos educaron, por ello, traspasándonos gran parte de sus neurosis y miedos. Pero no sé si es necesario abundar en ello, o simplemente, hacer de la creación un acto libre y, por tanto, revelador.

7. ¿En qué cree que se diferencia más ostensiblemente la literatura dramática escrita por mujeres y por hombres?

Creo que no conozco hombres ni mujeres, que dos géneros son muy pocos. 
MISCELÁNEA 



\title{
LA «REVOLUCIÓN» DE TERESA DE LA PARRA: ESCRIBIR LA ABNEGACIÓN MARIANA DESDE LA CELOSÍA
}

\author{
TERESA DE LA PARRA'S «REVOLUTION»: \\ TO WRITE THE MARIAN ABNEGATION FROM THE LATTICE
}

\author{
Michelle ROCHE RODRÍGUEZ \\ Universidad Autónoma de Madrid \\ michiroche@gmail.com \\ orcid.org/0000-0002-4334-3682
}

\section{Resumen}

El objetivo de este artículo es desmontar la interpretación tradicional del ensayo de 1930 de la autora venezolana Teresa de la Parra, titulado «Influencia de las mujeres en la formación del alma americana». Investigaciones hechas desde la perspectiva de género señalan que se trata del primer ensayo feminista de la literatura hispanoamericana; sin embargo, un análisis de su contenido podría evidenciar que promueve modelos femeninos patriarcales inscritos en la cultura hispanoamericana por los siglos de adoctrinamiento católico, fortaleciendo el canon androcéntrico del ensayo en el continente.

Palabras clave: Teresa de la Parra, literatura hispanoamericana, marianismo, historia y catolicismo.

\begin{abstract}
The objective of this article is to dismantle the traditional interpretation made of the 1930's essay by Venezuelan writer Teresa de la Parra, entitled «The influence of women in the formation of the American soul». Research done from the gender studies perspective declares that this may be the first feminist essay of Hispanic literature; however, a content analysis may be evidence that it promotes patriarchal female models built in the Hispanic culture by centuries of catholic indoctrination, making stronger the continent's andocentric essay canon.
\end{abstract}

Keywords: Teresa de la Parra, Hispanic literature, marianism, history Catholicism.

Feminismo/s 30, diciembre 2017, pp. 257-277

Los contenidos de la revista se publican bajo una licencia de Creative Commons Reconocimiento 4.0 Internacional (CC BY 4.0) 



\section{INTRODUCCIÓN}

«Influencia de las mujeres en el alma americana» es la única pieza de prosa analítica escrita por Teresa de la Parra (1889-1936), autora de las novelas Ifigenia: Diario de una señorita que escribió porque se fastidiaba (1924) y Memorias de Mamá Blanca (1926). Se trata de un texto creado para un ciclo de tres conferencias que la escritora venezolana dictó en Colombia en el año 1930, aunque no fue hasta 1961 cuando se publicó en forma de ensayo. Gracias al desarrollo de la perspectiva de género en la academia hispanoamericana en la década siguiente, la obra y su autora comenzaron a estudiarse como parte del contra-canon del ensayo producido durante la primera mitad del siglo XX en la región. A partir de ahí muchas investigadoras presupusieron que, por señalar el lugar de la mujer en la historia, la obra debía considerarse feminista y, en nuestra opinión, obviaron el uso que hace de modelos femeninos basados en el catolicismo.

Si se limitara a promover una naturaleza femenina particular, aunque fuera religiosa, podría argumentarse que el tipo de feminismo que De la Parra suscribe es el radical-cultural, el cual, según Rosemarie Tong, no se enfrenta a la construcción social de un concepto de femineidad basado en atributos como la empatía, la generosidad o la sensibilidad, sino con la atribución de un valor superior a las características tomadas por masculinas, como la asertividad, agresividad y capacidad de abstracción, entre otras (2-4). Pero los modelos femeninos en el texto parecen evidenciar una estrategia de invisibilización de las mujeres, encasillándolas en el único valor de ayudar a la ejecución del destino del hombre. Por ello, en los párrafos que siguen argumentaremos que este modelo es específicamente «mariano», por cuanto la sola función de la Virgen María en el relato cristiano fue permitir la encarnación de Dios y la realización del héroe patriarcal. El propósito de este artículo es analizar, pues, la impronta católica poscolonial en los modelos femeninos propuestos por el ensayo, con la finalidad de demostrar cómo esta supuesta precursora del feminismo, lejos de revolucionar el canon patriarcal del ensayo hispanoamericano de principios del siglo XX, lo fortalece. 
La metodología para lograr ese objetivo será la investigación cualitativa de modelo dialéctico, donde la revisión documental se complementará con el análisis de contenido de "Influencia de las mujeres en el alma americana», con el objeto de dilucidar la manera expresa o latente en que las ideas de la autora sobre lo femenino provienen del catolicismo y, lo que es más importante, cómo promueven un comportamiento donde la mujer queda relegada a una situación de complementariedad respecto al hombre.

Dos partes conforman este artículo. En la primera se explicarán las características de la obra, así como su situación en el contexto del canon del ensayo hispanoamericano. La revisión de la valoración que de ese ensayo han hecho las investigaciones realizadas hasta la fecha, permitirá señalar el supuesto alcance de la «revolución» propuesta por De la Parra y ofrecer una lectura novedosa a la que dedicaremos la segunda parte. A su vez, con el objeto de dar sentido a los resultados del análisis de contenido, esta segunda sección comenzará definiendo en qué consiste el modelo mariano que propone el catolicismo hispanoamericano para las mujeres.

La relación entre las características del modelo y las ideas de la autora venezolana permitirán evidenciar cómo esa obra fortalece la visión androcéntrica de las relaciones entre géneros. Para comprender este fenómeno usaremos la interpretación que hace Michel Foucault del patriarcado, donde la visión masculina del mundo y de las relaciones sociales no se impone en la multiplicidad de relaciones entre economía y cultura como un choque entre dos grupos, sino que el poder de los hombres sobre las mujeres se ejerce en una red discursiva donde ellas mismas son partícipes de su propia subyugación. De la Parra demostrará cómo operaba el discurso del poder en los años veinte, incluso sobre las mujeres más liberales, como era el grupo que ella representaba, el de las escritoras.

\section{LA «REVOLUCIÓN» DE TERESA DE LA PARRA}

Un día de mayo del año 1930 la celebridad que visitaba la Universidad de Bogotá era Teresa de la Parra. La conocían en toda Hispanoamérica porque en 1924 publicó una novela que obtuvo el beneplácito de los lectores y de la crítica cuando ganó el Grand Prix de Roman Américain en Francia. En esta ocasión su charla trataba sobre el papel de la mujer en la sociedad moderna, respondiendo así a la cuestión fundamental que por aquella época se planteaba el movimiento sufragista. Se titulaba «Influencia de las mujeres en el alma americana» y la presentó como un ciclo de conferencias dividido en tres bloques cronológicos y temáticos que impartió en tres jornadas. La primera publicación de estas charlas data del año 1961 y se hizo en los talleres de Ediciones Garrido, en 
Caracas, por instancia de la hermana de la autora, María Parra Sanojo. Las tres décadas de retraso en su edición obedecieron a que De la Parra falleció en 1936, a la edad de 41 años, después de una prolongada agonía. A pesar del desfase entre su escritura y su publicación, la academia ha sido unánime en ubicar a esta obra y a su autora en el grupo de las tempranas ensayistas hispanoamericanas, donde también figuran, entre otras, las argentinas Victoria Ocampo y Alfonsina Storni, la dominicana Camila Henríquez Ureña y la chilena Gabriela Mistral(121-122).

La ponencia de De la Parra estudiaba un tema nunca antes tratado: el papel de las mujeres en la historia de las colonias hispanohablantes del Nuevo Mundo, y puesto que en ella abogaba por establecer el compañerismo entre mujeres y hombres en la vida pública, la investigación en la perspectiva de género la considera una revuelta feminista, sin reparar en las oportunidades que ofrece para describir las relaciones de poder entre géneros durante los años veinte. El retrato que hace de los modelos femeninos que resultaron de siglos de colonización española muestra la fuerte influencia de la religión católica, y la necesidad de tomar esa coyuntura en cuenta para la comprensión de los procesos sociales y la lucha del feminismo en la región.

Es cierto que las reflexiones de la autora eran revolucionarias para su época. Por un lado, el asunto del que se ocupa es el papel que los personajes femeninos tuvieron en la historia de las antiguas colonias españolas en América y, por otro, el texto expresa su visión sobre la posición de la mujer en la sociedad moderna. «La verdad histórica, la otra, la oficial, resulta ser una especie de banquete de hombres solos», se queja De la Parra, y continúa: «Se dicen con etiqueta alrededor de una mesa cosas inteligentes y se pronuncian discursos elocuentes a los cuales no acude el corazón. [...] Excluidas las mujeres se ha cortado uno de los hilos conductores de la vida» (30). Con estas palabras expresa su crítica al relato oficial de la historia producido por los «hombres solos», quienes no solo prescindían de las mujeres como personajes narrados o voces de la literatura, sino que también evitaban una forma de narrar que la autora identifica como «femenina». Ese supuesto estilo de hacer literatura era de tipo sentimental y en líneas anteriores a la cita reproducida aquí, la autora la ha clasificado como «romance en prosa». En esta manera de caracterizar lo femenino en la cultura, De la Parra no parece muy diferente de la crítica literaria patriarcal de su época. Ella también sintetiza el pensamiento de las mujeres como una homogénea otredad a lo masculino, polo que toma automáticamente como si fuera universal y apela también al cliché que identifica a los hombres con el cerebro o el raciocinio y a las mujeres con el corazón y la sentimentalidad. 
La misma preocupación por la (llamémosla) «espiritualidad de la mujer» caracteriza sus opiniones sobre el papel que su género debía representar durante aquella época:

Para que la mujer sea fuerte, sana y verdaderamente limpia de hipocresía, no se la debe sojuzgar frente a la nueva vida, al contrario, debe ser libre ante sí misma, consciente de los peligros y de las responsabilidades, útil a la sociedad, aunque no sea madre de familia, e independiente pecuniariamente por su trabajo y su colaboración junto al hombre, ni dueño, ni enemigo, ni candidato explotable, sino compañero y amigo. (18-19)

La cita evidencia que para De la Parra la mujer moderna tenía el deber moral de hacerse «útil a la sociedad» empleándose fuera de casa, solo en el caso de que no tuviera familia que cuidar. Entre el año 1880 y 1930, el mundo se había hecho más cosmopolita y al menos tres generaciones de mujeres habían luchado por que el ideal de la nueva civilización incluyera la equidad de género, que es a lo que parece referirse la autora cuando reclama al hombre como «compañero y amigo» de la mujer. El enorme movimiento social que se articuló alrededor de los derechos de las mujeres tomó la consigna del sufragio femenino en Estados Unidos y varios países de Europa, pero en las naciones de Hispanoamérica esta fue una discusión que llegó con varias décadas de retraso. Como ocurrió también en España, el feminismo comenzó reclamando una educación igualitaria. A eso se refiere también la cita. Porque para la autora el trabajo podía ennoblecer a las mujeres: «Los verdaderos enemigos de la virtud femenina no son los peligros a que pueda exponerla una actividad sana, no son los libros, ni las universidades, ni los laboratorios, ni las oficinas, ni los hospitales, es la frivolidad, es el vacío mariposeo mundano»(19).

Aunque declararse a favor de que las mujeres trabajen y estudien podría indicar que ella era una feminista, no es así; de hecho, rechazaba el adjetivo:«Mi feminismo es moderado». En el siguiente párrafo suscribe: «Las mujeres debemos agradecerles mucho a los hombres el que hayan tenido la abnegación de acaparar de un todo para ellos el oficio de políticos», y cuando explica por qué no es defensora del sufragismo afirma que «Me parece que junto con el de los mineros de carbón es uno de los trabajos más duros y menos limpios que existen. ¿A qué reclamarlo?» (19). La autora parece olvidar que la igualdad entre hombres y mujeres, a la que alude como «compañerismo» en una de las citas anteriores, solo iba a poder lograrse cuando los estados consideraran a ambos géneros sujetos políticos en la igualdad.

La necesidad de proteger una esencia femenina asociada con la pureza es evidente en estas palabras y podría estar relacionada con que los modelos de comportamiento disponibles entonces provenían del catolicismo, que 
equiparaba la valía de la mujer como sujeto social con la virginidad, entendida como «limpieza» del alma y, en consecuencia, con la bondad. Sobre este tema nos detendremos más adelante, cuando tomemos en cuenta el modelo mariano, porque lo que resulta interesante ahora no es el tono de la cita ni la postura contraria al sufragismo que adopta allí De la Parra, sino que al proclamarla como feminista, los análisis críticos hechos desde la perspectiva de género olvidaron su rechazo al derecho de las mujeres a votar. En la búsqueda de una genealogía de mujeres escritoras, muchas académicas han eludido el rechazo que sentía la venezolana por la lucha política, y que expresa en ese mismo ensayo, a favor de la visibilización que hace de los personajes femeninos en la historia y de su defensa de la educación para la mujer moderna. El argumento que proponemos en las siguientes líneas es que resulta exagerado considerar el procedimiento discursivo empleado por De la Parra en el ensayo como una maniobra propiamente feminista, tal y como lo proclamaron algunas académicas que estudiaron su obra como un ejemplo de lucha por la igualdad de género.

El ensayo que nos ocupa no fue objeto de análisis hasta la llegada del siglo XXI, por lo cual el cuerpo crítico que tratamos es pequeño, no pasa de la decena de artículos, de los cuales tomaremos en cuenta los tres que tratan el supuesto feminismo de la obra. Uno es el de Natalia Cisterna y Alicia N. Salomone, «Identidades femeninas y reescritura de la historia en los ensayos de Teresa de la Parra», publicado en 2002 por la Revista Universum. Otro es el de Luz Horne, «La interrupción del banquete de los hombres solos: una lectura de Teresa de la Parra como contra-canon del ensayo latinoamericano», que apareció en 2005 en la Revista de Crítica Literaria Latinoamericana. El tercero data de 2016, lo firma Valentina Salinas Carvacho y se publicó en la chilena Mitologías hoy: revista de pensamiento, crítica y estudios latinoamericanos con el título «Reescribir la historia, reivindicar la identidad: lecturas femeninas del período colonial a través de la escritora Teresa de la Parra».

Para Natalia Cisterna y Alicia N. Salomone, «Influencia de las mujeres en la formación del alma americana» reconstruye los límites de la nación y añade una galería de heroínas a la retórica del relato patrio sustentado en la identidad, la lengua y el binomio público/privado. Prefieren enfocarse en las declaraciones sobre la época moderna que hace De la Parra, asumiendo que ella la veía como una era «propicia para involucrarse de forma activa en las transformaciones del entorno, en cuyo marco las definiciones de identidad pueden ser reconfiguradas por los sujetos desde opciones nuevas» (231). Este pensamiento las lleva a concluir que la visión de la autora es «femenina feminista» porque, siendo una mujer, ofrece un contra-discurso distinto al de los hombres, representado en el canon del ensayo vigente entonces (220). Desde 
nuestro punto de vista, el problema con la postura de Cisterna y Salomone es que no toma en consideración ninguno de los pasajes en donde la autora se muestra contraria al feminismo de su época y específicamente al sufragismo, así que sus conclusiones se pueden calificar de parciales.

El artículo de Valentina Salinas Carvacho, en cambio, se aleja de la discusión sobre la modernidad y se enfoca en La Colonia, analizando la lectura que hace la venezolana del período en donde supuestamente «se propone reescribir la historia y la identidad en clave femenina y subalterna, construyendo otro canon de intelectualidad, otro tipo de narración y otro tipo de imaginarios de la historia» (59). A Salinas Carvacho le basta con que De la Parra sea mujer y proponga un tema diferente al tomado en cuenta en aquella época por autores como José Carlos Mariátegui, Pedro Henríquez Ureña o Alfonso Reyes, nombres que hoy se encuentran en el núcleo del canon del ensayo hispanoamericano. Sin embargo, nada en la obra de la venezolana indica que su objetivo fuera desafiar al patriarcado. Su propuesta más bien parece obedecer a la necesidad de ampliar el canon con la inclusión de otra perspectiva en la discusión sobre la identidad hispanoamericana en boga en aquellos momentos.

Antes de continuar con la descripción de la situación actual de los estudios sobre «Influencia de las mujeres en el alma americana», debemos definir las características del tipo de ensayo que se producía entonces en Hispanoamérica. La académica mexicana Mayuli Morales Faedo se refiere al canon, contraponiéndolo a la experiencia de las autoras, en su obra «Para llegar al fin de la espera: las ensayistas de finales del siglo XX y los problemas de su recepción». Allí define el canon como conformado por textos políticos en donde la voz del escritor se identifica con la del autor (invariablemente un hombre) y "pretende representar la voz nacional o 'verdaderamente nacional' que se opone a voces o intereses particulares y a las pretensiones extranjeras» (126). En otras palabras, el autor se erige como un discurso nacional y político que pretende instruir al lector sobre una manera de pensar que considera positiva para los intereses del país. Añade que esa voz pretende representar la «totalidad de los intereses de los componentes de lo nacional»(126). Vista desde la perspectiva de género, esta reflexión quiere decir que, puesto que la norma a lo largo de historia de la literatura ha sido tomar la voz masculina, y por ende su perspectiva, como lo universal y la voz femenina como la alteridad, esos supuestos intereses de la nación son androcéntricos y, peor aún, consideran los asuntos enunciados por las mujeres como preocupaciones particulares de su género, incluso cuando ellas se refieren a temas como la patria o la identidad nacional, temas que cuando los enuncia un hombre se toman por universales. 
El tipo de ensayo que se producía en aquella época sirvió de marco conceptual para la construcción de los estados nacionales en la región. Por esa razón, entre sus temas fundamentales se encuentran la identidad de sus habitantes, su relación con la modernidad, la caracterización de los resultados del mestizaje en la mentalidad y cultura hispanoamericanas, los enfrentamientos entre civilización y barbarie o las luchas entre el campo y la ciudad. Además, Morales Faedo toma en cuenta motivos recogidos en el trabajo de María Andueza, «Trayectoria y función del ensayo hispanoamericano del siglo XX», que incluyen la crítica al intervencionismo de Estados Unidos en los países de la región, la necesidad de formar una consciencia americana y el derecho a la educación de los pueblos (126).

De los temas señalados como típicos del canon, la identidad hispanoamericana y el mestizaje son los que explora De la Parra. Todo su ensayo es un ejercicio para ampliar el alcance de la identidad hispanoamericana a través de la inclusión de la mujer y de un cierto «hacer» femenino en la retórica de la formación de la cultura regional. En cuanto al mestizaje, hay una reflexión justo antes de referirse a Isabel la Católica, donde De la Parra analiza el estado de la discusión sobre la independencia en su época. Se refiere a dos fórmulas que se enfrentan «como dos teas de discordia dentro de la misma casa» (22). Una es la del «inhumano desdén del blanco ininteligente [sic.] e insensible que se cree todavía dueño y señor» y la otra es «el indianismo romántico, el odio sordo del mestizo hacia la raza intrusa» (22). Como vemos, son afirmaciones que colocan a nuestra autora como defensora de La Conquista y La Colonización, en una época en la que los discursos de los estados nacionales preferían tomar a los procesos emancipadores como génesis del pensamiento republicano y de la restitución de la justicia en la región, mientras asumían La Conquista como la expoliación del legado amerindio. "iComo si solo de destrucción se tratara, como si La Conquista de América fuese un caso aislado en la historia del mundo y no la eterna y odiosa ley de todas las guerras y de todas las invasiones!» (22), advierte la autora, refiriéndose al discurso oficial de su época. Aquí, de nuevo, De la Parra tiene un gesto que es revolucionario, aunque a medias, frente al discurso dominante. Se opone a las tesis de los ensayos de Mariátegui y Vasconcelos, pero no puede tomarse por feminista porque no alude a la perspectiva de género.

Realizadas estas reflexiones, abandonamos aquí la descripción de la postura de la autora sobre el mestizaje, pues los dos estudios mencionados sobre su ensayo no se detienen en ello, ni el artículo «Identidades Femeninas y reescritura de la historia en los ensayos de Teresa de la Parra», ni el titulado 
«Reescribir la historia, reivindicar la identidad: lecturas femeninas del período colonial a través de la escritora Teresa de la Parra».

Mayuli Morales Faedo contextualiza bien el ambiente intelectual en el que se redactó "Influencia de las mujeres en la formación del alma americana», porque permite ver que De la Parra tenía una postura propia frente al tema del mestizaje, sin llegar a desafiar la mentalidad de su época. Es lo mismo que hace con el asunto de la mujer en la sociedad en otro apartado del ensayo. Estas estrategias evidencian que la autora venezolana tenía opiniones propias sobre el papel de las mujeres en la sociedad, sin que estas llegaran a ser propiamente subversivas. Como el estudio firmado por Cisterna y Salomone, el de Salinas Corvacho afirma la disrupción del canon del ensayo hispanoamericano que significó la inclusión de personajes femeninos en la historia, pero ninguno ofrece pruebas concluyentes sobre cómo tal ruptura impactó en la crítica, los lectores o los colegas masculinos de la época. Es verdad que el gesto puede tomarse por revolucionario, pero para ser propiamente feminista tendría que haber incluido una reflexión crítica más allá de la queja sobre «el banquete de los hombres solos» al que antes se hizo alusión.

Por su parte, Luz Horne señala que De la Parra hace más que incluir una nómina de mujeres en la historia y se pregunta de qué manera -entendida en su peculiaridad de política y de escritura «femenina»-perturbó el relato patriótico el discurso de su ensayo, cuya originalidad, según escribe, se sustenta en «identificar, por un lado, un modo de hacer política que ella reconoce en los personajes históricos que rescata y, por el otro, un modo de escribir la historia en la cual los personajes femeninos tienen un lugar» (8). En otras palabras, la importancia del ensayo no estaría tanto en la visibilización de las mujeres en la historia, sino en su estrategia retórica, pues al nombrarlas les otorga un valor dentro de la historia oficial. Con esta afirmación, Horne vuelve a la discusión sostenida unos párrafos atrás sobre la caracterización de la agencia femenina en el pasado de Hispanoamérica. Como De la Parra, la académica describe el pensamiento y la actuación de las mujeres como una otredad de lo masculino, como si las mujeres, por ser mujeres, actuaran de manera distinta a los hombres, cuyo comportamiento es tomado como el racional. Vuelve así sobre la vieja y ya citada dicotomía sobre razón y sentimiento, donde los hombres representan lo primero y las mujeres lo segundo.

Aunque De la Parra señala que las mujeres no tienen nada que hacer en la política, Horne se empeña en considerarla feminista y prefiere leer su afirmación como una estrategia discursiva que le permite llamar la atención sobre el tema que quiere tratar: los casos de las mujeres que, si bien no han sido recogidas como protagonistas de la historia, han ejercido una acción crucial 
en los procesos políticos del continente. De este modo, lo que Horne no toma en consideración es que el discurso de la venezolana afirma una mística de la feminidad sustentada en la supuesta abnegación natural de las mujeres como seres moralmente superiores a los hombres, y el resultado de eso es la elevación de lo masculino, porque valora al hombre por lo que hace y a la mujer por lo que es, eternizando la concepción binaria de la realidad donde él es el elemento activo y ella el pasivo. Por esta razón pensamos que la escritura de la autora venezolana no puede ser considerada feminista. A lo largo de la historia, los estereotipos sobre lo que se considera la naturaleza de lo femenino han sido maneras de construir una otredad a la medida del patriarcado, y en esas formas esenciales el machismo de los hombres encuentra su contraparte en las mujeres, bajo el nombre de «marianismo». La afirmación de que la mujer debe sacrificarse por el otro que propone el pensamiento de la autora venezolana, está firmemente enraizada en la cultura católica de Hispanoamérica, la cual toma como modelo femenino a la Virgen María, en su advocación de La Dolorosa. Cómo se presenta y cuáles son sus características será lo que analicemos en siguiente sección.

\section{EL MARIANISMO EN LA CULTURA HISPANOAMERICANA}

La tradición iberoamericana define lo mariano como lo relativo al culto de la Virgen María, pero las investigaciones de antropólogos estadounidenses emprendidas en los años setenta, emplearon ese término para describir el comportamiento a un tiempo sumiso y elevado de las mujeres de la comunidad de inmigrantes hispanoamericanos en ese país. El marianismo se funda en la noción de que las mujeres son espiritualmente superiores a los hombres debido a su capacidad de soportar sufrimientos por el bienestar de la familia, subyugando así su realización personal a la de sus parejas e hijos. De este modo, su único valor social es la abnegación, lo cual las convierte en una suerte de sujetos de segunda clase con aspiraciones propias prescindibles o inexistentes.

La politóloga Evelyn P. Stevens fue la primera que, en el ámbito de las ciencias sociales, usó este término como contrapunto del machismo, el cual definió como el culto a la virilidad. Según escribe en «Marianismo: The other face of machismo in Latin America», el marianismo «enseña que las mujeres son semi-divinas, moralmente superiores y espiritualmente más fuertes que los hombres» (91). Sin embargo, aunque en las décadas de los años setenta y ochenta Stevens publicara casi una decena más de investigaciones sobre este tema, fue poco el interés que ese fenómeno despertó en áreas diferentes a la antropología. A pesar de que esta denominación sea virtualmente desconocida en las investigaciones académicas de Hispanoamérica y España, podemos 
afirmar que esta no ha caído en desuso, pues permite entender el papel que la mujer latina pretende jugar en Estados Unidos. Por otra parte, es importante precisar que si tomamos en cuenta en este punto el marco teórico anglosajón es porque observa desde fuera un fenómeno que parece normal dentro de la cultura hispanoamericana, y permite establecer sus características para desnaturalizarlo, que es uno de los objetivos de este artículo.

El marianismo no se refiere a una definición teológica, sino a un patrón de comportamiento que define una práctica inconsciente y auto-regulatoria según la cual la conducta apropiada de la mujer es imitar a la Virgen María, comportándose con los hombres como una madre capaz de soportar profundos dolores. Tal abnegación no se limita al hijo varón, sino que con frecuencia incluye un sentimiento de protección y abnegación con respecto a su pareja, a hermanos $\mathrm{u}$ otros miembros varones de la familia, perpetuando la imagen propuesta en el Nuevo Testamento por la Virgen María, cuyo relato la convierte a la vez en madre, hija y esposa de su hijo, Jesús. El marianismo es el resultado de siglos de influencia de la Iglesia católica en la cultura híbrida hispanoamericana y del empleo de la Virgen María como modelo fundamental para dictar el comportamiento de las mujeres.

La devoción mariana que España exportó a las colonias americanas estuvo influenciada por la cultura del fin de la Reconquista y el desarrollo de la Reforma católica, dos procesos históricos que subrayaron la espiritualidad de la Virgen y la experiencia religiosa individual sustentada en la mortificación del cuerpo. Con la Reconquista, completada en 1492, el mismo año que Cristóbal Colón llegó a América, la corona castellana terminó con más de 700 años de reinos musulmanes sobre la península ibérica. En todo ese tiempo, la influencia del islam sobre el catolicismo practicado en España configuró un perfil de la Virgen María más abstracto que el descrito en los Evangelios. Si bien rechazan que Cristo (a quien llaman Isa) fuera el Mesías, los musulmanes creen en la existencia de María (Maryam) y la adoran como a una iluminada propensa a los accesos místicos. Esa caracterización se profundizó por la necesidad de fortalecer la piedad popular y la experiencia religiosa individual que impulsó a partir del siglo XVI la reacción de la Iglesia católica a la Reforma de Martín Lutero. En su transformación del clero, que incluyó la creación de nuevas órdenes religiosas para la evangelización y el fortalecimiento de las antiguas, el Concilio de Trento, finalizado en 1563, estableció como modelo de práctica religiosa personal a la experiencia contemplativa. En esta forma de reflexión sobre la divinidad y los atributos de la fe, destacó la experiencia mística de clérigos castellanos como San Juan de la Cruz y Santa Teresa del Ávila, quienes promovieron la idea de que el alma solo llega al estado de gracia y comunión 
con Dios desde la mortificación de la carne. La espiritualidad y las capacidades conmutativas del dolor se encuentran en la advocación española (y luego hispanoamericana) conocida en latín como Mater Dolorosa: la Virgen María cuando sufre la muerte de Jesús, La Dolorosa.

A excepción de Juan, que la ubica brevemente al lado de la cruz y del «discípulo amado», ningún evangelista del Nuevo Testamento se ocupa de relatar qué estaba haciendo la Virgen María cuando su hijo fue apresado, condenado a muerte y torturado. Sin embargo, la tradición popular, la literatura producida en los monasterios y las artes plásticas han colmado con creces esa falta al suponer que ella observó todo su suplicio, acompañándolo y consolándolo, hasta el momento en que lo bajaron de la cruz y recibió su cuerpo inerte. De esas suposiciones surgieron devociones como la del Vía Crucis, que relata los últimos momentos de la vida de Jesús en quince estaciones. Allí aparece La Dolorosa: la madre que llora la muerte del hijo. Representada por la imagen de la Virgen María con el corazón atravesado por una o siete espadas, esta manifestación propone un tipo de maternidad sustentada en la abnegación que trasciende su condición de Madre de Dios para describirla como el ejemplo más radical del sacrificio por su hijo: verlo morir. Una imagen fundamental de este dolor está en el motivo de La Piedad, muy común en el arte barroco de la Contrarreforma, que describe el momento posterior al descendimiento de la cruz, cuando María recibe el cuerpo de su hijo muerto. Esta imagen evoca al arquetipo de la maternidad con la mujer sosteniendo en brazos a su hijo, pero con una perspectiva siniestra donde lo que carga no es un bebé con su vida por delante, sino el cuerpo adulto de su hijo muerto. Vida y la muerte en una instantánea. La Madre Naturaleza en su aspecto positivo y negativo; la síntesis del arquetipo materno y el vínculo fundamental de cada quien con la existencia.

El motivo de la Madre Tierra que llora la muerte de su hijo, el héroesemilla, que en la antigüedad celebraba la transformación vegetal, los ciclos y la sucesión del tiempo, como atestiguan las leyendas de Osiris e Isis en Egipto, de Tammuz y Astarté en Babilonia o de Adonis y Afrodita en Grecia, encontró imágenes cruentas en la sombría espiritualidad española del siglo XV, cuando la producción de imágenes religiosas fue una herramienta fundamental en las políticas de conversión de judíos y musulmanes al catolicismo emprendidas por la reina Isabel I. En su libro Imagining the passion in multiconfessional Castille, Cynthia Robinson cuenta que entonces comenzó una formidable proliferación de imágenes religiosas porque la ley obligaba a todos los súbditos de la reina, y en especial a los nuevos conversos, a tener en casa escenas pías para su devoción personal. El cardenal Cisneros y fray Fernando de Talavera, ambos 
asesores de la reina, consideraban que las imágenes de la Pasión eran las más apropiadas para la contemplación.

Los devocionarios producidos entonces ofrecían un sistema de recreación de la narrativa de la Pasión para facilitar los ejercicios de devoción íntima y se caracterizaron por realzar las características simbólicas de la muerte de Cristo y del sufrimiento de María. Además de facilitar el vínculo con la nueva religión desde la madre que sufre frente al hijo torturado, la Virgen ofrecía a sus devotos más que un camino alternativo al ejercicio espiritual de la Pasión de Cristo: su humanidad era la única vía para la perfección espiritual que aseguraba la gracia divina, ya que la experiencia somática de la Pasión en Jesús estaba fuera de discusión, porque él también es considerado Dios. Dos obras pueden demostrar hasta dónde llegaron los clérigos españoles para exaltar el sentimiento de los feligreses y nuevos conversos: Meditaciones sobre la vida de Cristo y La vida de la Virgen (Robinson).

En la primera, Francesc Eiximenis se refiere a la Virgen desde sus diez «dignidades», donde recoge dogmas marianos, como que nació sin pecado original, y creencias populares, como que estaba predestinada a encarnar al Mesías. A su descripción como una iluminada bastante parecida a la Maryam musulmana, el monje añade un rasgo que hubiera escandalizado a los patriarcas cristianos medio milenio antes: que María fue creada antes del comienzo del mundo y que, cuando nació, Dios mandó al ángel Miguel para que avisara a los padres del Antiguo Testamento. En La vida de la Virgen, el otro devocionario, la propia María habla en primera persona y aparece caracterizada como una doctora de la Iglesia que responde a las preguntas de la condesa de Plascencia sobre los dogmas y su exégesis, los métodos de la espiritualidad y las formas de devoción. Compuesta para Leonor de Pimentel por su confesor, el dominico Juan López de Salamanca, esta obra invita a imaginar la muerte de Jesús en sus detalles más sórdidos con el objeto de llegar a la iluminación.

Tanto López de Salamanca como Eiximenis consideraban que María había llegado al éxtasis místico cuando la visión de su hijo crucificado le causó una pena insoportable. Lo que proponen ambos devocionarios es que la Madre de Dios es una suerte de "corredentora mística», pues la intensidad de sus dolores psicológicos al ver a su hijo sufrir le permitieron transformar el dolor en alegría cuando supo sobre la Resurrección, igual que el catolicismo supone que el pecador puede cambiar el sufrimiento de sus faltas por la alegría de la comunión con Dios a través de la gracia divina. La noción de que la Virgen María es un vehículo de gracia es fundamental para esta confesión, pero lo característico del catolicismo español es considerarla al mismo tiempo el objeto y el agente de la transformación necesaria para una unión eventual con Dios. 
La afirmación de que María accedió a la comunión con el Padre a través del dolor psicológico que le causó la Pasión de Cristo caló en España (y luego en Hispanoamérica) porque la noción de que el dolor podía transformar el alma era fundamental en la mística castellana de la época. Las obras de san Juan de la Cruz y de santa Teresa de Ávila, por ejemplo, señalan que solo la mortificación de la carne permitía llegar a un estado espiritual que anulaba los sentidos para lograr el éxtasis contemplativo y la intimidad con Dios. El origen de esta creencia es la interpretación que hicieron los escolásticos del tratado De Anima de Aristóteles, donde se explica que nada entra en el alma sin que lo perciba el cuerpo, en contraste con la teoría de san Agustín sobre la carne concupiscente. Si el alma adquiere gracia a través del contacto de los sentidos con el mundo, ¿cómo podía llegarse al «limpio» entendimiento de Dios por medio del cuerpo inclinado naturalmente al pecado?

La solución que postularon los místicos castellanos fue el sufrimiento, que suponían aniquilaba la experiencia temporal del cuerpo privilegiando la comunión espiritual con Dios. En el ensayo «The Spiritual Uses of Pain in Spanish Mysticism», Maureen Flynn desmiente esta afirmación ofreciendo datos que prueban que no existe un momento en el que la mente esté más en conjunción con el cuerpo que cuando hay dolor, lo que hace imposible que pueda llegarse a una experiencia extática con el tormento, que solo sirve para hacer a la persona más consciente de su materialidad. El problema es que estos datos no se conocían hace siglos, cuando la cultura española estableció una poética del sufrimiento que fue el fundamento espiritual, primero, de la conversión de los herejes musulmanes (y judíos) en la península ibérica y, luego, de la evangelización de las tribus indígenas del continente americano.

La misma poética del sufrimiento se manifiesta en el marianismo como aspecto determinante del modelo femenino central en Hispanoamérica y que puede definirse a través de tres rasgos fundamentales. El primero es que considera a la mujer una herramienta para la apoteosis del hombre, igual que la Virgen lo fue de la encarnación del Mesías. El segundo es la primacía del dolor como método de esa apoteosis, que se vincula con la actuación como corredentora de la Virgen cuando el dolor de la Pasión le permitió el proceso inverso a la encarnación: la transformación del dolor en el gozo de la gracia divina. El corolario de estas afirmaciones es que puesto que se sacrifica y sufre por otros, la mujer (como la Virgen) representa un ser superior al hombre. Es decir: el sufrimiento le otorga valor social, convirtiéndola en un ser espiritual, casi fuera del mundo material. Según la Enciclopedia of Women's Health, el marianismo está en el núcleo de los dictados de esta cultura tradicional en áreas como los roles de género, familia, maternidad, relaciones y comportamiento, 
enfatizando los atributos de castidad y falta de interés por el sexo e, incluso, los mensajes sobre sexualidad que reciben en sus comunidades se relacionan con las nociones de honor, deber, seguridad o autoestima y nunca con las de satisfacción o placer (757-759).

El marianismo se concretó como modelo femenino en el continente a través de la educación religiosa que fue hasta la madrugada del siglo XX la única a la que accedieron las mujeres, incluso las de clases pudientes. Igual que los devocionarios dictaban las pautas de la experiencia religiosa, los libros de moral ofrecían las de conducta en la sociedad colonial y los clérigos eran autores de unos como de otros. El tratado La educación de la mujer cristiana que escribió Juan Luis de Vives en el siglo XVI fue referencia de comportamiento para las criollas hispanoamericanas por más de tres centurias. Por eso no es extraño que la perspectiva que usara De la Parra para estimar el valor de las mujeres en la historia fuera la católica. Lo importante aquí es que, si bien su visión no fue precisamente novedosa, permite entender cómo el marianismo ha servido para invisibilizar la agencia de la mujer hispanoamericana.

Las mismas palabras que escoge De la Parra en «Influencia de las mujeres en la formación del alma americana»prueban la presencia allí del modelo mariano. Donde es más evidente es en la caracterización que hace de las mujeres en la historia:

Las mujeres que figuran en la formación de nuestra sociedad americana imprimiéndole su sello suave y hondo son innumerables, son todas. Creo que pueden dividirse en tres vastos grupos. Las de La Conquista: son las dolorosas crucificadas por el choque de las razas. Las de La Colonia: son las místicas y soñadoras. Las de La Independencia: son las inspiradoras y las realizadoras. (25)

Cada tipo de mujer puede vincularse con una manifestación mariana. La alusión al sufrimiento se toma por ser una prueba de amor: «Obreras anónimas de la concordia, verdaderas fundadoras de las ciudades por el asiento de la casa, su obra más efectiva sigue todavía a través de las generaciones en su empresa silenciosa de fusión y amor» (22). La afirmación representa el legado de La Dolorosa. Y detrás de este imperativo de género De la Parra barre los maltratos y las vejaciones a las que fueron sometidas las indígenas durante La Conquista: se «fundían» en una nueva raza con quienes no podían sino considerar invasores de sus tierras. El valor del sufrimiento se aprecia en dos ejemplos de indígenas en la encrucijada de su cultura y la invasora: la Malinche, bautizada como doña Marina, la compañera de Hernán Cortés, y doña Isabel, madre del Inca Garcilaso. 
A la Malinche De la Parra le atribuye características maternales en su relación con Cortés. «Esa sagacidad misteriosa de Cortés se llama exclusivamente doña Marina», escribe sobre sus aptitudes políticas, entre las que se cuenta su capacidad de mediadora y sus acertados consejos, «mucho más frecuentes y sutiles de lo reconocido por los historiadores» (25). Pero la madre no puede estar sin el sufrimiento y ese es el gran atributo de doña Isabel, unida al conquistador Sebastián Garcilaso de la Vega, quien estaba al servicio del virrey Núñez de Vela y que como vasallo salió del Cuzco para tomar su bando en la guerra que le declaró Gonzalo Pizarro, abandonando a su familia. Durante años, doña Isabel y su hijo, el futuro Inca Garcilaso, vivieron escondiéndose, comiendo de la caridad de sus antiguos esclavos. «Como fruto de su mansa abnegación no recogerá sino gratitud y desamor», escribe De la Parra, y continúa: «Su dolor de abandonada madurado por su hijo en la añoranza y el destierro producirá, muchos años después, uno de los más bellos libros de la literatura clásica española: Los comentarios reales» (24). He aquí que las capacidades creativas del dolor tomadas de la espiritualidad barroca no benefician a la mujer, sino a su hijo, un escritor. El escritor invisibiliza a su madre.

A las mujeres de La Colonia las identifica como «las místicas y las soñadoras», y las celebra cuando han decidido enclaustrarse, o en su casa como esposas, o en el convento en el caso de tener inclinaciones intelectuales. «La Colonia se encierra toda dentro de la iglesia, de la casa y del convento», concluye la autora antes de señalar que el símbolo de esa época era «una voz femenina detrás de la celosía» (37). Hacemos notar que es de celebración el tono con que describe el encierro de las mujeres en la vida privada durante esta época. «En la paz de la celda se unía armoniosamente el cultivo de la inteligencia al cultivo de las virtudes, esos dos huertos cerrados y vecinos. Se crecía en sabiduría y se crecía al mismo tiempo en santidad» (43), escribe refiriéndose a sor Juana Inés de la Cruz. De este modo, señala que la virtud de la mujer está en alejarse de la vida pública como lo hizo en otra sección, citada con anterioridad, donde comparaba la política con un trabajo sucio, como el que se hace en las minas de carbón, agradeciendo la «abnegación» de los hombres que lo tomaban todo para ellos.

Tampoco parece que pensara que hombres y mujeres eran iguales, sino que su defensa del «compañerismo» entre los géneros pasaba por la construcción de un modelo de mujer ideal que cultivaba la inteligencia y las virtudes en privado, para dejar el espacio público a los hombres. La gravedad de esto es que se contradice con su postura sobre las mujeres contemporáneas: «La vida actual, la del automóvil conducido por su dueña, la del micrófono junto a la cama, la de la prensa y la de los viajes, no respeta puertas cerradas» (18). 
Quizá por esas diferencias entre hombres y mujeres el papel que ofrece a las «inspiradoras y las realizadoras» de La Independencia es el de permitir, de manera anónima, la entrada a la Historia (así, con mayúsculas) de soldados venezolanos opuestos a los realistas como Simón Bolívar y Carlos Soublette. $\mathrm{Si}$, como ha hecho buena parte de la historiografía, se asume que Bolívar es el héroe de la gesta emancipadora suramericana, se puede argumentar que algunas mujeres que lo rodearon hicieron el papel de "corredentoras», y de hecho este parece ser el modelo que De la Parra atribuye a Fany de Villars y Manuela Sáenz, entre otras. La primera, su prima, que vivía en París y «tenía uno de los más elegantes salones del tiempo del Consulado» (71), lo recibió después de que quedara viudo y lo introdujo a las corrientes de pensamiento de su época: «Después de haber sido el Emilio de Rousseau gracias a Simón Rodríguez [su maestro caraqueño], iba a ser ahora, gracias a Fany, el René de Chateaubriand. Todo contribuía a la transformación» (72). La segunda mujer fue su amante en su época de líder de La Independencia, Sáenz, «a quien el mismo Bolívar llamó la Libertadora del Libertador por haberle salvado la vida en dos ocasiones» (75). De esta manera introduce en la historia a dos mujeres, una de pensamiento y otra de acción, apenas como sombras del Libertador: una por haber contribuido a su educación y la otra a que sobreviviera en tiempos de guerra. Ambas son artífices de la independencia de varios países a través de la gesta de un hombre, un pariente o pareja.

En la sección anterior decíamos que el trabajo de Luz Horne se empeñaba en leer como feminista la obra de Teresa De la Parra, aunque a la autora no le interesaba la lucha de género. Y una cita de Horne, refiriéndose a la caracterización que hace el ensayo de doña Marina y de Manuela Sáenz, resume el procedimiento mariano que expone el ensayo, donde supone que la autora venezolana les atribuye a las mismas mujeres que ha incluido en el relato histórico la importancia de "permitir anónimamente que sus hombres entren a la historia» (11). Pero el anonimato es una forma de invisibilización. Por eso el título del ensayo se refiere al «alma americana» y no a un aspecto visible como el cuerpo: si bien a veces el alma puede identificar de forma genérica a una energía, como sustancia espiritual de los humanos, su definición más común es la religiosa, que la supone como el lugar dentro de cada uno donde se articula la inclinación hacia el bien o el mal.

Por su apego a las afirmaciones católicas sobre lo femenino, por la contradicción de exaltar a la vez el encierro y la libertad de las mujeres y por analizar su papel en la historia a través del vocabulario católico, el ensayo de Teresa De la Parra muestra de qué manera la ideología patriarcal actuaba en su pensamiento, convirtiéndola no en la feminista que muchas académicas 
en las escuelas de estudios de género quisieran, sino en una colaboradora del status quo. Su caso permite volver a las teorías de Michel Foucault sobre la configuración del poder en las sociedades modernas como un discurso en el que todos participan por igual. En este sentido, el marianismo puede asumirse como aquello que el filósofo francés llamaba un «dispositivo de poder». Considerando al poder más como productivo que como represivo, la obra de Foucault muestra cómo este pasa a través de dominantes y dominados sin llegar a ser propiedad de nadie ni de nada, puesto que opera como una estrategia de intercambio de discursos. Según explica Rosa María Rodríguez Magda, parafraseando a Foucault, «el saber no se constituye en una superestructura enfrentada al poder, sino como una condición de posibilidad de las prácticas culturales que nos producen a nosotros mismos y a través de las cuales podemos reconocernos» (145). El resultado es que entre el poder y las formas del saber se establece un sistema de fuerzas en transformación incesante que se apoyan o se aíslan entre ellas, donde se incluyen las estrategias que tornan efectivas a estas fuerzas y que se manifiestan en aparatos institucionales como la religión, la familia o la escuela.

En otras palabras, el poder está en todas partes porque es intrínseco al lenguaje que usamos. Es por esa razón que cuando De la Parra intenta incorporar a la mujer en la historia de Hispanoamérica no puede sino observarla como secundaria al hombre: su educación la ha preparado para eso. Cree que exigiéndoles a los intelectuales que añadan el corazón a su lectura de la nación hace un alegato a favor de la inclusión de la mujer en la vida pública, pero termina extendiendo estereotipos sobre lo femenino que la mantenían en una posición inferior a la del hombre.

\section{CONCLUSIONES}

Si bien no hay duda de que constituye un gesto revolucionario la visibilización de mujeres como la Malinche, sor Juana Inés de la Cruz o Manuela Sáenz, considerar por eso feminista a la obra de Teresa de la Parra es darle proporciones excesivas al alcance de su crítica al status quo, en especial porque ella misma declara a su feminismo «moderado» y, en oposición a las sufragistas de su época, escribió que las mujeres debían «agradecerles mucho a los hombres el que hayan tenido la abnegación de acaparar de un todo para ellos el oficio de políticos» (19). Los escritos de la autora venezolana en general, y la ponencia leída en Colombia en particular, permiten disentir de una parte de la academia feminista latinoamericana que quiere leer la obra de las primeras autoras incluidas en el canon literario de la región como enfocada en el esfuerzo de desafiar el pensamiento androcéntrico de su época. 
El objetivo de este artículo era analizar cómo la impronta católica de la colonización española concibió un modelo femenino basado en la Virgen María, y más específicamente en su advocación de La Dolorosa, que se naturalizó en la sociedad hispanoamericana de tal manera que creó la expectativa de que la mujer debe servir como herramienta de la realización del hombre. El estudio de las características de «Influencia de las mujeres en la formación del alma americana» en el contexto del canon del ensayo hispanoamericano de su época, y de las aportaciones más recientes sobre la obra realizadas desde la perspectiva de género, ha permitido limitar el alcance de la revolución propuesta por De la Parra en esa obra a la inclusión de personajes femeninos en la historia de la región. La valoración de la actuación de ese elenco ha resultado más problemática y ha constituido la materia de la segunda parte del artículo. La caracterización de la devoción mariana para el momento de la Conquista y durante la colonización ha permitido establecer el modelo femenino impuesto en Hispanoamérica a través de la educación fundamentalmente religiosa de las mujeres. Con el análisis de contenido del ensayo hemos podido reconocer las características del modelo mariano en la agencia femenina que preocupaba a De la Parra. Así se comprobó la teoría del poder de Michel Foucault, según la cual este no es una fuerza que ejerce un grupo sobre otro, sino un discurso, una estructura de saberes o pensamientos, que está en el lenguaje y en la cual participan todos. Como demuestra la lectura que en este artículo se ha hecho del ensayo, el modelo mariano, a pesar de que parece celebrar lo femenino, es una herramienta del patriarcado que resultó de siglos de colonización católica a través de la cual se hace a las mujeres cómplices de su propia subyugación.

La lectura propuesta de «Influencia de las mujeres en la formación del alma americana» prueba que, al estar aferrado a los postulados del catolicismo, el pensamiento de la autora estudiada era tan misógino como el de los hombres de su época. No se trata solo de que no reconozca a la mujer moderna como sujeto político en igualdad de condiciones que el hombre, sino que aun cuando se ha propuesto desentrañar la huella femenina en la historia oficial, haciendo una inclusión bastante parcial de las mujeres en la historia, no hace sino subrayar la cualidad complementaria que el catolicismo propone a las mujeres.

Si el feminismo quiere descubrir cuáles fueron las estrategias para la invisibilización de las mujeres, debe dejar de pensar en la historia de la literatura escrita por ellas como en una serie de agregados al canon y observar la manera en la que, como una manifestación de la ideología imperante, el canon operó en el intelecto y la obra de las propias autoras, incluso cuando escribían desde las periferias del mismo canon, por más revolucionario que su trabajo fuera para su época. La estrategia comienza entendiendo los mecanismos que escondieron 
la agencia de las mujeres a través de los tiempos por medio de las relaciones discursivas del poder y continúa con el cuestionamiento sobre por qué las intelectuales se hicieron sus cómplices, muchas veces de buena gana, como fue el caso de Teresa De la Parra.

\section{REFERENCIAS BIBLIOGRÁFICAS}

Cisternas, Natalia y Alicia N. Salomone. «Identidades femeninas y reescritura de la historia en los ensayos de Teresa de la Parra». Revista Universum 17 (2002): 219-232.

De la Parra, Teresa. Obra Escogida. Tomo II. Colección Tierra Firme. Ciudad de México: Fondo de Cultura Económica de México, 1992.

Flynn, Maureen. «The Spiritual Uses of Pain in Spanish Mysticism». Journal of the American Academy of Religion 64 (1996): 258-278.

Foucault, Michel. Las palabras y las cosas. Ciudad de México: Editorial Siglo XXI, 2005.

Horne, Luz. «La interrupción del banquete de los hombres solos: una lectura de Teresa de la Parra como contracanon del ensayo latinoamericano». Revista de Crítica Literaria Latinoamericana 61 (2005): 7-23.

Morales Faedo, Mayuli. «Para llegar al fin de la espera: las ensayistas hispanoamericanas de la primera mitad del siglo XX y los problemas de su recepción». Signos Literarios 15 (2012): 119-140.

Rivero Marano, Melissa. «Marianismo». Encyclopedia of Women's Health. Ed. Sana Loue y Martha Sajatovic. Cleverland: Plenum Publishers, 2004, 757-759.

Robinson, Cynthia. Imagining the Passion in Multiconfessional Castille: the Virgin, Christ, Devotions and Images in the 14th and 15th century. Primera edición. Pennsylvania: The Pennsilvania State University Press, 2013.

Rodríguez Magda, Rosa María. Foucault y la genealogía de los sexos. Barcelona: Anthropos Editorial, 2004.

Salinas Corvacho, Valentina. «Reescribir la historia, reivindicar la identidad: lecturas femeninas del período colonial a través de la escritora Teresa de la Parra». Mitologías hoy: revista de pensamiento, crítica y estudios latinoamericanos 13 (2016): 57-71.

Stevens, Evlyn P. «Marianismo: The other face of machismo in Latin America». Female and Male in Latin America. Ed. Ann M. Pescatello. Pittsburgh: University of Pittsburgh Press, 1973, 89-100.

Tong, Rosemarie. Feminist thought: A more comprehensive introduction. Colorado: Westview Press, 2009. 



\section{RESEÑAS}





\title{
Reseña de: Di Tullio Arias, Anabella. Teoría feminista y libe- ralismo. El devenir de una relación problemática. Universidad de Málaga, 2016
}

\author{
Isabel G. GAMERO \\ Universidad Nacional de La Plata - CONICET
}

\section{TEORÍA FEMINISTA Y LIBERALISMO, UNA RELACIÓN COMPLEJA}

«Feminismo»y «liberalismo» se dicen de muchas maneras, pero, en todas ellas, su relación es problemática, como sostiene Anabella Di Tullio en el subtítulo de su libro Teoría feminista y liberalismo (XXVI Premio Victoria Kent).

En este libro la autora trata de dirimir esas complejas relaciones, con el objetivo de matizar la visión dominante del feminismo que asegura ser incompatible con el liberalismo. Para ello, en los primeros capítulos, reconstruye y aclara las teorías de las principales autoras que se entienden como feministas y liberales: Jean Hampton, Martha Nussbaum y Susan Moller Okin. Mediante la exposición de estas propuestas, Di Tullio argumenta que muchas críticas feministas en oposición al liberalismo (por ejemplo, por su estricta separación entre lo público y lo privado y su comprensión formal y neutra de la justicia) pueden resultar adecuadas para objetar propuestas como la de Rawls. No obstante, estas críticas no resultan tan certeras cuando se profundiza en la obra de estas tres autoras, quienes fueron muy críticas con la propuesta rawlsiana y lograron transformar y ampliar el liberalismo para hacerlo más feminista y más consistente con los propios principios liberales.

Sin embargo, Di Tullio no se limita a hacer una descripción teórica e histórica de estas propuestas, ni acepta sin ambages su feminismo liberal, sino que las «pone a prueba», esto es, traslada estas teorías a temas y polémicas actuales, como el aborto (135), las injusticias o desigualdades que se dan en el ámbito privado o familiar (125 y ss.), la subordinación o instrumentalización de las mujeres en muchas esferas (153 y ss.) y las dificultades ligadas al consentimiento y la libre elección, con especial atención a los casos en los que una mujer decide sacrificarse y anteponer los intereses de otras personas 
a los suyos propios (165 y ss.). Di Tullio reconstruye las respuestas que estas autoras han dado (o podrían dar) sobre estas cuestiones y da así una imagen más completa y adecuada del liberalismo feminista, para mantener que (al menos según estas tres autoras) estas dos corrientes no sólo son compatibles sino que se refuerzan entre sí. Es decir, por un lado, la concepción liberal de un sujeto autónomo puede servir para empoderar a las mujeres y el concepto de justicia liberal se puede trasladar a otros ámbitos (como la esfera privada y familiar) para apoyar la lucha feminista. Por otro lado, la crítica feminista puede dar lugar a un liberalismo sin sesgos patriarcales y más atento a otros ámbitos, desatendidos por los autores liberales varones, como la vida familiar y los cuidados; así como a un liberalismo preocupado por las diferencias culturales, que intenta no imponer sus conceptos occidentales sobre otras formas de vida, sino entender las diferencias y crear luchas comunes. Ahora bien, éste ya no es el liberalismo clásico de los libros de texto y que teorizó Rawls sino que, al vincularse con el feminismo, emerge un nuevo liberalismo, no jerárquico y basado en la igualdad, real y material, de oportunidades que Di Tullio denomina «liberalismo in between» (siguiendo un término de Okin, 128), «ilustrado» (expresión de Hampton, 128), «radical» (202), «parcial» (135) o «híbrido» (196 y 203).

A modo de ejemplo de esta transformación o hibridez, se propone la crítica social feminista de Brooke Ackerly, quien hace una revisión crítica de la obra de Nussbaum y traslada el enfoque de las capacidades a los procesos de toma de decisiones en distintas culturas, con el objetivo de que todas las opiniones se puedan expresar y se promueva el empoderamiento de las mujeres. De este modo, Di Tullio muestra que las teorías o corrientes de pensamiento no son tan simples y claras como se describe en los manuales de filosofía, sino que resulta necesario situarlas, contextualizarlas y ponerlas en práctica para comprobar si funcionan y superar así el debate teórico abstracto.

Ahora bien, no todo van a ser halagos al liberalismo. En la segunda parte del libro, y siguiendo las obras de Carole Pateman, Catharine MacKinnon y Virginia Held, Di Tullio desarrolla otras críticas, menos superficiales y más radicales y certeras, que se han dirigido desde el feminismo al liberalismo. También en este caso, la autora no se limita a exponer estas propuestas teóricas, sino que las problematiza y pone a prueba, trasladándolas a polémicas y preocupaciones actuales. Esto lo hace a través de distintos dilemas que constituyen la argumentación más elaborada, fértil y compleja del libro, ya que las fuentes teóricas se multiplican tanto como la amplitud de temas y enfoques. Por ejemplo, Di Tullio plantea los límites del feminismo cuando oscila entre la igualdad y la diferencia (365 y ss.) y vuelve a traer a colación las polémicas 
sobre la libre decisión de las mujeres, el consentimiento y la sumisión (394 y ss.). También destaca dilemas clásicos de la teoría política, como los de igualdad versus libertad y libertad versus necesidad (398 y ss.) o el que enfrenta derechos universales a derechos particulares de grupos y colectivos (397 y ss.). Asimismo, tiene en cuenta dilemas de la filosofía contemporánea, como el que pregunta si hay identidades fijas o esenciales (como «la mujer») o si somos identidades construidas, posmodernas y cambiantes ( 378 y ss.), en el enfrentamiento entre la «fiebre deconstructiva que intenta eliminar el sujeto» y la «multiplurimanía» que multiplica las diferencias culturales y las aísla en culturas cerradas (383).

Llevando estas tensiones y dilemas hasta sus límites, Di Tullio muestra algunas debilidades del liberalismo feminista y, al mismo tiempo, dirige objeciones a las autoras que son críticas con esta corriente. Elabora así una metacrítica, o crítica dentro de la crítica, para aclarar el panorama, tan complejo, de la teoría feminista contemporánea y sus contiendas, y mostrar, de nuevo, que no todo es tan sencillo y delimitable en claras categorías teóricas sino que, por el contrario, las teorías afectan a las vidas y las experiencias vividas impactan en la forma de teorizar, considerando que toda teoría y práctica feminista debe tener en cuenta esta interconexión (421).

Para cerrar la argumentación y dar alternativas, en las consideraciones finales del libro Di Tullio se posiciona con su propia voz, y aporta una lúcida reflexión sobre la libertad y sobre cómo lograr una concepción más adecuada de lo que significa ser humano y de cómo nos relacionamos con los demás, no sólo en un plano teórico sino también en nuestras vidas.

A pesar de la amplitud de temas y enfoques, la lectura del libro es sencilla y amena, ya que la autora no se aparta de su tema de interés (las relaciones entre feminismo y liberalismo) e hila los argumentos con soltura y fluidez, relacionándolos con temas cercanos y actuales. En definitiva, Teoría feminista y liberalismo es un libro altamente recomendable, no sólo para enseñantes y estudiantes de filosofía y feminismo, sino también para activistas, personas interesadas en teoría política contemporánea y para quien desee conocer en profundidad y con justeza las distintas manifestaciones del liberalismo. También puede resultar de gran utilidad para eliminar prejuicios debidos a la comprensión superficial de esta corriente, y poder criticarla de modo más adecuado y certero (al menos quien escribe esta reseña ha logrado superar algunos de sus prejuicios sobre el liberalismo, ahora entiende mejor esta forma de pensar y, aunque sigue sin estar de acuerdo con ella, en el libro ha encontrado mejores argumentos para reforzar sus críticas). Asimismo, en la necesaria imbricación entre lo público y lo privado que se destaca en todo momento 
en el libro, se proponen contenidos y direcciones para debatir y reflexionar sobre otras preocupaciones, acuciantes aunque poco frecuentes en la filosofía, como los cuidados y la maternidad. Por último, todo el libro es un argumento contundente (de cuatrocientas páginas y un centenar de fuentes teóricas) para refutar a quien todavía ose mantener que no hay mujeres pensadoras o filósofas.

Para finalizar, resulta destacable, consecuente con el planteamiento crítico del libro y muy de agradecer que Anabella Di Tullio haya decidido utilizar el plural inclusivo para escribir su texto. Este recurso le sirve para ilustrar que, tanto en el lenguaje como en los conceptos liberales, el plural genérico masculino parecía ser neutro y universal, referirse a toda la humanidad, cuando en realidad se trataba de un uso particular y de una concepción sesgada del mundo que surgió en un ámbito occidental y eminentemente masculino. Argumenta de este modo la autora que ni este uso genérico ni esta concepción formal y liberal se van a transformar, simple y automáticamente, porque las mujeres comiencen a seguirlos, sino que es necesario un análisis más profundo y crítico (como el que presenta este libro), así como un cambio en las prácticas, en las creencias y en las actitudes. De este modo, el lenguaje, los argumentos, las prácticas y las críticas se entrelazan en el texto de Di Tullio para promover una verdadera igualdad entre hombres y mujeres, no la pretendida igualdad formal que propugnaba el liberalismo, anterior al feminismo. 


\section{RESEÑA BIO-BIBLIOGRÁFICA DE LAS/OS COLABORADORAS/ES}

\section{Eléonore BERGER}

Licenciada en Lettres Modernes por la Universidad de la Sorbonne NouvelleParis 3, cuenta con un Máster 2 en Lettres Modernes (2015) y otro en Etudes Théâtrales (2015) realizados en esta misma universidad. Ha participado en el coloquio internacional titulado «Les Folles littéraires: folies lucides. Les états borderline du genre et ses créations», organizado en la Sorbonne-Nouvelle (2016). En la actualidad realiza su tesis doctoral en dicha universidad sobre la trayectoria de las mujeres escritoras en la editorial Gallimard.

\section{Cristina CASADO PRESA}

Profesora asociada del departamento de Lenguas Modernas en Washington College, Maryland. Su área de estudio es la literatura española de los siglos XX y XXI, centrada primordialmente en dos ámbitos, las mujeres escritoras del periodo postfranquista y las representaciones de brujería en la literatura. Así, ha publicado, entre otros, los artículos «La bruja como paradigma de poder femenino en dos dramas españoles contemporáneos», aparecido en Monographic Review/Revista Monográfica XXVII: Lo oculto en la literatura hispánica, y «El silencio como conflicto en un drama de Pilar Pombo», publicado en Letras Femeninas, vol. 36. Asimismo, ha contribuido al volumen The Changing Spanish Family: Essays on New Views in Literature, Cinema and Theater, de Tiffany Trotman, con el capítulo «Mother-Daughter Relationships in Contemporary Spanish Theater». Actualmente está trabajando en un monográfico dedicado a la figura de la bruja y su representación en la literatura española contemporánea.

\section{Helen FREEAR-PAPIO}

Profesora titular de Filología Española y directora del Programa de Lectores de Lenguas Extranjeras en College of the Holy Cross, Worcester, Massachusetts, 
Estados Unidos. Se doctoró en la Universidad de Connecticut con una tesis sobre la primera generación de dramaturgas españolas de la democracia (Female Protagonists in Contemporary Spanish Drama by Women: Their Quest for SelfAuthentication, Power and Independence, 1996). Su investigación actual sigue centrándose en el teatro de las dramaturgas españolas contemporáneas, con especial atención a los siguientes temas: la construcción de identidad femenina, la autoría femenina, la violencia de género, la alteridad, la memoria histórica y el mito. Tiene numerosos artículos y reseñas críticas sobre obras de Carmen Romero, Maribel Lázaro, Diana de Paco Serrano, Gracia Morales, Itziar Pascual, Beth Escudé y Juana Escabias.

\section{Eva GARCÍA-FERRÓN}

Doctora en Filología Hispánica por la Universidad de Alicante (1996). Profesora Asociada del Departamento de Filología Española, Lingüística General y Teoría de la Literatura de la Universidad de Alicante. Imparte docencia de ELE en el Centro Superior de Idiomas de dicha universidad.

Ha publicado artículos sobre temas teatrales en la revista Estreno. Cuadernos del Teatro Español Contemporáneo, de la Universidad de Pennsylvania. Ha presentado ponencias sobre teatro español y sobre géneros breves en seminarios y congresos internacionales, como el Encuentro Internacional sobre Federico García Lorca (Údine, Italia), el XIX Congreso de la Asociación Internacional de Hispanistas (Münster, Alemania) o el XXVI Seminario Internacional del Centro de Investigación de Semiótica literaria, teatral y Nuevas Tecnologías (Madrid).

Miembro del Proyecto «Red de investigación sobre la docencia de las TIC en los estudios de Filología Española», dentro del Programa Redes de Investigación en Docencia Universitaria de la UA. Es secretaria académica de la revista Anales de Literatura Española de la Universidad de Alicante.

Sus líneas de investigación son el teatro español contemporáneo y los géneros breves (aforismo, microrrelato).

\section{Luisa GARCÍA-MANSO}

Doctora en Filología Hispánica por la Universidad de Oviedo con Premio Extraordinario con una tesis titulada El drama histórico desde la Transición hasta nuestros días: la contribución de las mujeres a la construcción de la identidad colectiva española. Cuenta con un Máster Universitario en Estudios para la Igualdad de Género en Ciencias Humanas, Sociales y Jurídicas (UIMP/CSIC). Desde junio de 2017 es assistant professor en la Universiteit Utrecht. Previamente disfrutó de dos becas consecutivas de la Fundación Alexander von Humboldt 
y de la Bayerische Gleichstellungsförderung para el desarrollo de proyectos de investigación postdoctoral en la Universität Passau. Entre 2009 y 2013 fue beneficiaria de una beca-contrato JAE-Predoctoral en el Centro de Ciencias Humanas y Sociales del CSIC (Madrid) y realizó estancias en la University of Exeter y la Universität Passau. Forma parte del Grupo de Estudios de Género en Industrias Culturales y Artes Escénicas (InGenArTe), dirigido por Francisca Vilches de Frutos en el CSIC. Sus líneas de investigación principales comprenden el teatro español contemporáneo escrito por mujeres, la literatura dramática del exilio republicano español y la representación cultural de la justicia transicional en el ámbito hispanoamericano. Ha publicado artículos en las revistas Anales de la Literatura Española Contemporánea, Bulletin of Hispanic Studies, Estreno, Iberoromania, Foro Hispánico e Hispania, entre otras.

\section{Pilar JÓDAR PEINADO}

Doctora en Filología Hispánica por la Universidad de Salamanca y II Premio de Investigación Teatral de la Academia de las Artes Escénicas de España, con el trabajo Metateatro español en el siglo XXI: el mundo del teatro y el teatro del mundo (2016), surgido de la Tesis Doctoral Metateatro español: estudio del concepto y de su presencia en cien textos teatrales de los siglos XX y XXI (2016), dirigida por el prof. Dr. Emilio de Miguel Martínez.

Actualmente, profesora de Lengua de Secundaria en Cantabria y, anteriormente, en la Universidad de Salamanca y en Las Palmas de Gran Canaria, impartiendo Lengua y Literatura española e hispanoamericana, tanto a personas españolas como extranjeras, de diferentes niveles.

En cuanto a labor investigadora, ha participado en el volumen Miguel Mihura (1905-2005)... sino todo lo contrario, coordinado por el prof. Dr. Emilio de Miguel Martínez; así como en Literatura actual en Castilla y León. Actas del II Congreso de Literatura Contemporánea, con el trabajo «El metateatro en José Luis Alonso de Santos: ¡Viva el Duque, nuestro dueño!, La última pirueta y La sombra del Tenorio; y en el XXV Seminario Internacional del Centro de Investigación de Semiótica Literaria, Teatral y Nuevas Tecnologías (UNED), «El teatro como documento artístico, histórico y cultural en los inicios del siglo XXI», con la comunicación «El metateatro como testimonio del quehacer dramatúrgico y escénico en siete textos teatrales del siglo XXI»; también en las revistas Signa. Revista de la Asociación Española de Semiótica (UNED, Madrid) o Krypton (Università Roma Tre) (en prensa). 


\section{Maribel MARTÍNEZ LÓPEZ}

Profesora Contratada Doctora acreditada para Titular en el área de Literatura Española en la Universidad de La Rioja y Directora de la revista Cuadernos de Investigación Filológica (CIF). Sus investigaciones sobre el teatro español se inician con su proyecto de tesis doctoral «El teatro en la ciudad de Murcia durante la Guerra Civil», y más tarde se centran en el periodo áureo español a través de la figura del dramaturgo Álvaro Cubillo de Aragón. Actualmente es miembro del proyecto de investigación BITAE II. Nuevos paradigmas de interpretación teatral: respuestas para una sociedad en conflicto multicultural, cuya principal línea de estudio está orientada al impacto que producen los textos literarios en los discursos ideológicos, estéticos y sociales, incluyendo asimismo el análisis de los valores socio-ideológicos del teatro español contemporáneo y sus lenguajes estéticos. Sus últimos artículos ofrecen una exploración crítica del teatro español desde la década de 1990 hasta la actualidad desde diferentes ópticas, tales como: análisis temáticos sobre la evolución de arquetipos y la creación de nuevos paradigmas de comportamiento; influencia y presencia de la Biblia y del dogma católico a través de personajes y motivos que muestran tensiones de carácter ideológico, social, cultural y religioso; identidades de género y normalización de identidades sexuales; representación de los arquetipos femenino y masculino sobre los escenarios y estado actual de su cambio de roles y de la inversión de modelos como fruto de los cambios sociales; tratamiento de la violencia de género en el teatro y recuperación de la memoria histórica desde los escenarios.

\section{Nina NAMASTE}

Nina Namaste is Associate Professor of World Languages and Cultures at Elon University in North Carolina, USA. Her research investigates race, class and gender identity presented through culinary imagery within contemporary drama from Spain, Argentina, Chile and Mexico. Her latest publications on gender identity and/or culinary imagery include «Identifying the Male: Language, Humor, and Gender Performance in Companyia T de Teatre's Homes!» in Dynamics of Masculinity in Contemporary Spain (2017) and «The Myths We Tell Ourselves: Food, Globalisation and Identity in Milenio Carvalho» in Making Sense of Food: Exploring Cultural and Culinary Identities (2016).

\section{Adriana NICOLAU JIMÉNEZ}

Estudiante de doctorado en la Universitat Oberta de Catalunya. Posee una licenciatura en Filología Catalana, Itinerario Literatura, por la Universidad 
Autónoma de Barcelona (Premio Extraordinario de Licenciatura) y un máster en Teoría de la Literatura por la École Normale Supérieure (Paris) y la Universidad Sorbonne-Paris IV (Mención «Très bien»). Ha ejercido como lectora de Lengua y Literatura Catalanas en el Centre d'Études Catalanes de la Universidad Sorbonne-Paris IV durante el curso 2015-2016. Junto a Nathalie Koble ha publicado «Voix d'eau: Pascal Quignard et la «voix perdue» des lais bretons» (Tangence, 2016). Actualmente prepara, bajo la dirección de Teresa Iribarren, la tesis Interrogando el género en escena: protagonistas femeninas en el teatro contemporáneo representado en Barcelona en el siglo XXI.

\section{Francisco José PEÑA RODRÍGUEZ}

Doctor en Filología Hispánica por la Universidad Autónoma de Madrid. En la actualidad es profesor de Lengua Castellana y Literatura en Secundaria. Además, ha sido Asistant Teacher y Visiting Lecturer en Dartmouth College (2001-2002) y organizador del Seminario Internacional Edad de Oro de la UAM (1999-2001).

Sus campos de investigación y estudio filológicos son la novela y la poesía posteriores a 1975, siendo autor, entre otros, de «Rita Macau en la poesía de Luis Alberto de Cuenca» (Ínsula, mayo de 2016); «La guerra civil en la narrativa de José María Merino» (Universidad de Alcalá de Henares, 2018, en prensa); del ensayo La obra literaria de Joaquín Leguina (1985-2006) o entradas biográficas para el Diccionario Biográfico Español de la Real Academia de la Historia (Josefina Aldecoa, Álvaro Pombo y Vicente Molina Foix).

En el campo de la investigación histórica ha dedicado varios trabajos a la represión política y social durante guerra civil y la posguerra, siendo el más reciente «Depuración de maestros republicanos en el medio rural: el caso de un municipio de Albacete» (Cuadernos Republicanos, invierno de 2017).

\section{Michelle ROCHE RODRÍGUEZ}

Divide su actividad profesional entre el ámbito académico, el periodismo y la literatura de ficción. En 2008 obtuvo un Máster en Humanidades y Pensamiento Social de la New York University (Draper Program) con el proyecto «La representación del fracaso de lo moderno en la literatura venezolana». En 2002 obtuvo la licenciatura en Comunicación Social, mención «Periodismo», en la universidad Católica Andrés Bello de Caracas. Entre los artículos académicos que ha publicado se encuentran «La maldición de San Sebastián y las dos caras de la Virgen María», incluido en el libro Comunicación, género y disidencia sexual (Fragua: Madrid, 2011), y «Venezuelan Femininity: The 
Painfulembodiment of Beauty», en Anamesa 5 (2007). Ha sido profesora en la Escuela de Letras de la Universidad Católica y reportera de la sección cultural del periódico El Nacional de Venezuela. En 2014 fundó la publicación digital Colofón Revista Literaria. Ha publicado el libro de cuentos Gente decente (Musa A Las 9, 2017), el ensayo Madre mía que estás en el mito (Sílex Ediciones, 2016) y la colección de entrevistas periodísticas Álbum de familia: conversaciones con nuestra identidad nacional (Editorial Alfa, 2013). En la actualidad es candidata al Programa de Doctorado en Estudios Interdisciplinares de Género en la Universidad Autónoma de Madrid con una investigación sobre la persistencia de los modelos de mujer impuestos por el catolicismo en la obra de la autora venezolana Teresa de la Parra.

\section{Cristina ROS BERENGUER}

Doctora en Filología Hispánica por la Universidad de Alicante (1996) con la tesis doctoral Fernando Fernán-Gómez, autor. Desde 1997 es profesora titular en el Centro Superior de Idiomas de la Universidad de Alicante, donde imparte docencia en las clases de lengua y literatura española e hispanoamericana a estudiantes provenientes de universidades de todo el mundo. En 2014 comienza su vinculación como profesora Asociada al Departamento de Filología Española, Lingüística General y Teoría de la Literatura de la Universidad de Alicante. Secretaria académica de la revista Anales de Literatura Española del citado departamento. Sus líneas de investigación principales son el teatro español contemporáneo, las relaciones entre el teatro y el cine y la didáctica del teatro para ELE. En estos campos ha publicado artículos en volúmenes como Relaciones culturales entre Italia y España: Leopardi y España, Relaciones entre el cine y la literatura: un lenguaje común, o los siguientes de esta misma colección dedicados al guion y el teatro en el cine. Su trabajo docente e investigador lo compagina con los cursos de formación impartidos a través del Centro Superior de Idiomas, incluido el que anualmente se organiza en la UA a través de la Embajada Española en Washington para profesores norteamericanos que deseen profundizar en las técnicas dramáticas y la escritura teatral en las clases de ELE. Su última publicación aparece en el libro «El mundo sigue», de Fernando Fernán-Gómez. Redescubrimiento de un clásico, publicado por la editorial Peter Lang en 2017. 


\section{CÓMO PRESENTAR UN ORIGINAL}

1. Los trabajos serán el resultado de una investigación original y deberán contener conclusiones novedosas apoyadas en una metodología debidamente planteada y justificada. Sólo se admitirán trabajos inéditos que no estén en proceso de evaluación por otras revistas.

2. La extensión de los trabajos presentados no excederá de 9000 palabras, incluidas notas y bibliografía.

3. El número y extensión de las notas al pie se reducirá a lo indispensable.

4. Los autores someterán sus artículos en Word a través del correo electrónico de la revista (revistafeminismos@ua.es) y deberán aportar imprescindiblemente:

- Título del trabajo.

- Nombre del autor o de la autora, institución a la que pertenece, dirección profesional completa y dirección electrónica.

- Archivo del texto en formato Word, omitiendo el nombre del autor o autora, con:

- El título en español y en inglés.

- Un resumen de unas 150 palabras en español, y su correcta versión inglesa. Este resumen deberá atenerse al siguiente esquema: objetivos del trabajo, metodología y conclusiones o tesis.

- Cinco palabras-clave en español, y su correcta versión inglesa.

- El texto del original.

- Un breve C.V. (como máximo 300 palabras).

5. Los trabajos se someterán a un proceso de selección y evaluación anónimo y por pares, según el procedimiento y los criterios hechos públicos por la revista. 


\section{NORMAS EDITORIALES Y ESTILO DE LA REVISTA FEMINISMO/S}

1. Los artículos estarán redactados en Word con letra Times New Roman, tamaño de 12 puntos y con un interlineado de un espacio y medio.

2. La extensión no excederá de 9000 palabras, incluidas notas y bibliografía.

3. La primera línea de cada párrafo irá sangrada.

4. Las notas, que deberán reducirse a lo indispensable y se utilizarán sólo para información suplementaria, serán a pie de página, con letra de 10 puntos e interlineado sencillo. La llamada en el texto irá antes del signo de puntuación.

5. Las referencias bibliográficas irán entre paréntesis en el texto del artículo, no en las notas, siguiendo las siguientes indicaciones:

5.1. Referencia a una idea de un autor/a cuyo nombre no se cita expresamente en el texto:

- «En la cultura renacentista y humanística italiana este debate sobre los sexos tuvo una muy especial viveza» (Blanco 265).

- El debate sobre los sexos fue muy vivo en la cultura del Renacimiento y del Humanismo italianos (Blanco 265).

No se pone coma [,] entre el nombre y el número de página.

5.2. Referencia a una idea de un autor cuyo nombre sí se cita en el texto:

- Según Moi, «la obra de Kristeva no se puede considerar fundamentalmente feminista» (174).

5.3. Si el autor solo tiene una obra citada, no se incluye el año de edición.

5.4. Si se menciona más de una obra de un mismo autor, inclúyase la fecha de edición de cada una, detrás del nombre. Debe insertarse una coma [,] SOLAMENTE entre el año y la página:

- «En la cultura renacentista y humanística italiana este debate sobre los sexos tuvo una muy especial viveza» (Blanco 1997, 265).

5.5. Empleen «ver» o «Ver». No empleen «cfr.», «véase», «vid.» o «comp.». En ningún caso se emplean indicaciones como «op. cit.», «art. cit.», «loc. cit.», «id.», «ibid.», «supra», «infra», «passim», «et alii». 
6. Las citas extensas (cuatro o más líneas) se destacan del texto mediante un párrafo sangrado. No se usan comillas. El punto irá en este caso delante del paréntesis que contiene la referencia bibliográfica y no después.

7. Los diferentes apartados del texto se ordenarán siguiendo la numeración arábiga $(1,2,3, \ldots)$ y el título de cada uno de ellos irá en letra mayúscula y en negrita. Los subapartados se enumerarán de la siguiente manera: 1.1, 1.2, 1.3, etc. y sus títulos irán en minúscula y en negrita.

8. Las fotografías e imágenes deben entregarse en formato digital, separadas del texto, en formato tif, con una calidad de 300 puntos por pulgada. Deben ir identificadas convenientemente según sean citadas en el texto.

9. Lista de obras citadas:

9.1. Las entradas bibliográficas aparecerán al final del documento, ordenadas alfabéticamente y con sangría francesa.

9.2. Los nombres de los autores y editores se darán completos, y nunca en mayúsculas.

9.3. Al incluir una obra de varios autores, solo en el primero se hace preceder el apellido.

9.4. Cuando se incluye más de una obra de un mismo autor, se ordenan cronológicamente; en todos los casos se hace constar el nombre del autor.

9.5. En las revistas, el número de volumen y fascículo se dará siempre con caracteres arábigos.

9.6. Cada entrada se organizará de la siguiente manera:

\section{A. LIBROS}

- Con un/a solo/a autor/a o editor/a: Apellido, Nombre. Título del libro en cursiva. Edición utilizada. Número de volúmenes [si más de uno]. Nombre de la serie o colección [si procede]. Lugar de publicación: Nombre de la editorial, Fecha de publicación.

Bloom, Harold. Poetry and Repression: Revision from Blake to Stevens. New Haven: Yale University Press, 1976.

Moi, Toril (ed.). The Kristeva Reader. Oxford: Blackwell Publishers, 1986.

- Con varios/as autores/as o editores/as: Apellidos, Nombre, y Nombre Apellidos. Título en cursiva. Ciudad: Editorial, año. 
Anderson, Bonnie, y Judith P. Zinsser. Historia de las mujeres: una historia propia. 2 vols. Barcelona: Crítica, 1991.

Perrot, Michelle, y Georges Duby (eds.). Historia de las mujeres. Madrid: Taurus, 1991.

\section{B. ARTÍ́CULOS}

- Con un/a solo/a autor/a: Apellidos, Nombre. «Título». Revista en cursiva n. ${ }^{\circ}$ volumen en arábigo. Fascículo en arábigo (año): páginas (sin p./pp.).

Valcárcel, Amelia. «El primer ensayo feminista de una teoría del poder». Panorama 9 (1990): 59-64.

Vogel, Lisa. «Erotica, the Academy and Art Publishing: A Review of Woman as Sex Object. Studies in Erotic Art, 1730-1970, New York, 1972». Art Journal 35.4 (1976): 378-385.

- Con varios/as autores/as: Apellidos, Nombre, y Nombre Apellidos. «Título». Revista en cursiva n. $^{\circ}$ volumen en arábigo. Fascículo en arábigo (año): páginas (sin p./pp.).

López-Zafra, Esther y Rocío García Retamero. «Mujeres y liderazgo: ¿discapacitadas para ejercer el liderazgo en el ámbito público?». Feminismo/s 13 (2009): 85-104.

C. COLABORACIÓN EN LIBRO COLECTIVO: Apellido del autor/ de la autora, Nombre del autor/ de la autora. «Título de la colaboración». Título del libro en cursiva. Ed./Eds. Nombre y apellidos del editor o de la editora. Edición utilizada. Número de volumen [si más de uno]. Lugar de publicación: Nombre de la editorial, fecha de publicación. Páginas.

Smith-Rosenberg, Carroll. «Writing History: Language, Class and Gender». Feminist Studies. Ed. Teresa de Lauretis. Bloomington: Indiana University Press, 1986, 31-54.

\section{TÍTULOS DE LIBROS CON VARIOS VOLÚMENES}

- Si cada volumen tiene un título propio, se hará constar así:

Díaz-Diocaretz, Myriam, e Iris M. Zavala (coords.). Breve historia feminista de la literatura española (en lengua castellana), I: Teoría feminista: discursos y diferencias. Barcelona: Anthropos, 1993. 
- Si cada volumen no tiene título propio:

Pardo Bazán, Emilia. Obras completas. Vol. 2. Ed. Federico Carlos Sainz de Robles. Madrid: Aguilar, 1957.

E. CITAS DE PRENSA: Apellido del autor, Nombre del autor. «Título del trabajo». Nombre del periódico en cursiva [caso de que no sea universalmente conocido: Ciudad, País] Día Mes Año: páginas.

Lara, Fernando. «Victoria Kent, una mujer de suerte». Triunfo, 22 octubre 1977: 62.

F. PUBLICACIÓN EN INTERNET: Apellido del autor, Nombre del autor. «Título del trabajo». Nombre de la publicación en cursiva Volumen. Número (Año): páginas [si tiene]. Fecha de acceso.

Safa Barraza, Patricia, y Juan Manuel Ramírez Sáiz. «Deterioro urbano y calidad de vida en las grandes urbes: la participación de las mujeres en las organizaciones vecinales». La ventana 54 (2011): 110-145. 20 de abril de 2015.

G. Las WEBS se citarán de acuerdo al siguiente modelo:

<http://www.cis.es/cis/opencms/ES/2_barometros>, consultado el 19-06-2008

\section{CÓMO PROPONER UN MONOGRÁFICO}

La propuesta de un monográfico para la revista Feminismo/s se hará llegar a la directora de la revista (Helena.Establier@ua.es) y contendrá la siguiente información:

1. Título provisional del monográfico.

2. Un C.V. completo de la coordinadora/del coordinador (o de las coordinadoras/los coordinadores) del mismo.

3. Una descripción de sus objetivos y una justificación de la oportunidad del tema propuesto (300 palabras). 
4. Un listado provisional de participantes en el volumen, acompañado de una breve reseña bio-bibliográfica de cada una/uno de ellas/os y de los títulos de los trabajos previstos (a ellos se sumarán posteriormente aquellos recibidos a través del call for papers y que superen, como los anteriores, el proceso de evaluación de la revista).

5. Las propuestas serán consideradas por el Consejo de Redacción de Feminismo/s en el plazo máximo de un mes a partir de la fecha de recepción de las mismas.

\section{PROCESO DE EVALUACIÓN}

1) Los originales recibidos son valorados, en primera instancia, por el Consejo de Redacción de la revista para decidir sobre su adecuación a las áreas de conocimiento y a los requisitos que la revista ha publicado para los/las autores/as.

2) El Consejo de Redacción envía los originales, sin el nombre del autor o de la autora, a dos revisores/as externos/as al Consejo Editorial, quienes emiten su informe en un plazo máximo de seis semanas. Sobre esos dictámenes, el Consejo de Redacción decide rechazar o aceptar el artículo o solicitar modificaciones al autor o autora del trabajo. Los/las autores/as reciben una notificación detallada y motivada donde se expone, retocado, el contenido de los informes originales, con indicaciones concretas para la modificación si es el caso. Feminismo/s puede enviar a los/las autores/as los informes originales recibidos, íntegros o en parte, siempre de forma anónima. En el caso de discrepancia en los informes de evaluación, la revista se reserva el derecho de someter el trabajo a la valoración de la Coordinadora/del Coordinador del volumen y del Consejo de Redacción, o de solicitar una tercera evaluación del mismo.

3) El informe emitido por los/las revisores/as incluye:

a) una valoración global del artículo y de los resúmenes.

b) una valoración cuantitativa de la calidad (buena | aceptable | insuficien-

te) según estos cinco criterios: originalidad e interés del tema; pertinencia en relación con las investigaciones actuales en el área; rigor metodológico y articulación expositiva; bibliografía significativa y actualizada; pulcritud formal y claridad de discurso.

c) una recomendación final: publicar | solicitar modificaciones | rechazar. 


\section{COBERTURA, DIFUSIÓN Y PRESENCIA EN BASES DE DATOS}

La revista está indizada en las bases de datos ISOC (Base de datos del Centro de Información y Documentación Científica del CSIC), ERIH PLUS (European Reference Index for the Humanities and Social Sciencies), MLA (Modern Language Association), CIRC, DICE, MIAR, Latindex, Dialnet.

\section{PRINCIPIOS ÉTICOS DE PUBLICACIÓN}

La publicación de artículos en una revista con revisión por pares es un reflejo directo de la calidad del trabajo de sus autoras/es, y del compromiso y cualificación de los investigadoras/es que actúan como revisoras/es. Por ello Feminismo/s es una publicación comprometida con los principios éticos de la actividad científica en los siguientes términos:

\section{Publicación y autoría}

Todos los artículos deben incluir un listado de referencias, así como indicar si han recibido apoyo económico. Los trabajos deben estar libres de plagio o fraude científico, cuyos supuestos* se enumeran de manera no exhaustiva a continuación:

- Plagio: copia literal sin entrecomillar y citar la fuente; copia sustancial (materiales de investigación, procesos, tablas...); parafrasear o reproducir ideas sin citar la fuente y/o cambiando el significado original; reutilizar y enviar textos propios ya publicados sin indicar la fuente y el parafraseo abusivo incluso citando la fuente.

- Fraude científico: no reconocimiento de todas/os las/los investigadoras/es participantes en la elaboración del trabajo, el envío simultáneo a varias publicaciones, la división de un trabajo en partes diferentes que comparten las mismas hipótesis, población y métodos, así como la utilización de datos falsos o no probados. Finalmente, las/los autoras/es deben declarar a la revista los potenciales conflictos de interés cuando envían un trabajo.

* Fuente: http://www.ethics.elsevier.com/ 


\section{Responsabilidad de las/los autoras/es}

- El envío de trabajos a Feminismos/s supone la lectura y aceptación de las normas editoriales y de publicación de la revista, incluida la participación en un proceso anónimo de evaluación por pares.

- Todas/os las/los autoras/es que firman un trabajo deben haber contribuido de manera significativa a su elaboración y deben estar de acuerdo con el resultado final y con el envío del trabajo para su evaluación.

- Los trabajos deben reconocer a todas/os las/los autoras/ que han participado en su elaboración.

- Los datos utilizados en el artículo deben ser reales y auténticos.

- Las/los autoras/es asumen la obligación de corregir y/o retractarse ante posibles errores detectados posteriormente.

- Los artículos han de ser inéditos y no pueden ser enviados simultáneamente a ninguna otra publicación.

\section{Proceso de revisión}

Todos los artículos enviados a la revista se someten a un proceso de revisión por pares con las siguientes características:

- La selección de los revisores se realiza en función de normas y principios previos basados tanto en su cualificación como en la calidad de su producción científica.

- El proceso de revisión será totalmente anónimo tanto para las/ los autoras/es como para las/los revisoras/es. Los artículos y sus revisiones serán tratados confidencialmente.

- Las/los revisoras/es consideran, entre sus criterios de evaluación, el respeto a los principios éticos esenciales en la investigación científica.

- Los juicios expresados en las revisiones deben ser objetivos.

- Tanto autoras/es como revisoras/es deben revelar las relaciones y fuentes de financiación que puedan generar potenciales conflictos de intereses.

\section{Responsabilidades de las editoras/editores}

- El equipo editorial tiene la responsabilidad y la autoridad para aceptar o rechazar un artículo basándose en las revisiones.

- El equipo editorial revelará en su caso las relaciones o fuentes de financiación que puedan ser potencialmente consideradas como conflictos de intereses respecto a los artículos que rechaza o acepta. 
- Sólo se aceptarán los artículos en los que existe una evidencia cierta sobre el cumplimiento de las normas editoriales.

- El Consejo de Redacción de Feminismo/s se reserva el derecho de retirar cualquier trabajo recibido, aceptado o ya publicado en caso de constatarse plagio, falsificación o publicación duplicada, así como los diversos supuestos de fraude científico anteriormente enumerados. Del mismo modo, promoverá la publicación de correcciones o retractaciones frente a errores detectados.

- El equipo editorial se compromete a preservar el anonimato de las/ los revisoras/revisores de manera que nunca puedan asociarse con los artículos revisados.

\section{Cuestiones éticas de publicación}

El equipo editorial se compromete a:

- Vigilar y preservar los principios éticos de publicación.

- Mantener la integridad del expediente académico.

- Evitar la publicación de material plagiado o elaborado de manera fraudulenta.

- Estar abierto a la publicación de correcciones, clarificaciones, retractaciones y disculpas siempre que sea necesario.

- Ofrecer apoyo en el proceso de retractación de artículos.

- Realizar todas las acciones necesarias para cumplir los estándares de compromiso intelectual y ético.

\section{Aviso legal}

A efectos de lo estipulado en los artículos 138-143 de la Ley de Propiedad Intelectual, la publicación de un trabajo que atente contra dichos derechos será responsabilidad del autor/a. El equipo editorial de Feminismo/s no se hace responsable, en ningún caso, de la credibilidad y autenticidad de los trabajos. Del mismo modo, las opiniones y hechos expresados en cada artículo son de exclusiva responsabilidad de sus autoras/es y Feminismo/s no se identifica necesariamente con ellos. 


\section{CÓMO OBTENER LA REVISTA}

La revista se vende a un precio de 12 euros a través del Servicio de Publicaciones de la Universidad de Alicante

\section{Ventas:}

Teléfono: 965909445

Fax: 965909445

E-Mail: Publicaciones.Ventas@ua.es

La revista mantiene intercambios con publicaciones pertenecientes a otras instituciones académicas y/o investigadoras, españolas y extranjeras. 


\section{COM PRESENTAR UN ORIGINAL}

1. Els treballs seran el resultat d'una investigació original i hauran de contenir conclusions noves recolzades en una metodologia plantejada i justificada degudament. Només s'admetran treballs inèdits que no estiguen en procés d'avaluació per altres revistes.

2. L'extensió dels treballs presentats no excedirà de 9000 paraules, inclosent-hi notes i bibliografia.

3. El nombre i extensió de les notes al peu es reduirà a l'indispensable.

4. Els autors sotmetran els seus articles en Word a través del correu electrònic de la revista (revistafeminismos@ua.es) i hauran d'aportar imprescindiblement:

- Títol del treball.

- Nom de l'autor o de l'autora, institució a la qual pertany, adreça professional completa i adreça electrònica.

- Arxiu del text en format Word, que no continga el nom de l'autor o autora, amb:

- El títol en espanyol i en anglès.

- Un resum d'unes 150 paraules en espanyol, i la seua correcta versió anglesa. Aquest resum haurà d'atenir-se a l'esquema següent: objectius del treball, metodologia i conclusions o tesis.

- Cinc paraules clau en espanyol, i la seua correcta versió anglesa.

- El text de l'original.

- Un breu CV (com a màxim 300 paraules).

5. Els treballs se sotmetran a un procés de selecció i avaluació anònim i per experts, segons el procediment i els criteris fets públics per la revista. 


\section{NORMES EDITORIALS I D'ESTILS}

1. Els articles estaran redactats en Word amb lletra Times New Roman, mida de 12 punts i amb un interlineat d'un espai i mig.

2. L'extensió no excedirà de 9000 paraules, incloent-hi notes i bibliografia.

3. La primera línia de cada paràgraf anirà sagnada.

4. Les notes, que s'hauran de reduir a l'indispensable i s'utilitzaran només per a informació suplementària, seran a peu de pàgina, amb lletra de 10 punts i interlineat senzill. La crida en el text anirà abans del signe de puntuació.

5. Les referències bibliogràfiques aniran entre parèntesis en el text de l'article, no en les notes, seguint les indicacions següents:

5.1. Referència a una idea d'un autor/a el nom del/la qual no se cita expressament en el text:

- «En la cultura renacentista y humanística italiana este debate sobre los sexos tuvo una muy especial viveza» (Blanco 265).

- El debate sobre los sexos fue muy vivo en la cultura del Renacimiento y del Humanismo italianos (Blanco 265).

No es posa coma [,] entre el nom i el número de pàgina.

5.2. Referència a una idea d'un autor el nom del qual sí se cita en el text:

- Según Moi, «la obra de Kristeva no se puede considerar fundamentalmente feminista» (174).

5.3. Si l'autor solament té una obra citada, no s'inclou l'any d'edició.

5.4. Si se cita més d'una obra d'un mateix autor, cal incloure la data d'edició de cadascuna, darrere del nom. Ha d'inserir-se una coma [,] SOLAMENT entre l'any i la pàgina:

- «En la cultura renacentista y humanística italiana este debate sobre los sexos tuvo una muy especial viveza» (Blanco 1997, 265).

5.5. Utilitzeu «ver» o «Ver». No empren «cfr.», «véase», «vid.» o «comp.». En cap cas s'usen indicacions com «op. cit.», «art. cit.», «loc. cit.», «id.», «ibid.», «supra», «infra», «passim», «et alii». 
6. Les cites extenses (quatre o més línies) es destaquen del text mitjançant un paràgraf sagnat. No s'usen cometes. El punt anirà en aquest cas davant del parèntesi que conté la referència bibliogràfica i no després.

7. Els diferents apartats del text s'ordenaran seguint la numeració aràbiga $(1,2,3, \ldots)$ i el títol de cadascun anirà en lletra majúscula i en negreta. Els subapartats s'enumeraran de la manera següent: 1.1, 1.2, 1.3, etc. i els seus títols aniran en minúscula i en negreta.

8. Les fotografies i imatges s'han de lliurar en format digital, separades del text, en format tif, amb una qualitat de 300 punts per polzada. Han d'estar identificades convenientment segons siguen citades en el text.

9. Llista d'obres citades:

9.1. Les entrades bibliogràfiques apareixeran al final del document, ordenades alfabèticament i amb sagnat francès.

9.2. Els noms dels autors i editors es donaran complets, i mai en majúscula.

9.3. Quan s'incloga una obra de diversos autors, solament en el primer es fa precedir el cognom.

9.4. Quan s'inclou més d'una obra d'un mateix autor, s'ordenen cronològicament; en tots els casos es fa constar el nom de l'autor.

9.5. En les revistes, el número de volum i fascicle es donarà sempre amb caràcters aràbics.

9.6. Cada entrada s'organitzarà de la manera següent:

\section{A. LLIBRES}

- Amb únic/a autor/a o editor/a: Cognom, Nom. Títol del llibre en cursiva. Edició utilitzada. Número de volums [si més d'un]. Nom de la sèrie o collecció [si escau]. Lloc de publicació: Nom de l'editorial, data de publicació.

Bloom, Harold. Poetry and Repression: Revision from Blake to Stevens. New Haven: Yale University Press, 1976.

Moi, Toril (ed.). The Kristeva Reader. Oxford: Blackwell Publishers, 1986.

- Amb diversos/es autors/es o editors/es: Cognoms, Nom, i Nom Cognoms. Titol en cursiva. Ciutat: Editorial, any. 
Anderson, Bonnie, y Judith P. Zinsser. Historia de las mujeres: una historia propia. 2 vols. Barcelona: Crítica, 1991.

Perrot, Michelle, y Georges Duby (eds.). Historia de las mujeres. Madrid: Taurus, 1991.

\section{B. ARTICLES}

- Amb un/a únic/a autor/a: Cognoms, Nom. «Títol». Revista en cursiva núm. Volum en aràbic. Fascicle en aràbic (any): pàgines (sense p./pàg.).

Valcárcel, Amelia. «El primer ensayo feminista de una teoría del poder». Panorama 9 (1990): 59-64.

Vogel, Lisa. «Erotica, the Academy and Art Publishing: A Review of Woman as Sex Object. Studies in Erotic Art, 1730-1970, New York, 1972». Art Journal 35.4 (1976): 378-385.

- Amb diversos/es autors/es: Cognoms, Nom, i Nom Cognoms. «Títol». Revista en cursiva núm. volum en aràbic. Fascicle en aràbic (any): pàgines (sense p./pàg.).

López-Zafra, Esther y Rocío García Retamero. «Mujeres y liderazgo: ¿discapacitadas para ejercer el liderazgo en el ámbito público?». Feminismo/s 13 (2009): 85-104.

C. COL.LABORACIÓ EN LLIBRE COL-LECTIU: Cognom de l'autor o de l'autora, Nom de l'autor o de l'autora. «Títol de la col-laboració». Títol del llibre en cursiva. Ed./Eds. Nom i cognoms de l'editor o de l'editora. Edició utilitzada. Número de volum [si més d'un]. Lloc de publicació: Nom de l'editorial, data de publicació. Pàgines.

Smith-Rosenberg, Carroll. «Writing History: Language, Class and Gender». Feminist Studies. Ed. Teresa de Lauretis. Bloomington: Indiana University Press, 1986, 31-54.

\section{TÍTOLS DE LLIBRES AMB DIVERSOS VOLUMS}

- Si cada volum té un títol propi, es farà constar així:

Díaz-Diocaretz, Myriam, e Iris M. Zavala (coords.). Breve historia feminista de la literatura española (en lengua castellana), I: Teoría feminista: discursos y diferencias. Barcelona: Anthropos, 1993. 
- Si cada volum no té títol propi:

Pardo Bazán, Emilia. Obras completas. Vol. 2. Ed. Federico Carlos Sainz de Robles. Madrid: Aguilar, 1957.

E. CITES DE PREMSA: Cognom de l'autor, Nom de l'autor. «Títol del treball». Nom del periodic en cursiva [cas que no siga universalment conegut: Ciutat, País] dia mes any: pàgines

Lara, Fernando. «Victoria Kent, una mujer de suerte». Triunfo, 22 octubre 1977: 62 .

F. PUBLICACIÓ EN INTERNET: Cognom de l'autor, Nom de l'autor. «Títol del treball». Nom de la publicació en cursiva Volum. Número (Any): pàgines [si en té]. Data d'accés.

Safa Barraza, Patricia, y Juan Manuel Ramírez Sáiz. «Deterioro urbano y calidad de vida en las grandes urbes: la participación de las mujeres en las organizaciones vecinales ». La ventana 54 (2011): 110-145. 20 de abril de 2015.

G. Les WEBS se citaran d'acord amb el model següent: $<$ http://www.cis.es/cis/opencms/ES/2_barometros>, consultado el 19-06-2008.

\section{COM PROPOSAR UN MONOGRÀFIC}

La proposta d'un monogràfic per a la revista Feminismo/s es farà arribar a la directora de la revista (Helena.establier@ua.es) i contindrà la informació següent:

1. Títol provisional del monogràfic.

2. Un CV complet de la coordinadora o del coordinador (o de les coordinadores o coordinadors) del monogràfic.

3. Una descripció dels objectius i una justificació de l'oportunitat del tema proposat (tres-centes paraules). 
4. Una llista provisional de participants en el volum, acompanyat d'una breu ressenya biobibliogràfica de cadascun o cadascuna i dels títols dels treballs previstos (als quals se sumaran posteriorment els rebuts a través de la convocatòria de comunicacions i que superen, com els anteriors, el procés d'avaluació de la revista).

5. Les propostes seran considerades pel Consell de Redacció de Feminismo/s en el termini màxim d'un mes a partir de la data de recepció.

\section{PROCÉS D'AVALUACIÓ}

1) Els originals rebuts són valorats, en primera instància, pel Consell de Redacció de la revista per a decidir sobre l'adequació a les àrees de coneixement $\mathrm{i}$ als requisits que la revista ha publicat per als autors o autores.

2) El Consell de Redacció envia els originals, sense el nom de l'autor o de l'autora, a dos revisors o revisores externs al Consell Editorial, els quals emeten el seu informe en un termini màxim de sis setmanes. Sobre aquests dictàmens, el Consell de Redacció decideix rebutjar o acceptar l'article o sol-licitar modificacions a l'autor o autora del treball. Els autors o autores reben una notificació detallada i motivada en què s'exposa, retocat, el contingut dels informes originals, amb indicacions concretes per a la modificació si és el cas. Feminismo/s pot enviar als autors o autores els informes originals rebuts, íntegres o en part, sempre de manera anònima. En cas de discrepància en els informes d'avaluació, la revista es reserva el dret de sotmetre el treball a la valoració de la coordinadora o coordinador del volum i del Consell de Redacció, o de sol-licitar-ne una tercera avaluació.

3) L'informe emès pels revisors o revisores inclou:

a) una valoració global de l'article i dels resums.

b) una valoració quantitativa de la qualitat (bona | acceptable | insuficient) segons aquests cinc criteris: originalitat i interès del tema; pertinència en relació amb les investigacions actuals en l'àrea; rigor metodològic i articulació expositiva; bibliografia significativa i actualitzada, netedat formal i claredat de discurs.

c) una recomanació final: publicar | sol-licitar modificacions | rebutjar. 


\section{COBERTURA, DIFUSIÓ I PRESÈNCIA EN BASES DE DADES}

La revista està indexada en les bases de dades d'ISOC (Base de dades del Centre d'Informació i Documentació Científica del CSIC), ERIH PLUS (European Reference Index for the Humanities and Social Sciencies), MLA (Modern Language Association), CIRC, DICE, MIAR, Latindex, Dialnet.

\section{PRINCIPIS ÈTICS DE PUBLICACIÓ}

La publicació d'articles en una revista amb avaluació d'experts és un reflex directe de la qualitat del treball dels/de les autors/es i del compromís i la qualificació dels/de les investigadors/es que actuen com a revisors/es. Per això Feminismo/s és una publicació compromesa amb els principis ètics de l'activitat científica en els termes següents:

\section{Publicació i autoria}

Tots els articles han d'incloure una llista de referències, com també indicar si han rebut suport econòmic. Els treballs han d'estar lliures de plagi o frau científic. Els supòsits* de plagi i frau científic són els esmentats a continuació:

- Plagi: còpia literal sense usar les cometes i citar la font; còpia substancial (materials d'investigació, processos, taules...); parafrasejar o reproduir idees sense citar la font o canviant el significat original; reutilitzar i enviar textos propis ja publicats sense indicar la font i parafrasejar de manera abusiva fins i tot citant la font.

- Frau científic: no reconeixement de tots/es els/les investigadors/es que participen en l'elaboració del treball; l'enviament simultani a diverses publicacions; la divisió d'un treball en parts diferents que comparteixen les mateixes hipòtesis, població i mètodes, com també la utilització de dades falses o no provades. Finalment, els/les autors/ es han de declarar a la revista els potencials conflictes d'interès quan envien un treball.

* Font: http://www.ethics.elsevier.com/ 


\section{Responsabilitat dels/de les autors/es}

- L'enviament de treballs a Feminismo/s implica la lectura i l'acceptació de les normes editorials i de publicació de la revista, incloent-hi la participació en un procés anònim d'avaluació d'experts.

- Tots/es els/les autors/es que signen un treball han d'haver contribuit de manera significativa en l'elaboració i han d'estar d'acord amb el resultat final i amb l'enviament del treball perquè siga avaluat.

- Els treballs han de reconèixer a tots/es els/les autors/es que hi han participat.

- Les dades utilitzades en l'article han de ser reals i autèntiques.

- Els/les autors/es assumeixen l'obligació de corregir o retractar-se davant possibles errors detectats posteriorment.

- Els articles han de ser inèdits i no poden ser enviats simultàniament a cap altra publicació.

\section{Procés de revisió}

Tots els articles enviats a la revista se sotmeten a un procés d'avaluació d'experts amb les característiques següents:

- La selecció dels/de les revisors/es es fa d'acord amb les normes i els principis previs basats tant en la seua qualificació com en la qualitat de la seua producció científica.

- El procés de revisió serà totalment anònim tant pels/per els autors/es com pels/per les revisors/es. Els articles i les revisions seran tractats confidencialment.

- Els/les revisors/es consideren, entre els criteris d'avaluació, el respecte als principis ètics essencials en la investigació científica.

- Els judicis expressats en les revisions han de ser objectius.

- Tant autors/es com revisors/es han de revelar les relacions i les fonts de finançament que puguen generar potencials conflictes d'interessos.

\section{Responsabilitats dels/de les editors/es}

- L'equip editorial té la responsabilitat i autoritat per a acceptar o rebutjar un article basant-se en les revisions.

- Lequip editorial revelarà, si escau, les relacions o les fonts de finançament que puguen ser potencialment considerades com a conflictes d'interessos pel que fa a l'acceptació o el rebuig dels treballs. 
- Només s'acceptaran els articles en els quals hi ha una evidència certa sobre el compliment de les normes editorials.

- El Consell de Redacció de Feminismo/s es reserva el dret de retirar qualsevol treball rebut, acceptat o ja publicat en cas de constatar-se plagi, falsificació o publicació duplicada, com també els diversos supòsits de frau científic anteriorment enumerats. De la mateixa manera, promourà la publicació de correccions o retractacions davant errors detectats.

- L'equip editorial es compromet a preservar l'anonimat dels/de les revisors/es de manera que mai puguen ser associats/des amb els articles revisats.

\section{Qüestions ètiques de publicació}

L'equip editorial es compromet a:

- Vigilar i preservar els principis ètics de publicació.

- Mantenir la integritat de l'expedient acadèmic.

- Evitar la publicació de material plagiat o elaborat de manera fraudulenta.

- Estar obert a la publicació de correccions, aclariments, retractacions i disculpes sempre que siga necessari.

- Oferir suport en el procés de retractació d'articles.

- Fer totes les accions necessàries per a complir els estàndards de compromís intel-lectual i ètic.

\section{Avís legal}

D'acord amb el que estableixen els articles 138-143 de la Llei de propietat intel-lectual, la publicació d'un treball que atempte contra aquests drets serà responsabilitat de l'autor/a. L'equip editorial de Feminismo/s no es fa responsable, en cap cas, de la credibilitat i autenticitat dels treballs. De la mateixa manera, les opinions i els fets expressats en cada article són de responsabilitat exclusiva dels/de les autors/es i Feminismo/s no s'identifica necessàriament amb aquests. 


\section{COM ES POT OBTENIR LA REVISTA}

La revista es ven a un preu de 12 euros a través del Servei de Publicacions de la Universitat d'Alacant

\section{Vendes:}

Telèfon: 965909445

Fax: 965909445

E-mail: Publicaciones.ventas@ua.es

La revista manté intercanvis amb publicacions pertanyents a altres institucions acadèmiques o investigadores, espanyoles i estrangeres. 


\section{HOW TO SUBMIT A MANUSCRIPT}

1. The works submitted should be unpublished under no evaluation process by other journals and must contain novel conclusions supported with a duly proposed and justified methodology.

2. The length of the papers should not exceed 9,000 words, including notes and bibliography.

3. The number and length of footnotes should be reduced to the minimum necessary.

4. Authors should submit their articles in Word via electronic mail (Revistafeminismos@ua.es) along with the following documents:

- Title of the work.

- Name of the author, the institution they belong to, full professional address and electronic mail.

- Text file in Word format, omitting the name of the author with:

- The title in Spanish and English.

- A 150-word abstract in Spanish and its correct English version. This abstract should follow the following outline: objectives of the paper, method and conclusions or thesis.

- Five key words in Spanish and its correct English version.

- Original text.

- A short curriculum vitae (maximum of 300 words).

5. Papers will will undergo a process of anonymous selection and evaluation peer review, according to the procedure and criteria published by the journal. 


\section{EDITORIAL GUIDELINES AND STYLE}

1. Articles should be drafted in Word with Times New Roman font, 12-point size with with one-and-a-half line spacing.

2. Length should not exceed 9,000 words, including notes and bibliography.

3. First line of each paragraph shall be indented.

4. Notes, which should be reduced to the minimum necessary and used only for supplementary information, will only be footnoted, with 10-point font and single spacing. Footnote number in the text should go before the punctuation mark.

5. Bibliographical references should go between parentheses in the text, and not in the notes, according to the following instructions:

5.1. Reference to an idea of an author whose name has not been expressly quoted in the text:

- «In the Italian Renaissance and humanistic culture, this debate on gender had a very special liveliness» (Blanco 265).

- This debate on gender had a very special liveliness in the Italian Renaissance and humanistic culture (Blanco 265).

No comma is used [,] between the name and page number.

5.2. Reference to an author's idea whose name is quoted in the text:

- According to Moi, «Kristeva's work cannot be considered fundamentally feminist» (174).

5.3. Should the author has an only work published, the year of publication will not be included.

5.4. Should more than work by the same author be mentioned, each year of publication should be included after the author's name. A comma should be used [,] ONLY between the year and the page number:

- «In the Italian Renaissance and humanistic culture, this debate on gender had a very special liveliness» (Blanco 1997, 265). 
5.5. Use «see» and not «cfr.», «véase», «vid.» o «comp.». Under no circumstances expressions such as «op. cit.», «art. cit.», «loc. cit.», «id.», «ibid.», «supra», «infra», «passim», «et alii» will be used.

6. Large figures (four or more lines) are highlighted in the text with an indented paragraph. Inverted commas are not used. Full stop goes, in this case, in front of the parentheses containing the bibliographical reference but never behind.

7. The different sections of the text are organised following the Arabic numerals $(1,2,3, \ldots)$ and the title for each section shall be capitalised in italics. Subsections shall be numbered as follows: 1.1, 1.2, 1.3, etc. and their titles shall be lowercase in Italics.

8. Photographs and images shall be submitted in a 300 pixels resolution as a.tiff, aside from the text. They should be duly identified according to the way they have quoted in the text.

9 List of quoted works:

9.1. Bibliographical references shall be mentioned at the bottom of the document, in alphabetic order with hanging indentation.

9.2. The names of authors and publishers shall be given in full and never capitalised.

9.3. In the case of a work with several authors, the surname shall only precede the first one.

9.4. In the case of more than work by the same author, a chronological order is needed and their name shall be mentioned in all cases.

9.5. In the case of journals, the number of issue and part shall be always given in Arabic numerals.

9.6. Each reference shall be organised as follows:

\section{A. BOOKS}

- With only one author or publisher: Surname, Name. Title of the book in Italics. Edition used. Number of volumes [if more than one]. Name of the series or collection [if appropriate]. Place of publication: Name of the publishing firm, Date of publication. 
Bloom, Harold. Poetry and Repression: Revision from Blake to Stevens. New Haven: Yale University Press, 1976.

Moi, Toril (ed.). The Kristeva Reader. Oxford: Blackwell Publishers, 1986.

- With several authors or publishers: Surnames, names and Names Surnames. Title in Italics. City: Publishing firm, year.

Anderson, Bonnie, and Judith P. Zinsser. Historia de las mujeres: una historia propia. 2 vols. Barcelona: Crítica, 1991.

Perrot, Michelle, and Georges Duby (eds.). Historia de las mujeres. Madrid: Taurus, 1991.

\section{B. ARTICLES}

- With one author : Surname, Name. «Title». Revista en cursiva volume no. in Arabic numerals. Issues in Arabic numerals (year): pages (without pg./pgs.).

Valcárcel, Amelia. «El primer ensayo feminista de una teoría del poder». Panorama 9 (1990): 59-64.

Vogel, Lisa. «Erotica, the Academy and Art Publishing: A Review of Woman as Sex Object. Studies in Erotic Art, 1730-1970, New York, 1972». Art Journal 35.4 (1976): 378-385.

-With several authors Surnames, Name, and Name surnames. «Titles». Revista en cursiva volume no. in Arabic numerals. Issues in Arabic numerals (year): pages (without pg./pgs).

López-Zafra, Esther and Rocío García Retamero. «Mujeres y liderazgo: ¿discapacitadas para ejercer el liderazgo en el ámbito público?». Feminismo/s 13 (2009): 85-104.

C. COLLABORATIVE BOOK: Author's surname, author's name. «Title of the collaboration». Title of the book in Italics. Publisher's name and surname. Edition no. Volume no. [if more than one]. Place of publication: Name of the publishing firm, publication date. Pages.

Smith-Rosenberg, Carroll. «Writing History: Language, Class and Gender». Feminist Studies. Ed. Teresa de Lauretis. Bloomington: Indiana University Press, 1986, 31-54. 


\section{BOOK TITLES WITH SEVERAL VOLUMES}

- Should every volume have its own title, state them as follows:

Díaz-Diocaretz, Myriam, and Iris M. Zavala (coords.). Breve historia feminista de la literatura española (in Spanish), I: Teoría feminista: discursos y diferencias. Barcelona: Anthropos, 1993.

- Should every volume have different titles:

Pardo Bazán, Emilia. Obras completas. Vol. 2. Ed. Federico Carlos Sainz de Robles. Madrid: Aguilar, 1957.

E. PRESS QUOTES: Author's surname, author's name. «Title of the article». Name of the newspaper in Italics [if not universally recognised: City, Country] Day Month Year: pages

Lara, Fernando. «Victoria Kent, una mujer de suerte». Triunfo, 22 October 1977: 62 .

F. PUBLICATION IN THE INTERNET: Author's surname, author's name. «Title of the work». Name of the periodical in Italics. Volume. No. (Year): pages [if any]. Date of consultation.

Safa Barraza, Patricia, and Juan Manuel Ramírez Sáiz. «Deterioro urbano y calidad de vida en las grandes urbes: la participación de las mujeres en las organizaciones vecinales ». La ventana 54 (2011): 110-145. 20 April 2015.

G. WEB SITES shall be quoted according to this model:

$<$ http://www.cis.es/cis/opencms/ES/2_barometros>, consulted on 19-06-2008

\section{HOW TO PROPOSE A MONOGRAPH}

The proposal for a monograph for Feminismo/s journal should be submitted to the editor of the journal (Helena.Establier@ua.es) with the following information:

1. Provisional title of the monograph.

2. A comprehensive CV of its coordinator/s. 
3. A description of their objectives and a justification for the timing of the proposed topic (300 words).

4. A provisional list of participants in the volume, along with a brief bio-bibliographical review of each participant and titles of the planned papers (and added to those submitted through our call for papers provided they pass the journal selection process).

5. Proposals will be considered by the Editorial Board of Feminismo/s within a maximum period of one month from the date of receipt.

\section{ASSESSMENT CRITERIA}

1) Original papers are firstly assessed by the Editorial Board of the journal on their suitability to the fields of knowledge and the requirements established for authors by the journal.

2) The Editorial Board submits originals (without the author's name written down) to two external reviewers, who shall release a report within six weeks. On these views, the Editorial Board decides on rejecting or accepting the article or apply for modifications to the author. Authors are given a detailed and reasoned notification where the content of original reports (retouched) is exposed with specific indications for modifications if appropriate. Feminismo/s can send authors the original reports submitted, either complete or in part and always anonymously. In the case of a discrepancy with assessment reports, the journal reserve the right to submit the paper for either assessment of the Issue Coordinator and the Editorial Board or to request a third party assessment.

3) The report submitted by reviewers includes:

a) a global assessment of both the article and abstracts.

b) a quantitative assessment of the quality (good | acceptable | insufficient) according to 5 criteria: originality and interest of the issue; appropriateness with respect to current research in the area; methodological rigour and expository articulation; relevant and updated bibliography; formal neatness and clear discourse.

c) a final recommendation: publish | apply for modifications | reject. 


\section{COVERAGE DISSEMINATION AND PRESENCE IN DATABASES}

The journal is indexed in ISOC (Database of CSIC's Scientific Information Documentation Centre, ERIH PLUS (European Reference Index for the $\mathrm{Hu}$ manities and Social Sciencies), MLA (Modern Language Association), CIRC, DICE, MIAR, Latindex, Dialnet.

\section{PUBLICATION ETHICS AND MALPRACTICE STATEMENT}

The publication of articles in a peer-review journal is a direct reflection of the quality of the work of their authors, and the commitment and qualifications of the researchers who act as reviewers. Therefore Feminismo/s is a publication committed to the ethical principles of scientific activity on the following terms:

\section{Publication and authorship}

All manuscripts must include a list of references, and indicate whether they have received financial support. Works must be free of plagiarism or scientific fraud. Illustrative cases* of plagiarism and scientific fraud can be consulted in a non-exhaustive list below:

- Plagiarism: literal copy without quoting and referencing the source; substantial copying (research materials, processes, tables...); paraphrasing or reproducing ideas without citing the source and/or changing the original meaning; text-recycling (reusing a published own text) without indicating the source, and abusive paraphrasing even quoting the source.

- Scientific fraud: no recognition of all the participating researchers in the study, simultaneous submission to several publications, the division of a work in different parts ('slices') that share the same hypotheses, population and methods, as well as the use of false or unproven data. Finally, the authors should disclose potential conflicts of interest to the journal when a manuscript is sent.

* Source: http://www.ethics.elsevier.com/ 


\section{Authors' Responsibility}

- The manuscripts submission to Feminismo/s involves reading and acceptance of the journal publishing guidelines, including participation in an anonymous peer-review process.

- All authors signing a work must have contributed significantly to its development and must agree both with the end result and with the manuscript submission for evaluation.

- Manuscripts must acknowledge all authors who have participated in their elaboration.

- Data used in the article must be real and authentic

- The authors assume the obligation to retract/correct when possible errors are later detected.

- Articles must be original and cannot be sent simultaneously to any other publication.

\section{Review Process}

All articles submitted to the journal are subjected to a peer review process with the following characteristics:

- The selection of reviewers is done according to rules and principles based on both their qualification and the quality of their scientific production.

- The review process will be totally anonymous both for authors and for reviewers. Manuscripts and reviews will be treated confidentially.

- Reviewers will take into account for their evaluation criteria the respect for the ethical principles that are essential in scientific research.

- The judgments expressed in the reviews should be objective.

- Authors and reviewers should disclose all relationships and funding sources that could generate potential conflicts of interest.

\section{Editors' Responsibilities}

- The editorial board has the responsibility and authority to accept or reject a manuscript based on the peer reviews.

- The editorial board will reveal any relationships or funding sources that could potentially be considered conflicts of interest regarding the rejection or the acceptance of manuscripts.

- The journal only accepts manuscripts when reasonably certain of compliance with editorial standards. 
- The Editorial Team reserves the right to remove any received, accepted or already published work where plagiarism, falsification, duplicate publication or scientific fraud is found. Similarly, it will encourage the publication of retractions or corrections to errors detected.

- The editorial team is committed to preserve the anonymity of the reviewers so that they can never be associated with the reviewed manuscripts.

\section{Publishing ethical Issues}

The editorial board is committed to:

- Monitoring and maintaining the publishing ethics.

- Maintaining the integrity of the academic record.

- Avoid publishing plagiarized or fraudulently prepared material.

- Be willing to publish corrections, clarifications, retractions and apologies when needed.

- Provide support in the process of retracting articles.

- Perform all actions required to meet the standards of intellectual and ethical commitment.

\section{Disclaimer}

Regarding the provisions in articles 138-143 of the Spanish Law on Intellectual Property, the publication of a work prejudicial to those rights shall be the responsibility of the author. The editorial team of Feminismo/s is not responsible, in any case, for the credibility and authenticity of the works. In the same way, the opinions and facts expressed in each article are the sole responsibility of the authors and Feminismo/s does not necessarily agree with them. 


\section{HOW TO GET THE JOURNAL}

The journal is on sale at $€ 12$ through the University of Alicante Publications Service

Sales:

Tel. 965909445

Fax: 965909445

E-Mail: Publicaciones.Ventas@ua.es

The journal exchanges publications with other journals from Spanish and international academic and/or research institutions. 


\section{Números anteriores publicados}

Feminismo/s 1. Feminismo y multidisciplinariedad. Helena Establier (coord.)

Feminismo/s 2. Imagin/ando a la mujer. Pilar Amador Carretero (coord.) y Mónica Moreno Seco (ed.)

Feminismo/s 3. Mujer y participación política. Mónica Moreno Seco y Clarisa Ramos Feijóo (coords.)

Feminismo/s 4. Writing, memoirs, autobiography and history. Silvia Caporale Bizzini (coord.)

Feminismo/s 5. Habitar / escribir / conquistar el espacio. Teresa Gómez Reus (ed.)

Feminismo/s 6. Violencia estructural y directa: mujeres y visibilidad. Carmen Mañas Viejo (coord.)

Feminismo/s 7. Hèléne Cixous: Huellas de intertextos. Maribel Peñalver Vicea y Rosa María Rodríguez Magda (eds.)

Feminismo/s 8. Mujeres y derecho. Nieves Montesinos Sánchez y M. ${ }^{a}$ del Mar Esquembre Valdés (coords.). Nieves Montesinos Sánchez (ed.)

Feminismo/s 9. Género, conflicto y construcción de la paz. Reflexiones y propuestas. Eva Espinar Ruiz y Eloisa Nos Aldás (coords.)

Feminismo/s 10. Medicines i Gènere. El torsimany necessari. Elizabeth Mora Torres, Albert Gras i Martí (coords.)

Feminismo/s 11. La representación/presencia de la mujer en los Medios de Comunicación. Sonia Núñez Puente (coord.) y Helena Establier Pérez (ed.)

Feminismo/s 12. Mujeres en democracia. Nieves Montesinos Sánchez y M. ${ }^{a}$ del Mar Esquembre Valdes (coords. y eds.)

Feminismo/s 13. Mujeres y diversidad funcional (discapacidad): construyendo un nuevo discurso. Carmen Mañas (coord.)

Feminismo/s 14. Género y nuevas tecnologías de la información y la comunicación. Eva Espinar Ruiz (Coord.)

Feminismo/s 15. ¿Feminismo de la igualdad y feminismo de la diferencia? Elena Nájera (Coord.)

Feminismo/s 16. Género e imagen del poder en la historia contemporánea. Mónica Moreno Seco y Alicia Mira Abad (Coords.) 
Feminismo/s 17. La arquitectura y el urbanismo con perspectiva de género. María Elia Gutiérrez Mozo (Coord.)

Feminismo/s 18. Salud pública desde la perspectiva de género: Hitos e innovación. María Teresa Ruiz Cantero (Coord.)

Feminismo/s 19. Mirada/s trans/identitarias. Ángel Amaro (Coord.)

Feminismo/s 20. La Diosa y el poder de las mujeres. Reflexiones sobre la espiritualidad femenina en el siglo XXI. Angie Simonis (Coord.)

Feminismo/s 21. Mujeres, actividad física, deporte y ocio. Juan Tortosa Martínez y Lilyan Vega Ramírez (Coords.)

Feminismo/s 22. Ecofeminismo/s: Mujeres y Naturaleza. Lorraine Kerslake y Terry Gifford (Coords.)

Feminismo/s 23. Todo sobre mi familia. Perspectivas de género. Adrián GrasVelázquez (Coord.)

Feminismo/s 24. Género y humor en discursos de mujeres y hombres. G. Angela Mura y Leonor Ruiz Gurillo (Coords.)

Feminismo/s 25. Violencia escolar y género. Almudena Iniesta Martínez (Coord.)

Feminismo/s 26. Feminismos en las sociedades árabes. Eva Lapiedra Gutiérrez (Coord.)

Feminismo/s 27. Comunicación y relaciones de género: prácticas, estructuras, discursos y consumo. Alejandra Hernández Ruiz y Marta Martín Llaguno (Coords.)

Feminismo/s 28. Laicidad y creencias. Nieves Montesinos Sánchez y Beatriz Souto Galván (Coords.)

Feminismo/s 29. La (in)visibilidad de las mujeres en la Educación Superior: retos y desafíos en la Academia. Marcos Jesús Iglesias Martínez e Inés Lozano Cabezas (Coords.) 




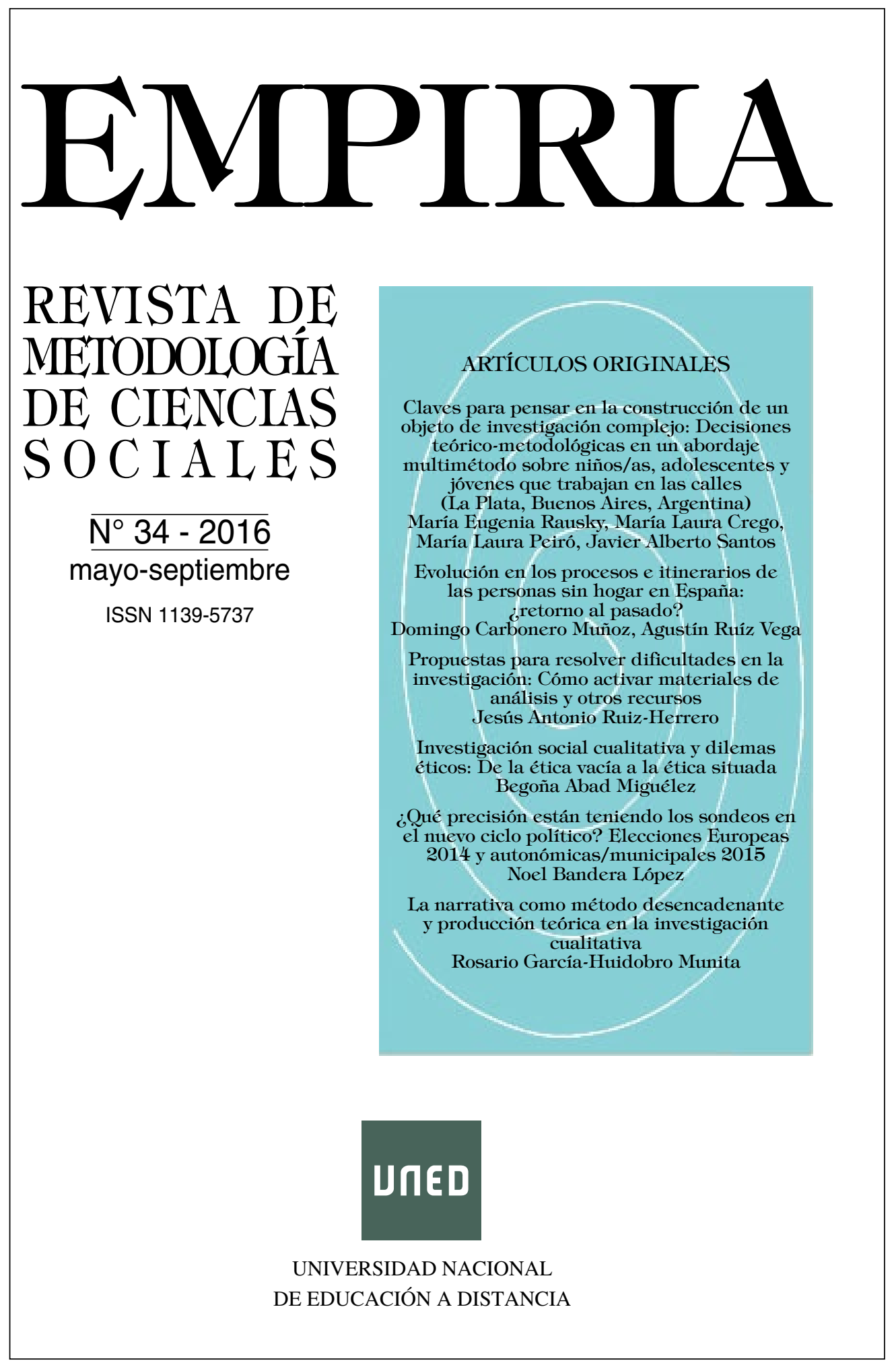


